\title{
Airflow and Indoor Air Quality Models of DOE Prototype Commercial Buildings
}
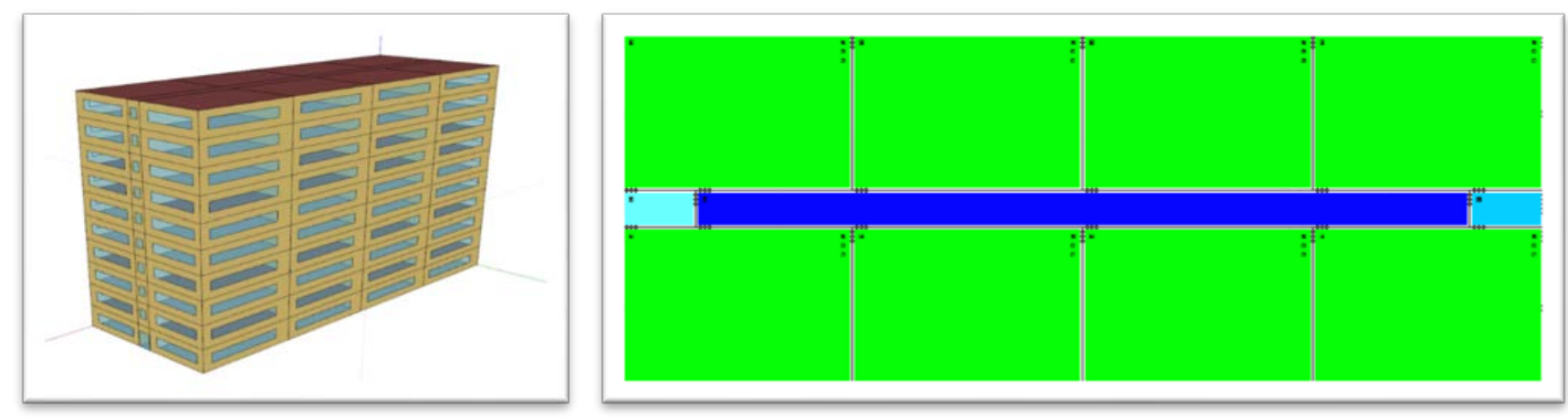

Lisa C. Ng Amy Musser Andrew K. Persily Steven J. Emmerich

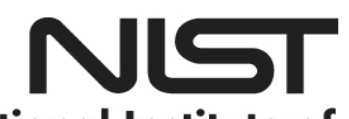

National Institute of Standards and Technology U.S. Department of Commerce 
NIST Technical Note 2072

\title{
Airflow and Indoor Air Quality Models of DOE Prototype Commercial Buildings
}

\author{
Lisa C. Ng \\ Andrew K. Persily \\ Steven J. Emmerich \\ Energy and Environment Division \\ Engineering Laboratory
}

Amy Musser

Vandemusser Design PLLC

This publication is available free of charge from:

https://doi.org/10.6028/NIST.TN.2072

October 2019

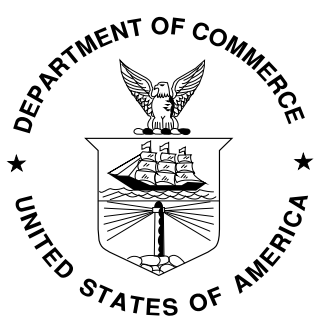

U.S. Department of Commerce

Wilbur L. Ross, Jr., Secretary

National Institute of Standards and Technology Walter Copan, NIST Director and Undersecretary of Commerce for Standards and Technology 
Certain commercial entities, equipment, or materials may be identified in this document in order to describe an experimental procedure or concept adequately. Such identification is not intended to imply recommendation or endorsement by the National Institute of Standards and Technology, nor is it intended to imply that the entities, materials, or equipment are necessarily the best available for the purpose.

National Institute of Standards and Technology Technical Note 2072

Natl. Inst. Stand. Technol. Tech. Note 2072, 135 pages (October 2019)

CODEN: NTNOEF

This publication is available free of charge from:

https://doi.org/10.6028/NIST.TN.2072 


\section{Table of Contents}

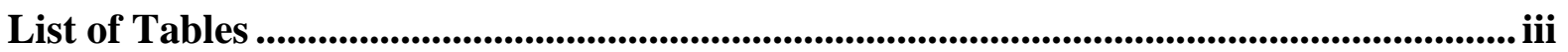

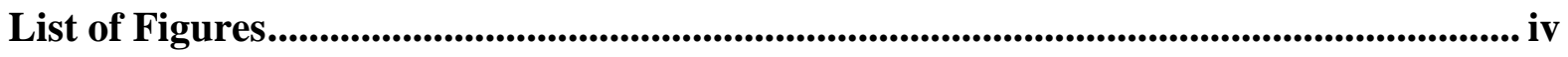

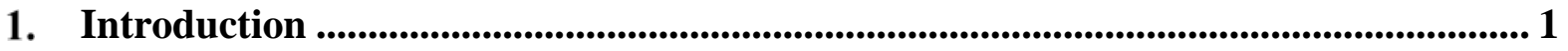

2. Multizone Modeling: CONTAM ......................................................................... 5

3. Building types and modeling approaches..................................................................6 6

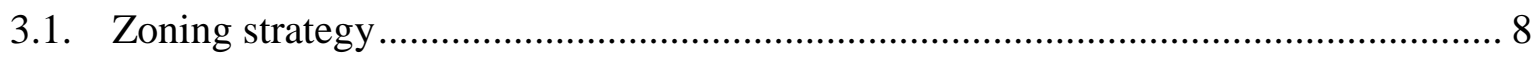

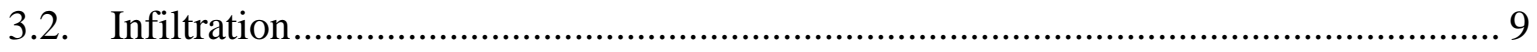

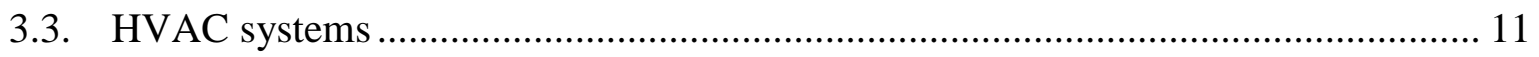

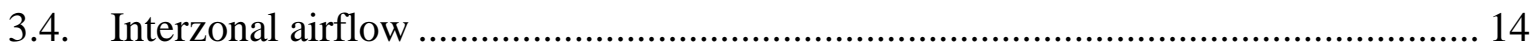

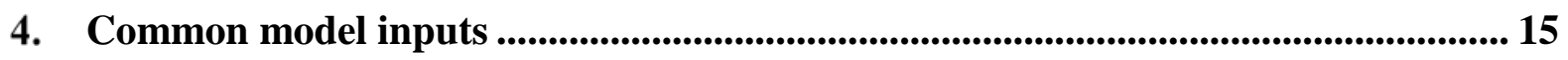

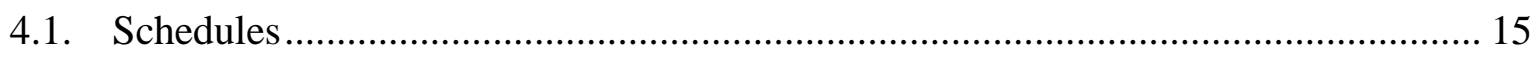

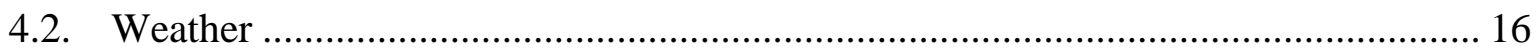

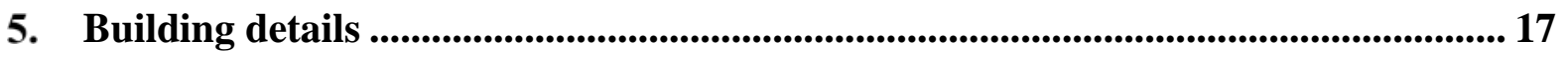

5.1. Quick Service Restaurant ............................................................................ 17

5.2. Full Service Restaurant ................................................................................... 20

5.3. Small Office .................................................................................................... 24

5.4. Medium Office ............................................................................................. 27

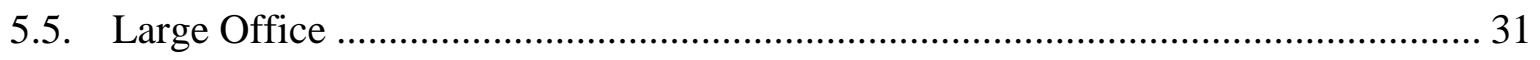

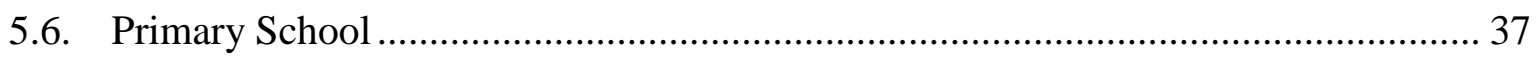

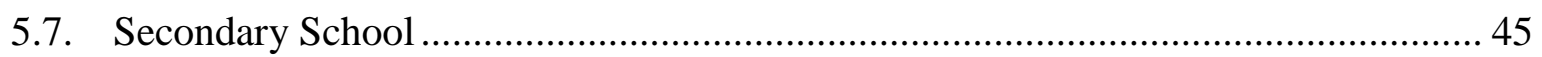

5.8. Stand Alone Retail........................................................................................ 56

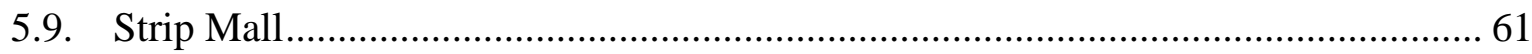

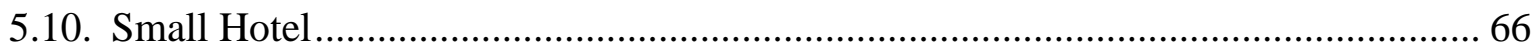

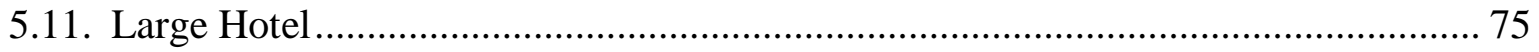

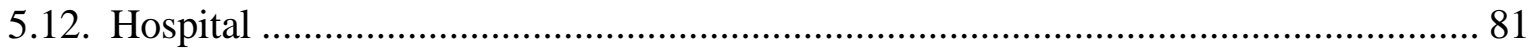

5.13. Outpatient Health Care ................................................................................. 93

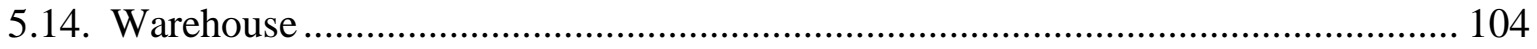

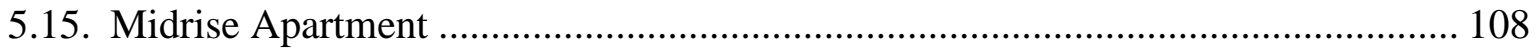

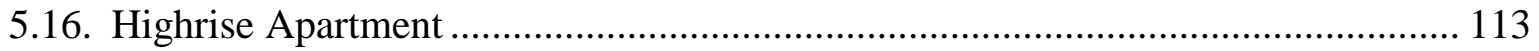

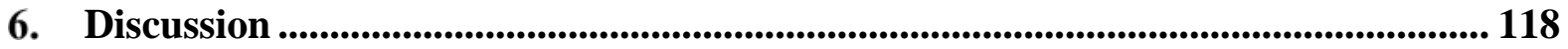

6.1. Building models for airflow and energy analyses ........................................... 118

6.2. Limitations of CONTAM models .................................................................. 120

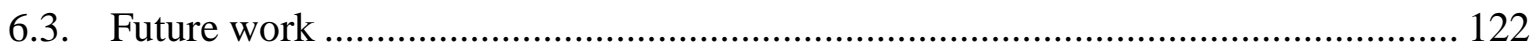




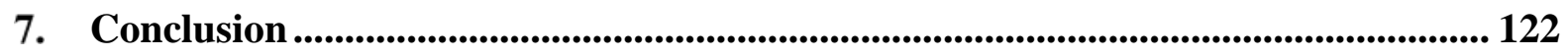

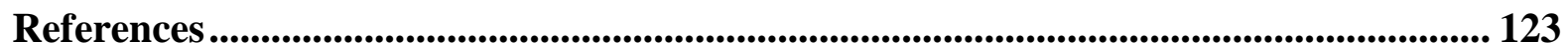




\section{List of Tables}

Table 1. List of building types in DOE reference and prototype building sets ...................... 2

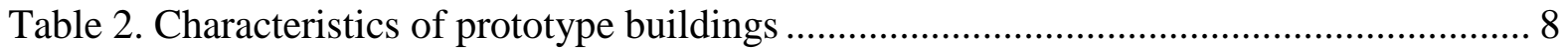

Table 3. Assigning CONTAM day types to events for prototype buildings ........................ 15

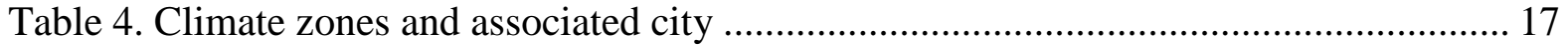

Table 5. Summary of zones in Quick Service Restaurant ............................................... 17

Table 6. Summary of HVAC system flow rates ( $\left.\mathrm{m}^{3} / \mathrm{s}\right)$ in Quick Service Restaurant (V1,V2)

Table 7. Summary of zones in Full Service Restaurant.................................................... 20

Table 8. Summary of HVAC system flow rates $\left(\mathrm{m}^{3} / \mathrm{s}\right)$ in Full Service Restaurant (V1,V2) 23

Table 9. Summary of zones in Small Office....................................................................... 25

Table 10. Summary of HVAC system flow rates $\left(\mathrm{m}^{3} / \mathrm{s}\right)$ in Small Office.............................. 26

Table 11. Summary of zones in Medium Office............................................................. 27

Table 12. Summary of VAV system flow rates $\left(\mathrm{m}^{3} / \mathrm{s}\right)$ and transfer grill sizes $\left(\mathrm{m}^{2}\right)$ in Medium

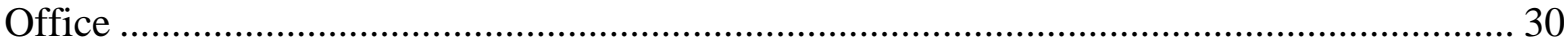

Table 13. Summary of zones in Large Office................................................................. 31

Table 14. Summary of VAV system flow rates $\left(\mathrm{m}^{3} / \mathrm{s}\right)$ and Return Grille sizes $\left(\mathrm{m}^{2}\right)$ in Large

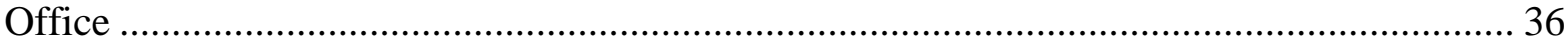

Table 15. Summary of zones in Primary School ............................................................... 38

Table 16. Summary of HVAC system flow rates $\left(\mathrm{m}^{3} / \mathrm{s}\right)$ in Primary School ......................... 42

Table 17. Summary of zones in Secondary School ......................................................... 46

Table 18. Summary of HVAC system flow rates $\left(\mathrm{m}^{3} / \mathrm{s}\right)$ in Secondary School .................... 54

Table 19. Summary of zones in Stand Alone Retail....................................................... 56

Table 20. Summary of HVAC system flow rates $\left(\mathrm{m}^{3} / \mathrm{s}\right)$ in Stand Alone Retail .................... 58

Table 21. Summary of zones in Strip Mall .................................................................. 61

Table 22. Summary of HVAC system flow rates $\left(\mathrm{m}^{3} / \mathrm{s}\right)$ in Strip Mall ................................. 64

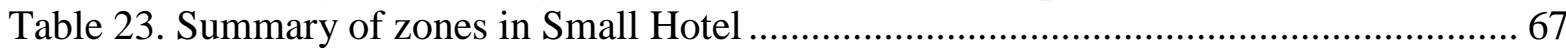

Table 24. Summary of HVAC system flow rates $\left(\mathrm{m}^{3} / \mathrm{s}\right)$ in Small Hotel (common areas) ..... 72

Table 25. Summary of PTAC flow rates $\left(\mathrm{m}^{3} / \mathrm{s}\right)$ in Small Hotel (guestrooms) ...................... 73

Table 26. Annual average temperature of zones with no thermostat setpoint schedules in

EnergyPlus model of Small Hotel.............................................................................. 74

Table 27. Summary of zones in Large Hotel ................................................................. 75

Table 28. Summary of VAV system flow rates $\left(\mathrm{m}^{3} / \mathrm{s}\right)$ in Large Hotel (common areas)........ 80

Table 29. Summary of DOAS flow rates $\left(\mathrm{m}^{3} / \mathrm{s}\right)$ in Large Hotel (guestrooms)...................... 80

Table 30. Summary of zones in Hospital....................................................................... 82

Table 31. Summary of VAV and CAV system flow rates $\left(\mathrm{m}^{3} / \mathrm{s}\right)$ in Hospital ....................... 92

Table 32. Summary of zones in Outpatient Health Care .................................................. 93

Table 33. Summary of VAV system flow rates $\left(\mathrm{m}^{3} / \mathrm{s}\right)$ in Outpatient Healthcare................. 102

Table 34. Summary of zones in Warehouse ...................................................................... 104

Table 35. Summary of CAV system flow rates $\left(\mathrm{m}^{3} / \mathrm{s}\right)$ in Warehouse ................................ 107

Table 36. Summary of zones in Midrise Apartment........................................................ 109

Table 37. Summary of CAV system flow rates $\left(\mathrm{m}^{3} / \mathrm{s}\right)$ in Midrise Apartment..................... 112

Table 38. Summary of zones in Highrise Apartment ..................................................... 113

Table 39. Summary of CAV system flow rates $\left(\mathrm{m}^{3} / \mathrm{s}\right)$ in Highrise Apartment ................... 116 


\section{List of Figures}

Figure 1. Wind pressure profile simulated in CONTAM for exterior walls.......................... 10 Figure 2. CONTAM models of Medium Office showing (a) ducted restroom exhaust fan in reference building and (b) simple AHS restroom exhaust system in prototype building ....... 13

Figure 3. Occupancy schedule for Quick Service Restaurant........................................... 18

Figure 4. Floor plan of Quick Service Restaurant (height $3.05 \mathrm{~m}$ )...................................... 18

Figure 5. Thermostat setpoint schedule for Quick Service Restaurant (htg=heating,

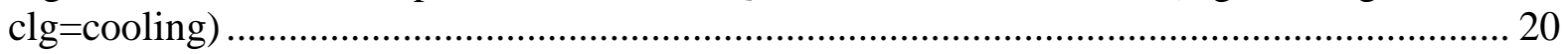

Figure 6. Occupancy schedule for Full Service Restaurant .............................................. 21

Figure 7. Floor plan of Full Service Restaurant (height 3.05 m) ..................................... 22

Figure 8. Thermostat setpoint schedule for Full Service Restaurant .................................. 23

Figure 9. Occupancy schedule for Small Office .............................................................. 24

Figure 10. Floor plan of Small Office (height $3.05 \mathrm{~m}$ ) .................................................... 25

Figure 11. Thermostat setpoint schedule for Small Office ............................................. 26

Figure 12. Occupancy schedule for Medium Office...................................................... 27

Figure 13. Floor plan of Medium Office (height $2.74 \mathrm{~m}$ )................................................ 28

Figure 14. Thermostat setpoint schedule for Medium Office (wkdy=weekday,

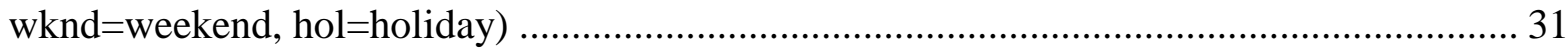

Figure 15. Occupancy schedule for Large Office ............................................................ 32

Figure 16. Basement floor plan of Large Office (height $2.44 \mathrm{~m}$ ). Basement Data Center

carved out of Basement in prototype model. ................................................................... 33

Figure 17. First floor plan of Large Office (height $2.74 \mathrm{~m}$ ). Second through twelfth floors are

identical to first floor. Data Center carved out of Core Zones in prototype model................ 34

Figure 18. First floor plenum plan of Large Office (height $1.26 \mathrm{~m}$ ). Second through twelfth

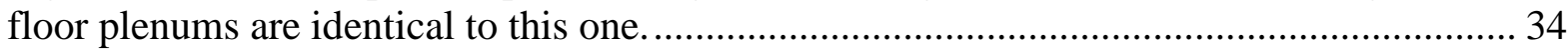

Figure 19. Thermostat setpoint schedule for Large Office ............................................... 37

Figure 20. Occupancy schedules for Primary School (Non-classrooms) - School Year ....... 38

Figure 21. Occupancy schedules for Primary School (Non-classrooms) - Summer Break ... 39

Figure 22. Occupancy schedules for Primary School (Classrooms) - School Year.............. 39

Figure 23. Occupancy schedules for Primary School (Classrooms) - Summer Break .......... 40

Figure 24. Plan of Primary School (height $4.0 \mathrm{~m}$ ) ............................................................ 41

Figure 25. Thermostat setpoint schedule for Primary School (Temp_Class) - Weekday...... 44

Figure 26. Thermostat setpoint schedule for Primary School (Temp_Other) - Weekday ..... 44

Figure 27. Occupancy schedules for Secondary School (Non-classrooms) - School Year ... 47

Figure 28. Occupancy schedules for Secondary School (Non-classrooms) - Summer Break 47

Figure 29. Occupancy schedules for Secondary School (Classrooms, Office) - School Year

Figure 30. Occupancy schedules for Secondary School (Classrooms, Office) - Summer

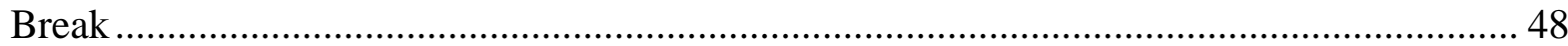

Figure 31. First floor plan of Secondary School (height $4.0 \mathrm{~m}$ ) ........................................ 50

Figure 32. Second floor plan of Secondary School (height $4.0 \mathrm{~m}$ )................................... 51

Figure 33. Thermostat setpoint schedule for Secondary School (Temp_Class - Weekday).. 55

Figure 34. Occupancy schedule for Stand Alone Retail ................................................ 56

Figure 35. Floor plan of Stand Alone Retail (height $6.1 \mathrm{~m}$ ) ............................................ 57

Figure 36. Partial CONTAM model of Stand Alone Retail showing controls for scheduling

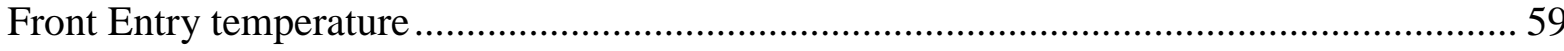


Figure 37. Thermostat setpoint schedule for Stand Alone Retail (Temp_CR)...................... 60

Figure 38. Thermostat setpoint schedule for Stand Alone Retail (Temp_Other) .................. 60

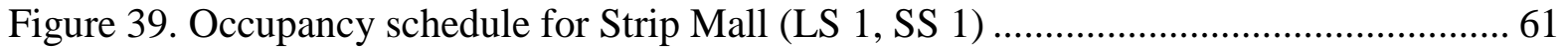

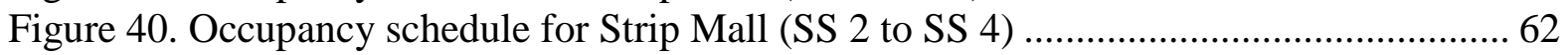

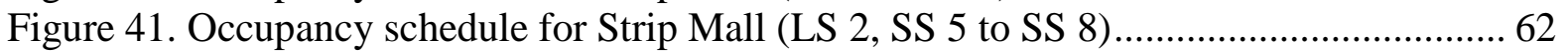

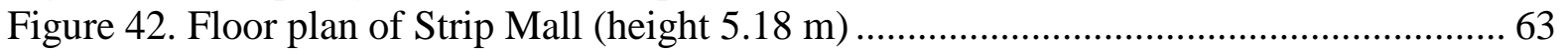

Figure 43. Thermostat setpoint schedule for Strip Mall (Temp_1) ..................................... 65

Figure 44. Thermostat setpoint schedule for Strip Mall (Temp_2) ..................................... 65

Figure 45. Thermostat setpoint schedule for Strip Mall (Temp_3) ...................................... 66

Figure 46. Occupancy schedules for Small Hotel (Restroom and Front Lounge)................. 68

Figure 47. Occupancy schedules for Small Hotel (Laundry, Exercise Room, Meeting Room)

Figure 48. Occupancy schedules for Small Hotel (Employee Lounge)................................ 69

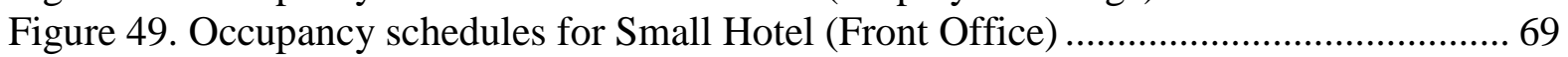

Figure 50. Occupancy schedule for Small Hotel (Guestrooms) ......................................... 70

Figure 51. (a) First and (b) upper floor (2-4) plans of Small Hotel .................................... 71

Figure 52. Thermostat setpoint schedule for Small Hotel (T:NGR, T:SGR) ...................... 74

Figure 53. Occupancy schedules for Large Hotel (guestrooms)........................................ 76

Figure 54. Occupancy schedule for Large Hotel (non-guestrooms) ................................... 76

Figure 55. (a) First, (b) second to fifth, and (c) sixth floors plans of Large Hotel ................. 78

Figure 56. Thermostat setpoint schedule for Large Hotel (Temp-GR-N, Temp-GR-S) ........ 81

Figure 57. Occupancy schedule for Hospital ................................................................... 84

Figure 58. Extended occupancy schedule for Hospital................................................... 84

Figure 59. First floor plan of Hospital (height $4.27 \mathrm{~m}$ ), all dimensions in meters ................ 87

Figure 60. Second floor plan of Hospital (height $4.27 \mathrm{~m}$ ), all dimensions in meters ............ 88

Figure 61. Third/Fourth floor plans of Hospital (height $4.27 \mathrm{~m}$ ), all dimensions in meters... 89

Figure 62. Fifth floor plans of Hospital (height $4.27 \mathrm{~m}$ ), all dimensions in meters .............. 90

Figure 63. Occupancy schedule for Outpatient Health Care ............................................. 96

Figure 64. First floor plan of Outpatient Health Care, all dimensions in meters................... 98

Figure 65. Second floor plan of Outpatient Health Care, all dimensions in meters .............. 99

Figure 66. Third floor plan of Outpatient Health Care, all dimensions in meters ............... 100

Figure 67. Occupancy schedule for Warehouse (Office zone) ......................................... 105

Figure 68. Floor plan of Warehouse (height $8.534 \mathrm{~m}$, except for Office which is $4.267 \mathrm{~m}$

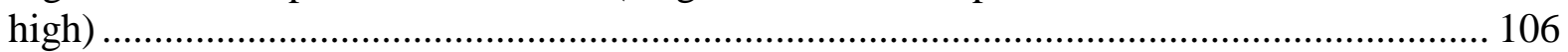

Figure 69. Thermostat setpoint schedule for Warehouse (Office zone) .............................. 108

Figure 70. Occupancy schedules for Midrise Apartment ............................................... 110

Figure 71. Floor plan of Midrise Apartment (height 3.05 m) .......................................... 111

Figure 72. Thermostat setpoint schedule for Midrise Apartment (Office zone).................. 113

Figure 73. Occupancy schedules for Highrise Apartment ............................................... 114

Figure 74. Floor plan of Highrise Apartment (height 3.05 m) ....................................... 115

Figure 75. Thermostat setpoint schedule for Highrise Apartment (Office zone) ................. 118 


\begin{abstract}
A previous report, NIST Technical Note 1734, Airflow and Indoor Air Quality Models of DOE Reference Commercial Buildings [1], detailed the CONTAM models of the 16 U. S. Department of Energy (DOE) reference commercial building models [2]. DOE developed the EnergyPlus building models for use in assessing new technologies and supporting the development of energy codes in pursuing building energy efficiency improvements. The DOE commercial reference buildings were developed to represent buildings that were constructed before 1980, constructed between 1980-2003, and constructed in 2004. Further details on the DOE reference building models can be found in Deru, et al. (2).

Since the release of the DOE reference building models, updates have been made by Pacific Northwest National Laboratory (PNNL) so that the modeled buildings comply with newer versions of ASHRAE Standard 90.1 Energy Standard for Buildings Except Low-Rise Residential Buildings [3] and the International Energy Conservation Code (IECC) [4]. These building models are referred to as the "prototype” buildings, rather than the "reference” buildings. Thus, NIST Technical Note 1734 is updated in this report to reflect the changes to the CONTAM models to match the prototype buildings that comply with ASHRAE Standard 90.1-2013. Updates to the NIST Technical Note 1734 are denoted by red text in this document.

In general, the building geometry and layout of the prototype buildings are the same as the reference buildings, with minor changes to the layout of the Large Office only. In addition, both the reference and prototype building models contain 16 building types. However, the reference buildings include a Supermarket while the prototype buildings include a Highrise Apartment. DOE did not provide reasoning for excluding a Supermarket from the prototype set [5]. All CONTAM models of the prototype buildings required updates to the building envelope airtightness, ventilation airflow rates, ventilation system operation, occupancy, and thermostat setpoint schedules.
\end{abstract}

\title{
Key words
}

Airflow; energy; CONTAM; EnergyPlus; prototype buildings; ventilation; building simulation. 


\section{Introduction}

Heating, ventilating, and air conditioning (HVAC) systems in buildings are designed to provide thermally comfortable conditions and to maintain acceptable indoor air quality (IAQ). At the same time, the operating costs of HVAC systems are often a large percentage of the total energy consumption of commercial buildings, which constitutes about $20 \%$ of the primary energy consumed in the U.S. [6]. In order to address the need to reduce the building sector's contribution to the nation's energy consumption, a number of organizations and government agencies have set energy-related goals and are pursuing research and other activities to support achieving those goals. The U.S. Department of Energy (DOE) has set net-zero energy goals for both residential and commercial buildings by 2025 [7]. The DOE Building Technologies Program (BTP) supports research and development (R\&D) activities to achieve these goals by improving the efficiency of buildings. One of these R\&D activities is the development of the building energy simulation software EnergyPlus and its application to analyze building energy consumption and energy efficiency opportunities. Under the BTP, 16 building models were previously created in EnergyPlus to characterize more than $60 \%$ of the commercial building stock in the U.S. [2]. These buildings were developed to represent buildings that were constructed before 1980 (“pre-1980”), between 1980 and 2003 (“post-1980”), and in 2004 (“new”). For buildings built after 2004, Pacific Northwest National Laboratory (PNNL) updated the reference buildings in support of the development of newer versions of ASHRAE Standard 90.1 Energy Standard for Buildings Except Low-Rise Residential Buildings (2007, 2010, 2013, and 2016) and the International Energy Conservation Code (IECC) (2006, 2009, 2012, 2015). These building models are referred to as the prototype buildings, rather than the reference buildings. The prototype buildings represent $80 \%$ of new commercial construction [5]. Both the reference and prototype building models contain 16 building types (Table 1). However, the reference buildings include a Supermarket while the prototype buildings include a Highrise Apartment as noted in Table 1. DOE did not provide an explanation for excluding a Supermarket from the prototype set [5].

The reference buildings were created to assess new technologies and support the development of energy codes and standards, and therefore their definitions are focused on capturing energy performance. However, many discussions of building energy efficiency neglect potential impacts 
Table 1. List of building types in DOE reference and prototype building sets

\begin{tabular}{lcc}
\hline Building & Reference & Prototype \\
\hline Apartments & & \\
Highrise & $\mathrm{N}$ & $\mathrm{Y}$ \\
Midrise & $\mathrm{Y}$ & $\mathrm{Y}$ \\
\hline Restaurants $^{\text {Full Service }}{ }^{\mathrm{a}}$ & $\mathrm{Y}$ & $\mathrm{Y}$ \\
Quick Service $^{\mathrm{b}}$ & $\mathrm{Y}$ & $\mathrm{Y}$ \\
\hline Healthcare centers $^{\text {Hospital }}$ & $\mathrm{Y}$ & \\
Outpatient & & $\mathrm{Y}$ \\
\hline
\end{tabular}

\begin{tabular}{ccc}
\hline Hotels & & \\
Small & $\mathrm{Y}$ & $\mathrm{Y}$ \\
Large & $\mathrm{Y}$ & $\mathrm{Y}$ \\
\hline Offices & & \\
Small & $\mathrm{Y}$ & $\mathrm{Y}$ \\
Medium & $\mathrm{Y}$ & $\mathrm{Y}$ \\
Large & $\mathrm{Y}$ & $\mathrm{Y}$ \\
\hline
\end{tabular}

\section{Schools}

\begin{tabular}{ccc} 
Primary & $\mathrm{Y}$ & $\mathrm{Y}$ \\
Secondary & $\mathrm{Y}$ & $\mathrm{Y}$ \\
\hline Retail & & \\
Stand Alone & $\mathrm{Y}$ & $\mathrm{Y}$ \\
Strip mall & $\mathrm{Y}$ & $\mathrm{Y}$ \\
Supermarket & $\mathrm{Y}$ & $\mathrm{N}$ \\
\hline Warehouse & $\mathrm{Y}$ & $\mathrm{Y}$ \\
\hline
\end{tabular}

Notes:

a. The Full Service Restaurant was the name given to the model in the reference building set. It was changed to Sit Down Restaurant in the prototype building set. Nevertheless, the name Full Service Restaurant will be used throughout this report and is the name of the CONTAM model available for download on the NIST Multizone Modeling website under Case Studies as discussed below.

b. Similarly, the name of the Quick Service Restaurant was changed to Fast Food Restaurant in the prototype building set but was not changed in this report or the CONTAM models.

on indoor air quality (IAQ) or view acceptable IAQ as being in conflict with energy efficiency [8]. However, saving energy at the expense of IAQ has the potential to significantly impact the 
health, comfort, and productivity of building occupants. In addition, there are many approaches to building design and operation that can improve both energy efficiency and IAQ, such as heat recovery ventilation, demand control ventilation and economizer operation [8]. One limitation in the implementation of certain energy efficiency technologies and the consideration of their impacts on IAQ is that current energy design and analysis tools are limited in their ability to model building airflow and IAQ in a physically reasonable fashion.A review of the airflow and IAQ analyses capabilities of five of the most widely used energy simulation software tools, including EnergyPlus, found that many of the infiltration models employed by energy simulation software are based on calculation methods developed for low-rise, residential buildings [9]. These methods are not generally appropriate for other types of buildings, specifically taller buildings with mechanical ventilation systems, more airtight separations between floors, and vertical shafts. Also, these empirical infiltration models require the user to specify air leakage coefficients that are best obtained from building pressurization tests [10], for which only limited data are available for larger buildings [11]. Many energy simulation software users assume constant infiltration rates, which do not reflect known dependencies on indoor-outdoor conditions and ventilation system operation. However, airflow calculations, using existing theory and methods, are the only technically sound means of determining the airflow rates that are important for analyzing energy use and IAQ.

Thus, models of the 16 reference buildings were created (pre-1980, post-1980, and new versions) in the current version of CONTAM (3.0) in order to perform airflow and IAQ analyses. The full report describing those models can be found in [1] and are free to download on the NIST Multizone Modeling website under Case Studies, where airflow and contaminant analyses were also performed using the "new" (modeled to comply with ASHRAE 90.1-2004 [12]) reference models in Chicago, IL USA. In this report, updates to these previous CONTAM models are documented in order to reflect the updates made to the reference building models to create the prototype building models. Together the EnergyPlus and CONTAM models allow more physically realistic analyses of the energy and IAQ impacts of envelope airtightness and airflowrelated building retrofits and upgrades. The availability of the CONTAM models also supports the study of technologies and approaches that can simultaneously reduce building energy consumption while maintaining or improving IAQ. 
The reference buildings were created to assess new technologies and support the development of energy codes and standards, and therefore their definitions are focused on capturing energy performance. However, many discussions of building energy efficiency neglect potential impacts on indoor air quality (IAQ) or view acceptable IAQ as being in conflict with energy efficiency [8]. However, saving energy at the expense of IAQ has the potential to significantly impact the health, comfort, and productivity of building occupants. In addition, there are many approaches to building design and operation that can improve both energy efficiency and IAQ, such as heat recovery ventilation, demand control ventilation and economizer operation [8]. One limitation in the implementation of certain energy efficiency technologies and the consideration of their impacts on IAQ is that current energy design and analysis tools are limited in their ability to model building airflow and IAQ in a physically reasonable fashion.

While EnergyPlus has an "Airflow Network" capability that implements multizone airflow theory, it is based on an earlier and limited version of AIRNET [13] and COMIS [14]. Airflow Network can calculate infiltration rates arising from pressure differences due to indoor-outdoor conditions and ventilation system operation. It can also model ventilation and duct systems. Advances in the EnergyPlus Airflow Network have been made, and EnergyPlus version 9.1 allows multiple forced air systems to be included, only if the fan types are either constant-air volume or variable-air volume but is limited to only one air handling system per building and wo types of fans. The other fan types in EnergyPlus (Fan: SystemModel, Fan: OnOff, Fan:ZoneExhaust, FanPerformance:NightVentilation, Fan: ComponentModel) cannot be incorporated. The Airflow Network capability was not incorporated into the EnergyPlus models of the reference buildings in order to simplify modeling and reduce simulation times [2].

The CONTAM models of the reference buildings were updated to reflect (1) advances in CONTAM modeling capability, namely its ability to produce scaled models and (2) the requirements in ASHRAE Standard 90.1-2013 [15] and ASHRAE Standard 62.1-2013 [16] that were included in the prototype buildings, and (3) to add temperature schedules that reflect the thermostat setpoints in the EnergyPlus models of the prototype buildings. These updates included changes to the building envelope airtightness, ventilation airflow rates, ventilation system operation, occupancy, and thermostat setpoint schedules. This report documents those 
changes. Together the EnergyPlus and CONTAM models allow more physically realistic analyses of the energy and IAQ impacts of envelope airtightness and airflow-related building retrofits and upgrades. The availability of the CONTAM models also supports the study of technologies and approaches that can simultaneously reduce building energy consumption while maintaining or improving IAQ.

NIST has used the reference and prototype buildings to: perform airflow and IAQ analyses [1, 17], develop weather-correlated infiltration inputs for the EnergyPlus models of the buildings [18-22], and develop an online airtightness savings calculator in collaboration with Air Barrier Association of America (ABAA) and Oak Ridge National Laboratory [23, 24], for developing and exercising the CONTAM-EnergyPlus coupling capability [25, 26] and CONTAM-TRNSYS coupling capability [27], and for studying the potential energy savings from air sealing of commercial buildings [28].

Sec. 2 briefly describes multizone airflow modeling and CONTAM. Sec. 3 describes the prototype buildings and compares the CONTAM and EnergyPlus models in terms of zoning and airflow. Sec. 4 describes the model inputs that are common to both the CONTAM and EnergyPlus models. Sec. 0 gives the details of the CONTAM models, such as geometry, HVAC (heating, ventilating, and air-conditioning) airflow rates, and schedules. Sec. 6 discusses challenges in matching CONTAM (airflow) and EnergyPlus (building energy simulation) models, limitations of modeling airflow and energy separately, the implication for coupled airflow-energy modeling, and future work.

\section{Multizone Modeling: CONTAM}

Multizone network airflow modeling is a method for calculating building pressures, airflows and contaminant transport. Buildings are represented by a network of "zones" connected by "airflow paths". Zones are discrete volumes of air within which mass is conserved, and that generally have uniform temperature, pressure, and contaminant concentration. Air moves between zones along airflow paths with defined flow rates or pressure-dependent resistance to airflow. Contaminants move through the building with the bulk airflow, and can be generated or removed, and may undergo chemical reactions. CONTAM is a multizone airflow simulation software developed at the National Institute of Standards and Technology (NIST) [29]. CONTAM captures infiltration, room-to-room airflows driven by temperature differences, wind 
pressures acting on the building exterior, and mechanically-driven pressure differences. CONTAM is useful for whole-building simulation because its computational time is not as intensive as other airflow simulation methods (e.g., computational fluid dynamics (CFD)) and can model HVAC system interaction with airflows. CONTAM has been validated in terms of program integrity, laboratory experiments and field studies [30-33]. The CONTAM software and more information specific to it can be found at the NIST Multizone Modeling website.

In general, the building geometries and layouts of the prototype buildings are the same as the reference buildings, with were minor changes to the layout of the Large Office only. In addition, both the reference and prototype set of building models contain 16 building types. However, the reference buildings include a Supermarket while the prototype buildings include a Highrise Apartment.

All CONTAM models, except for the Hospital and Outpatient Healthcare buildings, were redrawn to-scale using the pseudo-geometry feature of CONTAM that was not available when the reference models were created. The pseudo-geometry feature simplifies coupling of CONTAM models with EnergyPlus in order to perform combined airflow, contaminant transport and thermal co-simulation [25]. In the CONTAM models of the reference buildings, the floor area was manually entered to match the floor area of the EnergyPlus models. The SketchPad upon which CONTAM models are created implements a rectilinear drawing platform that was not meant to capture detailed geometry. Therefore, the resolution of the model drawn on the SketchPad and a user-defined scaling factor will determine the accuracy of the zone floor areas of the scaled model. The differences between the floor areas of the scaled CONTAM and EnergyPlus models were $1 \%$ for most buildings, but were $2 \%$ for the Stand Alone Retail and $3 \%$ for the Small Hotel.

\section{Building types and modeling approaches}

Table 2 lists the 16 prototype buildings and their floor area, number of floors, and number of zones in the EnergyPlus and CONTAM models. The number of zones is different between the two models in cases where the CONTAM models need additional zones to support more realistic airflow and IAQ analyses. For example, zones that were added to the CONTAM models include restrooms, stairwells, elevator shafts, and storage rooms. In some buildings, zones were also 
resized in order to create more realistic access between adjacent zones. For instance, in the schools, some zones were made smaller in order to create access to them from the corridor. Differences in individual building will be described in Sec. 0 .

In some buildings, "multipliers" are used in the EnergyPlus models to indicate that the thermal load for one particular zone is to be applied to several other ones. This technique is employed to eliminate the need to model each individual zone in EnergyPlus. Zones with multipliers were either on the same floor or on different floors, depending on the building configuration. The building models with multipliers were: Midrise Apartment, Hospital, Large Hotel, and Large Office. In contrast, zone multipliers are not used in the CONTAM models since modeling all or at least more of the building zones is generally important for airflow and IAQ analyses. Therefore, when multiplied zones in EnergyPlus were on the same floor, they were modeled as one large zone in CONTAM. When zones with multipliers were on different floors, they were modeled as separate zones in CONTAM with leakage between them. Though zone areas and the number of zones may be different between the EnergyPlus and CONTAM models, the total building area is consistent between the two models. Further, the CONTAM models employed the occupancy and outdoor air ventilation requirements that were modeled in EnergyPlus.

The following subsections compare the differences between the CONTAM and EnergyPlus models in terms of zoning (Sec. 3.1), how infiltration is modeled (Sec. 3.2), modeling of HVAC systems (Sec. 3.2), and interzonal airflow (Sec. 3.4). 
Table 2. Characteristics of prototype buildings

\begin{tabular}{|c|c|c|c|c|}
\hline Building & $\begin{array}{c}\text { Floor area } \\
\qquad\left(\mathbf{m}^{2}\right)\end{array}$ & $\begin{array}{l}\text { No. of } \\
\text { floors }\end{array}$ & $\begin{array}{c}\text { No. of } \\
\text { EnergyPlus } \\
\text { zones }\end{array}$ & $\begin{array}{c}\text { No. of } \\
\text { CONTAM } \\
\text { zones }\end{array}$ \\
\hline \multicolumn{5}{|l|}{ Apartments } \\
\hline Highrise & 7837 & 10 & 90 & $110^{\mathrm{a}}$ \\
\hline Midrise & 3135 & 4 & 27 & $44^{\mathrm{a}, \mathrm{e}}$ \\
\hline \multicolumn{5}{|l|}{ Restaurants } \\
\hline Full service & 511 & 1 & 2 & $3^{\mathrm{b}}$ \\
\hline Quick service & 232 & 1 & 2 & $3^{\mathrm{b}}$ \\
\hline \multicolumn{5}{|c|}{ Health care centers } \\
\hline Hospital & 22422 & 6 & 55 & $84^{\mathrm{a}, \mathrm{b}}$ \\
\hline Outpatient & 3804 & 3 & 118 & 118 \\
\hline \multicolumn{5}{|l|}{ Hotels } \\
\hline Small & 4013 & 4 & 67 & 67 \\
\hline Large & 11345 & 6 & 22 & $225^{\mathrm{a}, \mathrm{b}, \mathrm{e}}$ \\
\hline \multicolumn{5}{|l|}{ Offices } \\
\hline Small & 511 & 1 & 5 & $6^{\mathrm{a}, \mathrm{b}}$ \\
\hline Medium & 4982 & 3 & 18 & $33^{\mathrm{a}, \mathrm{b}}$ \\
\hline Large & 46320 & 13 & $23^{c}$ & $146^{\mathrm{a}, \mathrm{b}, \mathrm{c}}$ \\
\hline \multicolumn{5}{|l|}{ Schools } \\
\hline Primary & 6871 & 1 & 25 & 25 \\
\hline Secondary & 19592 & 2 & 46 & 46 \\
\hline \multicolumn{5}{|l|}{ Retail } \\
\hline Stand-alone & 2294 & 1 & 5 & $6^{\mathrm{b}}$ \\
\hline Strip mall & 2090 & 1 & 10 & $30^{\mathrm{b}, \mathrm{d}}$ \\
\hline Warehouse & 4835 & 1 & 3 & $4^{\mathrm{b}}$ \\
\hline
\end{tabular}

a) Includes stairwell(s) and elevator shaft(s) not in the EnergyPlus models.

b) Includes restroom(s) not in the EnergyPlus models.

c) Zones were added in the prototype models that were not in the reference models. Changes are reflected in the CONTAM model.

d) Includes storage rooms not in the EnergyPlus models.

e) Zone multipliers

\subsection{Zoning strategy}

The predominant zoning strategy used in the CONTAM models is one zone per physical room.

The zoning generally matches that used in the EnergyPlus models. In some cases, similar rooms are grouped together into a single zone in EnergyPlus in order to simplify thermal calculations. 
"Multipliers" are used in the EnergyPlus models to indicate that the thermal load for one particular zone is to be applied to several other ones, or simply multiplied. Each zone is served by the same system and has the same occupancy and usage profiles in EnergyPlus. In CONTAM, each zone also experiences the same wind and stack effects. Examples of zones with multipliers in the EnergyPlus models are guest rooms in the hotels and examination rooms in the Hospital. How these multiplied zones are modeled in CONTAM will be discussed in Sec. 0 when describing each building model in detail.

In some buildings, zones are added or subdivided to make the models more realistic and useful as multizone models. These changes are noted on the drawings of the individual buildings in Sec. 0 . The changes mostly involve the addition of restrooms, stairwells, and elevator shafts. These are zones whose unique features can significantly influence building airflow, and are thus desirable to include in a multizone network airflow model of a building.

\subsection{Infiltration}

In CONTAM, infiltration is calculated based on building envelope airtightness, weather, and ventilation system operation. In contrast, infiltration in the EnergyPlus models was simplified to only include the effects of wind speed based on a sensitivity study by Gowri, Winiarski and Jarnagin (34) using the Medium Office model only. A factor of 0.25 was applied in the EnergyPlus models to the "design infiltration rate" when the ventilation system was on that reduces the calculated infiltration rate. This arbitrary reduction is not reflected in CONTAM results because CONTAM calculates infiltration based on weather and system effects [1, 17, 21, 22]. The following subsections describe how infiltration was calculated in CONTAM and EnergyPlus in detail.

\section{CONTAM}

Building exterior envelope leakage was modeled in CONTAM using an effective leakage area $\left(A_{L}\right)$ of $2.2 \mathrm{~cm}^{2} / \mathrm{m}^{2}$ at a reference pressure difference $\left(\Delta P_{r}\right)$ of $4 \mathrm{~Pa}$, a discharge coefficient $\left(C_{D}\right)$ of 1.0, and a pressure exponent ( $n$ ) of 0.65 for the prototype buildings designed to comply with ASHRAE Standard 90.1-2013 [3]. This envelope leakage was applied to all above-grade exterior walls, ceilings, roofs, and floors. Basement walls and slab floors were modeled with no leakage. The infiltration airflow through these leaks is calculated by CONTAM using a power-law relationship: 


$$
Q=\frac{C_{D} A_{L}}{10000} \sqrt{\frac{2}{\rho}}\left(\Delta P_{r}\right)^{0.5-n} \Delta P^{n}
$$

where the indoor-outdoor pressure difference $(\Delta P)$ is calculated by CONTAM based on wind and stack effects and ventilation equipment operation, as well as interior zone pressure relationships. CONTAM also calculates the air density $(\rho)$ based on the temperature of the air entering the leakage site. Detailed discussion on how CONTAM calculates these values is found in Dols and Polidoro (29). To capture the stack effect more accurately, exterior wall leakage was divided into three portions on each wall, representing the lower third, middle third, and upper third of each wall. Wind effects are calculated using a wind pressure profile, which describes the wind pressure coefficients $\left(C_{P}\right)$ as a function of wind directions $(\theta)$. Figure 1 is the wind pressure profile that was used [35]. A wind speed modifier of 0.36, which corresponds to "suburban” terrain [36], was applied to all exterior leakage paths.

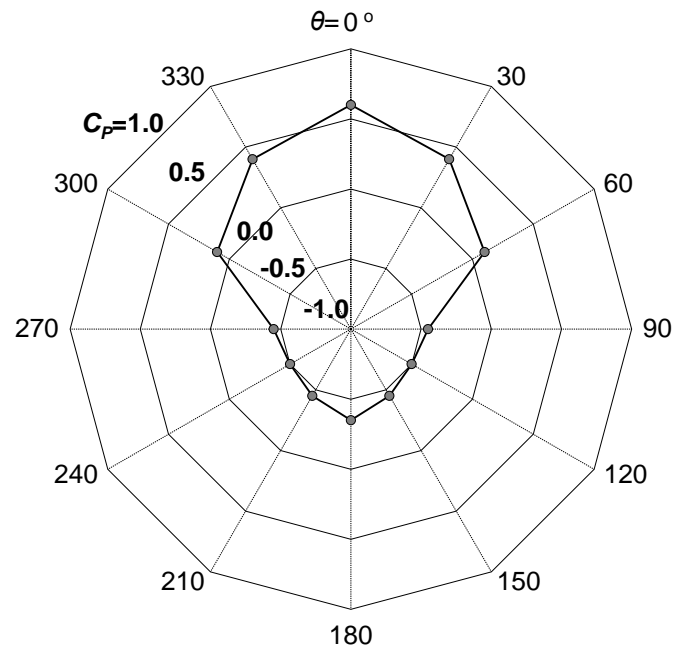

Figure 1. Wind pressure profile simulated in CONTAM for exterior walls

For openings on roofs, $C_{P}$ was -0.5 for all wind directions. This was an average value for roofs with less than a 15 degree slope shown in the ASHRAE Handbook of Fundamentals [6]. For buildings with attics, leakage from the roof was modeled with venting equal to $1 / 150$ of the floor area [37].

The effective leakage area of partitions between floors and between zones used the same value as the exterior wall leakage $\left(2.2 \mathrm{~cm}^{2} / \mathrm{m}^{2}\right.$ at $\left.4 \mathrm{~Pa}\right)$. The connections between zones that would not have a physical partition, such as within an open office or retail space, were modeled as large 
openings with discharge coefficient $C_{D}=0.6$ and $n=0.5$. The size of these openings ranged from $50 \%$ to $75 \%$ of the wall area between zones. Transfer grilles, ranging from $0.186 \mathrm{~m}^{2}$ to $0.372 \mathrm{~m}^{2}$, and door undercuts of $0.025 \mathrm{~m}^{2}$, were modeled between restrooms and adjacent zones.

\section{EnergyPlus}

A simplified approach for modeling infiltration was used in the EnergyPlus models of the prototype buildings in order to simplify the assumptions needed and to reduce simulation times $[2,5]$. For the EnergyPlus models, building envelope leakage was also $2.2 \mathrm{~cm}^{2} / \mathrm{m}^{2}$ at a constant indoor-outdoor pressure of $4 \mathrm{~Pa}$. Using Equation (1), this building envelope leakage is equivalent to an airflow rate at $4 \mathrm{~Pa}$ of $5.69 \times 10^{-4} \mathrm{~m}^{3} / \mathrm{s} \cdot \mathrm{m}^{2}$ of exterior surface area, which is input into the EnergyPlus models as the “design infiltration rate”. Note that this building envelope leakage is $86 \%$ greater than that of the reference building models.

Infiltration was scheduled to be $100 \%$ of the input value when the ventilation system was scheduled to be off and reduced to $25 \%$ when the ventilation system was scheduled to be on based on simplified assumptions about infiltration. The exceptions to this approach were the Midrise and Highrise Apartment building models. The HVAC system for these buildings were scheduled to always be on and the EnergyPlus models had infiltration scheduled at $100 \%$ rather than a reduced value, presumably based on an assumption that these buildings would operate at neutral pressure. Thus, in CONTAM, these two apartment building models were modeled assuming the total supply airflow rates equaled total return airflow rates (see details in Sec. 5.15 and Sec. 5.16).

It should be noted that EnergyPlus assumes a constant indoor-outdoor pressure difference of $4 \mathrm{~Pa}$ whereas the indoor-outdoor pressure difference across the exterior envelope is actually calculated in CONTAM. Assuming a constant pressure difference does not reflect known dependencies of infiltration on indoor-outdoor pressure differences. Comparisons between the assumed infiltration rates in EnergyPlus and those calculated by CONTAM can be found in [1].

\subsection{HVAC systems}

The outdoor and exhaust systems, and heating/cooling systems, and their models are discussed below. 


\section{Outdoor and exhaust air systems}

The minimum amount of outdoor ventilation air for each zone (or HVAC system) was specified in EnergyPlus using the requirements in ASHRAE Standard 62.1-2013 [38]. Depending on the thermal load calculated at each time step and the indoor-outdoor conditions, EnergyPlus varied the amount of outdoor ventilation. However, the minimum amount of outdoor ventilation air for each zone (or HVAC system) was modeled in CONTAM with no economizer cycle to simplify the modeling inputs. Details on the supply, return, and outdoor ventilation rates modeled in CONTAM can be found in Sec. 0 for each building.

The Energy Plus models have a variety of system types, ranging from through-the-wall packaged single zone systems to variable-air volume (VAV) air handling units. All air handling units serving multiple zones were modeled using the "simple air handling system" (or "simple AHS”) in CONTAM. The simple air handling unit components were modeled as follows:

- The volume of supply ductwork was specified as $1 \%$ of the building volume served by the system.

- The volume of return ductwork was specified as $0.5 \%$ of the building volume served by the system (if no return air plenum is present) and $0.25 \%$ of the building volume served (if a return air plenum is present).

- Supply and return diffusers were located in the zones to provide the design (or maximum) airflow rate calculated by EnergyPlus. For VAV systems included in the EnergyPlus models, only the maximum airflow rates calculated by EnergyPlus were modeled in CONTAM.

- Outdoor ventilation rates were specified at the air handling unit to provide the minimum ventilation rate specified in EnergyPlus.

In most zones of the buildings, the EnergyPlus HVAC systems were modeled with the supply airflow rate equal to the return airflow rate. In some zones, such as dining and kitchen zones, there was an excess of exhaust, so that the return was reduced such that the sum of the return and exhaust equalled the supply. The effect of infiltration (either from outside or adjacent zones) on thermal loads is considered in EnergyPlus, but infiltration is not part of the mass balance of air into or out of the zones. In CONTAM, however, infiltration is calculated using the zone pressure.

Exhaust fans, such as those for restrooms and kitchens, were modified from the existing CONTAM models to be a "simple AHS" rather than ducted fan components. This allows the CONTAM models to be coupled with EnergyPlus since CONTAM ductwork elements cannot currently be incorporated into the coupling. An example is shown in Figure 2 for the Medium 
Office. Restrooms were not included in many of the EnergyPlus models. In these buildings, restrooms were added to the CONTAM models and the flow rates were based on ASHRAE Standard 62.1-2013 [38].

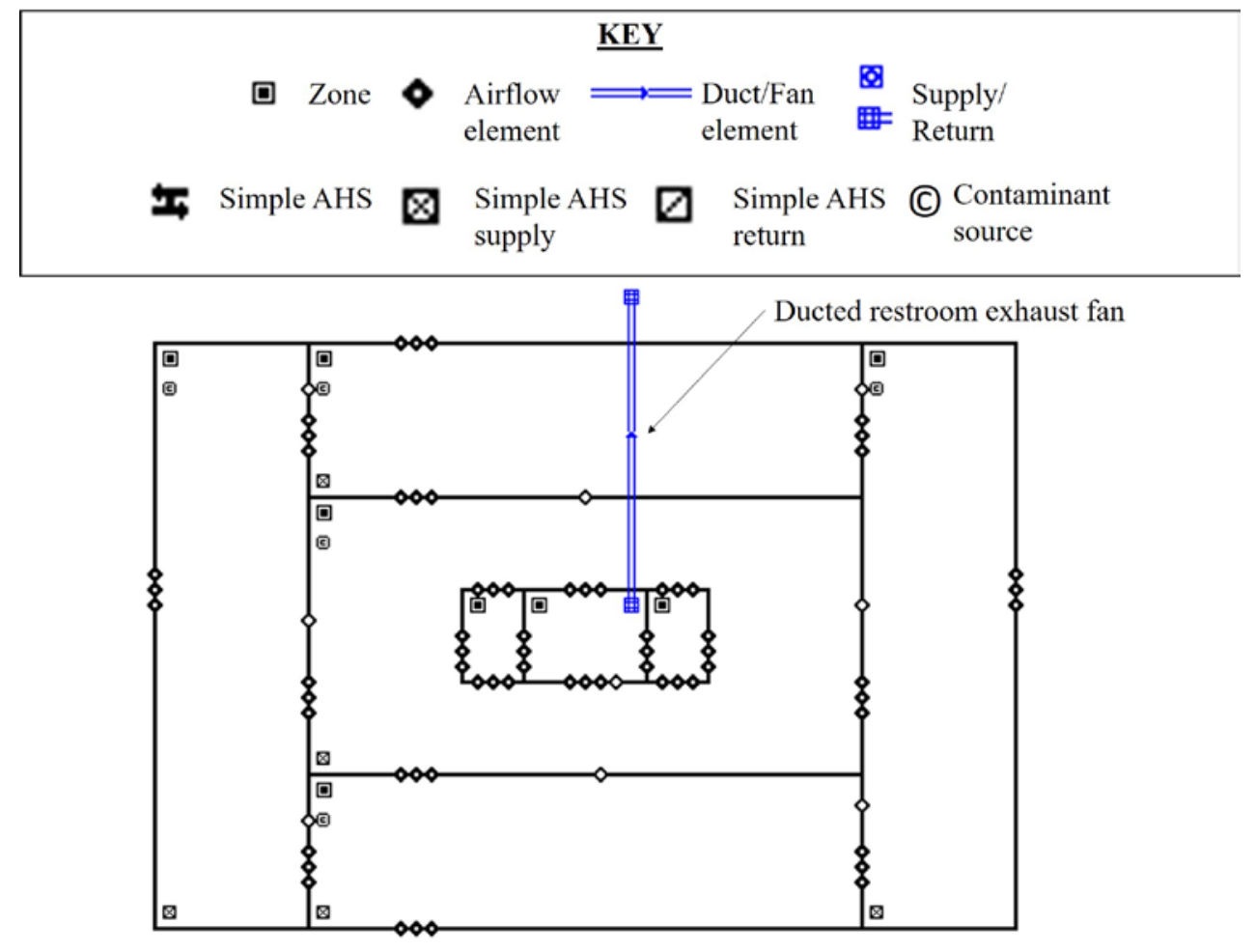

(a)

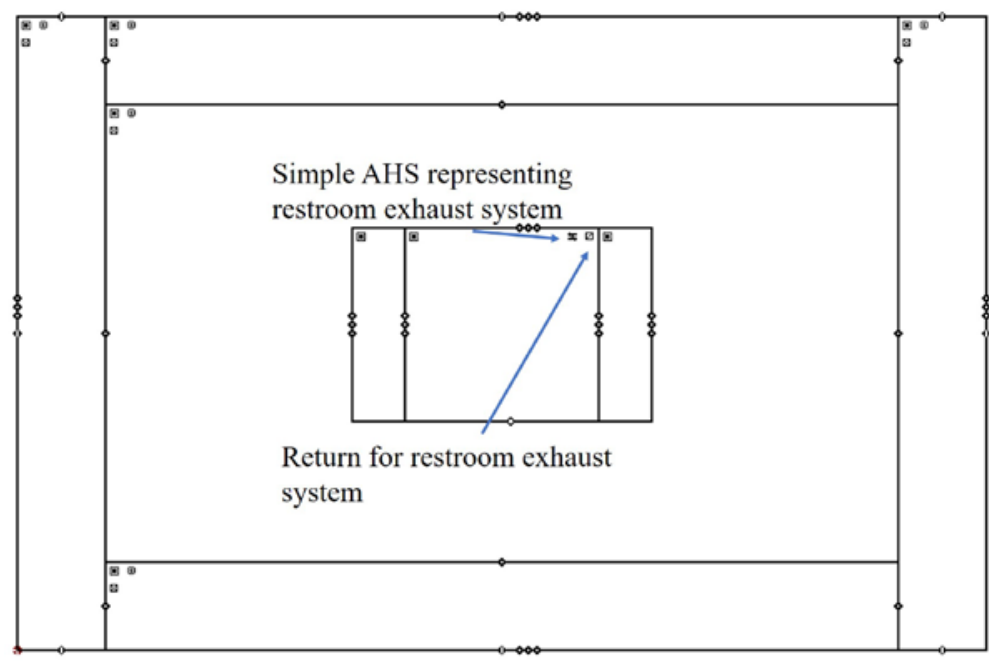

(b)

Figure 2. CONTAM models of Medium Office showing (a) ducted restroom exhaust fan in reference building and (b) simple AHS restroom exhaust system in prototype building 
Most of the EnergyPlus models of prototype buildings had economizer operation activated. The ones that did not were the: Highrise Apartment, Midrise Apartment, and Small Office. Economizer operation increased the ventilation rate above the minimum requirement when certain conditions were met. Goel, et al. (5) provide a detailed description of these conditions. Economizer operation was not implemented in the CONTAM models since most are temperature-based and CONTAM does not perform thermal calculation.

\section{Heating and cooling systems}

The maximum design flow rates determined by the EnergyPlus simulation for each building were used as inputs for the HVAC supplies in the CONTAM model. For the prototype buildings, Chicago TMY3 weather [39] was used in EnergyPlus to determine maximum design flow rates. The maximum design flow rates for Chicago were less than $5 \%$ different from the rates for other cities. Therefore, the design flow rates for Chicago are reported in Sec. 0 and are the rates used in the CONTAM models for all cities for download on the NIST Multizone Modeling website.

The common design goal of pressurizing commercial buildings was accounted for in the CONTAM models by returning $90 \%$ of the supply airflow rate. In CONTAM, the Midrise and Highrise Apartment building models were modeled assuming the total supply airflow rates equaled total return airflow rates, since the infiltration rate in the EnergyPlus models was not reduced while the ventilation system was scheduled to be on. In CONTAM, this was also the case for the Full Service and Quick Service Restaurants.

In the CONTAM reference building models, a constant indoor temperature of $20^{\circ} \mathrm{C}$ was assumed. In the updated CONTAM models, the cooling and heating setpoints specified for occupied and unoccupied hours in the EnergyPlus models were used to create CONTAM schedules. It was assumed that the cooling season was May $1^{\text {st }}$ through September $30^{\text {th }}$. Details on the cooling and heating setpoints for each building model are given in Sec. 0 .

\subsection{Interzonal airflow}

A physical wall (two layers of $1 / 2$ ” (13 mm) gypsum) was modeled in EnergyPlus between the zones for which no physical partition would actually exist (e.g., open floor plan in the office models). The walls were modeled in this way to produce temperature differences between the zones, but no airflow between these zones was modeled in EnergyPlus. 
In other building models, a simplified approach for interzone airflow was taken. In the Hospital model, the ZoneMixing object was used in EnergyPlus to transfer air to the Kitchen from the zones on the same floor. The transfer of air is only in one direction. In the Large Hotel and two Restaurant models, this approach was also used to transfer air to the Kitchen from the adjacent zones. A dummy exhaust fan was then modeled in the adjacent zones at a removal rate equal to the transferred airflow rate in order to balance flows in the zones. In CONTAM, however, the transfer of air is accomplished by modeling large openings between zones. Exhaust fans are modeled in CONTAM only if they are used for exhausting air to the outside, not transferring air.

There was no airflow between building floors in the EnergyPlus models. In contrast, large openings are modeled between the zones in CONTAM so that airflow can occur between floors.

\section{Common model inputs}

These were the inputs that were either the same or similar between the CONTAM and EnergyPlus models.

\subsection{Schedules}

CONTAM employs daily and weekly schedules [29]. Each week schedule consists of 12 days one for each day of the week (Sunday through Saturday) and five more days for special situations such as holidays. These are referred to as the 12 “day types”. Table 3 shows how the day types are assigned in CONTAM for the prototype buildings. Most of the schedules in the EnergyPlus prototype building models were converted to the default 12 day type format since they follow the format in Table 3. The building models that could not use the default 12 day type scheduling feature for all of the schedules were: Primary School, Secondary School, and Strip Mall.

Table 3. Assigning CONTAM day types to events for prototype buildings

\begin{tabular}{ccc}
\hline CONTAM Day Type & Actual Event & Season (Dates applicable) \\
\hline Sunday-Saturday & Sunday-Saturday & Heating $(10 / 1$ to $4 / 30)$ \\
8 & Holiday & \\
\hline 9 & Monday-Friday & \\
10 & Saturday & Cooling $(5 / 1$ to $9 / 30)$ \\
11 & Sunday & \\
12 & Holiday & \\
\hline
\end{tabular}


For buildings where the occupancy, HVAC operation schedule, or thermostat setpoint schedules did not coincide with the heating and cooling seasons (i.e., 10/1 to 4/30 and 5/1 to 9/30), or did not fit the default 12 day type schedules in CONTAM, continuous value files (CVF) were used instead. The format of the CVF is found in the CONTAM User Manual [29]. CVFs were used in the prototype models to indicate occupancy, fan status, and temperature for every hour of the year, though time steps less than one hour can be used in CONTAM.

The building models that utilized CVFs were: both Schools for occupancy and fan operation, Hospital for occupancy, Stand Alone Retail for the temperature schedule in the front entry zone, and Strip Mall for the schedules in two of the ten stores. Details on the CVFs are given in Sec. 0.

For all of the buildings, holidays fall on the following days:

- January 1

- November 11

- December 25

- July 4

- $3^{\text {rd }}$ Monday in January

- $3^{\text {rd }}$ Monday in February

- Last Monday in May

- $1^{\text {st }}$ Monday in September

- $\quad 2^{\text {nd }}$ Monday in October

- $4^{\text {th }}$ Thursday in November

Other calendar events included:

- Daylight savings is implemented from the $2^{\text {nd }}$ Sunday in March to the end of the day on the $1^{\text {st }}$ Sunday in November.

- January 1 is a Sunday

- No weekend holiday rule is used, meaning holidays that fall on a weekend are not observed on the following Monday

\subsection{Weather}

Weather files were imported into the CONTAM weather file format (.WTH) from TMY3 weather files [39] for eight U. S. cities in eight climate zones defined by ASHRAE [40] and listed in Weather files were imported into the CONTAM weather file format (.WTH) from TMY3 weather files [39] for eight U. S. cities in eight climate zones defined by ASHRAE [40] as listed in Table 4. 
Table 4. Climate zones and associated city

\begin{tabular}{|c|c|}
\hline Climate zone (CZ) & City, State (USA) \\
\hline \hline 1 & Miami, Florida \\
\hline 2 & Phoenix, Arizona \\
\hline 3 & Memphis, Tennessee \\
\hline 4 & Baltimore, Maryland \\
\hline 5 & Chicago, Illinois \\
\hline 6 & Helena, Montana \\
\hline 7 & Duluth, Minnesota \\
\hline 8 & Fairbanks, Alaska \\
\hline
\end{tabular}

\section{Building details}

The following subsections describe each of the 16 prototype buildings in terms of geometry and layout, and differences between the CONTAM and EnergyPlus models. It also describes the HVAC system model in each building and the associated operation schedules. In general, the operation and occupancy schedules in CONTAM were created to match those in the EnergyPlus models. However, it should be noted that the operation schedules in EnergyPlus are actually "availability” schedules, meaning they can be operated during the specified times but will not necessarily run if thermostat setpoints are already met. However, since CONTAM cannot perform thermal calculations, the availability schedules of ventilation systems in the EnergyPlus models were implemented as the operation schedules in CONTAM.

\subsection{Quick Service Restaurant}

Table 5 summarizes the zones modeled in CONTAM for the Quick Service Restaurant, their respective sizes, and maximum occupancy.

Table 5. Summary of zones in Quick Service Restaurant

\begin{tabular}{lrrr}
\hline Zone & Area $\left.\mathbf{( m}^{\mathbf{2}}\right)$ & Height $(\mathbf{m})$ & Maximum occupancy \\
\hline Dining & 116 & 3.05 & 87 \\
Kitchen & 100 & 3.05 & 6 \\
Restroom & 16 & 3.05 & 0 \\
Attic & 232 & 1.13 & 0 \\
\hline
\end{tabular}




\section{Occupants:}

The peak number of people for each zone is listed in Table 5. Occupants in all building zones are scheduled according to Figure 3. There is a different occupancy schedule for weekdays and weekends/holidays.

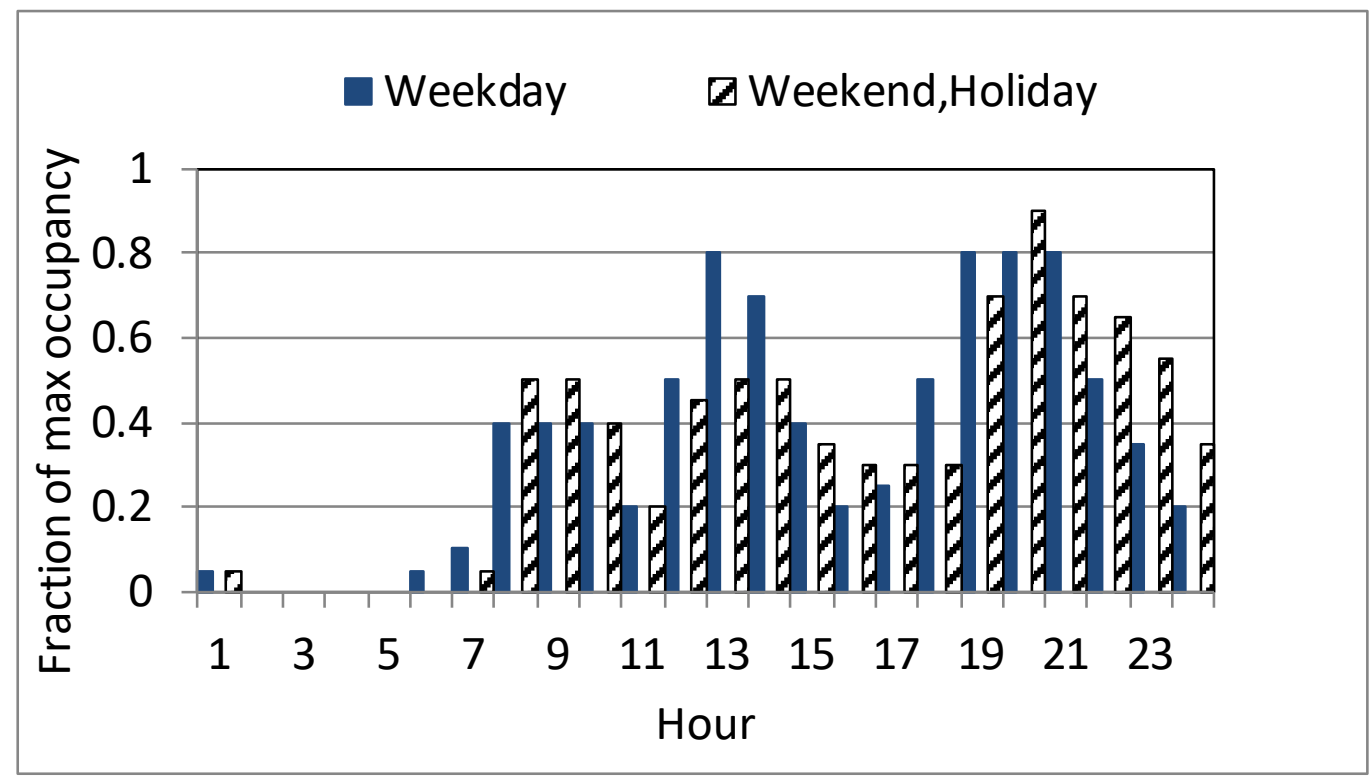

Figure 3. Occupancy schedule for Quick Service Restaurant

\section{Geometry:}

$232.2 \mathrm{~m}^{2}$ footprint, single-story building with attic. The EnergyPlus model has two zones (not including the Attic) - Dining and Kitchen. In the CONTAM model, a Restroom (shaded in Figure 4) with a footprint of $4 \mathrm{~m} \times 4 \mathrm{~m}$ was carved out of the Kitchen.

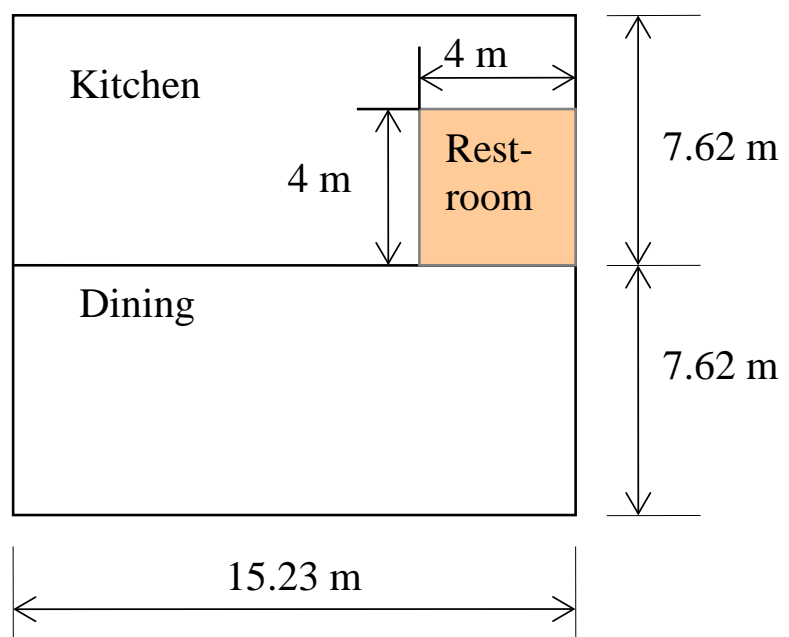

Figure 4. Floor plan of Quick Service Restaurant (height 3.05 m) 
Large interior leakage paths were defined as follows:

- Between the Dining and Kitchen zones, a single large leakage path of $25.7 \mathrm{~m}^{2}$ (75 \% of the total wall area between the two spaces) is modeled;

- Between the Restroom and Dining zones, a $0.186 \mathrm{~m}^{2}$ transfer grille is modeled.

\section{HVAC systems:}

The EnergyPlus model has two packaged constant-volume single-zone systems. In CONTAM, two versions were created. In the first ("V1"), both the Kitchen and Dining have constantvolume systems. The Kitchen is supplied with $100 \%$ outside air using a dedicated fan. The supply air, return air, outside air, and exhaust flow rates modeled in CONTAM are listed in Table 6. The Dining is supplied with the outside airflow rate listed in Table 6. The exhaust flow rate for the Restroom was modeled only in CONTAM, not in EnergyPlus. The Kitchen also has a dedicated exhaust system at the airflow rate listed in Table 6, which is modeled in EnergyPlus too.

The EnergyPlus model has a Dining exhaust fan $\left(0.41 \mathrm{~m}^{3} / \mathrm{s}\right)$ in addition to the Kitchen exhaust fan $\left(1.56 \mathrm{~m}^{3} / \mathrm{s}\right)$. The ZoneMixing object was used in EnergyPlus to transfer this air from Dining to the Kitchen. This is modeled in CONTAM using a large opening between the Dining and Kitchen zones (see above), and one exhaust fan in the Kitchen $\left(1.56 \mathrm{~m}^{3} / \mathrm{s}\right.$ ).

In EnergyPlus, balanced HVAC systems are modeled in all zones. Based on discussion with restaurant designers, it is most realistic to model the restaurant with a balanced system in CONTAM as well. Thus, with the large exhaust fan in the Kitchen, the return for the Dining was reduced to $0 \mathrm{~m}^{3} / \mathrm{s}$ and the Kitchen return reduced to $1.11 \mathrm{~m}^{3} / \mathrm{s}$ in CONTAM.

In V2 of the Quick Service Restaurant, both the Kitchen and Dining are served by a single AHS with the supply airflow and outdoor airflow rates listed in Table 6. The Kitchen and Restroom exhaust systems are modeled the same as in V1 and V2.

Table 6. Summary of HVAC system flow rates $\left(\mathrm{m}^{3} / \mathrm{s}\right)$ in Quick Service Restaurant $(\mathrm{V} 1, \mathrm{~V} 2)$

\begin{tabular}{lrrrr}
\hline Zone & Supply & Return & Outside air & Exhaust air \\
\hline Dining & 1.53 & 1.11 & 0.42 & 0.00 \\
Kitchen & 1.14 & 0.00 & 1.14 & 1.56 \\
Restroom & N/A & N/A & 0.00 & 0.04 \\
\hline
\end{tabular}




\section{HVAC Schedules:}

All HVAC and exhaust fans operate on the following schedule:

- Every day: on from 5:00 a.m. to 1:00 a.m., off otherwise

- Outside air is supplied according to this schedule as well.

Temperature setpoints:

The Dining and Kitchen each have their own thermostat setpoint schedules and are the same every day of the week including holidays. Both the heating and cooling thermostat setpoints are shown in Figure 5. The Restroom was maintained at $23^{\circ} \mathrm{C}$ throughout the year only in CONTAM since the EnergyPlus model did not have a Restroom zone.

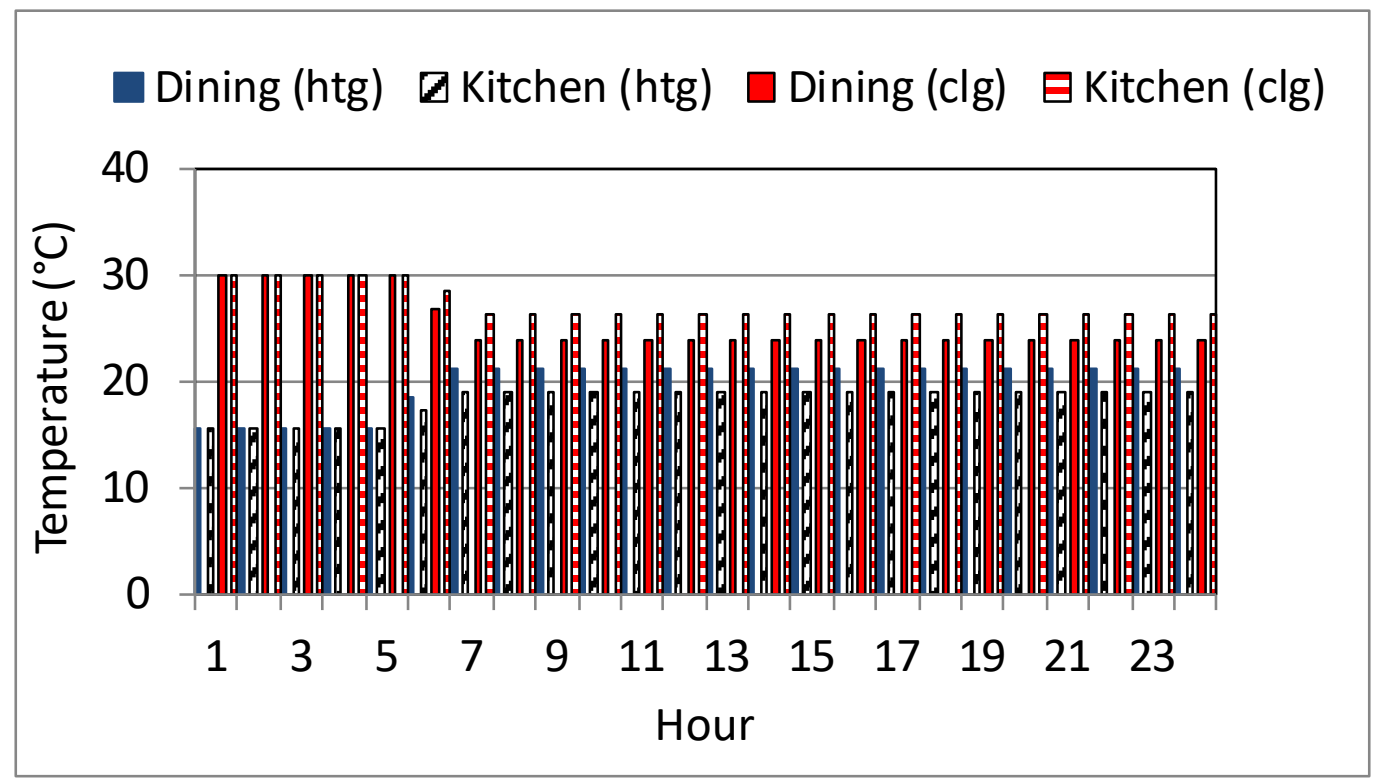

Figure 5. Thermostat setpoint schedule for Quick Service Restaurant (htg=heating, clg=cooling)

\subsection{Full Service Restaurant}

Table 7 summarizes the zones modeled in CONTAM for the Full Service Restaurant, their respective sizes, and maximum occupancy.

Table 7. Summary of zones in Full Service Restaurant

\begin{tabular}{lrrr}
\hline Zone & Area $\left.\mathbf{( m}^{\mathbf{2}}\right)$ & Height $(\mathbf{m})$ & Maximum occupancy \\
\hline Dining & 372 & 3.05 & 280 \\
Kitchen & 139 & 3.05 & 8 \\
Restroom & 16 & 3.05 & 0 \\
Attic & 511 & 1.68 & 0 \\
\hline
\end{tabular}




\section{Occupants:}

The peak number of people for each zone is listed in Table 7. Occupants in all building zones are scheduled according to Figure 6. There is a different occupancy schedule for weekdays, Saturdays, and Sundays/holidays.

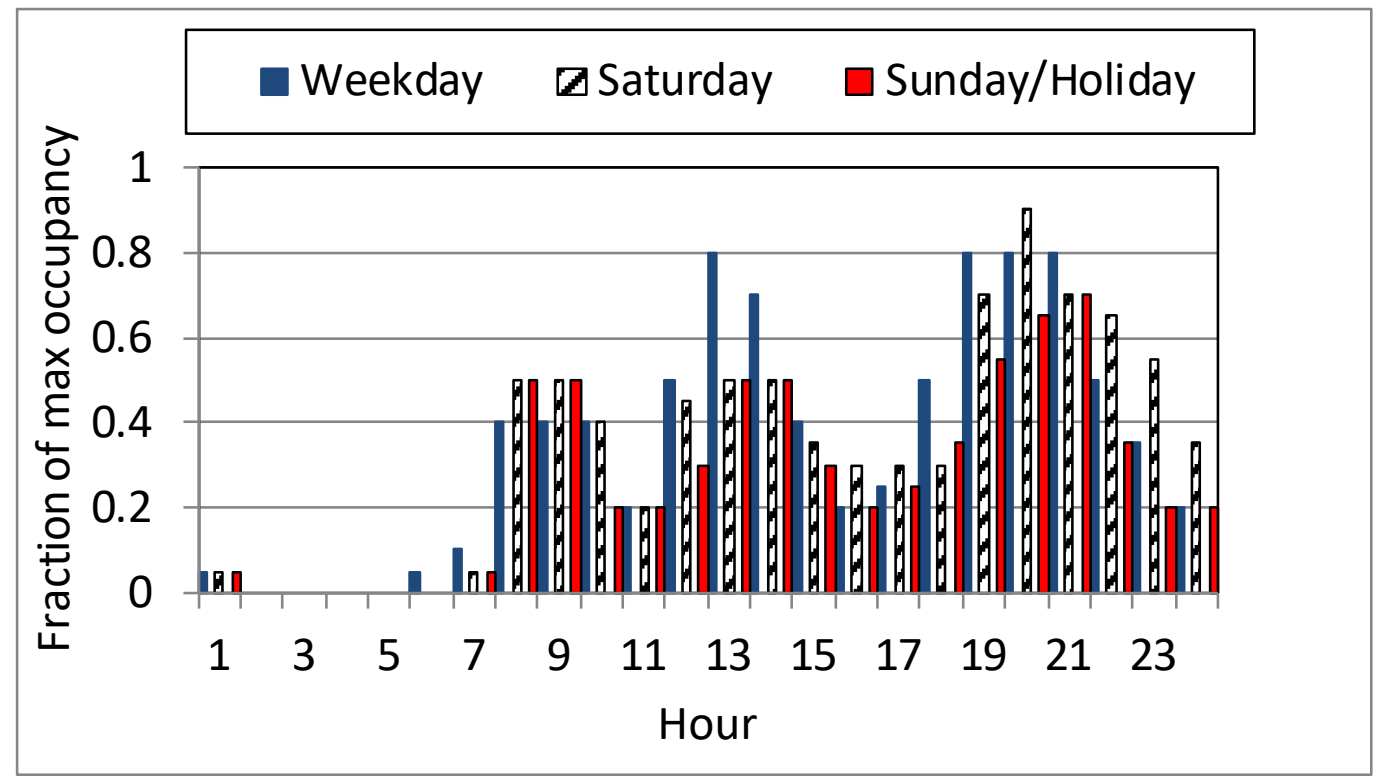

Figure 6. Occupancy schedule for Full Service Restaurant

\section{Geometry:}

$511 \mathrm{~m}^{2}$ footprint, single-story building with attic. The EnergyPlus model has two zones (not including the Attic) - Dining and Kitchen. In the CONTAM model, a Restroom (shaded in Figure 7) with a footprint of $4 \mathrm{~m} \times 4 \mathrm{~m}$ was carved out of the Kitchen.

Large interior leakage paths were defined as follows:

- Between the Dining and Kitchen zones, a single large leakage path of $42.57 \mathrm{~m}^{2}$ (75 \% of the total wall area between the two spaces) is modeled;

- Between the Restroom and Dining zones, a $0.186 \mathrm{~m}^{2}$ transfer grille is modeled. 


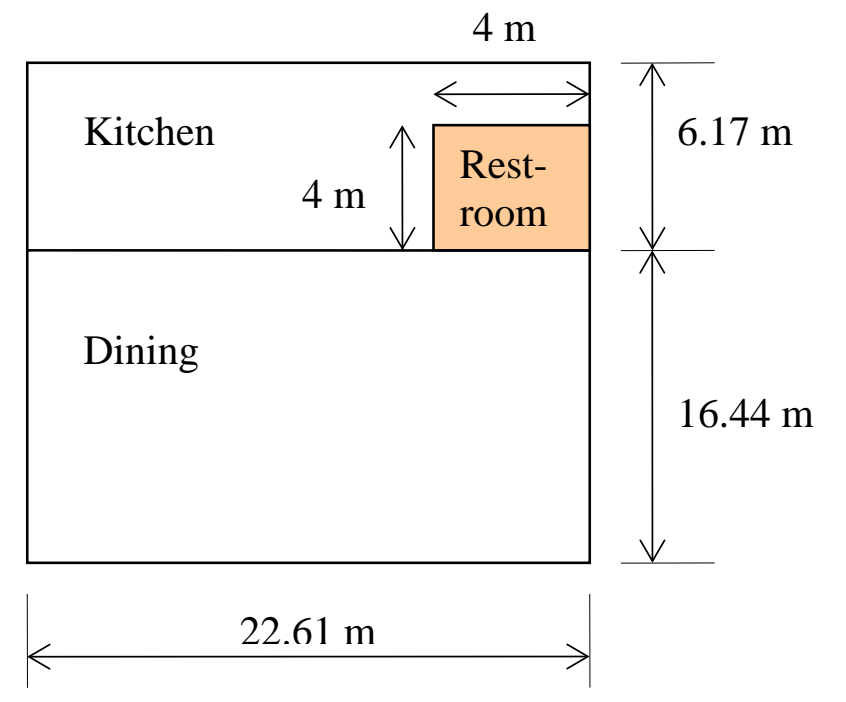

\section{Figure 7. Floor plan of Full Service Restaurant (height 3.05 m)}

\section{HVAC systems:}

The EnergyPlus model has two packaged constant-volume single-zone systems. In CONTAM, two versions were created. In the first ("V1"), both the Kitchen and Dining have constantvolume systems. The Kitchen is supplied with $100 \%$ outside air using a dedicated fan. The supply air, return air, outside air, and exhaust flow rates modeled in CONTAM are listed in Table 8. The Dining is supplied with the outside airflow rate listed in Table 8. The exhaust flow rate for the Restroom was modeled only in CONTAM, not in EnergyPlus. The Kitchen also has a dedicated exhaust system at the rate listed in Table 8.

The EnergyPlus model has a Dining exhaust fan $\left(1.33 \mathrm{~m}^{3} / \mathrm{s}\right)$ in addition to the Kitchen exhaust fan $\left(2.55 \mathrm{~m}^{3} / \mathrm{s}\right)$. The ZoneMixing object was used in EnergyPlus to transfer this air from Dining to the Kitchen. This is modeled in CONTAM using a large opening between the Dining and Kitchen zones (see above), and one exhaust fan in the Kitchen and one in the Restroom. In EnergyPlus, balanced HVAC systems are modeled in all zones. Based on discussion with restaurant designers, it is most realistic to model the restaurant with a balanced system in CONTAM as well. Thus, with the large exhaust fan in the Kitchen, the return for the Dining was reduced to $0 \mathrm{~m}^{3} / \mathrm{s}$ and the Kitchen return reduced to $1.54 \mathrm{~m}^{3} / \mathrm{s}$ in CONTAM.

In V2 of the Full Service Restaurant, both the Kitchen and Dining are served by a single AHS with the supply airflow and outdoor airflow rates listed in Table 8. The Kitchen and Restroom exhaust systems are modeled the same as in V1 and V2. 


\section{HVAC Schedules:}

All HVAC and exhaust fans operate on the following schedule:

- Every day: on from 5:00 a.m. to 1:00 a.m., off otherwise

- Outside air is supplied according to this schedule as well.

Table 8. Summary of HVAC system flow rates $\left(\mathrm{m}^{3} / \mathrm{s}\right)$ in Full Service Restaurant $(\mathrm{V} 1, \mathrm{~V} 2)$

\begin{tabular}{lrrrr}
\hline Zone & Supply & Return & Outside air & Exhaust air \\
\hline Dining & 2.77 & 1.54 & 1.33 & 0.00 \\
Kitchen & 1.32 & 0.00 & 1.22 & 2.55 \\
Restroom & N/A & N/A & 0.00 & 0.04 \\
\hline
\end{tabular}

Temperature setpoints:

The Dining and Kitchen each have their own thermostat setpoint schedules and are the same every day of the week including holidays. Both the heating and cooling thermostat setpoints are shown in Figure 8. The Restroom was maintained at $23^{\circ} \mathrm{C}$ throughout the year only in CONTAM since the EnergyPlus model did not have a Restroom zone.

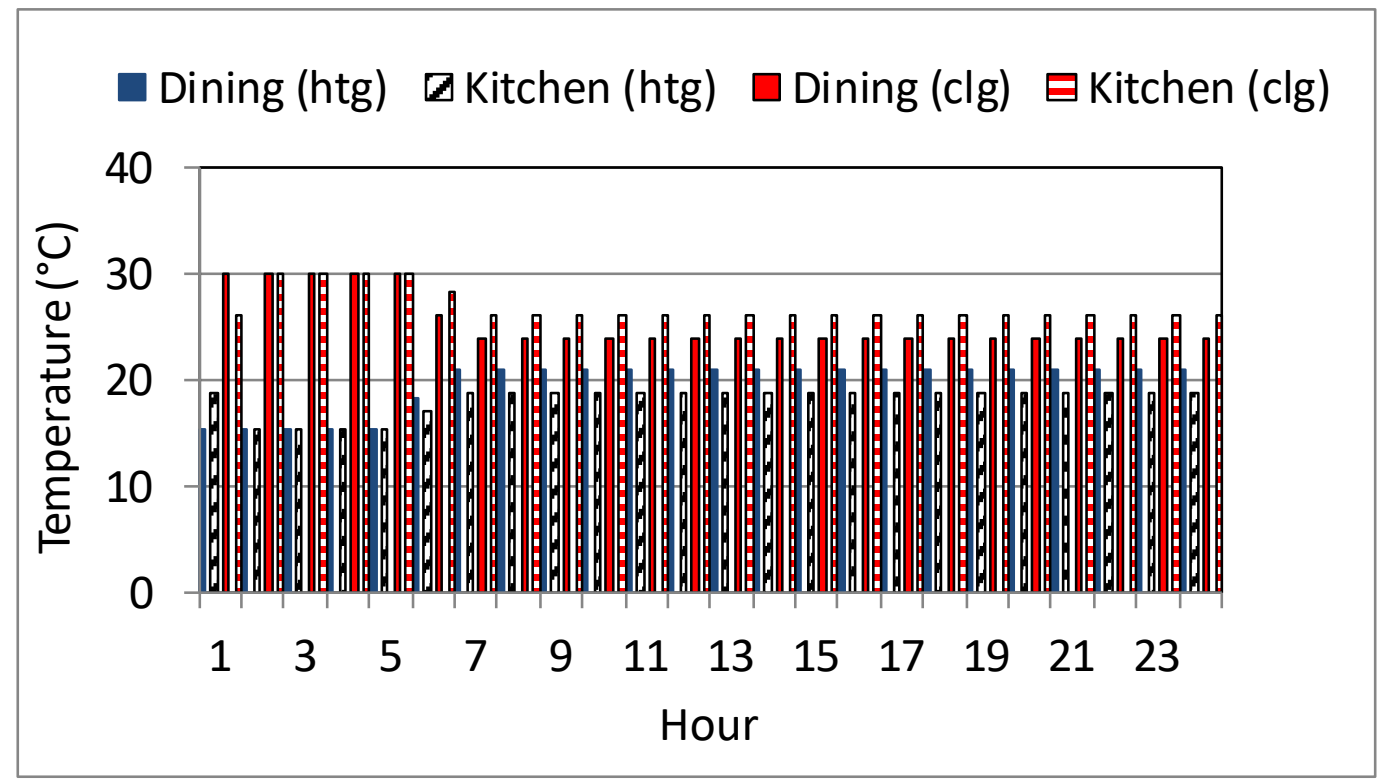

Figure 8. Thermostat setpoint schedule for Full Service Restaurant 


\subsection{Small Office}

Table 9 summarizes the zones modeled in CONTAM for the Small Office, their respective sizes, and maximum occupancy.

\section{Occupants:}

The peak number of people for each zone is listed in Table 9. Occupants in all building zones are scheduled according to Figure 9. There is a different occupancy schedule for weekdays.

Weekends and holidays are unoccupied, so fractional occupancy in Figure 9 is zero all day.

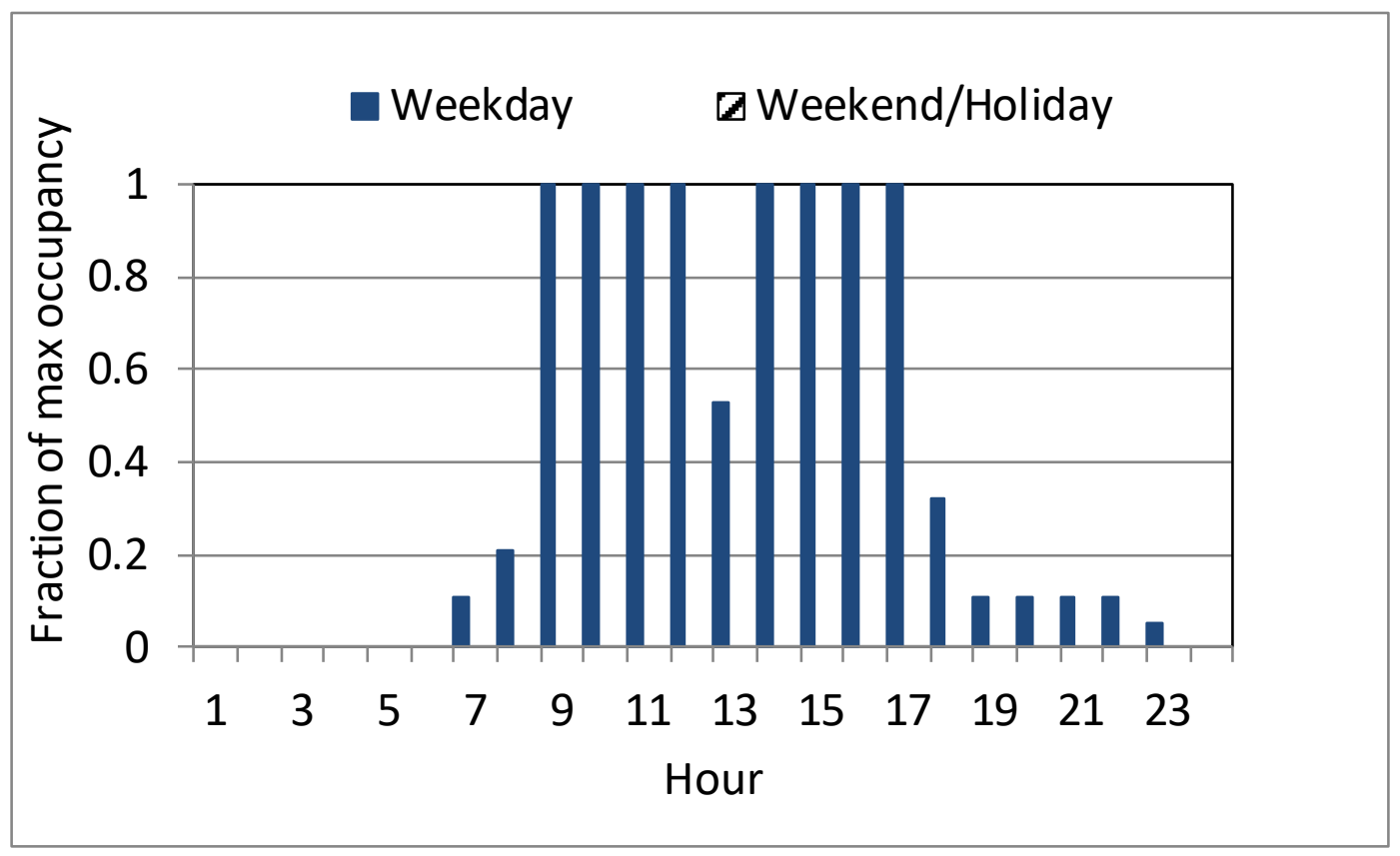

Figure 9. Occupancy schedule for Small Office

\section{Geometry:}

$511 \mathrm{~m}^{2}$ footprint, single-story building with attic. The EnergyPlus model has five zones - four perimeter zones and a core zone. In the CONTAM model, a Restroom (shaded in Figure 10) with a footprint of $4 \mathrm{~m} \times 4 \mathrm{~m}$ was carved out of the Core zone.

Large interior leakage paths were defined as follows:

- Between the perimeter and core zones, a single large leakage path (50\% of the total wall area between the two spaces) is modeled. This is representative of half-height office partitions; It should be noted that a physical wall was modeled between the zones in EnergyPlus. The walls were modeled in this way to produce temperature differences between the zones, but no airflow between these zones was modeled in EnergyPlus;

- Between the Restroom and Core zones, a $0.186 \mathrm{~m}^{2}$ transfer grille is modeled. 
Table 9. Summary of zones in Small Office

\begin{tabular}{lrrr}
\hline Zone & Area $\mathbf{( m}^{\mathbf{2}} \mathbf{)}$ & Height (m) & $\begin{array}{r}\text { Maximum } \\
\text { occupancy }\end{array}$ \\
\hline Core & 133.7 & 3.05 & 9 \\
Perimeter South & 113.5 & 3.05 & 7 \\
Perimeter East & 67.3 & 3.05 & 4 \\
Perimeter North & 113.5 & 3.05 & 7 \\
Perimeter West & 67.3 & 3.05 & 4 \\
Attic & 511.0 & 1.64 & 0 \\
Restroom & 16.0 & 3.05 & 0 \\
\hline
\end{tabular}

\section{HVAC systems:}

The EnergyPlus model has five packaged constant-volume single-zone systems. Similarly, each zone has a constant-volume system in CONTAM. The supply air, return air, outside air, and exhaust flow rates modeled in CONTAM are listed in Table 10. The exhaust flow rate for the Restroom was modeled only in CONTAM, not in EnergyPlus.

In EnergyPlus, balanced HVAC systems are modeled in all zones. In an attempt achieve building pressurization in CONTAM, less air is returned than is supplied to each zone. Specifically, the return airflow rate is $90 \%$ of the supply airflow rate. The building is neutrally pressurized between 6:00 a.m. and 7:00 a.m. on weekdays and Saturdays when the system operates but no outside air is being supplied, which reflects the operation modeled in EnergyPlus.

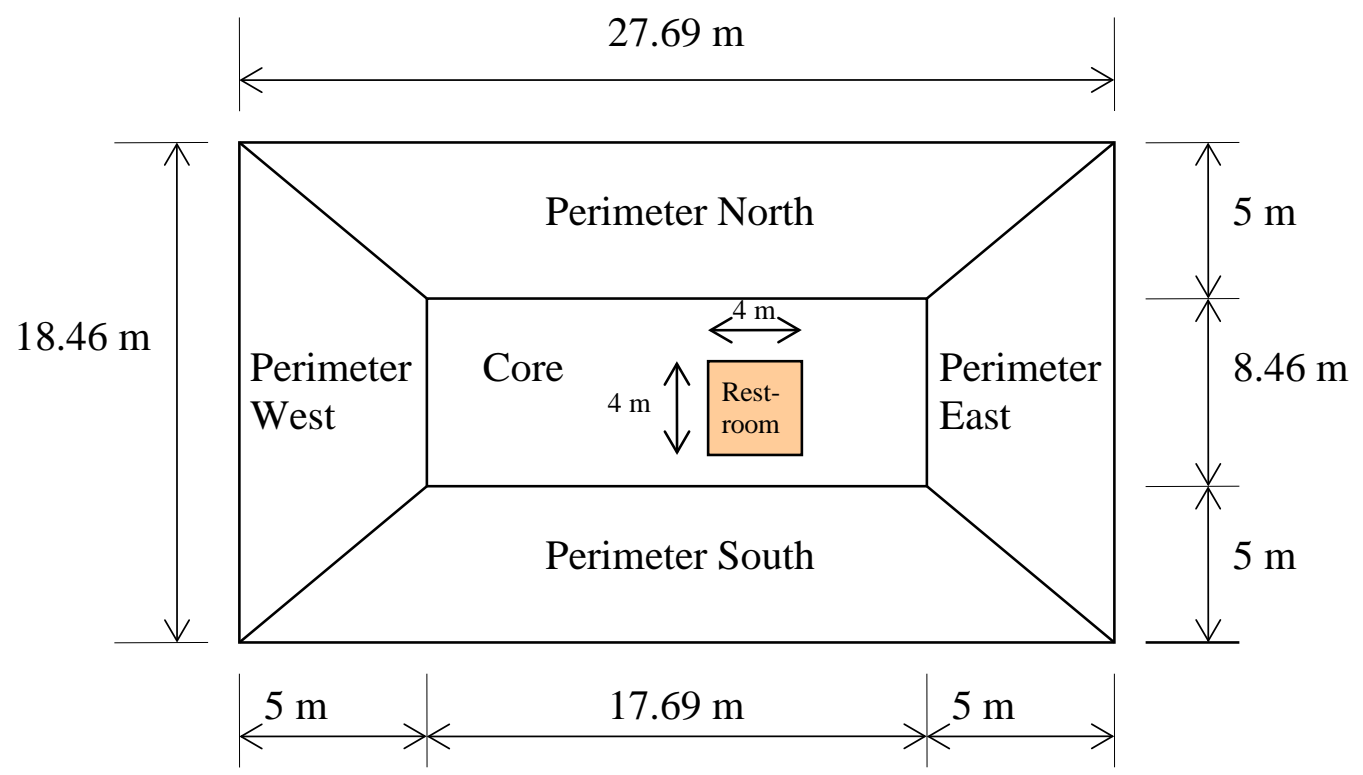

Figure 10. Floor plan of Small Office (height $3.05 \mathrm{~m}$ ) 
Table 10. Summary of HVAC system flow rates $\left(\mathrm{m}^{3} / \mathrm{s}\right)$ in Small Office

\begin{tabular}{lrrrr}
\hline Zone & Supply & Return & Outside air & Exhaust air \\
\hline Core & 0.27 & 0.24 & 0.06 & 0.00 \\
Perimeter South & 0.33 & 0.29 & 0.05 & 0.00 \\
Perimeter East & 0.28 & 0.25 & 0.03 & 0.00 \\
Perimeter North & 0.27 & 0.25 & 0.05 & 0.00 \\
Perimeter West & 0.31 & 0.28 & 0.03 & 0.00 \\
Restroom & N/A & N/A & 0.00 & 0.05 \\
\hline
\end{tabular}

\section{HVAC Schedules:}

All HVAC and exhaust fans operate on the following schedule:

- Weekdays: on from 6:00 a.m. to 7:00 p.m., off otherwise

- Saturday, Sunday, holidays: off all day

The outside air for the HVAC systems operates on the same schedules as those above except the start time is one hour later on all of them.

Temperature setpoints:

All occupied zones have the same thermostat setpoint schedule. There is a different schedule for weekdays (wkdy) and weekends/holidays (wknd/hol) (Figure 11). The Restroom was scheduled with the same temperature as the rest of the building only in CONTAM since the EnergyPlus model did not have a Restroom.

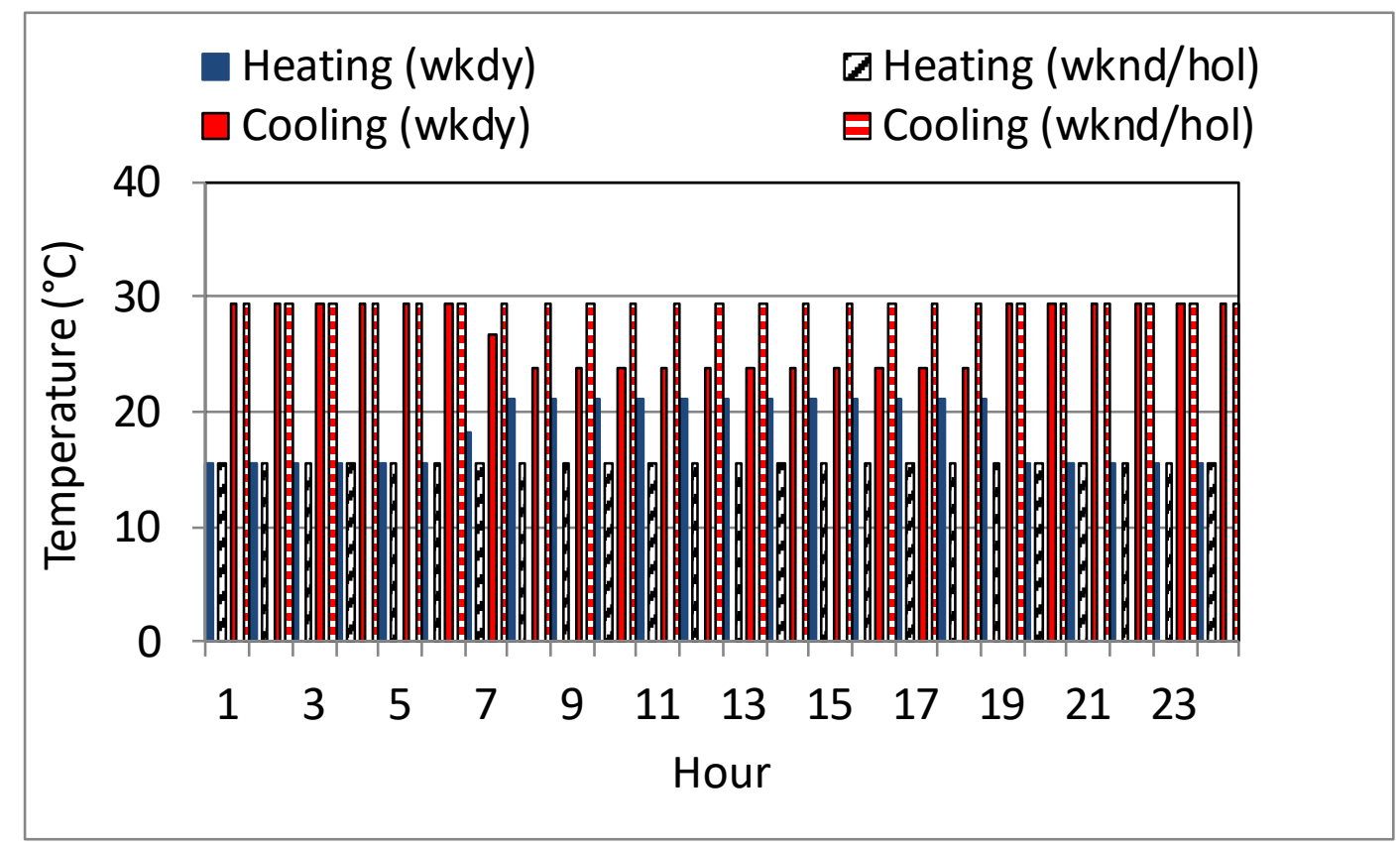

Figure 11. Thermostat setpoint schedule for Small Office 


\subsection{Medium Office}

Table 11 summarizes the zones modeled in CONTAM for the Medium Office, their respective sizes, and maximum occupancy.

Table 11. Summary of zones in Medium Office

\begin{tabular}{llrrr}
\hline Zone & Floor & Area (m $\mathbf{~ m}^{\mathbf{2}}$ & Height (m) & $\begin{array}{r}\text { Maximum } \\
\text { occupancy }\end{array}$ \\
\hline Core & $1-3$ & 823 & 2.74 & 53 \\
Perimeter South & $1-3$ & 207 & 2.74 & 11 \\
Perimeter East & $1-3$ & 131 & 2.74 & 7 \\
Perimeter North & $1-3$ & 207 & 2.74 & 11 \\
Perimeter West & $1-3$ & 131 & 2.74 & 7 \\
Restroom & $1-3$ & 100 & 2.74 & 0 \\
Stairwell & $1-3$ & 30 & 2.74 & 0 \\
Elevator shaft & $1-3$ & 30 & 2.74 & 0 \\
Plenum & Abv 1-3 & 1600 & 1.26 & 0 \\
Stair at Plenum & Abv 1-3 & 30 & 1.26 & 0 \\
Elev. at Plenum & Abv 1-3 & 30 & 1.26 & 0 \\
\hline
\end{tabular}

\section{Occupants:}

The peak number of people for each zone is listed in Table 11. Occupants in all building zones are scheduled according to Figure 12. There is a different occupancy schedule for weekdays and Saturdays, and Sundays/Holidays.

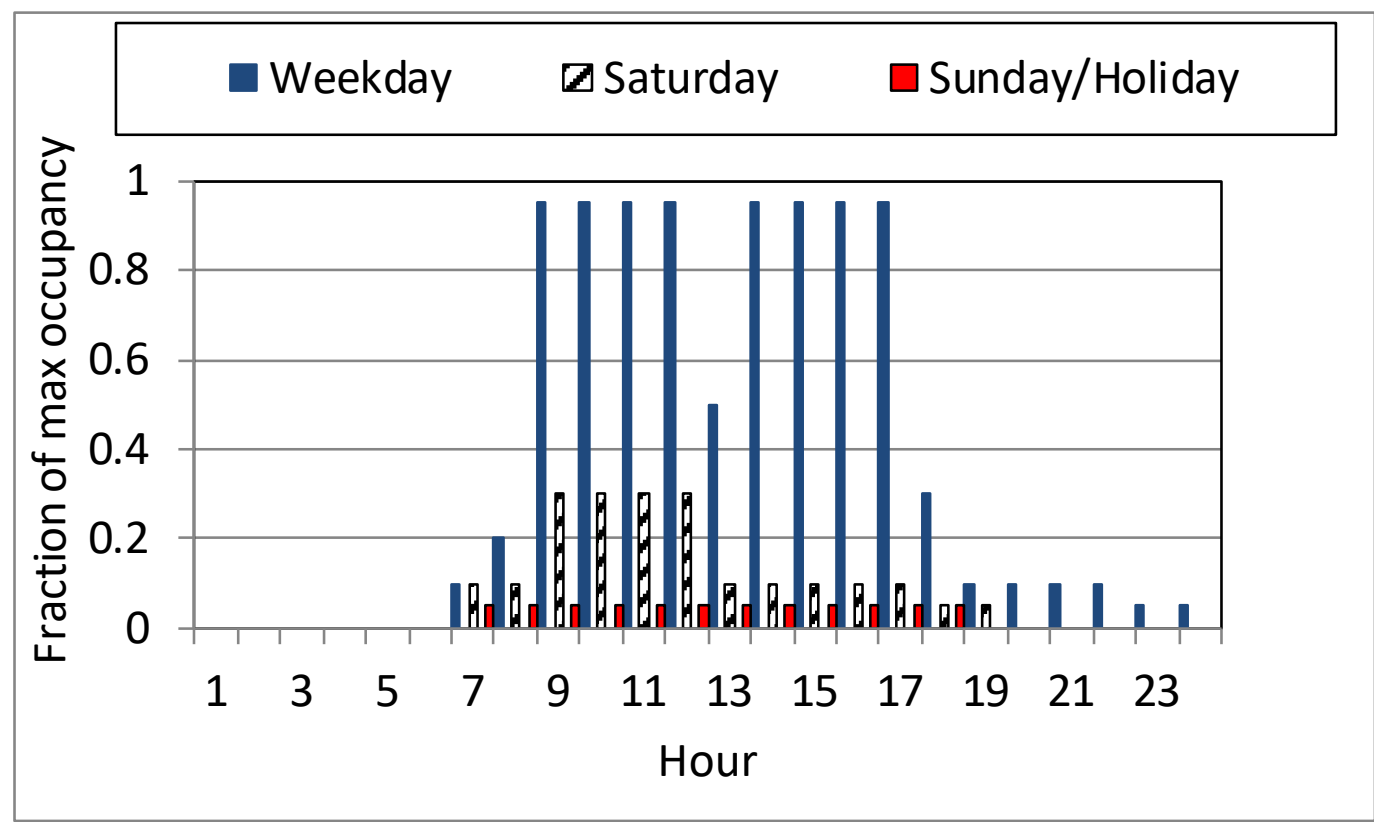

Figure 12. Occupancy schedule for Medium Office 


\section{Geometry:}

$1661 \mathrm{~m}^{2}$ footprint, three-story building with flat roof. Total floor area is $4982 \mathrm{~m}^{2}$. The EnergyPlus model has five zones per occupied floor - four perimeter zones and a core zone.

Floor to ceiling height is $2.74 \mathrm{~m}$ and floor to floor height is $4.0 \mathrm{~m}$. The additional height is due to plenums above each floor. Every floor (excluding the plenums) has the same floor plan. All of the plenums have the same floor plans. In the CONTAM model, a Restroom (shaded in Figure 13) with a footprint of $10 \mathrm{~m} \times 10 \mathrm{~m}$ was carved out of the Core zone. Also carved out of the Core zone are a $3 \mathrm{~m} \times 10 \mathrm{~m}$ Stairwell and a $3 \mathrm{~m} \times 10 \mathrm{~m}$ Elevator Shaft (shaded in Figure 13).

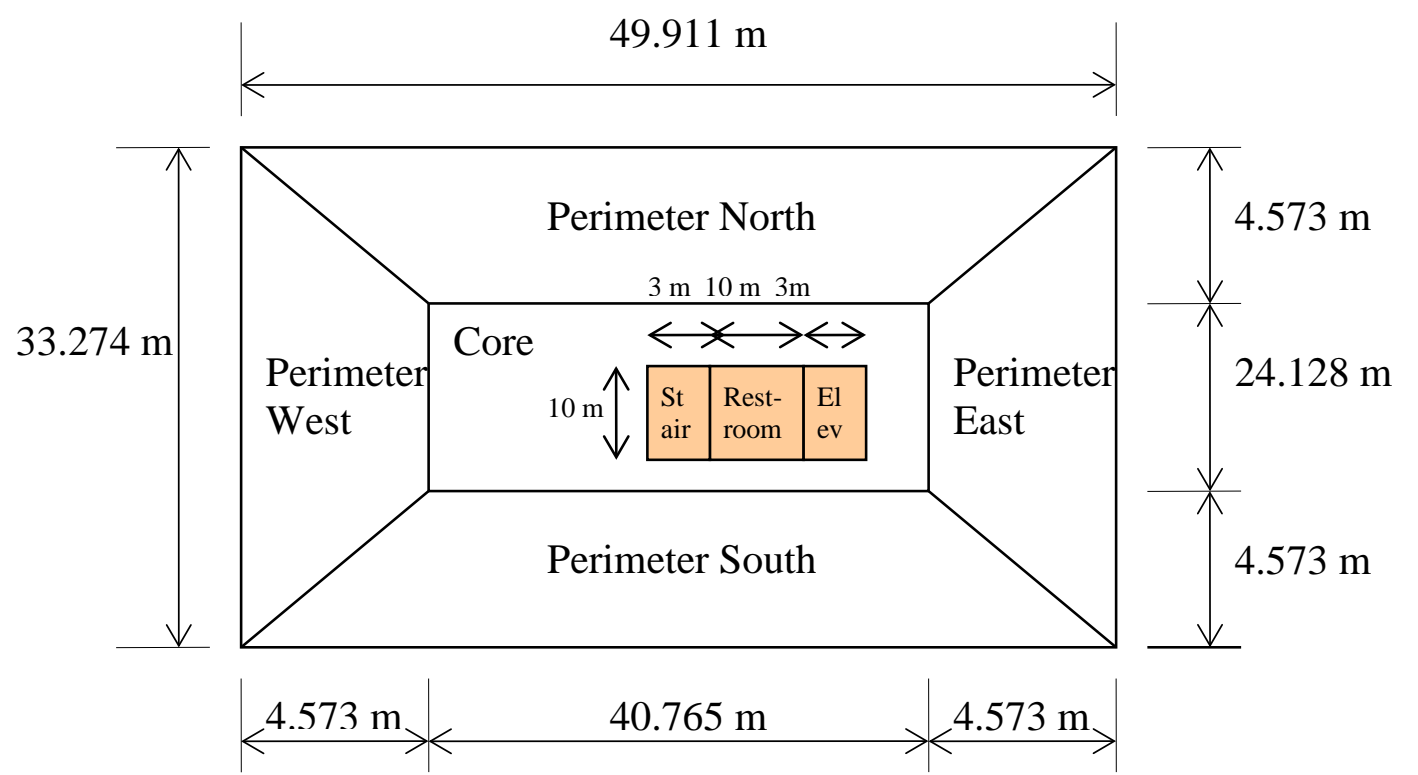

Figure 13. Floor plan of Medium Office (height $2.74 \mathrm{~m}$ )

Large interior leakage paths were defined as follows:

- Between the perimeter and core zones, a single large leakage path (50 \% of the total wall area between the two spaces) is modeled. This is representative of half-height office partitions. It should be noted that a physical wall was modeled between the zones in EnergyPlus. The walls were modeled in this way to produce temperature differences between the zones, but no airflow between these zones was modeled in EnergyPlus;

- Between the Restroom and Core zones, a $0.186 \mathrm{~m}^{2}$ transfer grille is modeled;

- A leakage path between each occupied zone and the plenum above, equal to $1 \%$ of the floor area of the occupied zone, is modeled to accommodate transfer of return air to the HVAC system through the plenum;

- A stairwell is defined using CONTAM's stair shaft model for closed treads and zero people;

- An elevator shaft is defined using CONTAM's elevator shaft model. 


\section{HVAC systems:}

The EnergyPlus model has three variable air volume (VAV) systems, each serving one floor. The design supply flow rate calculated by EnergyPlus for each VAV system is used as the supply flow rate for each constant-volume system modeled in CONTAM for simplicity. The systems modeled in CONTAM are still referred to as "VAV" systems in the body of this text. Varying the supply flow rate can be implemented in CONTAM using controls and/or schedules by users who wish to do so. The supply air, return air, outside air, and exhaust flow rates modeled in CONTAM are listed in Table 12. The design airflow rate rates for VAV-1, VAV-2, and VAV-3 in Table 12 are calculated by EnergyPlus given design heating and cooling conditions. The exhaust flow rates for the Restrooms were modeled only in CONTAM, not in EnergyPlus.

The return path for each VAV system in EnergyPlus travels through a plenum above the floor it serves. This is modeled in CONTAM with a large return located in each plenum and a passive opening between the zone and the plenum above that is sized to obtain a maximum velocity of 2 $\mathrm{m} / \mathrm{s}$ at the grille opening (grille sizes listed in Table 12).

In EnergyPlus, balanced HVAC systems are modeled in all zones. In an attempt achieve building pressurization in CONTAM, less air is returned than is supplied to each zone. The total return for each VAV system is set to $90 \%$ of the total supply airflow rate. The building is neutrally pressurized between 6:00 a.m. and 7:00 a.m. on weekdays and Saturdays when the system operates but no outside air is being supplied, which reflects the operation modeled in EnergyPlus.

\section{HVAC Schedules:}

All HVAC and exhaust fans operate on the following schedule:

- Weekdays: on from 6:00 a.m. to 10:00 p.m., off otherwise

- Saturday: on from 6:00 a.m. to 6:00 p.m., off otherwise

- Sunday, holidays: off all day

The outside air for the HVAC systems operates on the same schedules as those above except the start time is one hour later on all of them. 
Table 12. Summary of VAV system flow rates $\left(\mathrm{m}^{3} / \mathrm{s}\right)$ and transfer grill sizes $\left(\mathrm{m}^{2}\right)$ in Medium Office

\begin{tabular}{llccrrr}
\hline Zone & Floor & Supply & Return & $\begin{array}{r}\text { Return } \\
\text { Grille } \\
\text { Size }\end{array}$ & $\begin{array}{r}\text { Outside } \\
\text { Air }\end{array}$ & $\begin{array}{r}\text { Exhaust } \\
\text { air }\end{array}$ \\
\hline Core & 1 & & & & 0.0 \\
Perimeter South & 1 & 2.95 & & 1.76 & 0.023 & 0.0 \\
Perimeter East & 1 & 0.62 & & 0.38 & 0.005 & 0.0 \\
Perimeter North & 1 & 0.39 & & 0.43 & 0.003 & 0.0 \\
Perimeter West & 1 & 0.62 & & 0.33 & 0.005 & 0.0 \\
Restroom & 1 & 0.39 & & 0.55 & 0.003 & N/A \\
\hline VAV 1 total & & N/A & N/A & N/A & N/A \\
\hline Core & 2 & 4.98 & 4.48 & & $\mathbf{0 . 0 3 9}$ & \\
Perimeter South & 2 & 2.71 & & 1.73 & 0.023 & 0.0 \\
Perimeter East & 2 & 0.57 & & 0.49 & 0.005 & 0.0 \\
Perimeter North & 2 & 0.36 & & 0.51 & 0.003 & 0.0 \\
Perimeter West & 2 & 0.57 & & 0.43 & 0.005 & 0.0 \\
Restroom & 2 & 0.36 & & 0.62 & 0.003 & 0.0 \\
\hline VAV 2 total & & N/A & N/A & N/A & N/A & 0.1 \\
\hline Core & 3 & 4.58 & 4.12 & & $\mathbf{0 . 0 3 9}$ & \\
Perimeter South & 3 & 3.05 & & 1.65 & 0.023 & 0.0 \\
Perimeter East & 3 & 0.64 & & 0.50 & 0.005 & 0.0 \\
Perimeter North & 3 & 0.41 & & 0.50 & 0.003 & 0.0 \\
Perimeter West & 3 & 0.64 & & 0.46 & 0.005 & 0.0 \\
Restroom & 3 & 0.41 & & 0.64 & 0.003 & 0.0 \\
\hline VAV 3 total & & N/A & N/A & N/A & N/A & 0.1 \\
\hline
\end{tabular}

\section{Temperature setpoints:}

All occupied zones have the same thermostat setpoint schedule. There is a different schedule for weekdays and weekends/holidays (Figure 14). The Restrooms, Plenums, Stairwells, and Elevator shafts were scheduled with the same temperature as the rest of the building only in CONTAM since the EnergyPlus model did not have these zones except the Plenums. Nonetheless, the EnergyPlus model did not have temperature setpoints for the Plenums. 


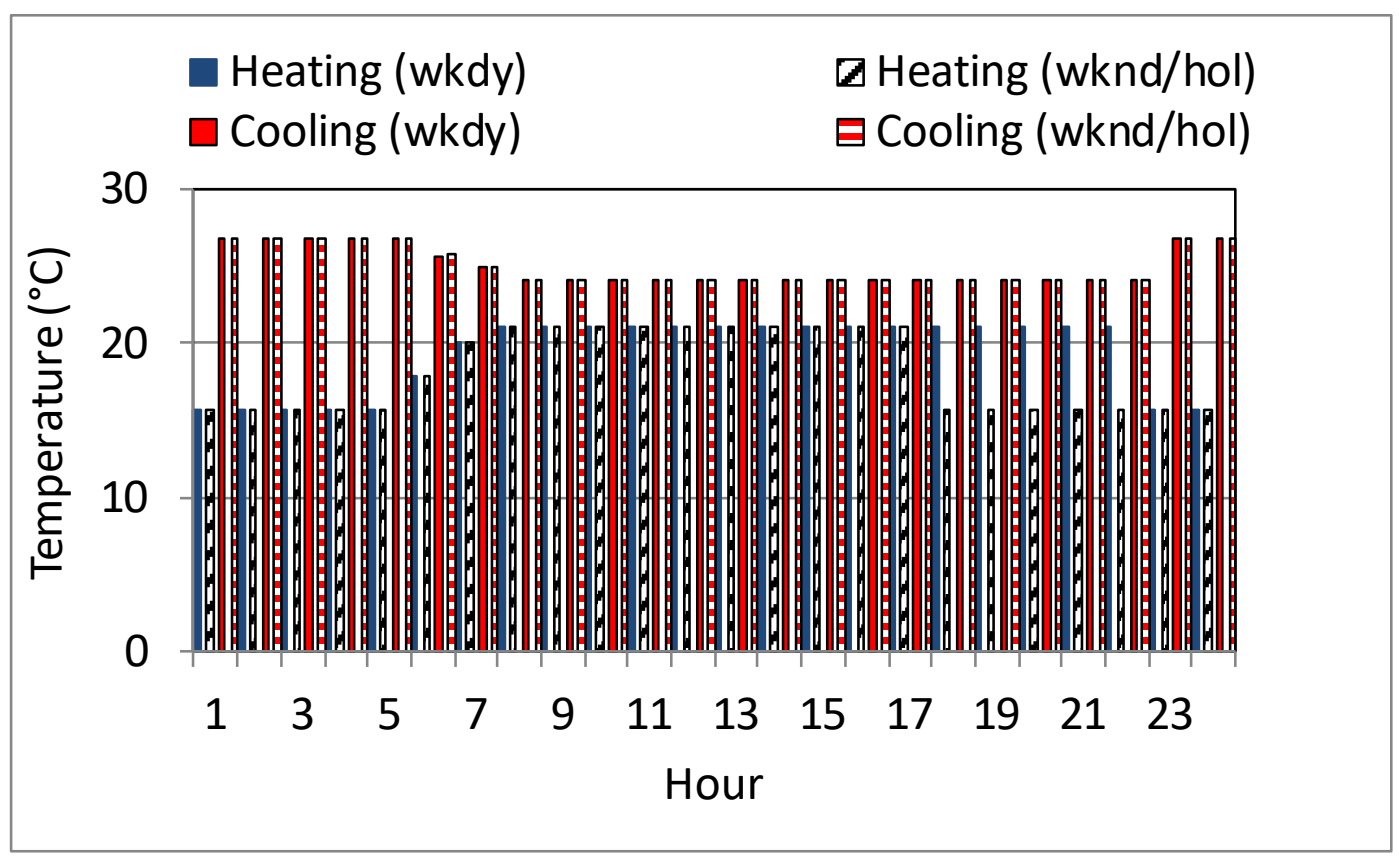

Figure 14. Thermostat setpoint schedule for Medium Office (wkdy=weekday, wknd=weekend, hol=holiday)

\section{5. $\quad$ Large Office}

Table 13 summarizes the zones modeled in CONTAM for the Large Office, their respective sizes, and maximum occupancy.

Table 13. Summary of zones in Large Office

\begin{tabular}{|c|c|c|c|c|}
\hline Zone & Floor & $\operatorname{Area}\left(\mathrm{m}^{2}\right)$ & Height (m) & $\begin{array}{l}\text { Maximum } \\
\text { occupancy }\end{array}$ \\
\hline Basement & B & 3563 & 2.44 & 150 \\
\hline Basement Data Center ${ }^{\mathrm{a}}$ & B & 798 & 2.44 & 0 \\
\hline Perimeter North & $1-12$ & 313 & 2.74 & 17 \\
\hline Perimeter East & $1-12$ & 313 & 2.74 & 11 \\
\hline Perimeter South & $1-12$ & 202 & 2.74 & 17 \\
\hline Perimeter West & $1-12$ & 202 & 2.74 & 11 \\
\hline Core & $1-12$ & 2372 & 2.74 & 134 \\
\hline Data Center ${ }^{\mathrm{a}}$ & $1-12$ & 36 & 2.74 & 0 \\
\hline Restroom & $1-12$ & 100 & 2.74 & 0 \\
\hline Stairwell & $1-12$ & 30 & 2.74 & 0 \\
\hline Elevator shaft & $1-12$ & 30 & 2.74 & 0 \\
\hline Plenum & Abv 1-12 & 3563 & 1.26 & 0 \\
\hline Stair at Plenum & Abv 1-12 & 30 & 1.26 & 0 \\
\hline Elev. at Plenum & Abv 1-12 & 30 & 1.26 & 0 \\
\hline
\end{tabular}

a. The data center zones were added to prototype building model and the addition reflected in the updated CONTAM models. 


\section{Occupants:}

The peak number of people for each zone is listed in Table 13. Occupants in all building zones are scheduled according to Figure 15. There is a different occupancy schedule for weekdays and Saturdays, and Sundays. The occupancy on Sunday is only 0.05 of maximum occupancy and only for hours between 7:00 a.m. to 6:00 p.m. There is no HVAC system scheduled to be on Sundays in the EnergyPlus and CONTAM models.

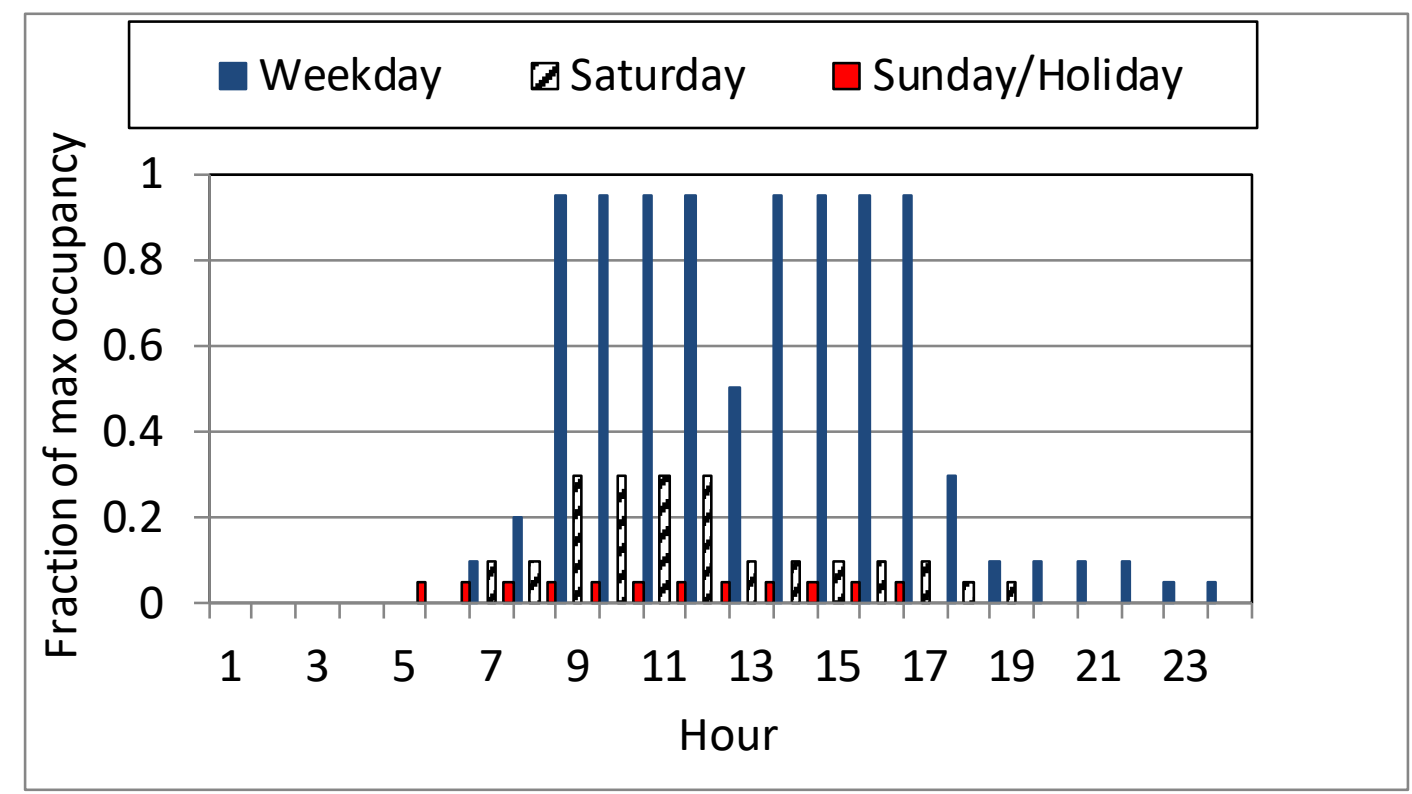

Figure 15. Occupancy schedule for Large Office

\section{Geometry:}

$3563 \mathrm{~m}^{2}$ footprint, 12-story building (plus a basement) with flat roof. Total floor area is $46320 \mathrm{~m}^{2}$ which includes the Basement. The EnergyPlus model has five zones per occupied floor - four perimeter zones and a core zone. Floor to ceiling height is $2.74 \mathrm{~m}$ and floor to floor height is $4.0 \mathrm{~m}$. The additional height is due to plenums above each floor. The Basement is a single zone with the same footprint as the upper floors, with a height of $2.44 \mathrm{~m}$. There is no plenum between the basement and the first floor. Every floor (excluding the Basement in Figure 16) has the same floor plan (Figure 17). All of the plenums have the same floor plans (Figure 18). In the CONTAM model, a Restroom (shaded in Figure 17) with a footprint of $10 \mathrm{~m} \times 10 \mathrm{~m}$ was carved out of the Core zone. Also carved out of the Core zone are a $3 \mathrm{~m} \times 10 \mathrm{~m}$ Stairwell and a $3 \mathrm{~m} \times 10 \mathrm{~m}$ Elevator Shaft (shaded in Figure 17).

The EnergyPlus Large Office building model remained nearly unchanged between the reference and prototype building sets. The only differences, as outlined in [5], were that Data Center zones 
were added to the Basement zone (Figure 16) and Core zones on floors 1 through 10 (Figure 17). The total floor area of the data center zone and the Basement (or Core) zones in both the EnergyPlus and CONTAM prototype models equaled the floor area of the Basement (or Core) zones in the reference model.

It should be noted that the EnergyPlus prototype model of the Large Office is $37.5 \mathrm{~m}$ tall, but was $47.5 \mathrm{~m}$ in the reference model [41]. The different height of the prototype model may be an error.

Large interior leakage paths were defined as follows:

- Between the perimeter and core zones, a single large leakage path (50\% of the total wall area between the two spaces) is modeled. This is representative of half-height office partitions; It should be noted that a physical wall was modeled between the zones in EnergyPlus. The walls were modeled in this way to produce temperature differences between the zones, but no airflow between these zones was modeled in EnergyPlus;

- Between the Restroom and Core zones, a $0.186 \mathrm{~m}^{2}$ transfer grille is modeled;

- A leakage path between each occupied zone and the plenum above, equal to $1 \%$ of the floor area of the occupied zone, is modeled to accommodate transfer of return air to the HVAC system through the plenum;

- A stairwell is defined using CONTAM's stair shaft model for closed treads and zero people;

- An elevator shaft is defined using CONTAM's elevator shaft model.

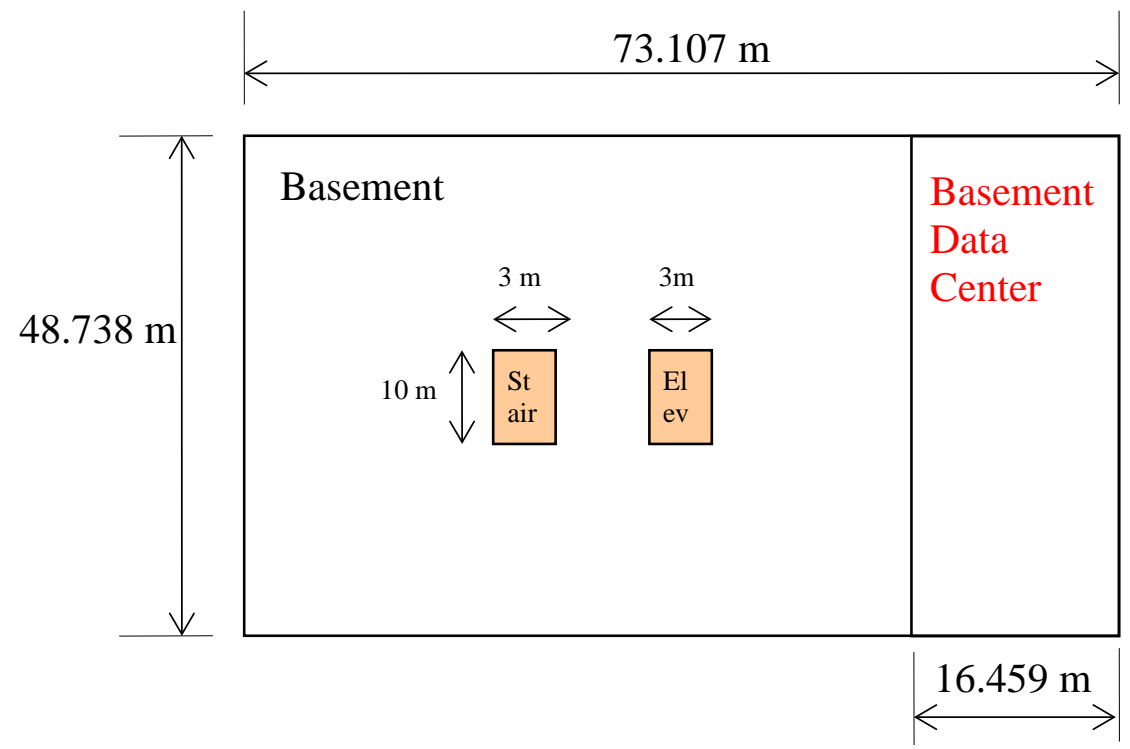

Figure 16. Basement floor plan of Large Office (height $2.44 \mathrm{~m}$ ). Basement Data Center carved out of Basement in prototype model. 


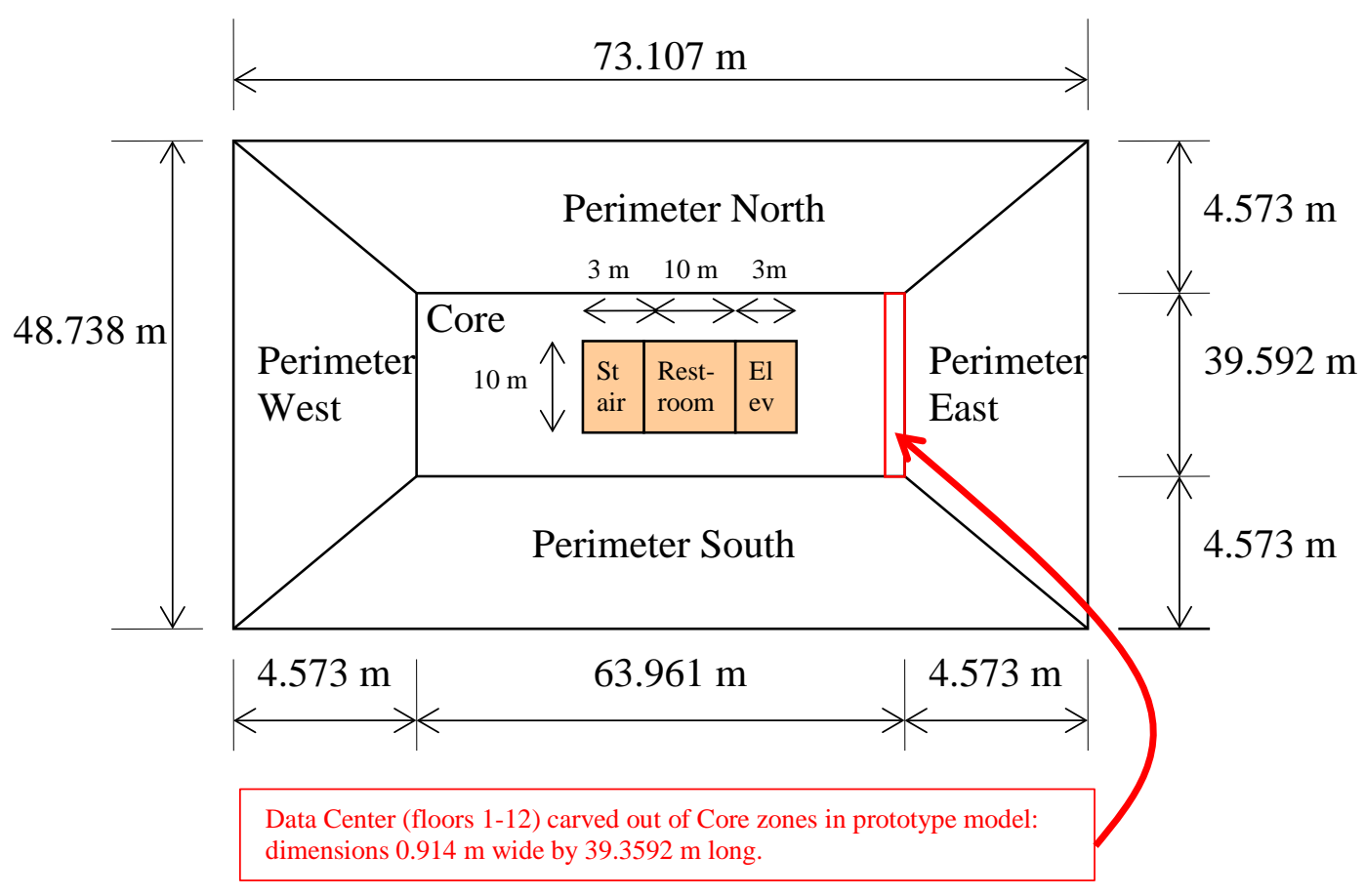

Figure 17. First floor plan of Large Office (height $2.74 \mathrm{~m}$ ). Second through twelfth floors are identical to first floor. Data Center carved out of Core Zones in prototype model.

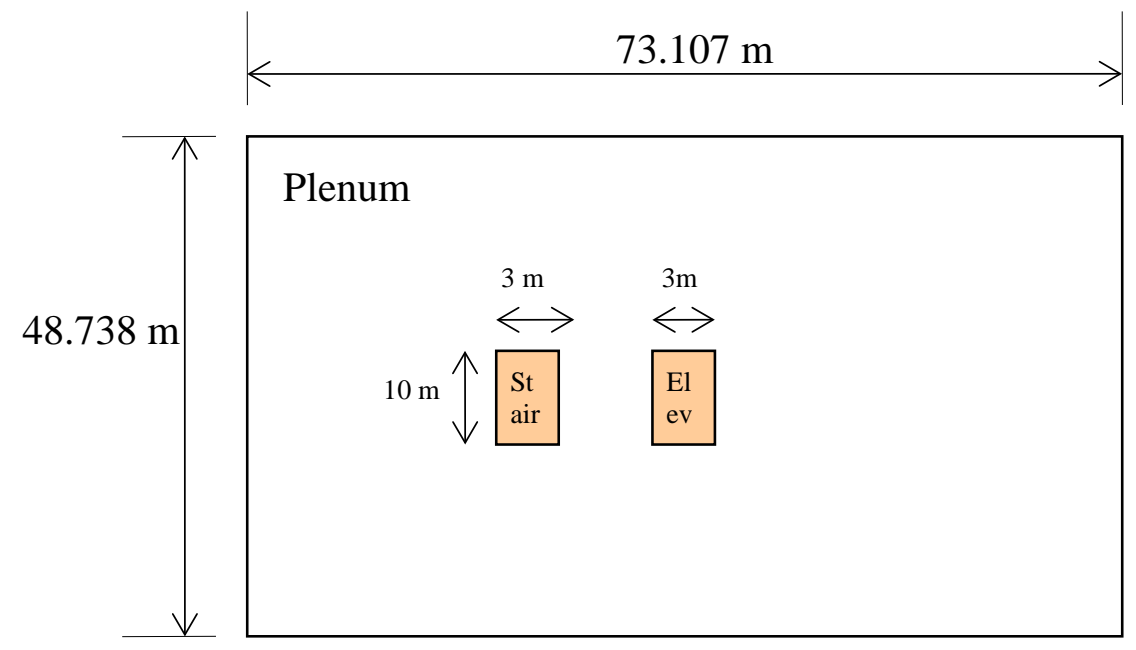

Figure 18. First floor plenum plan of Large Office (height $1.26 \mathrm{~m}$ ). Second through twelfth floor plenums are identical to this one.

HVAC systems:

The EnergyPlus model has four VAV systems. One serves the Basement, one serves the bottom $\left(1^{\text {st }}\right)$ floor, one serves the "middle" $\left(2^{\text {nd }}\right.$ through $\left.11^{\text {th }}\right)$ floors, and one serves the top $\left(12^{\text {th }}\right)$ floor. The design supply flow rate calculated by EnergyPlus for each VAV system is used as the supply 
flow rate for each constant-volume system modeled in CONTAM for simplicity. The systems modeled in CONTAM are still referred to as "VAV" systems in the body of this text. Varying the supply flow rate can be implemented in CONTAM using controls and/or schedules by users who wish to do so. The HVAC system, outside air, and exhaust flow rates modeled in CONTAM are listed in Table 14. The exhaust fans for the Restrooms were modeled only in CONTAM, not in EnergyPlus.

In EnergyPlus, a "middle floor" is multiplied by a factor of 10. Thus, a single VAV system serving the "middle floor" is actually serving 10 floors in EnergyPlus. In CONTAM, the middle floor VAV system is modeled as 10 separate systems.

The Basement has no plenum, so air is returned back to its system. For the remaining VAV systems, the return path travels through a plenum above that floor. This is modeled in CONTAM with a large return located in each plenum and a passive opening between the zone and the plenum above that is sized to obtain a maximum velocity of $2 \mathrm{~m} / \mathrm{s}$ at the grille opening.

In EnergyPlus, balanced HVAC systems are modeled in all zones. In an attempt achieve building pressurization in CONTAM, less air is returned than is supplied to each zone. The total return is set to $90 \%$ of the total supply airflow rate. The building is neutrally pressurized between 6:00 a.m. and 7:00 a.m. weekdays and Saturdays when the system operates but no outside air is being supplied, which reflects the operation modeled in EnergyPlus.

\section{HVAC Schedules:}

All HVAC and exhaust fans operate on the following schedule:

- Weekdays: on from 6:00 a.m. to 10:00 p.m., off otherwise

- Saturday: on from 6:00 a.m. to 6:00 p.m., off otherwise

- Sunday, holidays: off all day

The outside air for the HVAC systems operates on the same schedules as those above except the start time is one hour later on all of them. 
Table 14. Summary of VAV system flow rates $\left(\mathrm{m}^{3} / \mathrm{s}\right)$ and Return Grille sizes $\left(\mathrm{m}^{2}\right)$ in Large Office

\begin{tabular}{|c|c|c|c|c|c|c|}
\hline Zone & Floor & Supply & Return & $\begin{array}{r}\text { Return } \\
\text { Grille } \\
\text { Size }\end{array}$ & Outside air & $\begin{array}{r}\text { Exhaust } \\
\text { air }\end{array}$ \\
\hline Basement & B & 4.63 & 4.17 & N/A & 1.20 & 0.00 \\
\hline Perimeter North & 1 & 1.04 & & 0.75 & 0.14 & 0.00 \\
\hline Perimeter East & 1 & 0.67 & & 0.96 & 0.09 & 0.00 \\
\hline Perimeter South & 1 & 1.04 & & 0.90 & 0.14 & 0.00 \\
\hline Perimeter West & 1 & 0.67 & & 1.13 & 0.09 & 0.00 \\
\hline Core & 1 & 8.25 & & 5.20 & 1.14 & 0.00 \\
\hline Restroom & 1 & N/A & N/A & N/A & N/A & 0.15 \\
\hline "Bottom" system total & & 11.65 & 10.49 & & 1.60 & \\
\hline Perimeter North & $2-11$ & 0.84 & & 0.76 & 0.14 & 0.00 \\
\hline Perimeter East & $2-11$ & 0.54 & & 1.00 & 0.09 & 0.00 \\
\hline Perimeter South & $2-11$ & 0.84 & & 0.93 & 0.14 & 0.00 \\
\hline Perimeter West & $2-11$ & 0.54 & & 1.18 & 0.09 & 0.00 \\
\hline Core & $2-11$ & 6.68 & & 5.49 & 1.14 & 0.00 \\
\hline Restroom & $2-11$ & N/A & N/A & N/A & N/A & 0.15 \\
\hline “Middle" system total & & 9.44 & 8.49 & & 1.60 & \\
\hline Perimeter North & 12 & 0.92 & & 0.81 & 0.14 & 0.00 \\
\hline Perimeter East & 12 & 0.59 & & 0.95 & 0.09 & 0.00 \\
\hline Perimeter South & 12 & 0.92 & & 0.95 & 0.14 & 0.00 \\
\hline Perimeter West & 12 & 0.59 & & 1.22 & 0.09 & 0.00 \\
\hline Core & 12 & 7.31 & & 5.11 & 1.14 & 0.00 \\
\hline Restroom & 12 & N/A & N/A & N/A & N/A & 0.15 \\
\hline “Top” system total & & 10.33 & 9.30 & & 1.60 & \\
\hline
\end{tabular}

Temperature setpoints:

All occupied zones have the same thermostat setpoint schedule. There is a different schedule for weekdays/Saturdays and Sundays/holidays (Figure 19). The Restrooms, Plenums, Stairwells, and Elevator shafts were scheduled with the same temperature as the rest of the building only in CONTAM since the EnergyPlus model did not have these zones except the Plenums.

Nonetheless, the EnergyPlus model did not have temperature setpoints for the Plenums. The Data Center zones in EnergyPlus were scheduled to maintain $18{ }^{\circ} \mathrm{C}$ during the heating months and $27^{\circ} \mathrm{C}$ during the cooling months. 


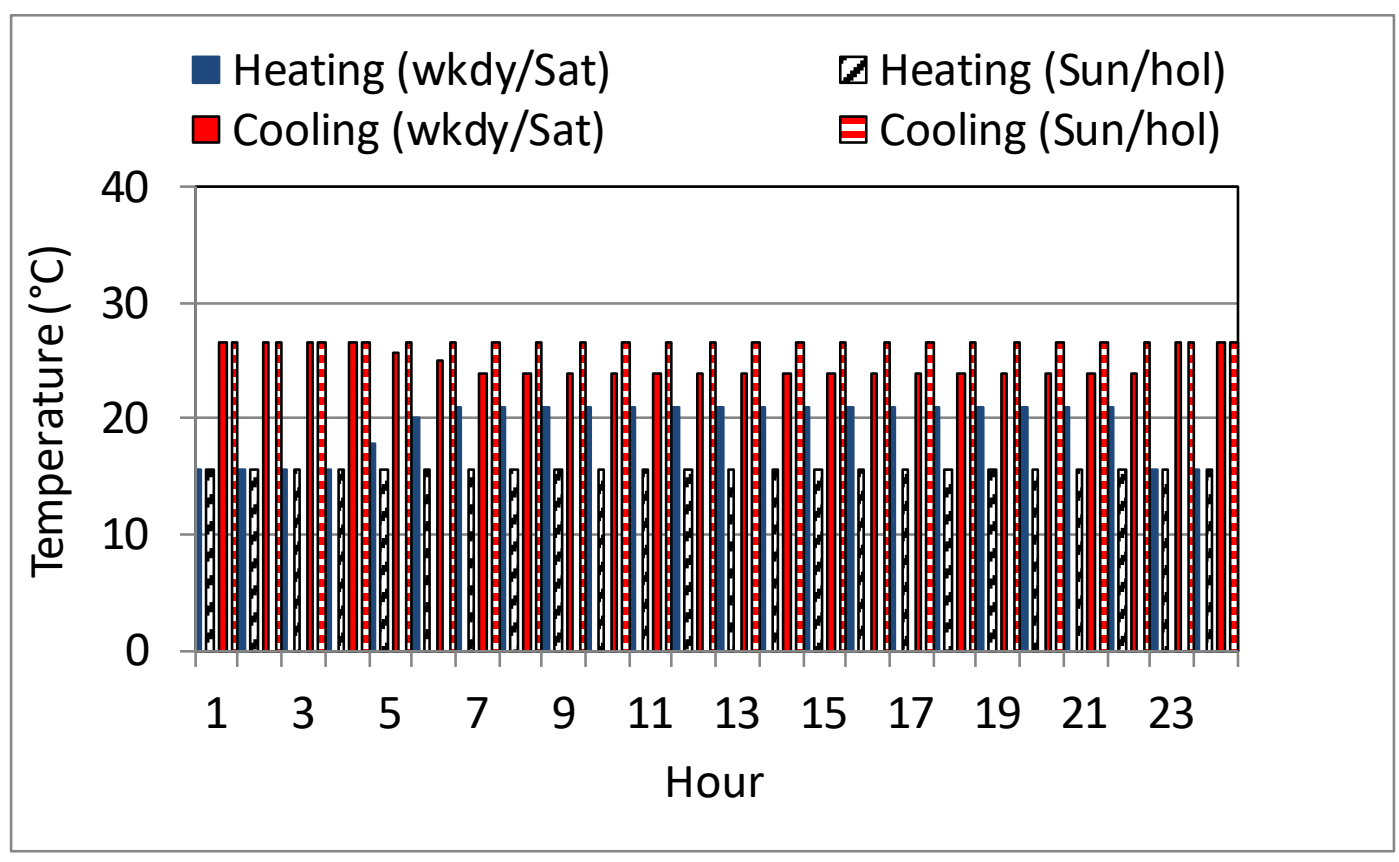

Figure 19. Thermostat setpoint schedule for Large Office

\subsection{Primary School}

Table 15 summarizes the zones modeled in CONTAM for the Primary School, their respective sizes, maximum occupancy, and thermostat temperature schedules (Temp_Class, Temp_MechBR and Temp_Other to be discussed in the Thermostat Setpoints section).

\section{Occupants:}

The peak number of people for each zone is listed in Table 15. Occupants in all building zones are scheduled according to Figure 20 through Figure 23. Weekends and holidays are unoccupied. There are five different occupant schedules for the building. The occupancy schedules for the Gym, Cafeteria, and Offices are shown in Figure 20 for the school year and Figure 21 for summer break. The occupancy schedules for the Classrooms and Classrooms with extended hours are shown in Figure 22 for the school year and Figure 23 for summer break. All of the schedules have the same summer break time period (6/30 to 9/1) except for the Classrooms, which has a summer break time period of 6/15 to 9/15.

There is only one zone with the "Classrooms with extended hours" schedule, the Computer Class. The "Classroom” and “Classroom with extended hours” occupancy schedules are the similar except the extended occupancy schedule has greater and constant occupancy from 8:00 a.m. to 5:00 p.m. during the school year and summer. 
Table 15. Summary of zones in Primary School

\begin{tabular}{lrrrl}
\hline Zone & $\begin{array}{r}\text { Area } \\
\left(\mathbf{m}^{2}\right)\end{array}$ & $\begin{array}{r}\text { Height } \\
(\mathbf{m})\end{array}$ & $\begin{array}{r}\text { Maximum } \\
\text { occupancy }\end{array}$ & $\begin{array}{l}\text { Thermostat } \\
\text { setpoint schedule }\end{array}$ \\
\hline Corner (“Cor”) Class 1 Pod 1 & 99 & 4.0 & 27 & Temp_Class \\
Multiple (“Mult”) Class 1 Pod 1 & 477 & 4.0 & 128 & Temp_Class \\
Corridor (“Corr”) Pod 1 & 192 & 4.0 & 0 & Temp_Class \\
Cor Class 2 Pod 1 & 99 & 4.0 & 27 & Temp_Class \\
Mult Class 2 Pod 1 & 477 & 4.0 & 128 & Temp_Class \\
Cor Class 1 Pod 2 & 99 & 4.0 & 27 & Temp_Class \\
Mult Class 1 Pod 2 & 477 & 4.0 & 128 & Temp_Class \\
Corr Pod 2 & 192 & 4.0 & 0 & Temp_Class \\
Cor Class 2 Pod 2 & 99 & 4.0 & 27 & Temp_Class \\
Mult Class 2 Pod 2 & 477 & 4.0 & 128 & Temp_Class \\
Cor Class 1 Pod 3 & 99 & 4.0 & 27 & Temp_Class \\
Mult Class 1 Pod 3 & 477 & 4.0 & 128 & Temp_Class \\
Corr Pod 3 & 192 & 4.0 & 0 & Temp_Class \\
Cor Class 2 Pod 3 & 99 & 4.0 & 27 & Temp_Class \\
Mult Class 2 Pod 3 & 315 & 4.0 & 85 & Temp_Class \\
Computer Class & 162 & 4.0 & 44 & Temp_Class \\
Main Corridor & 708 & 4.0 & 0 & Temp_Class \\
Lobby & 171 & 4.0 & 0 & Temp_Class \\
Mechanical Room & 156 & 4.0 & 0 & Temp_MechBR \\
Bathroom & 160 & 4.0 & 0 & Temp_MechBR \\
Offices & 441 & 4.0 & 24 & Temp_Class \\
Library Media Center & 363 & 4.0 & 43 & Temp_Class \\
Gym & 357 & 4.0 & 115 & Temp_Other \\
Kitchen & 168 & 4.0 & 27 & Temp_Other \\
Cafeteria & 315 & 4.0 & 339 & Temp_Other \\
\hline
\end{tabular}

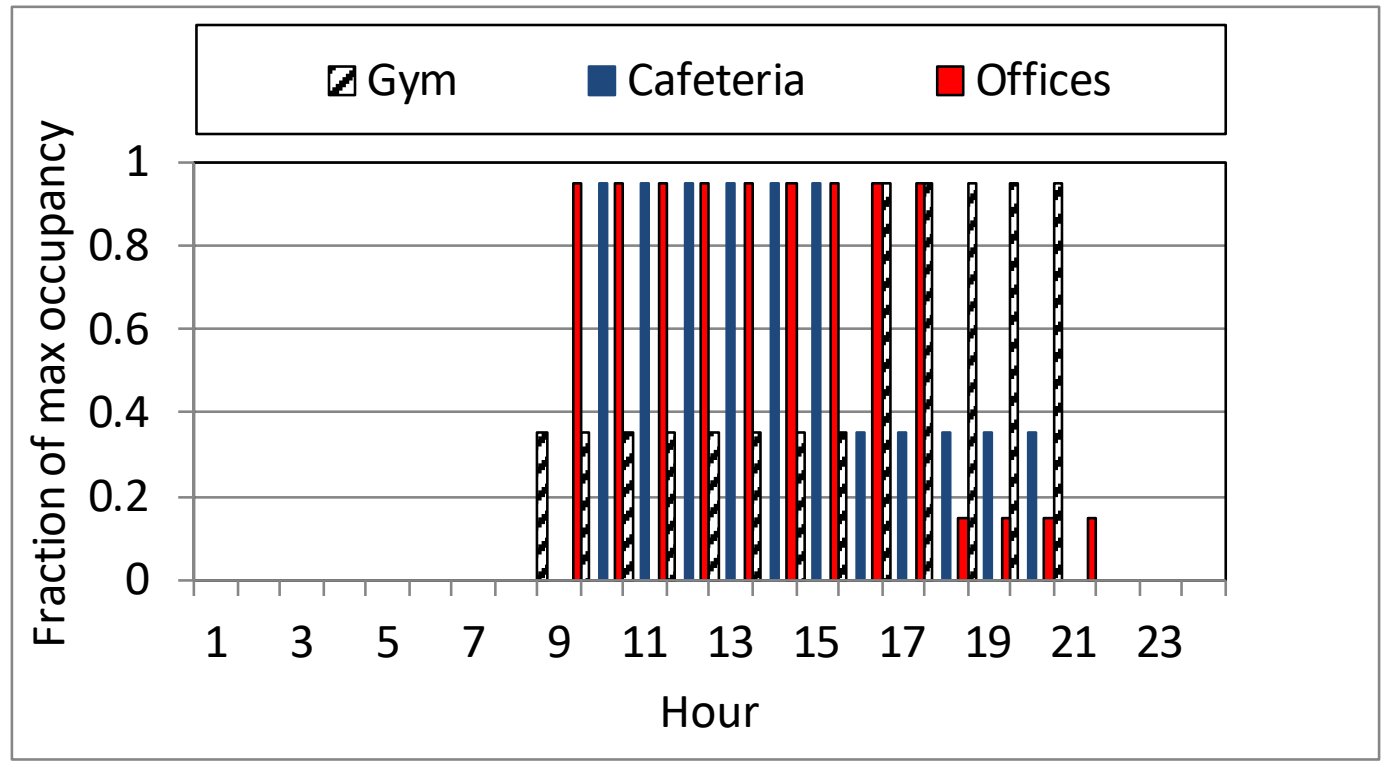

Figure 20. Occupancy schedules for Primary School (Non-classrooms) - School Year 


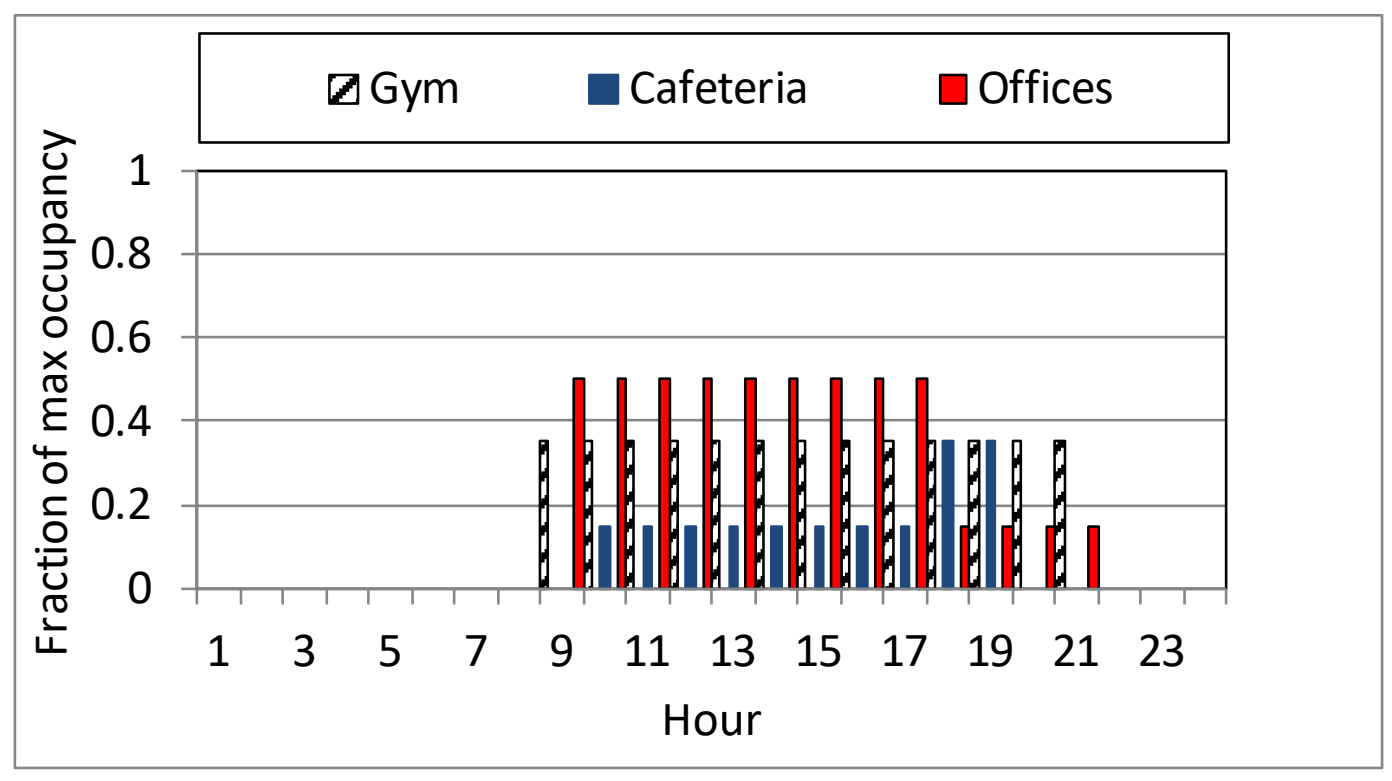

Figure 21. Occupancy schedules for Primary School (Non-classrooms) - Summer Break

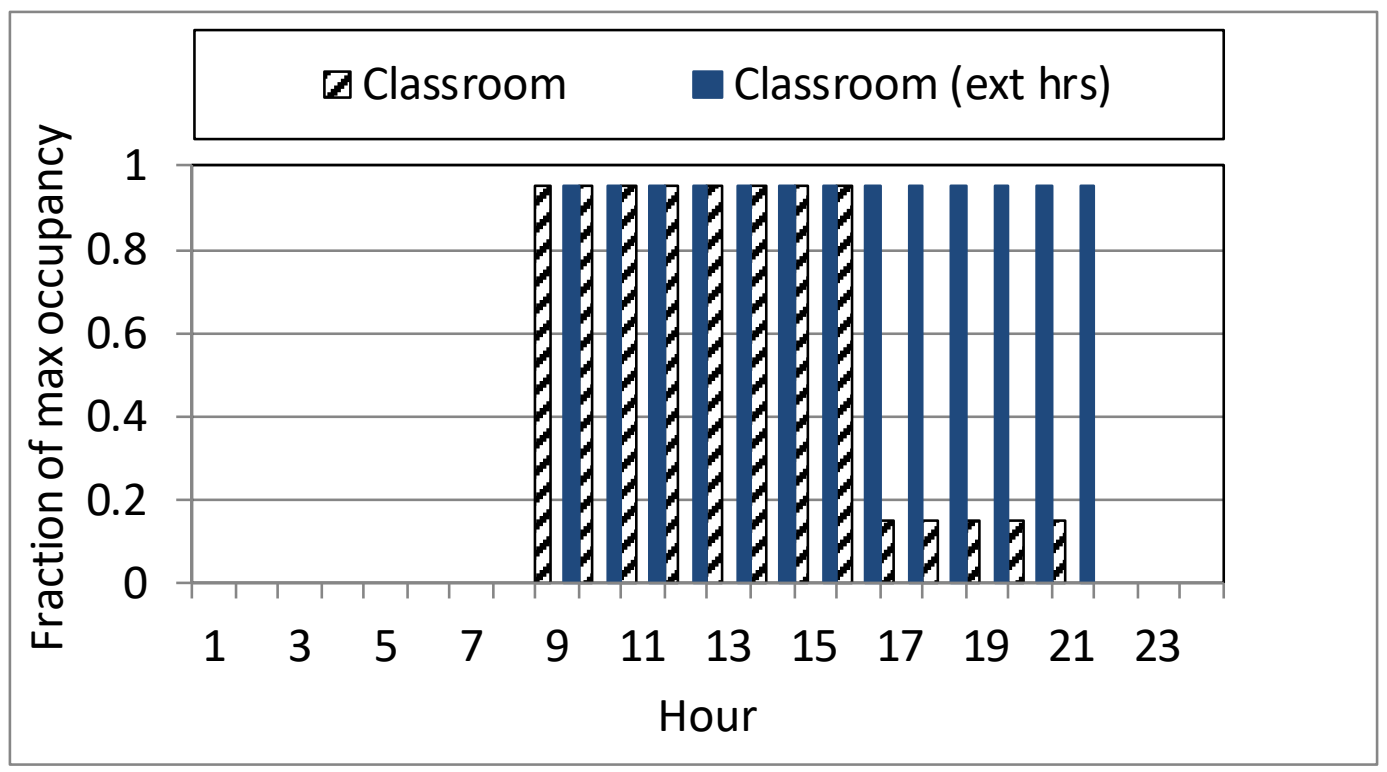

Figure 22. Occupancy schedules for Primary School (Classrooms) - School Year 


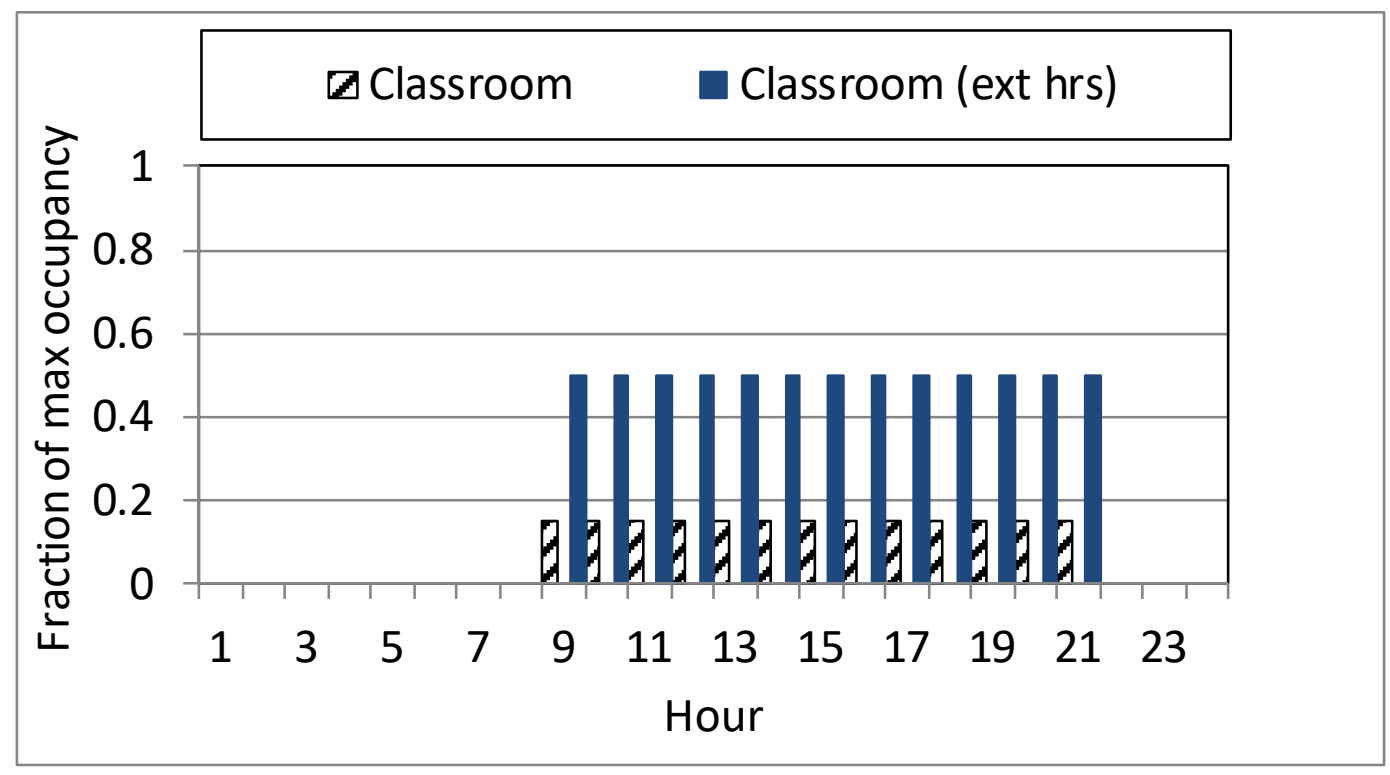

Figure 23. Occupancy schedules for Primary School (Classrooms) - Summer Break

\section{Geometry:}

$6871 \mathrm{~m}^{2}$ footprint (“E” shape), one-story building with flat roof. The EnergyPlus model has 25 zones. Most of the large spaces that are typical of schools are modeled as individual zones. Some of the classrooms are grouped together to form a single thermal zone, such as the "Mult" classrooms.

The CONTAM model was altered to create more realistic corridors with reasonable circulation patterns. In EnergyPlus, the Bathroom and Library Media Center blocked access to the Pod 3 corridor. This also prevented access to that section of the building from the Main Corridor. In CONTAM, a 3 m wide path was carved out of the Library Media Center and the Bathroom to connect the Main Corridor to Pod 3 (shaded in Figure 24).

In EnergyPlus, the Mechanical Room extended from the Lobby to the Bathroom, blocking access from the Main Corridor to the Cafeteria, Kitchen, and Gym. In CONTAM, the Mechanical Room was shortened to allow the Main Corridor to provide access to the Cafeteria, Kitchen, and Gym (shaded in Figure 24). These changes make the Main Corridor larger (shaded in Figure 24) and the Library Media Center, Bathroom, and Mechanical Room smaller in the CONTAM model than in the EnergyPlus model. Nevertheless, the occupancies and ventilation rates of the zones were not changed so that the CONTAM model matches the EnergyPlus model. 


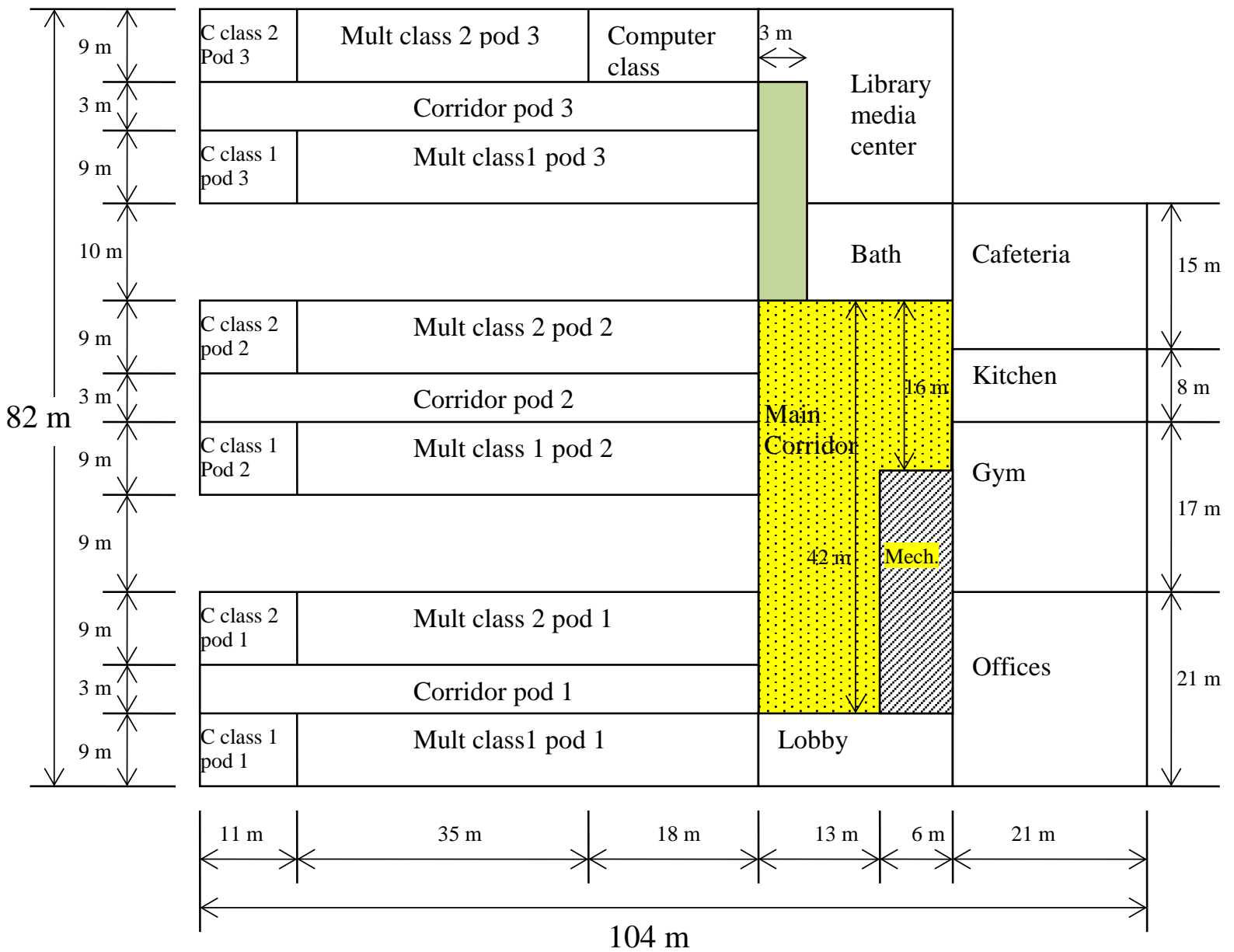

Figure 24. Plan of Primary School (height $4.0 \mathrm{~m}$ )

Large interior leakage paths were defined as follows:

- Between the Kitchen and Cafeteria zones, a single large leakage path of $42 \mathrm{~m}^{2}$ (50 \% of the total wall area between the two spaces) is modeled;

- Between each Pod's corridor and the Main Corridor, a $4.0 \mathrm{~m}^{2}$ open doorway is modeled;

- Between the Lobby and Main Corridor, two $4.0 \mathrm{~m}^{2}$ open doorways are modeled;

- Between the Bathroom and Main Corridor, a $0.186 \mathrm{~m}^{2}$ transfer grille is modeled.

\section{HVAC systems:}

The EnergyPlus model has three CAV and four VAV systems. The Kitchen, Gym, and Cafeteria each have a CAV system. The VAV systems are zoned as follows:

- VAV Pod 1: serves the zones in Pod 1

- VAV Pod 2: serves the zones in Pod 2

- VAV Pod 3: serves the zones in Pod 3

- VAV Other: serves the Computer Class, Main Corridor, Lobby, Mechanical Room, Bathroom, Offices, and Library Media Center (7 zones total) 
The design supply flow rate calculated by EnergyPlus for each VAV system is used as the supply flow rate for each constant-volume system modeled in CONTAM for simplicity. The systems modeled in CONTAM are still referred to as "VAV" systems in the body of this text. Varying the supply flow rate can be implemented in CONTAM using controls and/or schedules by users who wish to do so. The supply air, return air, outside air, and exhaust flow rates modeled in CONTAM are listed in Table 16.

Table 16. Summary of HVAC system flow rates $\left(\mathrm{m}^{3} / \mathrm{s}\right)$ in Primary School

\begin{tabular}{|c|c|c|c|c|}
\hline Zone & Supply & Return & Outside air & Exhaust air \\
\hline Cor Class 1 Pod 1 & 0.23 & 0.21 & 0.19 & 0.0 \\
\hline Mult Class 1 Pod 1 & 1.12 & 1.01 & 0.90 & 0.0 \\
\hline Corr Pod 1 & 0.45 & 0.41 & 0.06 & 0.0 \\
\hline Cor Class 2 Pod 1 & 0.23 & 0.21 & 0.19 & 0.0 \\
\hline Mult Class 2 Pod 1 & 1.12 & 1.01 & 0.90 & 0.0 \\
\hline VAV-Pod 1 total & 3.16 & 2.84 & 2.22 & \\
\hline Cor Class 1 Pod 2 & 0.23 & 0.21 & 0.19 & 0.0 \\
\hline Mult Class 1 Pod 2 & 1.11 & 1.00 & 0.90 & 0.0 \\
\hline Corr Pod 2 & 0.45 & 0.40 & 0.06 & 0.0 \\
\hline Cor Class 2 Pod 2 & 0.23 & 0.21 & 0.19 & 0.0 \\
\hline Mult Class 2 Pod 2 & 1.11 & 1.00 & 0.90 & 0.0 \\
\hline VAV-Pod 2 total & 3.12 & 2.81 & 2.22 & \\
\hline Cor Class 1 Pod 3 & 0.25 & 0.22 & 0.19 & 0.0 \\
\hline Mult Class 1 Pod 3 & 1.18 & 1.06 & 0.90 & 0.0 \\
\hline Corr Pod 3 & 0.48 & 0.43 & 0.06 & 0.0 \\
\hline Cor Class 2 Pod 3 & 0.25 & 0.22 & 0.19 & 0.0 \\
\hline Mult Class 2 Pod 3 & 0.78 & 0.70 & 0.59 & 0.0 \\
\hline VAV-Pod 3 total & 2.93 & 2.64 & 1.92 & \\
\hline Computer Class & 0.29 & 0.26 & 0.30 & 0.0 \\
\hline Main Corridor & 0.98 & 0.88 & 0.17 & 0.0 \\
\hline Lobby & 0.31 & 0.28 & 0.05 & 0.0 \\
\hline Mechanical Room & 0.45 & 0.41 & 0.00 & 0.0 \\
\hline Bathroom & 0.34 & 0.31 & 0.00 & 0.3 \\
\hline Offices & 0.79 & 0.71 & 0.19 & 0.0 \\
\hline Library Media Center & 0.71 & 0.64 & 0.34 & 0.0 \\
\hline VAV-Other total & 3.87 & 3.48 & 1.06 & \\
\hline Gym (CAV 2:5) & 0.77 & 0.70 & 0.54 & 0.00 \\
\hline Kitchen (CAV 1:6) & 2.12 & 1.91 & 2.12 & 2.12 \\
\hline Cafeteria (CAV 2:7) & 1.49 & 1.34 & 1.49 & 0.00 \\
\hline
\end{tabular}

In EnergyPlus, there was a Cafeteria exhaust fan $\left(1.38 \mathrm{~m}^{3} / \mathrm{s}\right)$ in addition to the Kitchen exhaust fan $\left(2.12 \mathrm{~m}^{3} / \mathrm{s}\right)$. It was included in order to transfer air from the Cafeteria to the Kitchen. This is 
modeled in CONTAM using a large opening between the Cafeteria and Kitchen zones (see above), and one exhaust fan in the Kitchen $\left(2.12 \mathrm{~m}^{3} / \mathrm{s}\right)$.

In EnergyPlus, balanced HVAC systems are modeled in all zones. In an attempt achieve building pressurization in CONTAM, less air is returned than is supplied to each zone. The return airflow rate is set to $90 \%$ of the supply airflow rate. Most of the building is neutrally pressurized between 7:00 a.m. and 8:00 a.m. on weekdays when the system operates but no outside air is being supplied, which reflects the operation modeled in EnergyPlus. The only zone that is not neutrally pressurized between 7:00 a.m. and 8:00 a.m. on weekdays is the bath which has an exhaust fan operating.

\section{HVAC Schedules:}

All HVAC systems and the bathroom exhaust operate on the following schedule:

- Weekdays: on from 7:00 a.m. to 9:00 p.m., off otherwise

- Weekends and holidays: off all day

The outside air for the HVAC systems operates on the same schedules as those above except the start time is one hour later on all of them.

The kitchen exhaust fan has the following schedule:

- From 1/1-6/29:

o Weekdays: on from 8:00 a.m. to 5:00 p.m., off otherwise

0 Weekends and holidays: off all day

- For the rest of the year (i.e., 6/30-12/31):

o Weekdays: on from 8:00 a.m. to 9:00 p.m., off otherwise

o Weekends and holidays: off all day

The kitchen exhaust fan schedule and occupancy schedules do not fit the default 12 day type scheduling feature in CONTAM, so a CVF was used instead. This allowed the operation of the kitchen exhaust and occupancy to be scheduled for every hour of the year. The file "PrimarySchool.cvf” is available for download with the prototype models on the NIST Multizone Modeling website under Case Studies.

\section{Temperature setpoints:}

There are three thermostat setpoint schedules used in the Primary School as listed in Table 15. For the Temp_Class and Temp_Other schedules, the thermostat setpoint changes through the day on the weekdays (Figure 25 and Figure 26). On the weekends and holidays, the thermostat 
setpoint remains constant at $15.6^{\circ} \mathrm{C}$ during the heating months and $26.7^{\circ} \mathrm{C}$ during the cooling months. The Temp_MechBR schedule maintained $15.6^{\circ} \mathrm{C}$ during the heating months and $26.7^{\circ} \mathrm{C}$ during the cooling months.

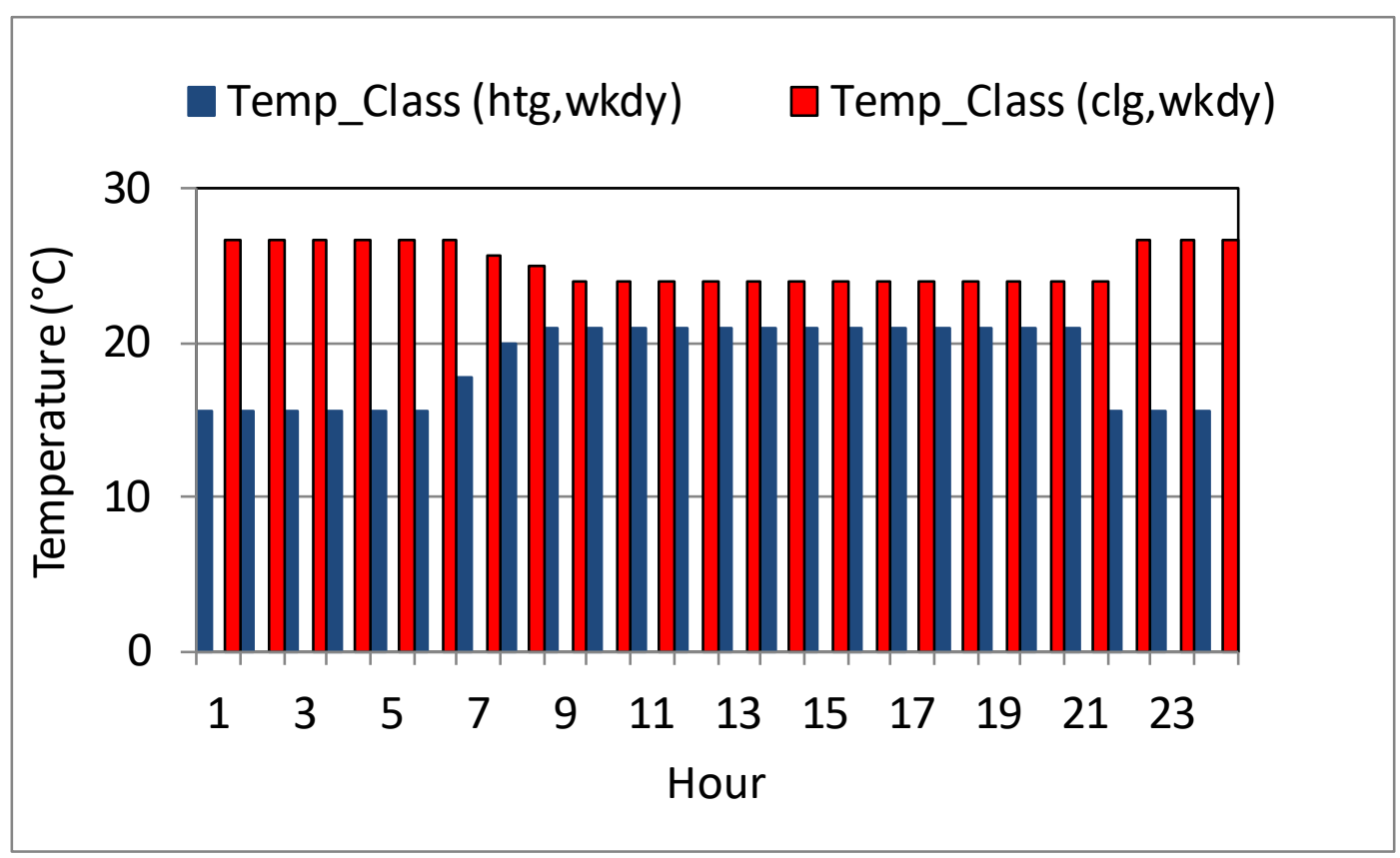

Figure 25. Thermostat setpoint schedule for Primary School (Temp_Class) - Weekday

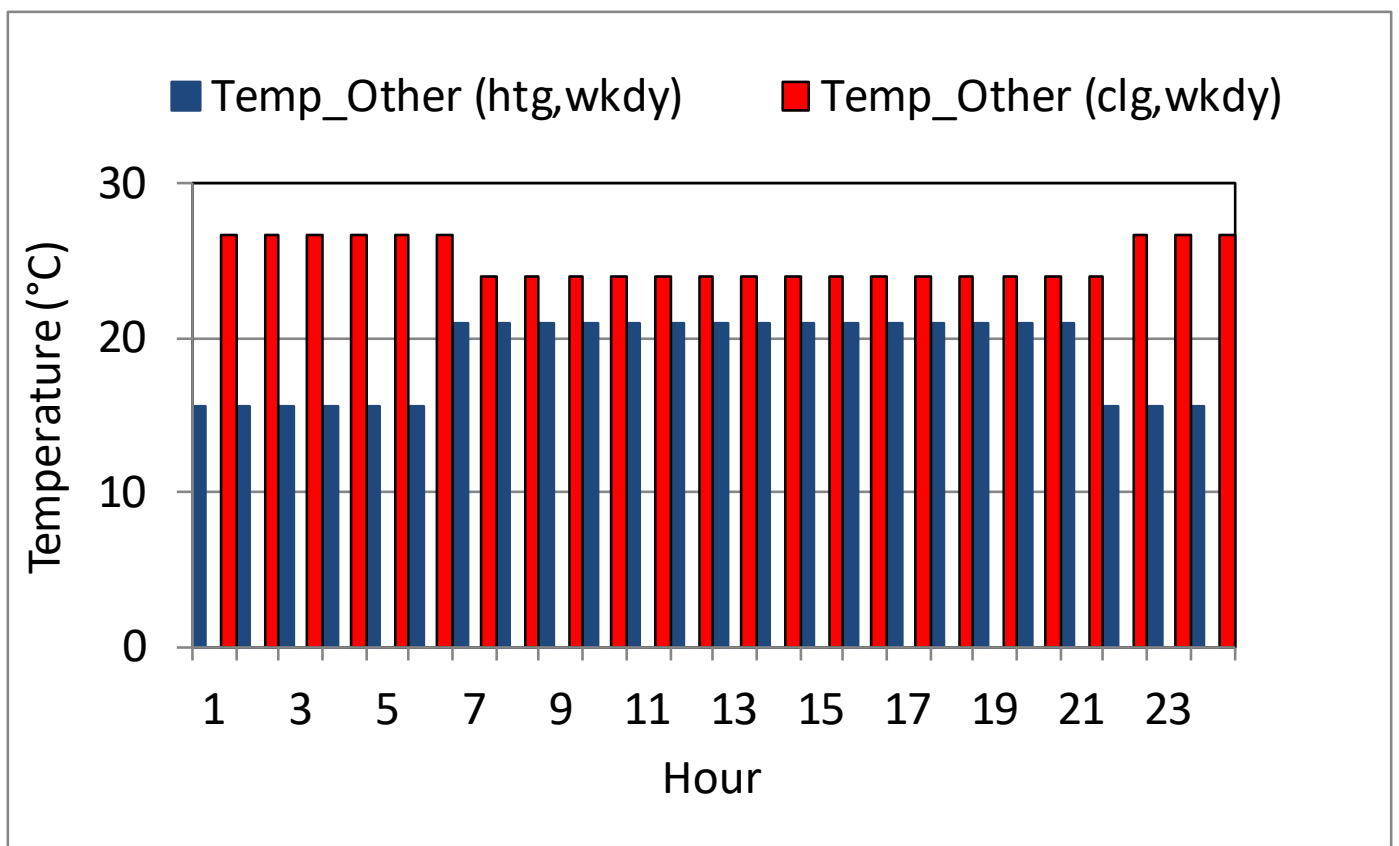

Figure 26. Thermostat setpoint schedule for Primary School (Temp_Other) - Weekday 


\subsection{Secondary School}

Table 17 summarizes the zones modeled in CONTAM for the Secondary School, their respective sizes, maximum occupancy, and thermostat setpoint schedules (Temp_Class and Temp_Other to be discussed in the Thermostat Setpoints section). Note that these are different schedules than the ones for the Primary School.

\section{Occupants:}

The peak number of people for each zone is listed in Table 17. Occupants in all building zones are scheduled according to Figure 27 to Figure 30. Weekends and holidays are unoccupied. There are six different occupant schedules for the building. The occupancy schedules for the Gym (and Auxiliary Gym), Cafeteria, and Auditorium are shown in Figure 27 for the school year and Figure 28 for summer break. The occupancy schedule for the remaining zones (referred to as “Classroom” occupancy), Classrooms with extended hours, and Offices are shown in Figure 29 for the school year and Figure 30 for summer break. All of the schedules have the same summer break time period (7/1 to 9/1) except for the Classrooms which has a summer break time period of $6 / 16$ to $9 / 15$.

The Classrooms with extended hours are for the "Mult Class 1" "Mult Class 2” zones in Pod 3 on the second floor. The "Classroom” and "Classroom with extended hours” occupancy schedules are the same except the extended occupancy schedule has greater and constant occupancy from 8:00 a.m. to 4:00 p.m. during the school year and summer.

The kitchen exhaust fan schedule and occupancy schedules do not fit the default 12 day type scheduling feature in CONTAM, so a CVF was used instead. This allowed the operation of the kitchen exhaust and occupancy to be scheduled for every hour of the year. The thermostat setpoint schedules were also included in the CVF even though the schedules fit the default 12 day type scheduling feature. The file "SecondarySchool.cvf" is available for download with the prototype models on the NIST Multizone Modeling website under Case Studies. 
Table 17. Summary of zones in Secondary School

\begin{tabular}{|c|c|c|c|c|c|}
\hline Zone & Floor & $\begin{array}{r}\text { Area } \\
\left(\mathbf{m}^{2}\right)\end{array}$ & $\begin{array}{r}\text { Height } \\
\text { (m) }\end{array}$ & $\begin{array}{l}\text { Maximum } \\
\text { occupancy }\end{array}$ & $\begin{array}{l}\text { Thermostat } \\
\text { setpoint } \\
\text { schedules }\end{array}$ \\
\hline Corner (“Cor”) Class 1 Pod 1 & 1 & 99 & 4.0 & 37 & Temp_Class \\
\hline Multiple (“Mult”) Class 1 Pod 1 & 1 & 477 & 4.0 & 180 & Temp_Class \\
\hline Corridor (“Corr”) Pod 1 & 1 & 320 & 4.0 & 37 & Temp_Class \\
\hline Cor Class 2 Pod 1 & 1 & 99 & 4.0 & 37 & Temp_Class \\
\hline Mult Class 2 Pod 1 & 1 & 477 & 4.0 & 180 & Temp_Class \\
\hline Cor Class 1 Pod 2 & 1 & 99 & 4.0 & 37 & Temp_Class \\
\hline Mult Class 1 Pod 2 & 1 & 477 & 4.0 & 180 & Temp_Class \\
\hline Corr Pod 2 & 1 & 320 & 4.0 & 0 & Temp_Class \\
\hline Cor Class 2 Pod 2 & 1 & 99 & 4.0 & 37 & Temp_Class \\
\hline Mult Class 2 Pod 2 & 1 & 477 & 4.0 & 180 & Temp_Class \\
\hline Cor Class 1 Pod 3 & 1 & 99 & 4.0 & 37 & Temp_Class \\
\hline Mult Class 1 Pod 3 & 1 & 477 & 4.0 & 180 & Temp_Class \\
\hline Corr Pod 3 & 1 & 320 & 4.0 & 0 & Temp_Class \\
\hline Cor Class 2 Pod 3 & 1 & 99 & 4.0 & 37 & Temp_Class \\
\hline Mult Class 2 Pod 3 & 1 & 477 & 4.0 & 180 & Temp_Class \\
\hline Main Corridor & 1 & 1524 & 4.0 & 0 & Temp_Class \\
\hline Lobby & 1 & 210 & 4.0 & 0 & Temp_Class \\
\hline Bathroom & 1 & 195 & 4.0 & 0 & Temp_Other \\
\hline Offices & 1 & 532 & 4.0 & 29 & Temp_Class \\
\hline Gym & 1 & 1976 & 8.0 & 637 & Temp_Class \\
\hline Auxiliary Gym & 1 & 1248 & 8.0 & 403 & Temp_Class \\
\hline Auditorium & 1 & 988 & 8.0 & 1594 & Temp_Class \\
\hline Kitchen & 1 & 189 & 4.0 & 35 & Temp_Class \\
\hline Cafeteria & 1 & 624 & 4.0 & 671 & Temp_Class \\
\hline Mechanical Room & 1 & 342 & 4.0 & 0 & Temp_Other \\
\hline Cor Class 1 Pod 1 & 2 & 99 & 4.0 & 37 & Temp_Class \\
\hline Mult Class 1 Pod 1 & 2 & 477 & 4.0 & 180 & Temp_Class \\
\hline Corr Pod 1 & 2 & 320 & 4.0 & 37 & Temp_Class \\
\hline Cor Class 2 Pod 1 & 2 & 99 & 4.0 & 180 & Temp_Class \\
\hline Mult Class 2 Pod 1 & 2 & 477 & 4.0 & 180 & Temp_Class \\
\hline Cor Class 1 Pod 2 & 2 & 99 & 4.0 & 37 & Temp_Class \\
\hline Mult Class 1 Pod 2 & 2 & 477 & 4.0 & 180 & Temp_Class \\
\hline Corr Pod 2 & 2 & 320 & 4.0 & 0 & Temp_Class \\
\hline Cor Class 2 Pod 2 & 2 & 99 & 4.0 & 37 & Temp_Class \\
\hline Mult Class 2 Pod 2 & 2 & 477 & 4.0 & 180 & Temp_Class \\
\hline Cor Class 1 Pod 3 & 2 & 99 & 4.0 & 37 & Temp_Class \\
\hline Mult Class 1 Pod 3 & 2 & 477 & 4.0 & 180 & Temp_Class \\
\hline Corr Pod 3 & 2 & 320 & 4.0 & 0 & Temp_Class \\
\hline Cor Class 2 Pod 3 & 2 & 99 & 4.0 & 37 & Temp_Class \\
\hline Mult Class 2 Pod 3 & 2 & 477 & 4.0 & 180 & Temp_Class \\
\hline Main Corridor & 2 & 1497 & 4.0 & 0 & Temp_Class \\
\hline Lobby & 2 & 210 & 4.0 & 0 & Temp_Class \\
\hline
\end{tabular}




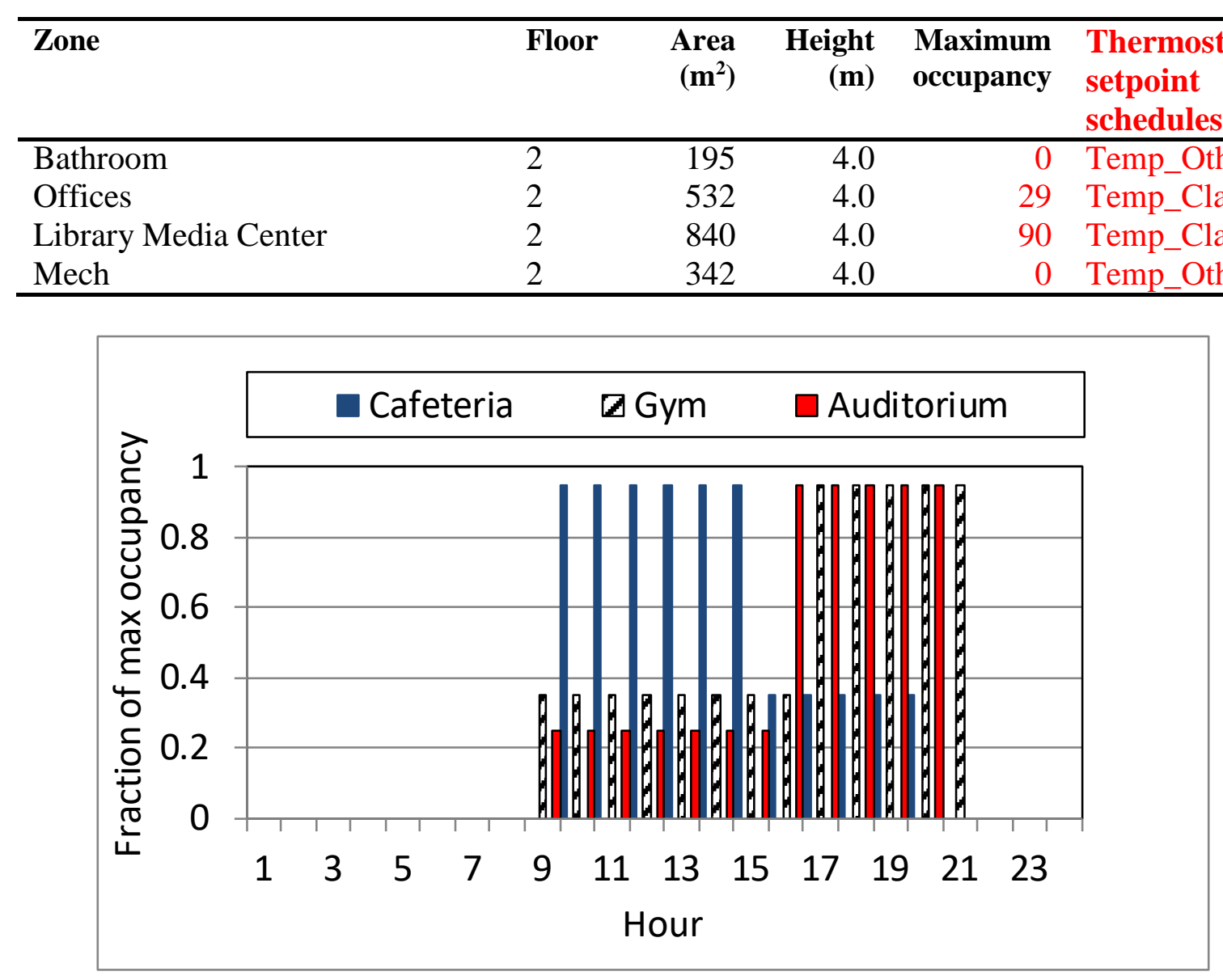

Figure 27. Occupancy schedules for Secondary School (Non-classrooms) - School Year

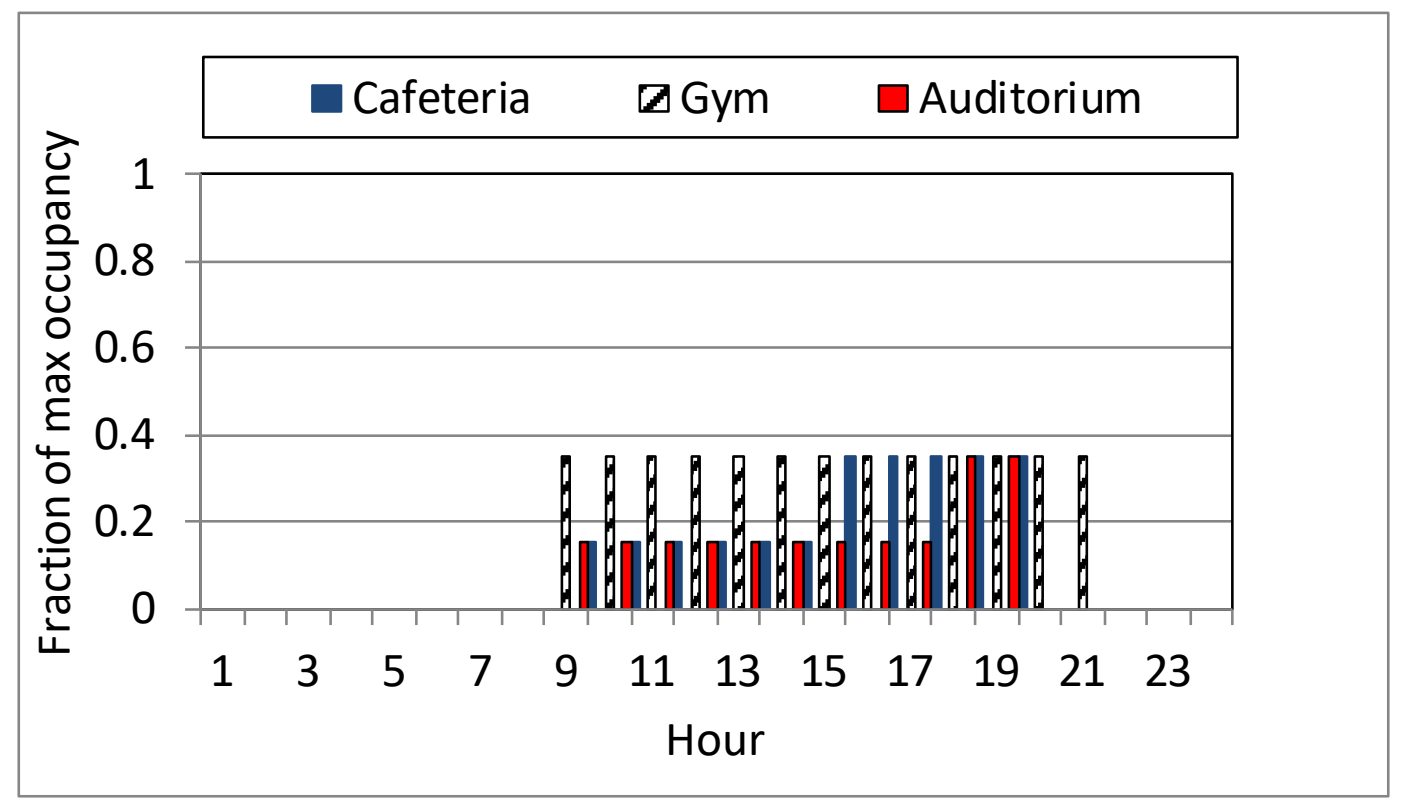

Figure 28. Occupancy schedules for Secondary School (Non-classrooms) - Summer Break 


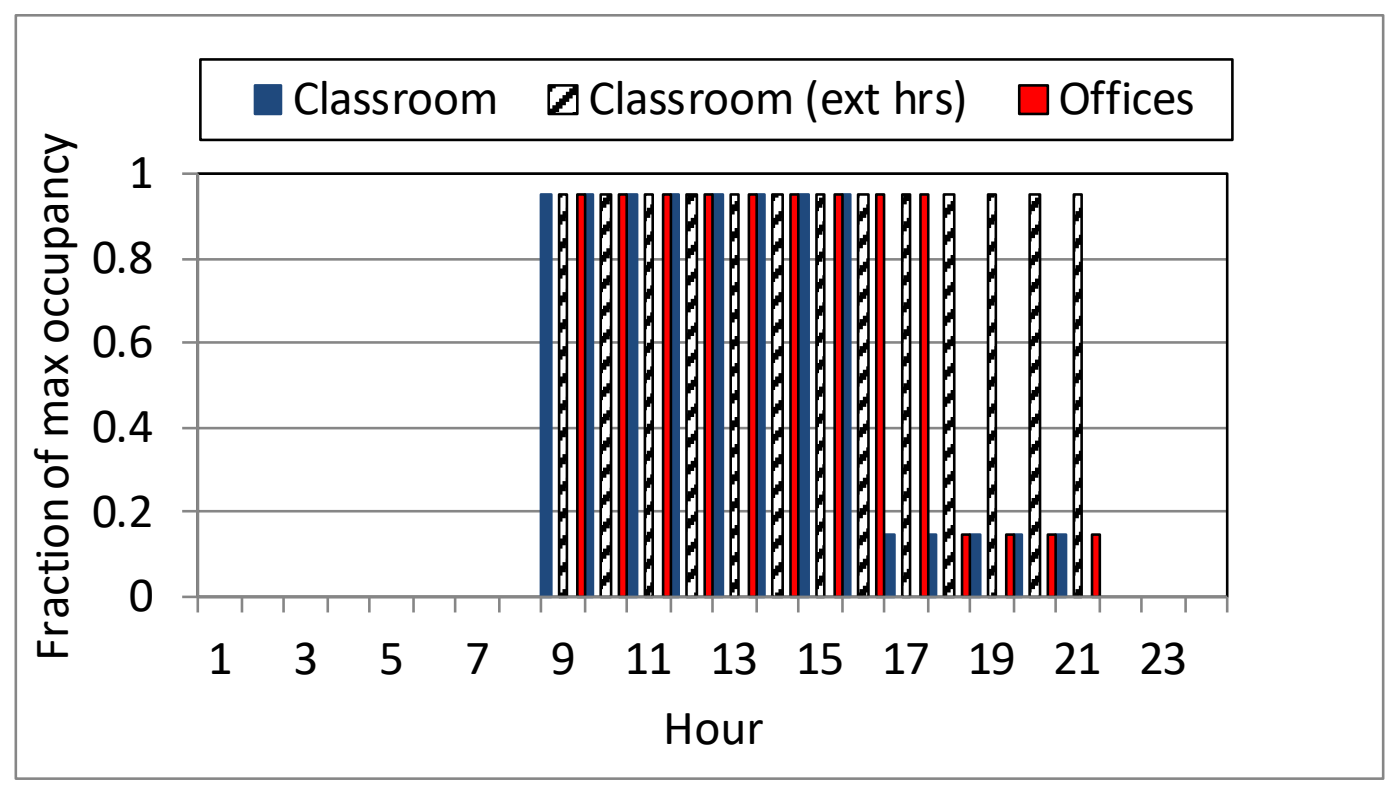

Figure 29. Occupancy schedules for Secondary School (Classrooms, Office) - School Year

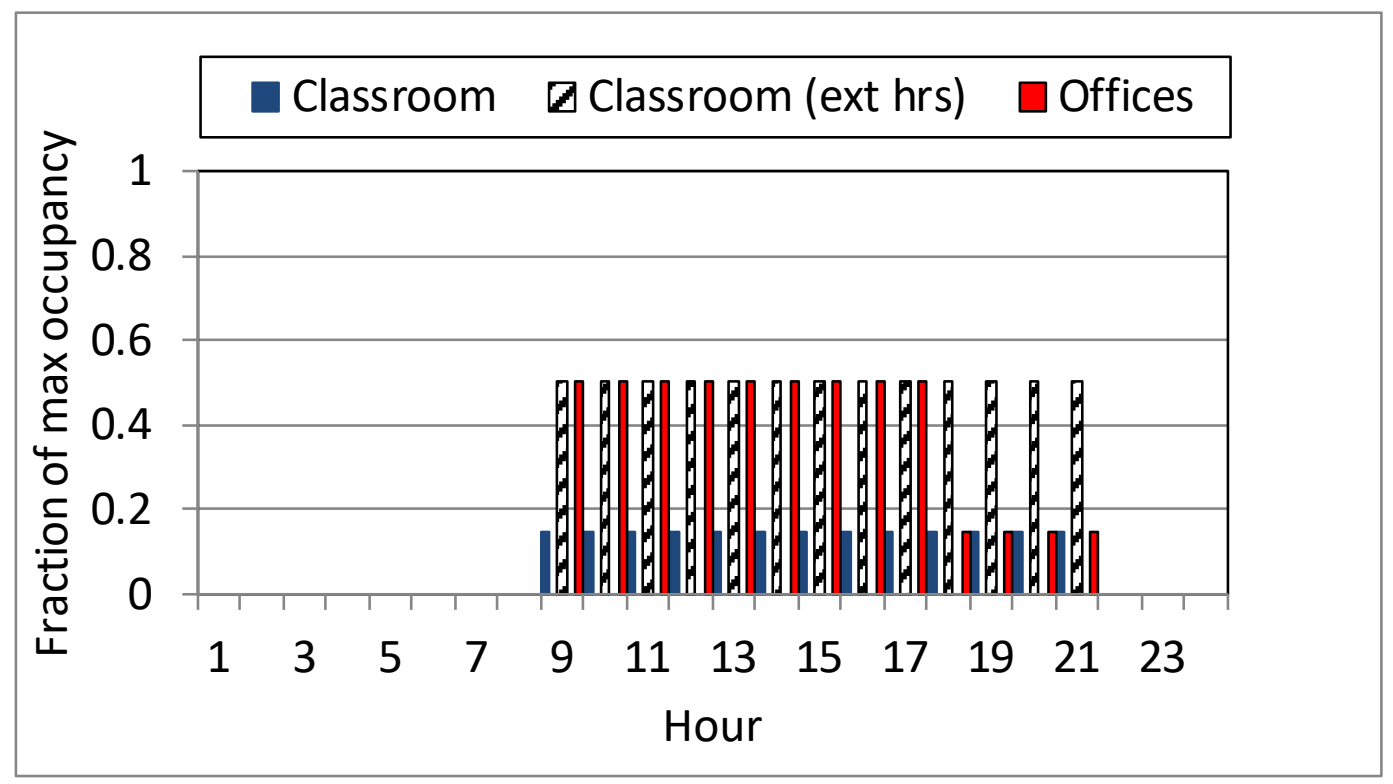

Figure 30. Occupancy schedules for Secondary School (Classrooms, Office) - Summer Break

\section{Geometry:}

$19592 \mathrm{~m}^{2}$ footprint ("E" shape), two-story building with flat roof. The EnergyPlus model has 25 zones on the first floor and 21 zones on the second floor. The first floor has an $11902 \mathrm{~m}^{2}$ footprint. The second floor is stacked on top of the first floor with a footprint of $7690 \mathrm{~m}^{2}$. Both floors have the same floor plan except that the Library Media Center on the second floor stacks on top of the Cafeteria and Kitchen. Most of the large spaces that are typical of schools are 
modeled as individual zones. Some of the classrooms are grouped together to form a single thermal zone. Three spaces (Auditorium, Gym, and Auxiliary Gym) on the first floor are twostories (8 $\mathrm{m}$ ) high. The remaining zones on both floors are all $4 \mathrm{~m}$ high.

The CONTAM model was altered to create more realistic corridors with reasonable circulation patterns. In EnergyPlus, the first and second floor Bathroom blocked access to the Pod 3 Corridor. This also prevented access to those sections of the building from the first and second floor Main Corridor. In CONTAM, a $3 \mathrm{~m}$ wide path was carved out of the first and second floor Bathroom to provide access from the Main Corridor to the Pod 3 (shaded in Figure 31 and Figure $32)$.

In EnergyPlus, the first floor Mechanical Room blocked access from the Main Corridor to the Cafeteria, Kitchen, and Auxiliary Gym. In EnergyPlus, the second floor Mechanical Room blocked access from the Main Corridor to the Library Media Center. In CONTAM, the first and second floor Mechanical Room were moved and carved out of the Gym (shaded in Figure 31 and Figure 32). In CONTAM, the first floor Kitchen was also shortened to provide access from the Main Corridor to the Cafeteria and Auxiliary Gym (shaded in Figure 31). These changes make the first and second floor Main Corridor larger (shaded in Figure 31 and Figure 32) and the first and second floor Bathroom, first floor Kitchen, and first floor Gym smaller in the CONTAM model than in the EnergyPlus model. Nevertheless, the occupancies and ventilation rates of the zones were not changed so that the CONTAM model matches the EnergyPlus model.

Large interior leakage paths were defined as follows:

- Between the Kitchen and Cafeteria zones, a single large leakage path of $42 \mathrm{~m}^{2}$ (50 \% of the total wall area between the two spaces) is modeled;

- The wall between each Pod's corridor and the Main Corridor is modeled with a $4.0 \mathrm{~m}^{2}$ open doorway;

- Two $4.0 \mathrm{~m}^{2}$ open doorways are modeled in the wall connecting the Lobby to the Main Corridor;

- Each Bathroom is modeled with a $0.186 \mathrm{~m}^{2}$ transfer grille in the door between the Bathroom and the Main Corridor. 


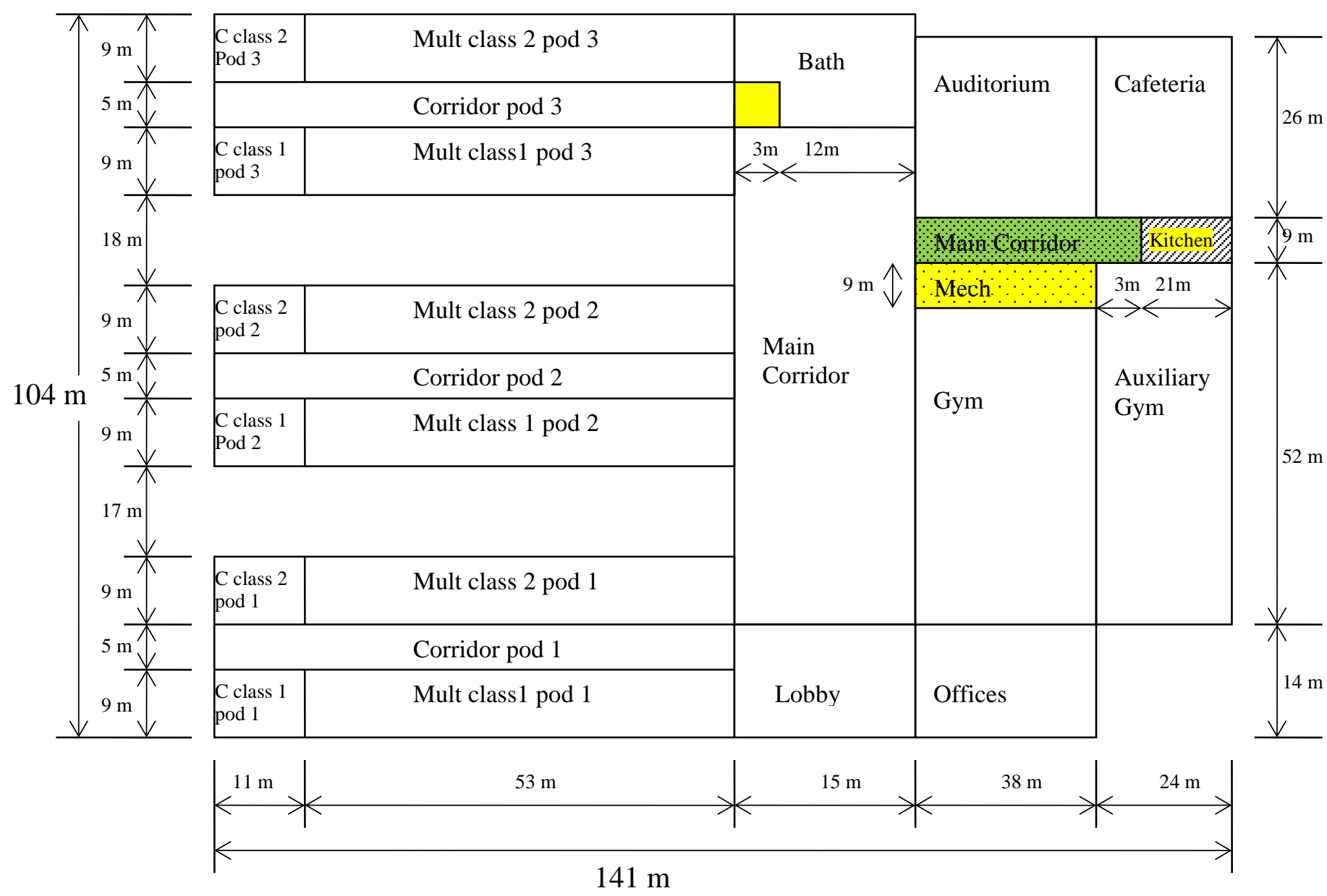

Figure 31. First floor plan of Secondary School (height $4.0 \mathrm{~m}$ ) 


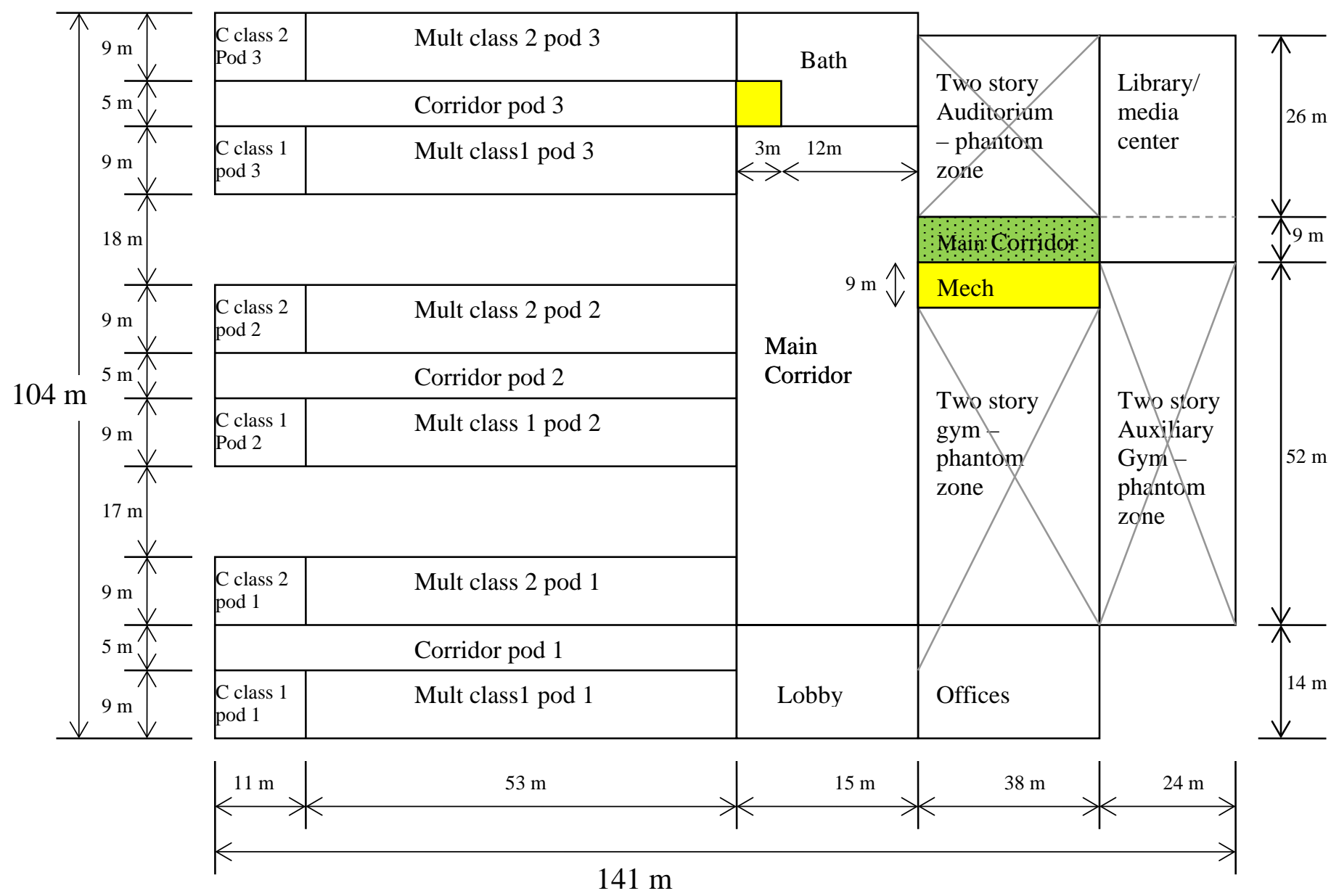

Figure 32. Second floor plan of Secondary School (height $4.0 \mathrm{~m}$ ) 


\section{HVAC systems:}

The EnergyPlus model has five CAV and four VAV systems. The Gym, Auxiliary Gym, Auditorium, Kitchen, and Cafeteria each have a CAV system. The VAV systems are zoned as follows:

- VAV Pod 1: serves the zones in Pod 1, first and second floor

- VAV Pod 2: serves the zones in Pod 2, first and second floor

- VAV Pod 3: serves the zones in Pod 3, first and second floor

- VAV Other: serves the first and second floors Main Corridor, Lobby, Mechanical Room, Bathroom, Offices, and the second floor Library Media Center (11 zones total)

The design supply flow rate calculated by EnergyPlus for each VAV system is used as the supply flow rate for each constant-volume system modeled in CONTAM for simplicity. The systems modeled in CONTAM are still referred to as "VAV" systems in the body of this text. Varying the supply flow rate can be implemented in CONTAM using controls and/or schedules by users who wish to do so. The supply air, return air, outside air, and exhaust flow rates modeled in CONTAM are listed in Table 18.

In the reference building model, there was a Cafeteria exhaust fan in addition to the Kitchen exhaust fan. It was included in order to transfer air from the Cafeteria to the Kitchen and vice versa. This is modeled in CONTAM using a large opening between the Cafeteria and Kitchen zones (see above), and one larger exhaust fan in the Kitchen. However, in the prototype building model, there was only a Kitchen exhaust fan in the EnergyPlus version (2.55 m³ $/ \mathrm{s})$. This was reflected in the CONTAM model.

In EnergyPlus, balanced HVAC systems are modeled in all zones. In an attempt achieve building pressurization in CONTAM, less air is returned than is supplied to each zone. The return airflow rate is set to $90 \%$ of the supply airflow rate. Most of the building is neutrally pressurized between 7:00 a.m. and 8:00 a.m. on weekdays when the system operates but no outside air is being supplied, which reflects the operation modeled in EnergyPlus. The only zone that is not neutrally pressurized between 7:00 a.m. and 8:00 a.m. on weekdays is the bathroom which has an exhaust fan operating. 


\section{HVAC Schedules:}

All HVAC and bathroom exhaust fans operate on the following schedule:

- Weekdays: on from 7:00 a.m. to 9:00 p.m., off otherwise

- Weekends and holidays: off all day

The outside air for the HVAC systems operates on the same schedules as those above except the start time is one hour later on all of them.

The kitchen exhaust fan has the following schedule:

- From 1/1-6/30:

o Weekdays: on from 8:00 a.m. to 5:00 p.m., off otherwise

0 Weekends and holidays: off all day

- From 7/1-12/31:

o Weekdays: on from 8:00 a.m. to 9:00 p.m., off otherwise

o Weekends and holidays: off all day 
Table 18. Summary of HVAC system flow rates $\left(\mathrm{m}^{3} / \mathrm{s}\right)$ in Secondary School

\begin{tabular}{llrrrr}
\hline Zone & Floor & Supply & Return & $\begin{array}{r}\text { Outsider } \\
\text { Air }\end{array}$ & $\begin{array}{r}\text { Exhaust } \\
\text { air }\end{array}$ \\
\hline Corner (“Cor”) Class 1 Pod 1 & 1 & 0.26 & 0.24 & & 0.00 \\
Multiple ("Mult”) Class 1 Pod 1 & 1 & 1.28 & 1.15 & & 0.00 \\
Corridor (“Corr”) Pod 1 & 1 & 0.86 & 0.77 & & 0.00 \\
Cor Class 2 Pod 1 & 1 & 0.26 & 0.24 & & 0.00 \\
Mult Class 2 Pod 1 & 1 & 1.28 & 1.15 & & 0.00 \\
Cor Class 1 Pod 1 & 2 & 0.26 & 0.24 & & 0.00 \\
Mult Class 1 Pod 1 & 2 & 1.28 & 1.15 & & 0.00 \\
Corr Pod 1 & 2 & 0.86 & 0.77 & & 0.00 \\
Cor Class 2 Pod 1 & 2 & 0.26 & 0.24 & & 0.00 \\
Mult Class 2 Pod 1 & 2 & 1.28 & 1.15 & & 0.00 \\
\hline VAV-Pod 1 Total & & 7.87 & 7.08 & 5.70 & \\
\hline Cor Class 1 Pod 2 & 1 & 0.26 & 0.24 & & 0.00 \\
Mult Class 1 Pod 2 & 1 & 1.27 & 1.14 & & 0.00 \\
Corr Pod 2 & 1 & 0.85 & 0.77 & & 0.00 \\
Cor Class 2 Pod 2 & 1 & 0.26 & 0.24 & & 0.00 \\
Mult Class 2 Pod 2 & 1 & 1.27 & 1.14 & & 0.00 \\
Cor Class 1 Pod 2 & 2 & 0.26 & 0.24 & & 0.00 \\
Mult Class 1 Pod 2 & 2 & 1.27 & 1.14 & & 0.00 \\
Corr Pod 2 & 2 & 0.85 & 0.77 & & 0.00 \\
Cor Class 2 Pod 2 & 2 & 0.26 & 0.24 & & 0.00 \\
Mult Class 2 Pod 2 & 2 & 1.27 & 1.14 & & 0.00 \\
\hline VAV-Pod 2 Total & & 7.84 & 7.06 & 5.70 & \\
\hline Cor Class 1 Pod 3 & 1 & 0.30 & 0.27 & & 0.00 \\
Mult Class 1 Pod 3 & 1 & 1.45 & 1.31 & & 0.00 \\
Corr Pod 3 & 1 & 0.97 & 0.88 & & 0.00 \\
Cor Class 2 Pod 3 & 1 & 0.30 & 0.27 & & 0.00 \\
Mult Class 2 Pod 3 & 1 & 1.45 & 1.31 & & 0.00 \\
Cor Class 1 Pod 3 & 2 & 0.30 & 0.27 & & 0.00 \\
Mult Class 1 Pod 3 & 2 & 1.45 & 1.31 & & 0.00 \\
Corr Pod 3 & 2 & 0.97 & 0.88 & & 0.00 \\
Cor Class 2 Pod 3 & 2 & 0.30 & 0.27 & & 0.00 \\
Mult Class 2 Pod 3 & 2 & 1.45 & 1.31 & & 0.00 \\
\hline VAV-Pod 3 Total & & $\mathbf{8 . 9 5}$ & $\mathbf{8 . 0 6}$ & 5.70 & \\
\hline Main Corridor & 1 & 2.37 & 2.13 & & 0.000 \\
Lobby & 1 & 0.44 & 0.39 & & 0.00 \\
Bathroom & 1 & 0.44 & 0.39 & & 0.28 \\
Offices & 1 & 1.11 & 0.99 & & 0.00 \\
Mechanical Room & 1 & 0.71 & 0.64 & & 0.00 \\
Main Corridor & 2 & 2.37 & 2.13 & & 0.00 \\
Lobby & 0.44 & 0.39 & & 0.00 \\
Bathroom & 0.44 & 0.39 & & 0.28 \\
Offices & 1.11 & 0.99 & & 0.00
\end{tabular}




\begin{tabular}{lcrrrr}
\hline Zone & Floor & Supply & Return & $\begin{array}{r}\text { Outside } \\
\text { Air }\end{array}$ & $\begin{array}{r}\text { Exhaust } \\
\text { air }\end{array}$ \\
\hline Library Media Center & 2 & 1.75 & 1.57 & & 0.00 \\
Mechanical Room & 2 & 0.71 & 0.64 & & 0.00 \\
\hline VAV-Other Total & & $\mathbf{1 1 . 8 6}$ & $\mathbf{1 0 . 6 7}$ & 2.01 & \\
\hline Gym (CAV 1:5) & 1 & 4.08 & 3.67 & 3.01 & 0.00 \\
Auxiliary Gym (CAV 2:6) & 1 & 4.63 & 4.17 & 1.90 & 0.00 \\
Auditorium (CAV 3:7) & 1 & 4.10 & 3.69 & 4.07 & 0.00 \\
Kitchen (CAV 4:8) & 1 & 2.55 & 2.30 & 2.55 & 2.55 \\
Cafeteria (CAV 5:9) & 1 & 2.95 & 2.66 & 2.95 & 0.000 \\
\hline
\end{tabular}

Temperature setpoints:

There are thermostat setpoint schedules used in the Secondary School as listed in Table 17. For the Temp_Class schedule, the thermostat setpoint changes through the day on the weekdays (Figure 33). The Temp_Other schedule for all days, and the Temp_Class schedule on the weekends and holidays, remains constant at $15.6^{\circ} \mathrm{C}$ during the heating months and $29.4{ }^{\circ} \mathrm{C}$ during the cooling months.

There are two thermostat setpoint schedules used in the Secondary School as listed in Table 17. For the Temp_Class schedule, the thermostat setpoint changes through the day on the weekdays (Figure 33). On the weekends and holidays, the thermostat setpoint remains constant at $15.6{ }^{\circ} \mathrm{C}$ during the heating months and $29.4{ }^{\circ} \mathrm{C}$ during the cooling months. The Temp_Other schedule follows the weekends/holiday schedule of Temp_Class all year round.

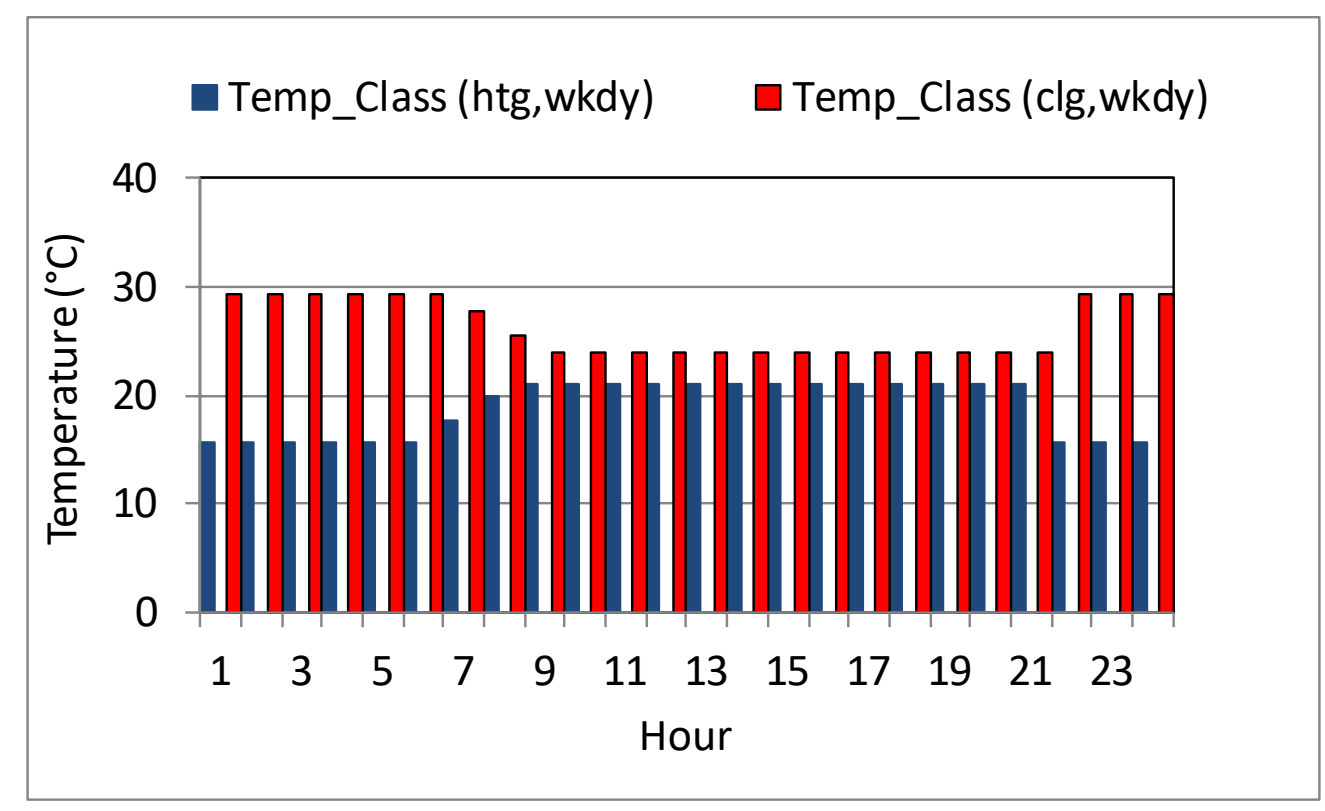

Figure 33. Thermostat setpoint schedule for Secondary School (Temp_Class - Weekday) 


\subsection{Stand Alone Retail}

Table 19 summarizes the zones modeled in CONTAM for the Stand-Alone Retail, their respective sizes, maximum occupancy, and thermostat setpoint schedules (Temp_CR and Temp_Other to be discussed in the Thermostat Setpoints section).

Table 19. Summary of zones in Stand Alone Retail

\begin{tabular}{lrrrl}
\hline Zone & Area $\mathbf{( m}^{\mathbf{2}}$ ) & Height (m) & $\begin{array}{r}\text { Maximum } \\
\text { occupancy }\end{array}$ & Thermostat setpoint schedule \\
\hline Back Space & 352 & 6.1 & 61 & Temp_Other \\
Core Retail & 1600 & 6.1 & 259 & Temp_CR \\
Point of Sale & 151 & 6.1 & 24 & Temp_Other \\
Front Retail & 151 & 6.1 & 24 & Temp_Other \\
Front Entry & 12 & 6.1 & 2 & See Section “Thermostat \\
& & & & setpoints” in text \\
Restroom & 28 & 6.1 & 0 & Temp_Other \\
\hline
\end{tabular}

\section{Occupants:}

The peak number of people for each zone is listed in Table 19. Occupants in all building zones are scheduled according to Figure 34. There is a different occupancy schedule for weekdays, Saturdays, and Sundays/holidays.

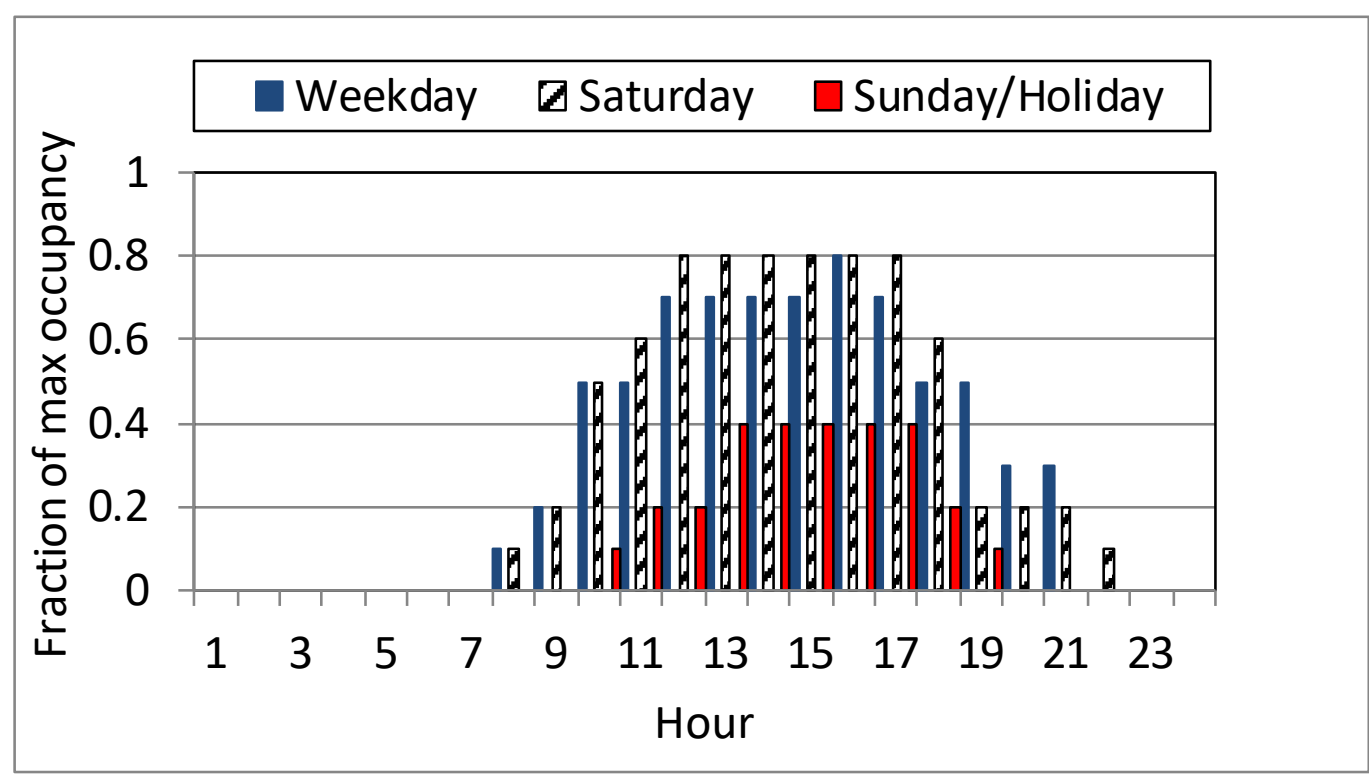

Figure 34. Occupancy schedule for Stand Alone Retail

\section{Geometry:}

$2294 \mathrm{~m}^{2}$ footprint, single-story building with flat roof. The EnergyPlus model has five zones. In the CONTAM model, a Restroom (shaded in Figure 35) with a footprint of $4 \mathrm{~m} \times 7 \mathrm{~m}$ was carved out of the Back Space. 


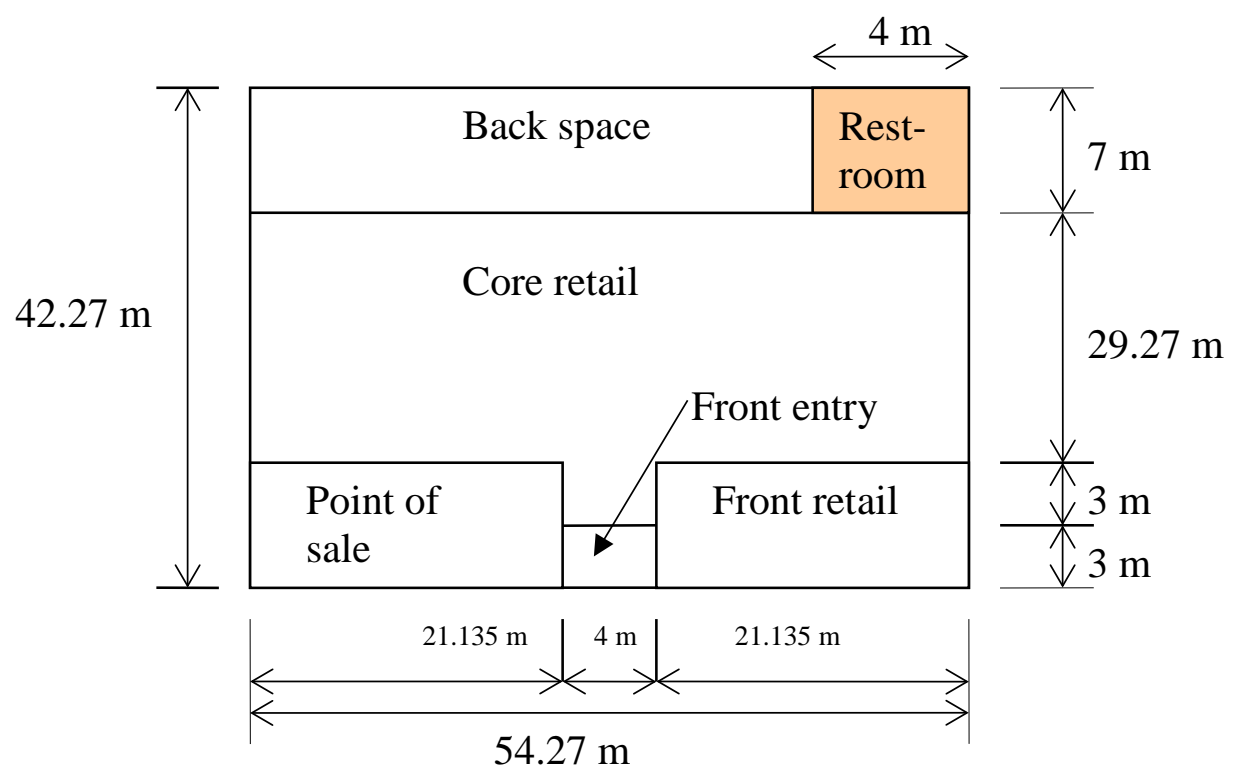

Figure 35. Floor plan of Stand Alone Retail (height $6.1 \mathrm{~m}$ )

Large interior leakage paths were defined as follows:

- Between Back Space and Core Retail, a single large leakage path of $3.0 \mathrm{~m}^{2}$ is modeled;

- Between Core Retail and Point of Sale, a single large leakage path of $96.7 \mathrm{~m}^{2}$ (75 \% of the total wall area between the spaces) is modeled;

- Between Core Retail and Front Retail, a single large leakage path of $96.7 \mathrm{~m}^{2}$ (75 \% of the total wall area between the spaces) is modeled;

- Between the Restroom and Back space, a $0.372 \mathrm{~m}^{2}$ transfer grille is modeled.

HVAC systems:

The EnergyPlus model of the building has five packaged constant-volume single-zone systems. Similarly, each zone has a constant-volume system in CONTAM. The supply air, return air, outside air, and exhaust flow rates modeled in CONTAM are listed in Table 20. The exhaust flow rate for the Restroom was modeled only in CONTAM, not in EnergyPlus.

The Front Entry has a unit heater in EnergyPlus that recirculates air locally within the zone and does not impact whole-building airflow or introduce outside air. Therefore, the unit heater is not modeled in CONTAM. However, to account for the heating of this unit, a temperature schedule is used in CONTAM, which is described below.

In EnergyPlus, balanced HVAC systems are modeled in all zones. In an attempt achieve building pressurization in CONTAM, less air is returned than is supplied to each zone. The return airflow 
rate is set to $90 \%$ of the supply airflow rate. The HVAC systems operate with balanced supply and return between 6:00 a.m. and 7:00 a.m. on weekdays and Saturdays, and between 8:00 a.m. and 9:00 a.m. pm on Sundays and Holidays, when the system operates but no outside air is being supplied. This reflects the operation modeled in EnergyPlus.

Table 20. Summary of HVAC system flow rates $\left(\mathrm{m}^{3} / \mathrm{s}\right)$ in Stand Alone Retail

\begin{tabular}{lrrrr}
\hline Zone & Supply & Return & Outside Air & Exhaust air \\
\hline Back Space & 1.55 & 1.40 & 0.23 & 0.00 \\
Core Retail & 5.67 & 5.10 & 1.89 & 0.00 \\
Point of Sale & 1.17 & 1.05 & 0.18 & 0.00 \\
Front Retail & 0.95 & 0.85 & 0.18 & 0.00 \\
Restroom & N/A & N/A & 0.00 & 0.05 \\
\hline
\end{tabular}

\section{HVAC Schedules:}

All HVAC and exhaust fans operate on the following schedule:

- Weekdays: on from 6:00 a.m. to 9:00 p.m., off otherwise

- Saturday: on from 6:00 a.m. to 10:00 p.m., off otherwise

- Sunday, holidays: on from 8:00 a.m. to 7:00 p.m., off otherwise

The outside air for the HVAC systems operates on the same schedules as those above except the start time is one hour later on all of them.

\section{Temperature setpoints:}

In the EnergyPlus, the Front Entry zone is heated with a unit heater. As stated above, because the unit heater provides no outdoor air ventilation and recirculates in the zone, a simple AHS was not modeled in CONTAM. However, because the unit heater provides heating in the winter, a combination of controls and a CVF are used to schedule the indoor temperature of the Front Entry. Figure 36 shows a partial image of the CONTAM model of the Stand Alone Retail. The control elements are located in the ambient zone (shaded blue) but can be drawn anywhere. During the heating months, the control elements schedule the indoor temperature in accordance with the thermostat setpoints scheduled in the EnergyPlus model (indicated by dark red). During the cooling months, the control elements make the indoor temperature of the Front Entry equal to the outdoor temperature. The control elements also use a CVF file to indicate when the heating and cooling months are. The file "StandAloneRetail.cvf” is available for download with the prototype models on the NIST Multizone Modeling website under Case Studies. For more details on control elements in CONTAM, refer to the User Manual [29]. 


\begin{tabular}{|c|c|c|c|c|}
\hline \multicolumn{5}{|c|}{$\underline{\text { KEY }}$} \\
\hline 口 & $\begin{array}{l}\text { Airflow } \\
\text { element }\end{array}$ & 45 Simple AHS & $\mathbf{Q}$ & $\begin{array}{l}\text { Simple AHS } \\
\text { supply }\end{array}$ \\
\hline$\square$ & $\begin{array}{ll}\text { Simple AHS } & \mathrm{C} \\
\text { return } & \end{array}$ & $\begin{array}{l}\text { Contaminant } \\
\text { source }\end{array}$ & $\begin{array}{l}\text { Control } \\
\text { elements }\end{array}$ & * Annotation \\
\hline
\end{tabular}

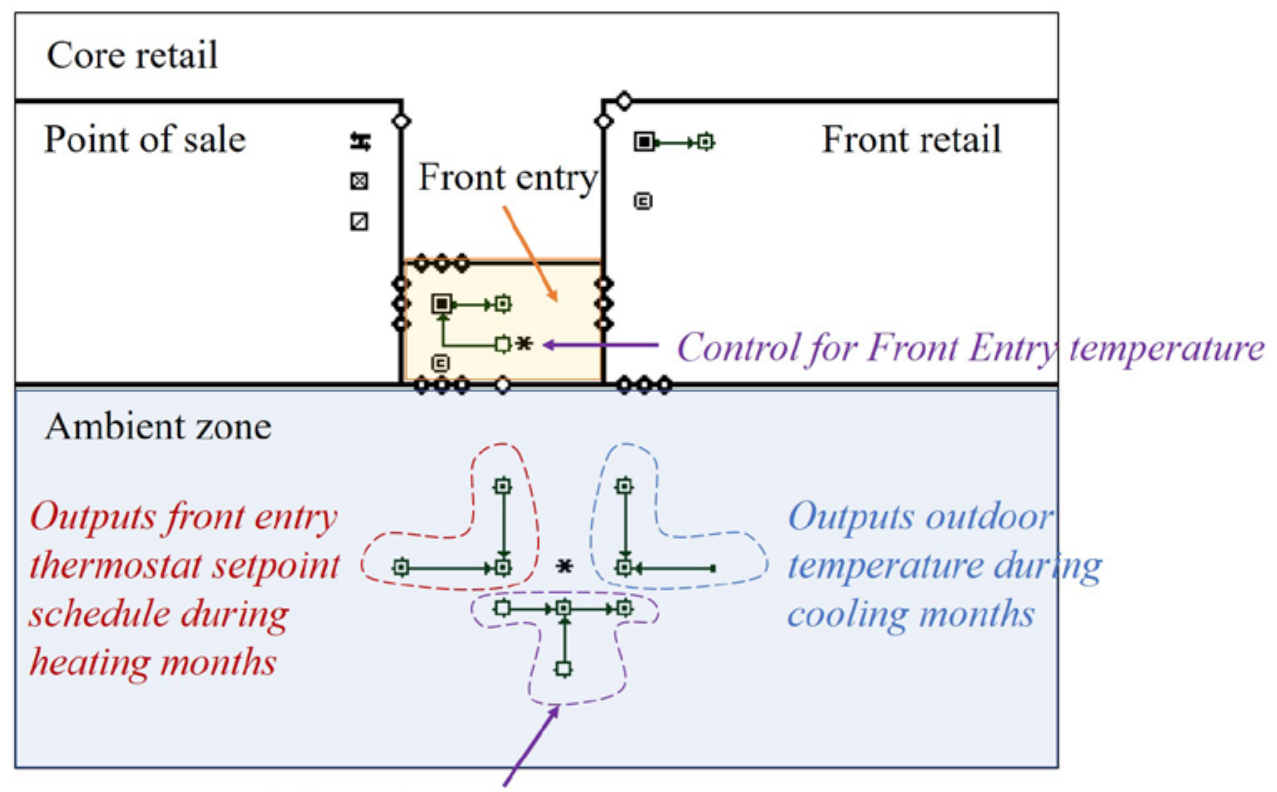

Controls Front Entry to thermostat setpoint in heating months and to outdoor temperature in cooling months

\section{Figure 36. Partial CONTAM model of Stand Alone Retail showing controls for scheduling Front Entry temperature}

There are two thermostat setpoint schedules that use the default 12 day type schedules in the Stand Alone Retail as listed in Table 19. For Temp_CR, the schedules changes for weekdays/Saturdays and Sundays/holidays (Figure 37). For Temp_Other, the schedules changes for weekdays/Saturdays and Sundays/holidays in the heating months only (Figure 38). For the cooling months, the temperature is maintained at $23.9^{\circ} \mathrm{C}$. 


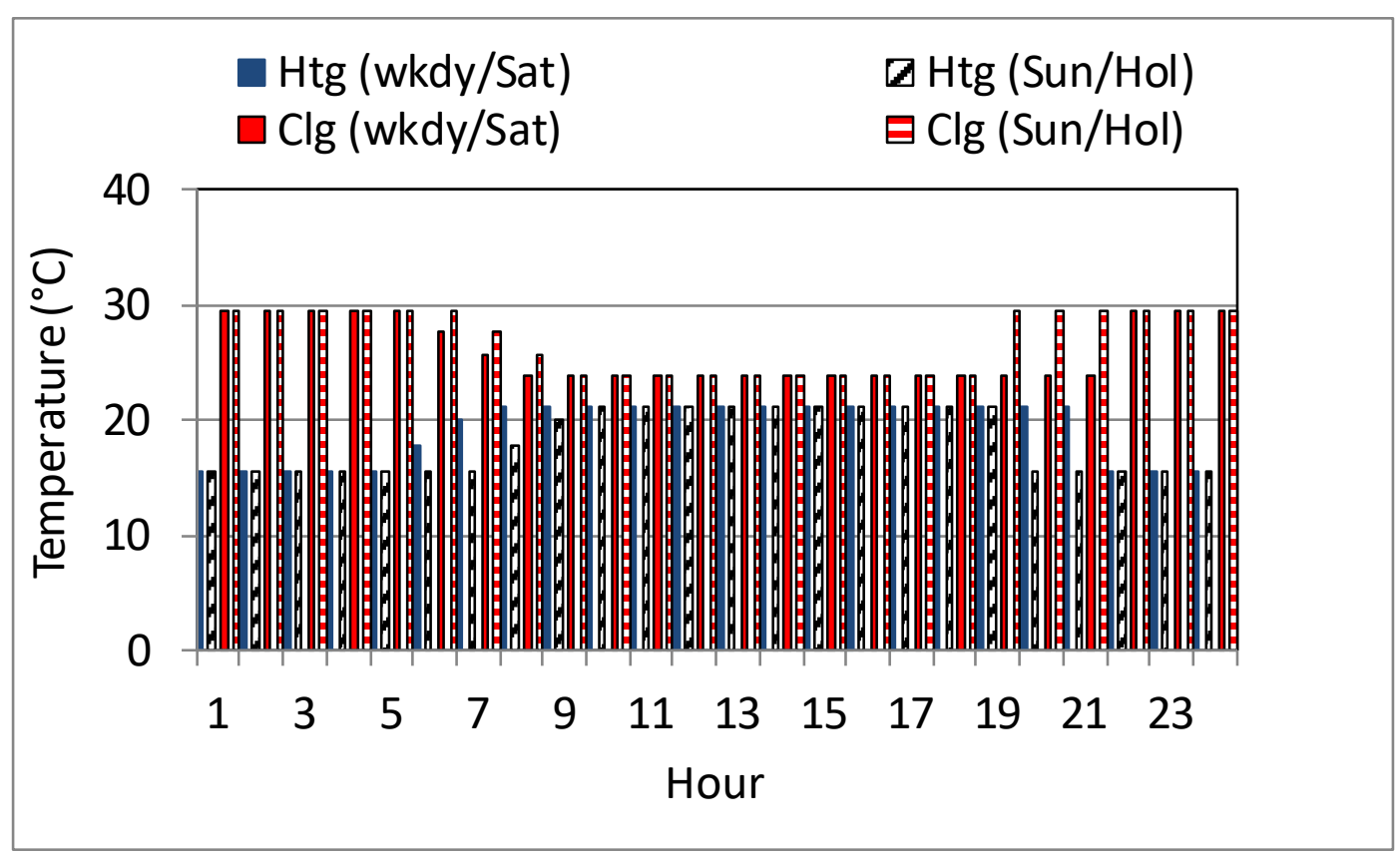

Figure 37. Thermostat setpoint schedule for Stand Alone Retail (Temp_CR)

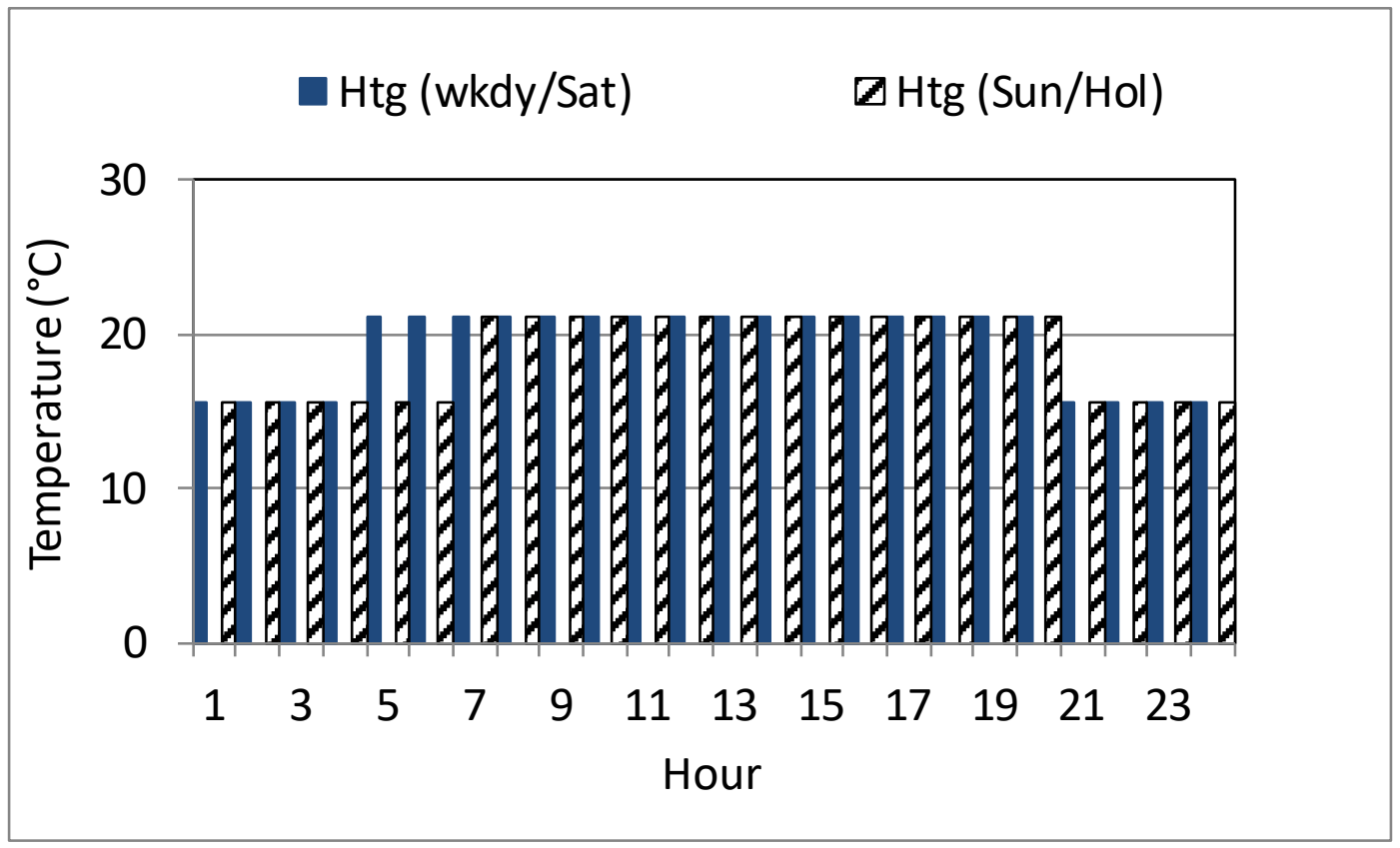

Figure 38. Thermostat setpoint schedule for Stand Alone Retail (Temp_Other) 


\subsection{Strip Mall}

Table 21 summarizes the zones modeled in CONTAM for the Strip Mall, their respective sizes, maximum occupancy, and thermostat setpoint schedules (Temp_1, Temp_2, and Temp_3 to be discussed in the Thermostat Setpoints section).

Table 21. Summary of zones in Strip Mall

\begin{tabular}{lrrrl}
\hline Zone & Area $\mathbf{( m}^{\mathbf{2}}$ ) & Height (m) & $\begin{array}{r}\text { Maximum } \\
\text { occupancy }\end{array}$ & $\begin{array}{l}\text { Thermostat setpoint } \\
\text { schedule }\end{array}$ \\
\hline Large Stores (LS) & 261.29 & 5.18 & 30 & LS 1: Temp_1 \\
& 52.81 & 5.18 & & LS 2: Temp_3 \\
LS storage & 34.29 & 5.18 & 0 & Same as store \\
LS restroom & 130.64 & 5.18 & 0 & Same as store \\
Small Stores (SS) & & & & SS 1: Temp_1 \\
& 39.55 & 5.18 & & SS 2-SS 4: Temp_2 \\
& 4.00 & 5.18 & 0 & SS 5-SS 8: Temp_3 \\
SS storage & & 0 & Same as store \\
SS restroom & & &
\end{tabular}

\section{Occupants:}

The peak number of people for each zone is listed in Table 21. Occupants in the building follow one of three occupant schedules as shown in Figure 39 to Figure 41. There is a different occupancy schedule for weekdays, Saturdays, and Sundays/holidays.

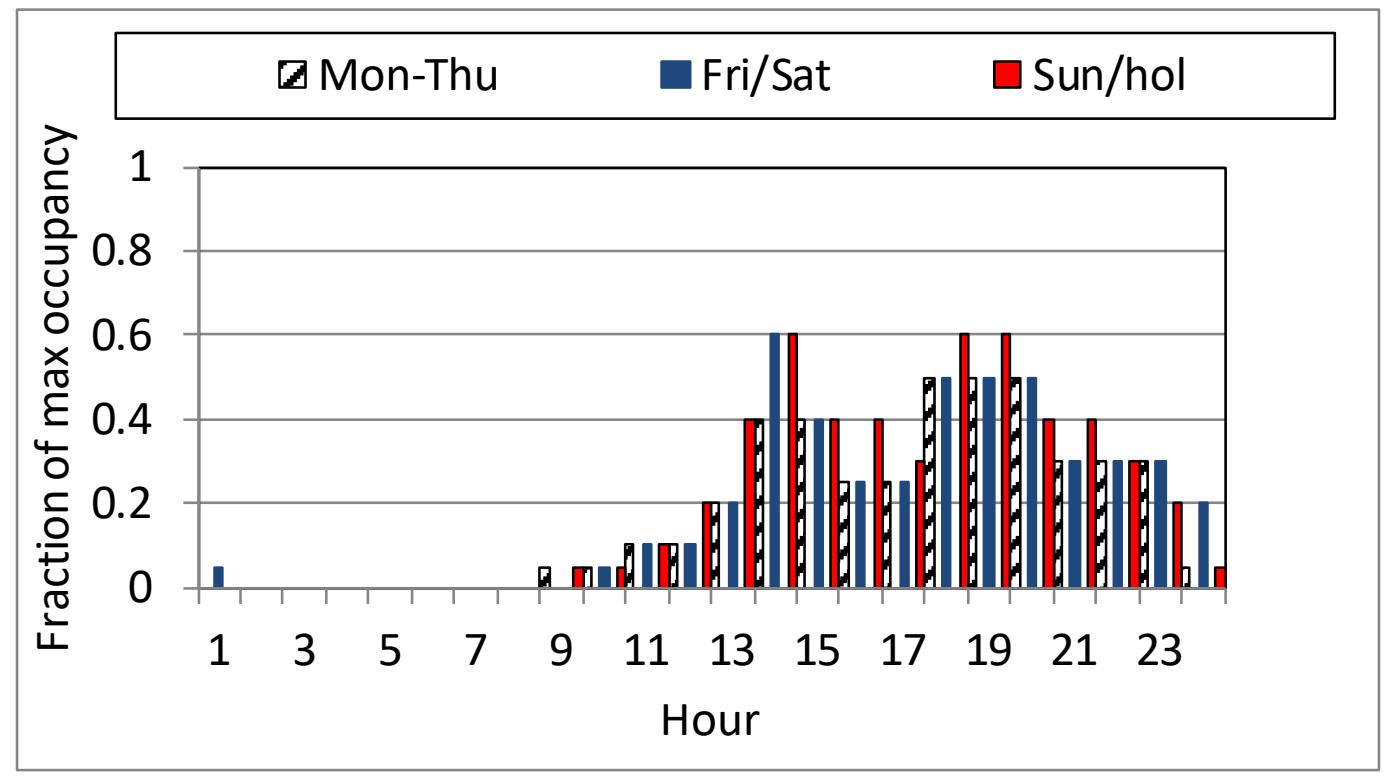

Figure 39. Occupancy schedule for Strip Mall (LS 1, SS 1) 


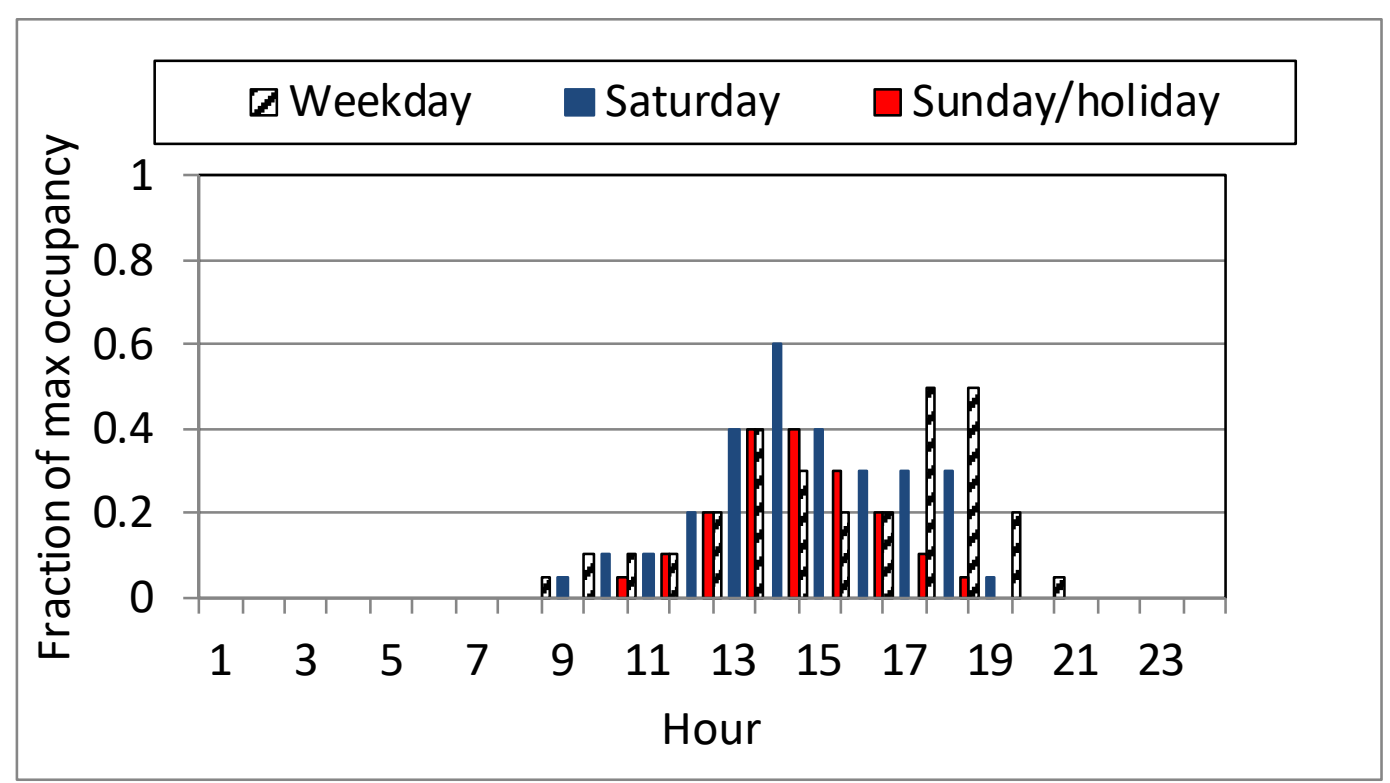

Figure 40. Occupancy schedule for Strip Mall (SS 2 to SS 4)

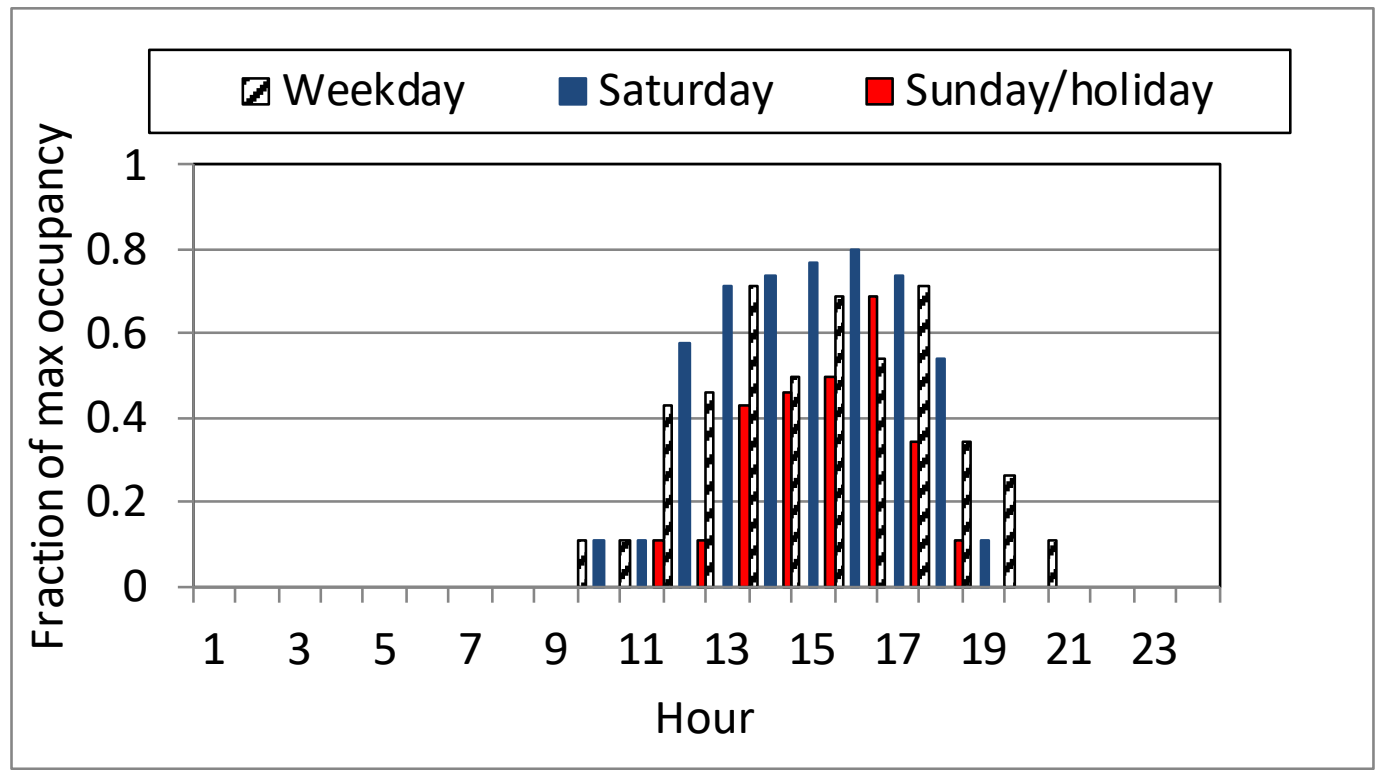

Figure 41. Occupancy schedule for Strip Mall (LS 2, SS 5 to SS 8)

\section{Geometry:}

$2090 \mathrm{~m}^{2}$ footprint, single-story building with flat roof. The EnergyPlus model has 10 zones.

There are two "Large Stores" (LS) and eight "Small Stores" (SS). In the CONTAM model, each store is sub-divided into three zones. The rear $25 \%$ of each store was divided into Storage and Restroom zones (Storage zones are shown in gray and Restrooms shown in black in Figure 42). 


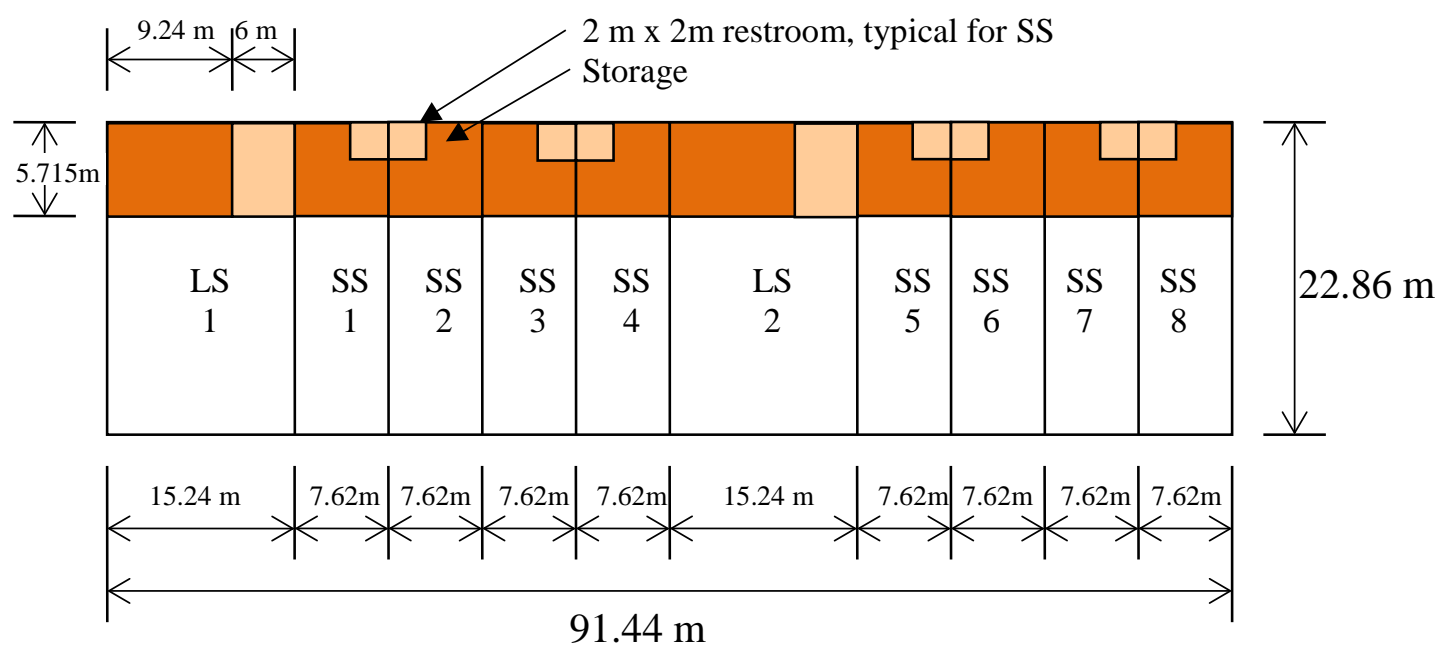

Figure 42. Floor plan of Strip Mall (height $5.18 \mathrm{~m}$ )

Large interior leakage paths were defined as follows:

- Between the store and storage zones, a $4 \mathrm{~m}^{2}$ opening is modeled;

- Between the Restrooms in the Large Stores and Storage zones, a $0.186 \mathrm{~m}^{2}$ transfer grille is modeled;

- Between the Restrooms in the Small Stores and Storage zones, a $0.025 \mathrm{~m}^{2}$ door undercut is modeled.

HVAC systems:

The EnergyPlus model has 10 packaged constant-volume single-zone systems. Similarly, each zone has a constant-volume system in CONTAM. The supply air, return air, outside air, and exhaust flow rates modeled in CONTAM are listed in Table 22. The exhaust flow rates for the Restrooms were modeled only in CONTAM, not in EnergyPlus.

In CONTAM, the design supply flow rate calculated by EnergyPlus for each constant-volume system is split between the store and storage zones. Seventy five percent of the design supply flow rate is directed to the store and $25 \%$ to the storage zone in CONTAM. In EnergyPlus, balanced HVAC systems are modeled in all zones. In an attempt achieve building pressurization in CONTAM, less air is returned than is supplied to each zone. The return for each zone is set to $90 \%$ of the supply airflow rate. The HVAC systems operate with balanced supply and return for the first hour of heating and cooling operation when that system operates but no outside air is being supplied. This reflects the operation modeled in EnergyPlus. 
Table 22. Summary of HVAC system flow rates $\left(\mathrm{m}^{3} / \mathrm{s}\right)$ in Strip Mall

\begin{tabular}{lrrrr}
\hline Zone & Supply & Return & Outside Air & Exhaust air \\
\hline LS 1 (CAV 1:1) & 1.57 & 1.41 & 0.41 & 0.00 \\
LS 2 (CAV 6:6) & 1.46 & 1.31 & 0.41 & 0.00 \\
SS 1 (CAV 2:2) & 0.81 & 0.73 & 0.21 & 0.00 \\
SS 2 (CAV 3:3) & 0.82 & 0.74 & 0.21 & 0.00 \\
SS 3 (CAV 4:4) & 0.81 & 0.73 & 0.21 & 0.00 \\
SS 4 (CAV 5:5) & 0.82 & 0.74 & 0.21 & 0.00 \\
SS 5 (CAV 7:7) & 0.76 & 0.68 & 0.21 & 0.00 \\
SS 6 (CAV 8:8) & 0.75 & 0.68 & 0.21 & 0.00 \\
SS 7 (CAV 9:9) & 0.75 & 0.67 & 0.21 & 0.00 \\
SS 8 (CAV 10:10) & 0.82 & 0.74 & 0.21 & 0.00 \\
LS Restroom & N/A & N/A & 0.00 & 0.03 \\
SS Restroom & N/A & N/A & 0.00 & 0.03 \\
\hline
\end{tabular}

Note: The supply and return rates are the sum of the rates to/from the store and storage zones.

\section{HVAC Schedules:}

LS 1 and SS 1 had the following HVAC and exhaust fans schedules:

- Monday through Thursday: on from 8:00 a.m. to 11:00 p.m., off otherwise

- Friday: on from 8:00 a.m. to 1:00 a.m. the next morning, off otherwise

- Sunday, holidays: on from 8:00 a.m. to 11:00 p.m., off otherwise

SS 2, SS 3, and SS 4 had the following HVAC and exhaust fans schedules:

- Weekday: on from 7:00 a.m. to 9:00 p.m., off otherwise

- Saturday: on from 7:00 a.m. to 7:00 p.m., off otherwise

- Sunday, holidays: on from 8:00 a.m. to 6:00 p.m., off otherwise

LS 2, SS 5, SS 6, SS 7, and SS 8 had the following HVAC and exhaust fans schedules:

- Weekday: on from 8:00 a.m. to 9:00 p.m., off otherwise

- Saturday: on from 8:00 a.m. to 7:00 p.m., off otherwise

- Sunday, holidays: on from 9:00 a.m. to 6:00 p.m., off otherwise

The outside air for the HVAC systems operates on the same schedules as those above except the start time is one hour later on all of them.

\section{Thermostat setpoints:}

The default 12 day type scheduling feature in CONTAM could not be used for the Temp_1 schedule (Figure 43) because day type 9 was used for all weekdays (Monday through Friday) during the cooling season and Temp_1 had a different Friday schedule. Thus, a CVF was used to schedule the thermostat setpoints, occupancy, and HVAC operation of the zones used the 
Temp_1 schedule (e.g., LS 1 and SM 1). The file "StripMall.cvf” is available for download with the prototype models on the NIST Multizone Modeling website under Case Studies. The StripMall.cvf also included the occupancy schedule for LS 1 and SS 1.

The Temp_2 and Temp_3 schedules (Figure 44 and Figure 45) used the default 12 day type scheduling feature in CONTAM. For Temp_2 and Temp_3, schedules changes for weekdays and weekends/holidays.

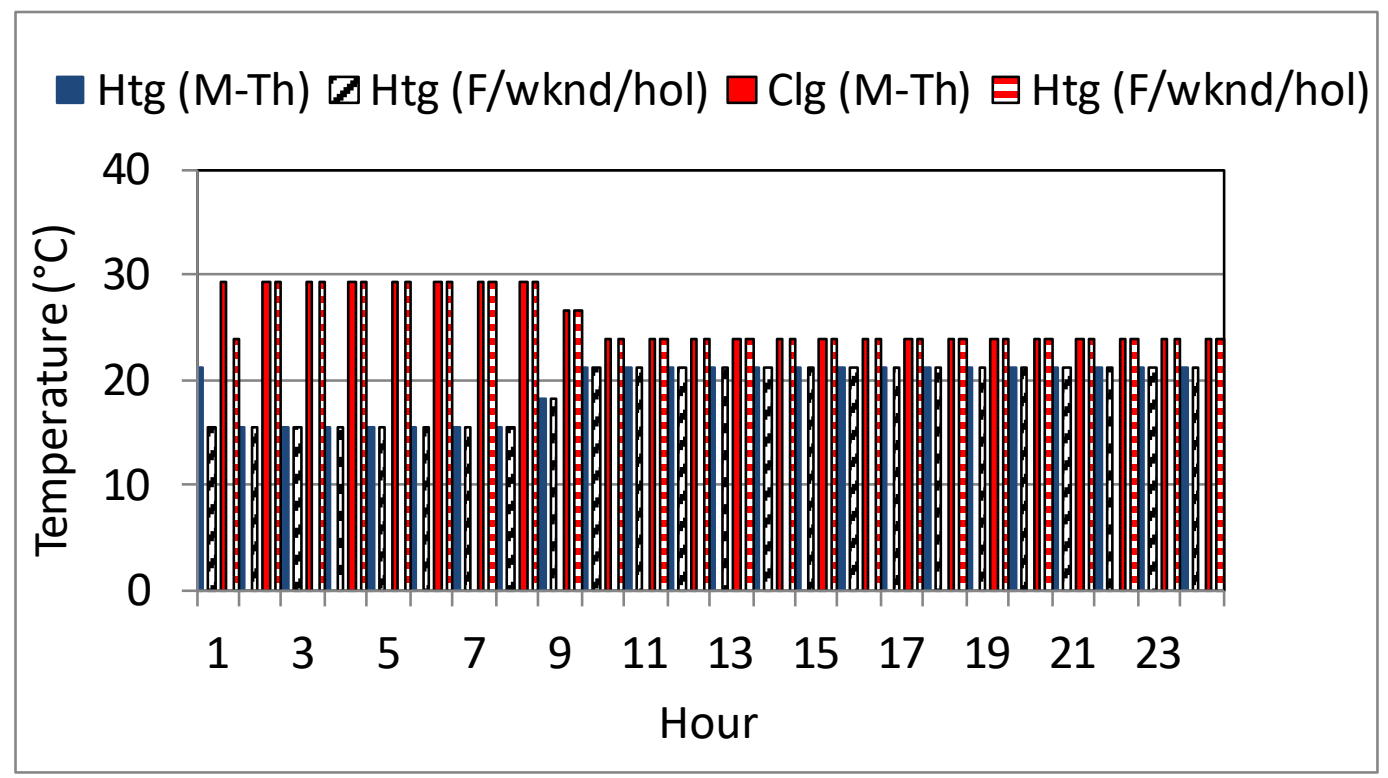

Figure 43. Thermostat setpoint schedule for Strip Mall (Temp_1)

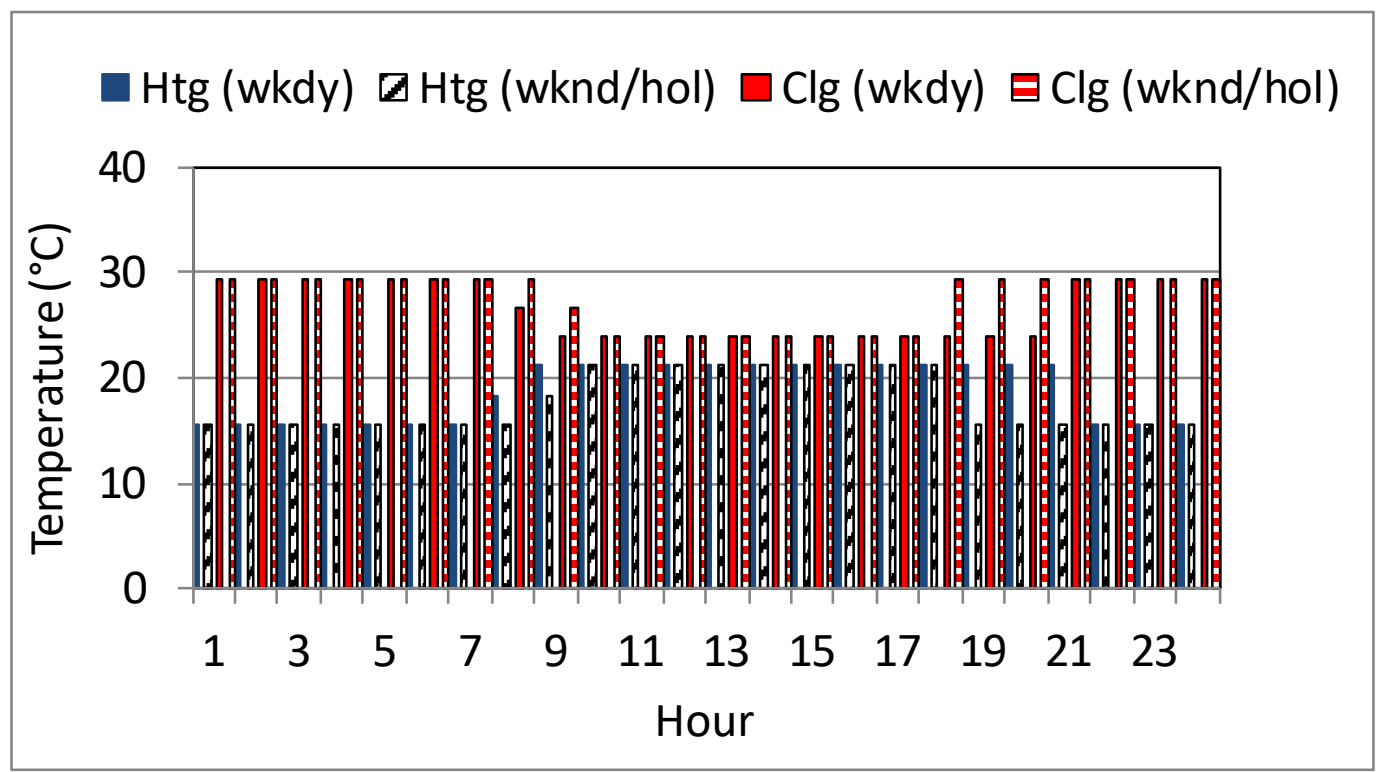

Figure 44. Thermostat setpoint schedule for Strip Mall (Temp_2) 


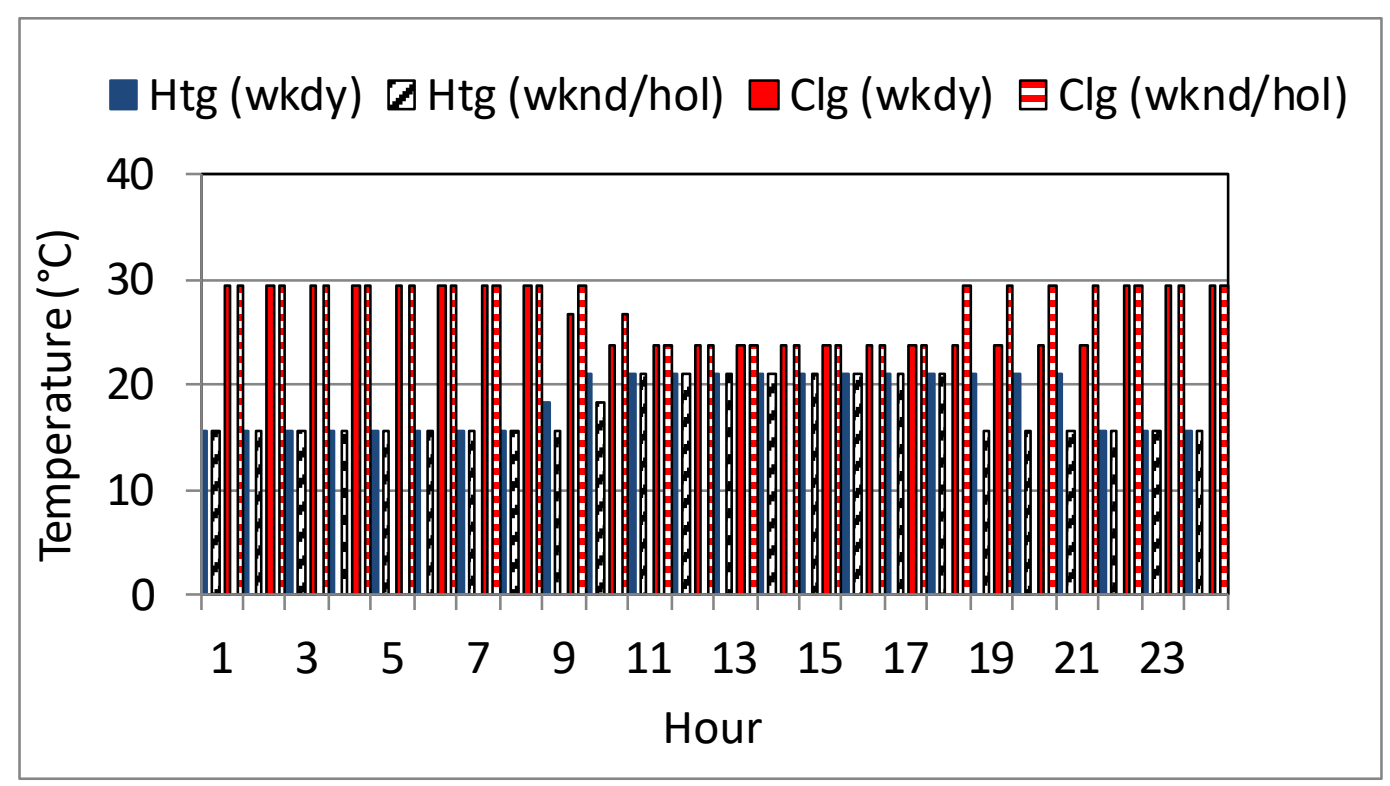

Figure 45. Thermostat setpoint schedule for Strip Mall (Temp_3)

\subsection{Small Hotel}

Table 23 summarizes the zones modeled in CONTAM for the Small Hotel, their respective sizes, maximum occupancy, and thermostat setpoint schedules ( $T$ :Common, T:Elevator xF, T:Front/RearStorage xF, T:Front/RearStairs xF, T:Mech, T:NGR, T:SGR, T:VGR, to be discussed in the Thermostat Setpoints section, where "x" denotes the floor number).

\section{Occupants:}

The peak number of people for each zone is listed in Table 23. Occupants in all building zones are scheduled according to Figure 46 to Figure 50. There are seven different occupant schedules for the building. The occupancy schedules for the Restroom and Front Lounge zones are shown in Figure 46. The occupancy schedule for the Laundry, Exercise Room, and Meeting Room is shown in Figure 47, for the Employee Lounge in Figure 48, and for the Front Office in Figure 49. The occupancy schedule for the guestrooms (referred to as "Guest" occupancy) is shown in Figure 50. For all zones, there is a different occupancy schedule for weekdays and weekend/holidays, except for the Laundry, Exercise Room and Meeting Room which have the same schedule throughout the year. 
Table 23. Summary of zones in Small Hotel

\begin{tabular}{|c|c|c|c|c|c|}
\hline Zone & Floor & Area $\left(\mathrm{m}^{2}\right)$ & Height (m) & $\begin{array}{l}\text { Maximum } \\
\text { occupancy }\end{array}$ & $\begin{array}{l}\text { Thermostat } \\
\text { setpoint schedules }\end{array}$ \\
\hline Rear Stairs & 1 & 20 & 3.35 & 0 & T:RearStair1F \\
\hline Corridor & 1 & 151 & 3.35 & 0 & $\mathrm{~T}:$ Common \\
\hline Rear Storage & 1 & 20 & 3.35 & 0 & $\mathrm{~T}:$ RearStorage1F \\
\hline Front Lounge & 1 & 163 & 3.35 & 53 & $\mathrm{~T}:$ Common \\
\hline Restroom & 1 & 33 & 3.35 & 1 & T:Mech \\
\hline Meeting Room & 1 & 80 & 3.35 & 43 & T:Common \\
\hline Mechanical Room & 1 & 33 & 3.35 & 0 & T:Mech \\
\hline Guest 101 & 1 & 33 & 3.35 & 2 & T:VGR \\
\hline Guest 102 & 1 & 33 & 3.35 & 2 & T:VGR \\
\hline Guest 103 & 1 & 33 & 3.35 & 2 & T:NGR \\
\hline Guest 104 & 1 & 33 & 3.35 & 2 & T:SGR \\
\hline Guest 105 & 1 & 33 & 3.35 & 2 & T:SGR \\
\hline Employee Lounge & 1 & 33 & 3.35 & 18 & T:Common \\
\hline Laundry & 1 & 98 & 3.35 & 11 & T:Laundry \\
\hline Elevator & 1 & 15 & 3.35 & 0 & $\mathrm{~T}:$ Elevator1F \\
\hline Exercise & 1 & 33 & 3.35 & 7 & $\mathrm{~T}:$ Common \\
\hline Front Office & 1 & 130 & 3.35 & 10 & T:Common \\
\hline Front Stairs & 1 & 20 & 3.35 & 0 & $\mathrm{~T}:$ FrontStair1F \\
\hline Front Storage & 1 & 13 & 3.35 & 0 & $\mathrm{~T}$ :FrontStorage1F \\
\hline Rear Stairs & $2-4$ & 20 & 2.74 & 0 & $\mathrm{~T}:$ RearStairs xF \\
\hline Corridor & $2-4$ & 125 & 2.74 & 0 & $\mathrm{~T}:$ Common \\
\hline Rear Storage & $2-4$ & 20 & 2.74 & 0 & $\mathrm{~T}$ :RearStorage $\mathrm{xF}$ \\
\hline Guest x01 & $2-4$ & 33 & 2.74 & 2 & T:NGR/ T:VGR \\
\hline Guest x02-5 & $2-4$ & 130 & 2.74 & 6 & T:NGR/ T:VGR \\
\hline Guest x06-8 & $2-4$ & 105 & 2.74 & 5 & T:NGR/ T:VGR \\
\hline Guest x09-12 & $2-4$ & 130 & 2.74 & 6 & T:NGR/ T:VGR \\
\hline Guest x13 & $2-4$ & 33 & 2.74 & 2 & T:NGR/ T:VGR \\
\hline Guest x14 & $2-4$ & 33 & 2.74 & 2 & T:SGR/ T:VGR \\
\hline Guest x15-18 & $2-4$ & 130 & 2.74 & 6 & T:SGR/ T:VGR \\
\hline Elevator & $2-4$ & 15 & 2.74 & 0 & T:Elevator xF \\
\hline Guest x19 & $2-4$ & 33 & 2.74 & 2 & T:SGR / T:VGR \\
\hline Guest x20-23 & $2-4$ & 130 & 2.74 & 6 & T:SGR / T:VGR \\
\hline Guest x24 & $2-4$ & 33 & 2.74 & 2 & T:SGR / T:VGR \\
\hline Front Storage & $2-4$ & 13 & 2.74 & 0 & $\mathrm{~T}$ :FrontStorage $\mathrm{xF}$ \\
\hline Front Stairs & $2-4$ & 20 & 2.74 & 0 & $\mathrm{~T}$ :FrontStairs xF \\
\hline
\end{tabular}




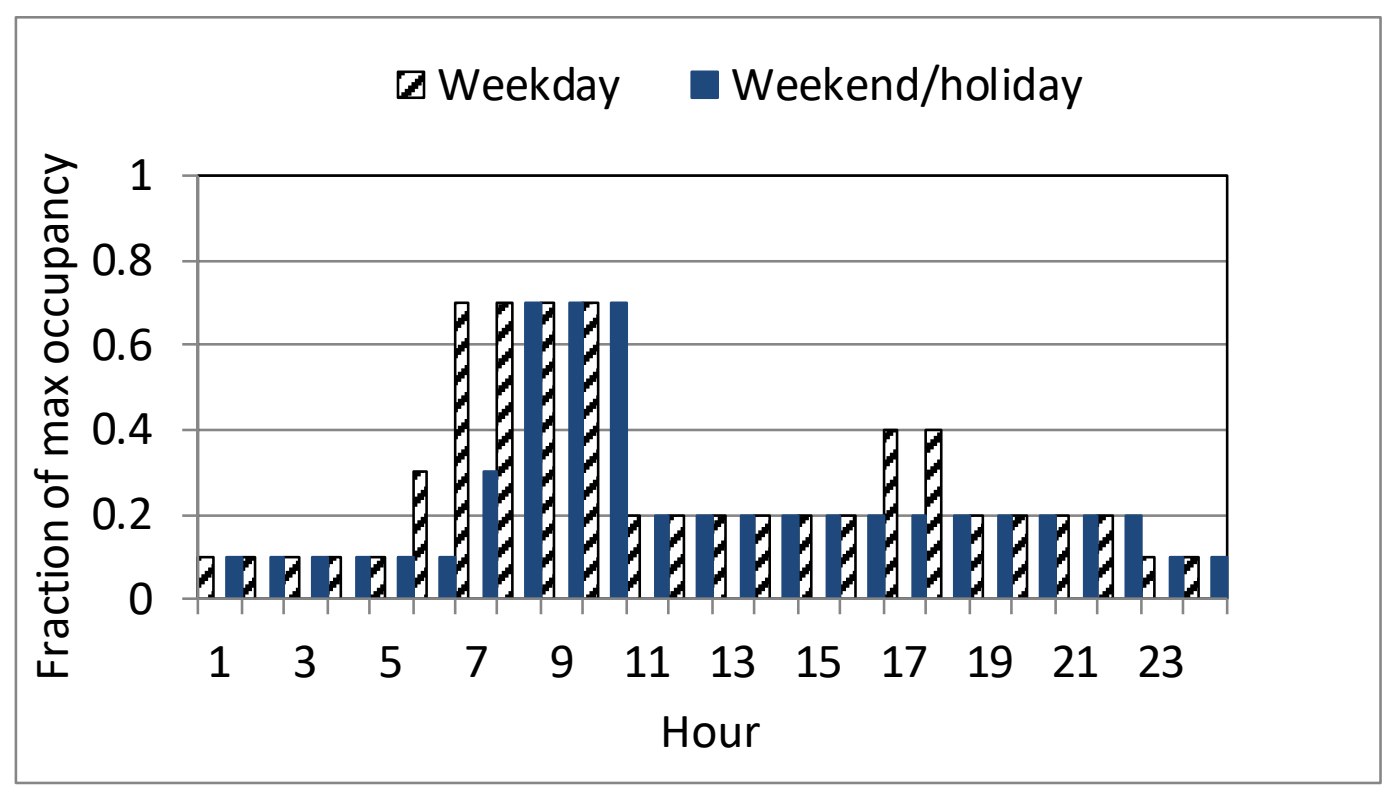

Figure 46. Occupancy schedules for Small Hotel (Restroom and Front Lounge)

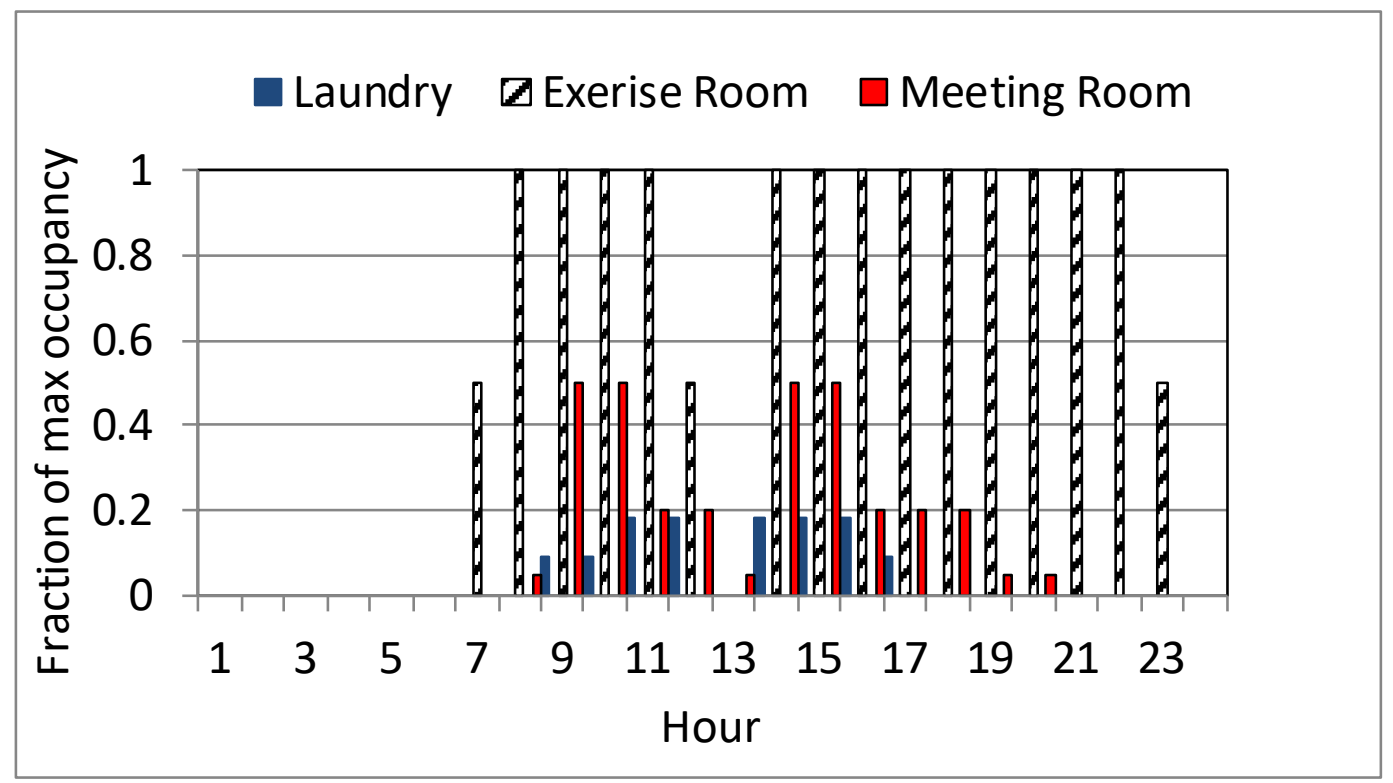

Figure 47. Occupancy schedules for Small Hotel (Laundry, Exercise Room, Meeting Room) 


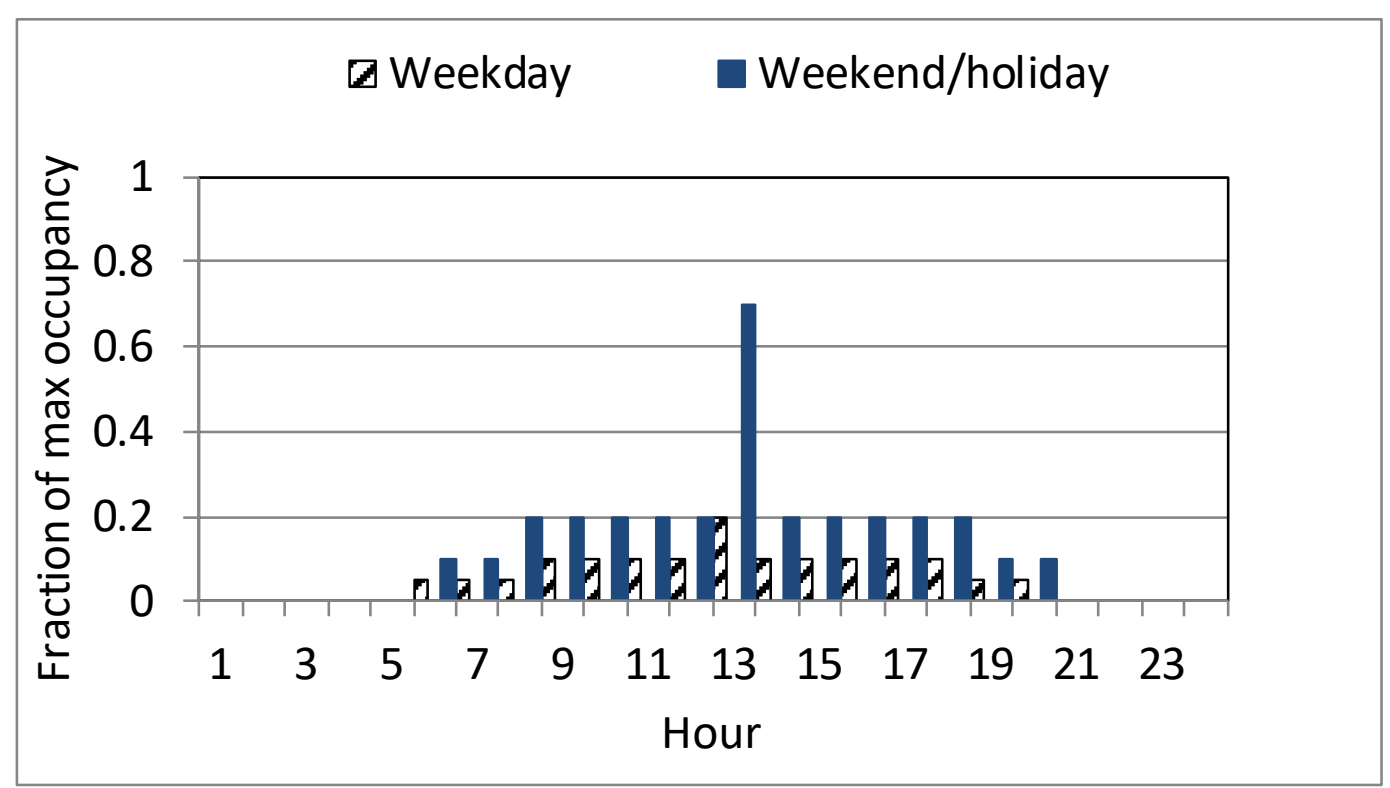

Figure 48. Occupancy schedules for Small Hotel (Employee Lounge)

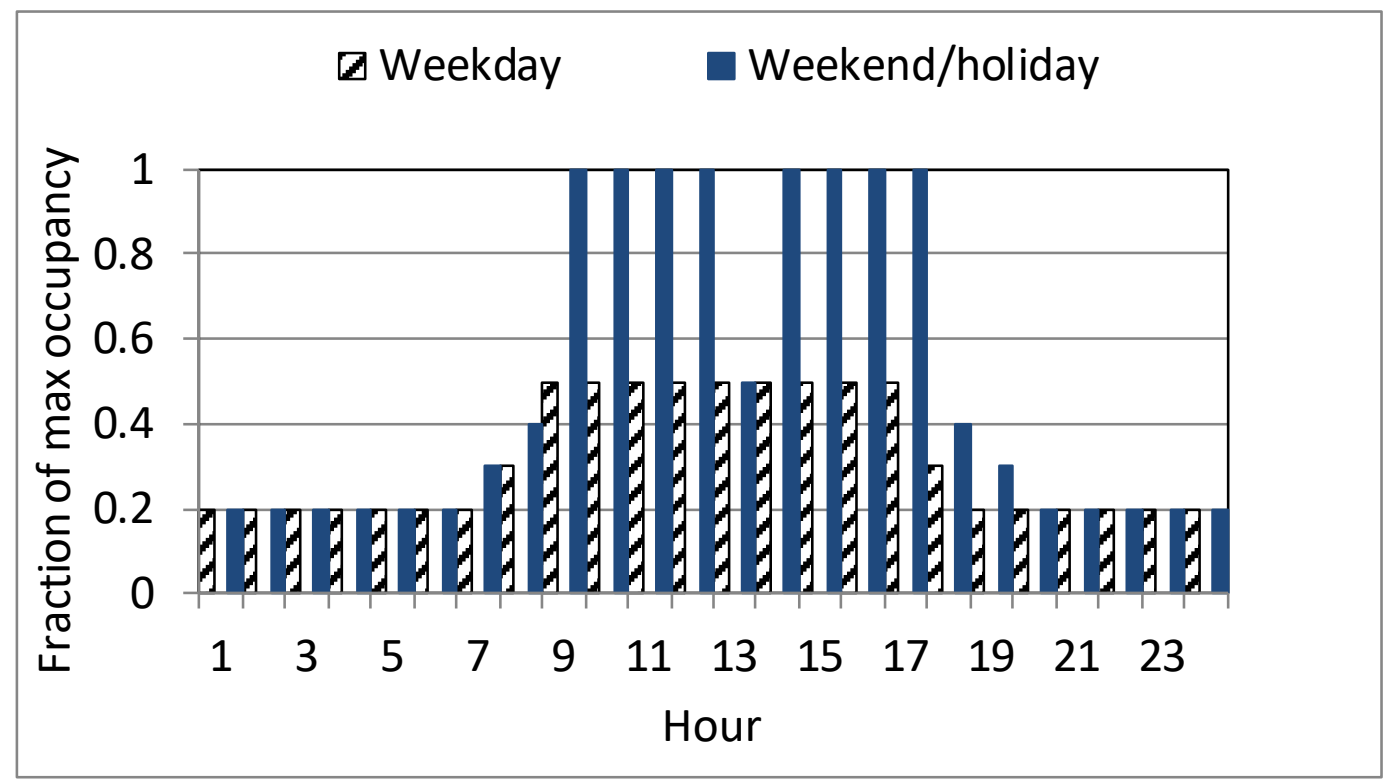

Figure 49. Occupancy schedules for Small Hotel (Front Office) 


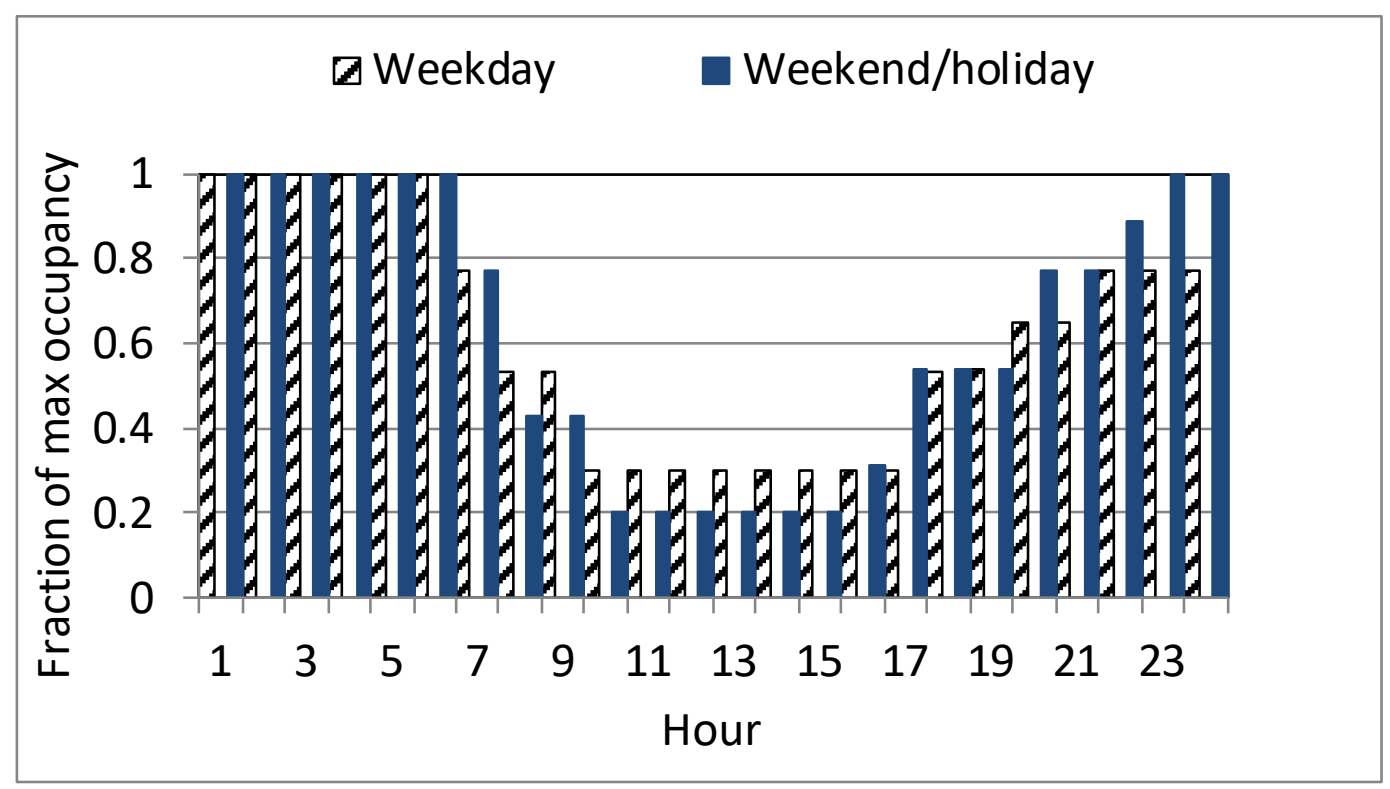

Figure 50. Occupancy schedule for Small Hotel (Guestrooms)

\section{Geometry:}

$1003 \mathrm{~m}^{2}$ footprint, four-story building with flat roof. Total floor area is $4014 \mathrm{~m}^{2}$. The EnergyPlus model has 19 zones on the first floor and 16 zones on each of the upper floors (Figure 51). The upper floor plans are identical. On the upper floors, there are five zones that represent three or four hotel rooms modeled as a single zone in EnergyPlus (e.g., Guest 209-212). These are also modeled as single zones in the CONTAM model.

Large interior leakage paths were defined as follows:

- Between Front Lounge and Corridor zones, a single large leakage path (50 \% of the total wall area between the spaces) is modeled;

- Between Restroom and Corridor, a $0.186 \mathrm{~m}^{2}$ transfer grille is modeled. 


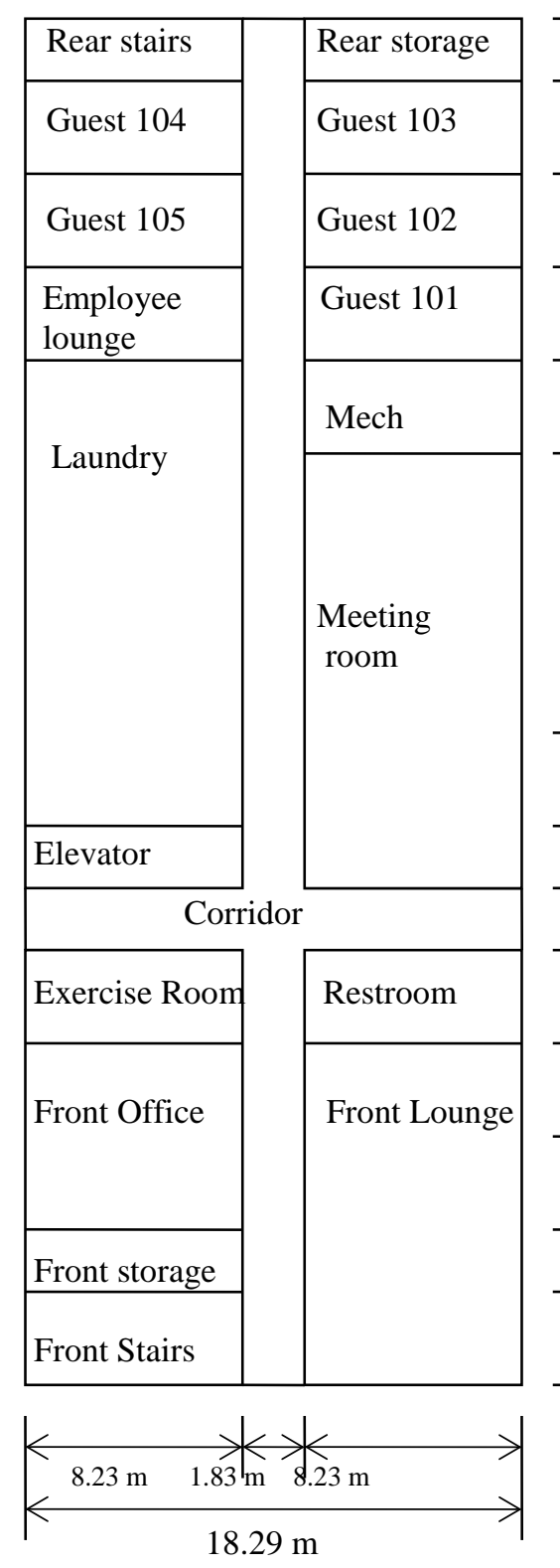

(a) Height $3.35 \mathrm{~m}$

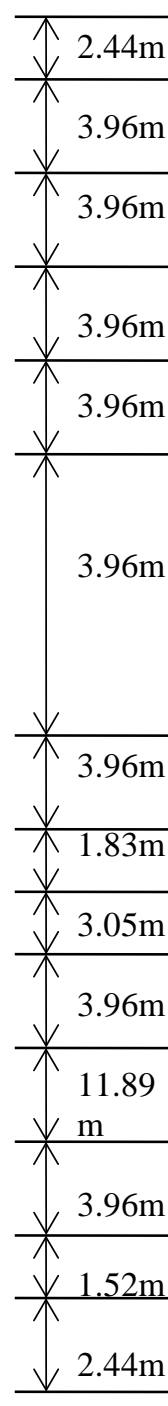

$8.23 \mathrm{~m}$
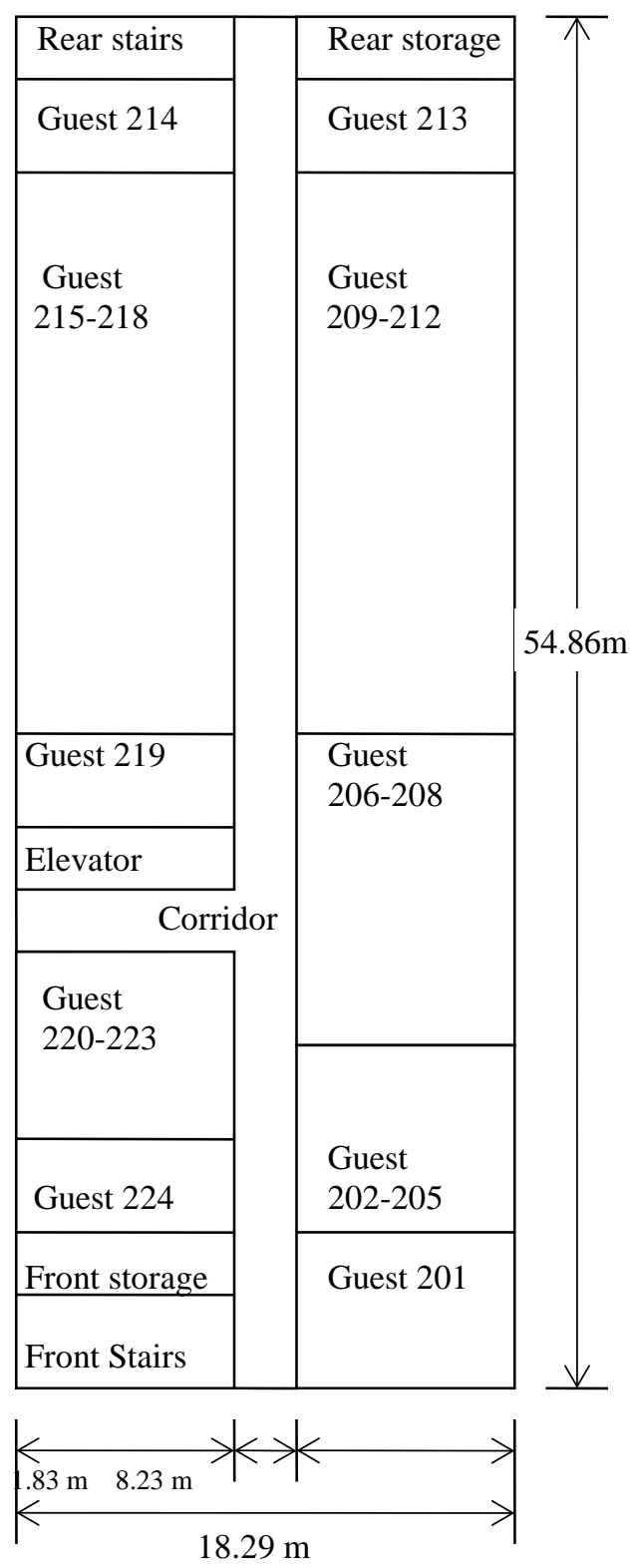

(b) Height $2.74 \mathrm{~m}$

Figure 51. (a) First and (b) upper floor (2-4) plans of Small Hotel

\section{HVAC systems:}

The EnergyPlus model has 12 packaged constant-volume single-zone systems serving the common areas. Each zone has a constant-volume system in CONTAM except one system serves the Exercise Room, Employee Lounge, and Restroom on the first floor. No separate restroom 
exhaust is modeled in EnergyPlus or CONTAM. A transfer grille in the door facilitates air exchange with the adjacent Corridor (see above).

The supply air, return air, outside air, and exhaust flow rates modeled in CONTAM are listed in Table 24 for the systems serving the common areas. In EnergyPlus, all of the guest rooms have individual packaged-terminal air conditioning (PTAC) units that do not use an economizer. The PTAC are modeled in CONTAM as simple AHS with equal supply and return airflow rates and the outdoor airflow rates listed in Table 25. In EnergyPlus, balanced HVAC systems are modeled in all zones. In CONTAM, this is modeled as well.

In EnergyPlus, the Front Stair, Rear Stair, Front Storage, and Rear Storage are heated using unit heaters that recirculate air locally within the zones and do not impact whole-building airflow or introduce outside air. Therefore, the unit heaters are not modeled in CONTAM.

Table 24. Summary of HVAC system flow rates $\left(\mathrm{m}^{3} / \mathrm{s}\right)$ in Small Hotel (common areas)

\begin{tabular}{llrrrr}
\hline Zone & Floor & Supply & Return & Outside Air & Exhaust air \\
\hline Corridor & 1 & 0.13 & 0.13 & 0.05 & 0 \\
Corridor & 2 & 0.13 & 0.13 & 0.04 & 0 \\
Corridor & 3 & 0.13 & 0.13 & 0.04 & 0 \\
Corridor & 4 & 0.13 & 0.13 & 0.04 & 0 \\
Employee Lounge & 1 & 0.24 & 0.24 & 0.55 & 0 \\
Exercise & 1 & 0.24 & 0.24 & 0.46 & 0 \\
Front Lounge & 1 & 0.73 & 0.73 & 0.51 & 0 \\
Front Office & 1 & 0.30 & 0.30 & 0.21 & 0 \\
Laundry Room & 1 & 0.00 & 0.00 & 0.00 & 0 \\
Mechanical Room & 1 & 0.00 & 0.00 & 0.00 & 0 \\
Meeting Room & 1 & 0.34 & 0.34 & 0.24 & 0 \\
Restroom & 1 & N/A & N/A & 0 & 0 \\
\hline
\end{tabular}


Table 25. Summary of PTAC flow rates $\left(\mathrm{m}^{3} / \mathrm{s}\right)$ in Small Hotel (guestrooms)

\begin{tabular}{llrrrr}
\hline Zone & Floor & Supply & Return & Outside Air & Exhaust air \\
\hline Guest 101 & 1 & 0.13 & 0.13 & 0.01 & 0 \\
Guest 102 & 1 & 0.13 & 0.13 & 0.01 & 0 \\
Guest 103 & 1 & 0.13 & 0.13 & 0.01 & 0 \\
Guest 104 & 1 & 0.13 & 0.13 & 0.01 & 0 \\
Guest 105 & 1 & 0.13 & 0.13 & 0.01 & 0 \\
Guest x01 & $2-4$ & 0.13 & 0.13 & 0.01 & 0 \\
Guest x02-5 & $2-4$ & 0.52 & 0.52 & 0.05 & 0 \\
Guest x06-8 & $2-4$ & 0.39 & 0.39 & 0.04 & 0 \\
Guest x09-12 & $2-4$ & 0.52 & 0.52 & 0.05 & 0 \\
Guest x13 & $2-4$ & 0.13 & 0.13 & 0.01 & 0 \\
Guest x14 & $2-4$ & 0.13 & 0.13 & 0.01 & 0 \\
Guest x15-18 & $2-4$ & 0.52 & 0.52 & 0.05 & 0 \\
Guest x19 & $2-4$ & 0.13 & 0.13 & 0.01 & 0 \\
Guest x20-23 & $2-4$ & 0.52 & 0.52 & 0.05 & 0 \\
Guest x24 & $2-4$ & 0.13 & 0.13 & 0.01 & 0 \\
\hline
\end{tabular}

\section{HVAC Schedules:}

All HVAC and exhaust fans operate 24 hours per day every day of the year. Outside air is also supplied all of the time.

\section{Temperature setpoints:}

Only four thermostat setpoint schedules listed in Table 23 were used in the EnergyPlus model of the Small Hotel (T:Common, T:NGR - north guestroom, T:SGR - south guestroom, and T:VGR - vacant guestroom). The storage rooms (front and rear), stairwells (front and rear), elevators, laundry room, mechanical room, and restroom in the EnergyPlus model were not assigned thermostat setpoint schedules since these spaces are typically not occupied and thus not actively conditioned. Thus, an EnergyPlus simulation was run and the average annual temperature of these zones was calculated and input into CONTAM as a constant temperature (Table 26).

T:NGR and T:SGR are the same and do not vary throughout the week (Figure 52). T:VGR is scheduled to maintain $18.9{ }^{\circ} \mathrm{C}$ during the heating months and $23.3^{\circ} \mathrm{C}$ during the cooling months. T:Common is scheduled to maintain $21.1^{\circ} \mathrm{C}$ during the heating months and $23.3^{\circ} \mathrm{C}$ during the cooling months. 
Table 26. Annual average temperature of zones with no thermostat setpoint schedules in EnergyPlus model of Small Hotel

\begin{tabular}{llrr}
\hline Zone & Floor & \multicolumn{2}{c}{ Temperature $\left({ }^{\circ} \mathbf{C}\right)$} \\
\cline { 3 - 4 } & & Heating & Cooling \\
\hline Rear Stairs & 1 & 18.2 & 24.2 \\
Rear Storage & 1 & 17.5 & 23.4 \\
Elevator & 1 & 68.9 & 68.9 \\
Front Stairs & 1 & 20.2 & 20.2 \\
Front Storage & 1 & 21.7 & 21.7 \\
Mechanical & 1 & 24.9 & 24.9 \\
Laundry & 1 & 51.7 & 51.7 \\
Restroom & 1 & 22.5 & 22.5 \\
\hline Rear Stairs & 2 & 18.2 & 24.2 \\
Rear Storage & 2 & 16.3 & 23.4 \\
Elevator & 2 & 31.8 & 31.8 \\
Front Stairs & 2 & 19.8 & 19.8 \\
Front Storage & 2 & 21.3 & 21.3 \\
\hline Rear Stairs & 3 & 16.7 & 24.2 \\
Rear Storage & 3 & 14.5 & 23.4 \\
Elevator & 3 & 22.4 & 25.9 \\
Front Stairs & 3 & 19.3 & 19.3 \\
Front Storage & 3 & 20.7 & 20.7 \\
\hline Rear Stairs & 4 & 15.7 & 24.2 \\
Rear Storage & 4 & 21.8 & 23.4 \\
Elevator & 4 & 20.4 & 24.3 \\
Front Stairs & 4 & 18.9 & 18.9 \\
Front Storage & 4 & 20.5 & 20.5 \\
\hline
\end{tabular}

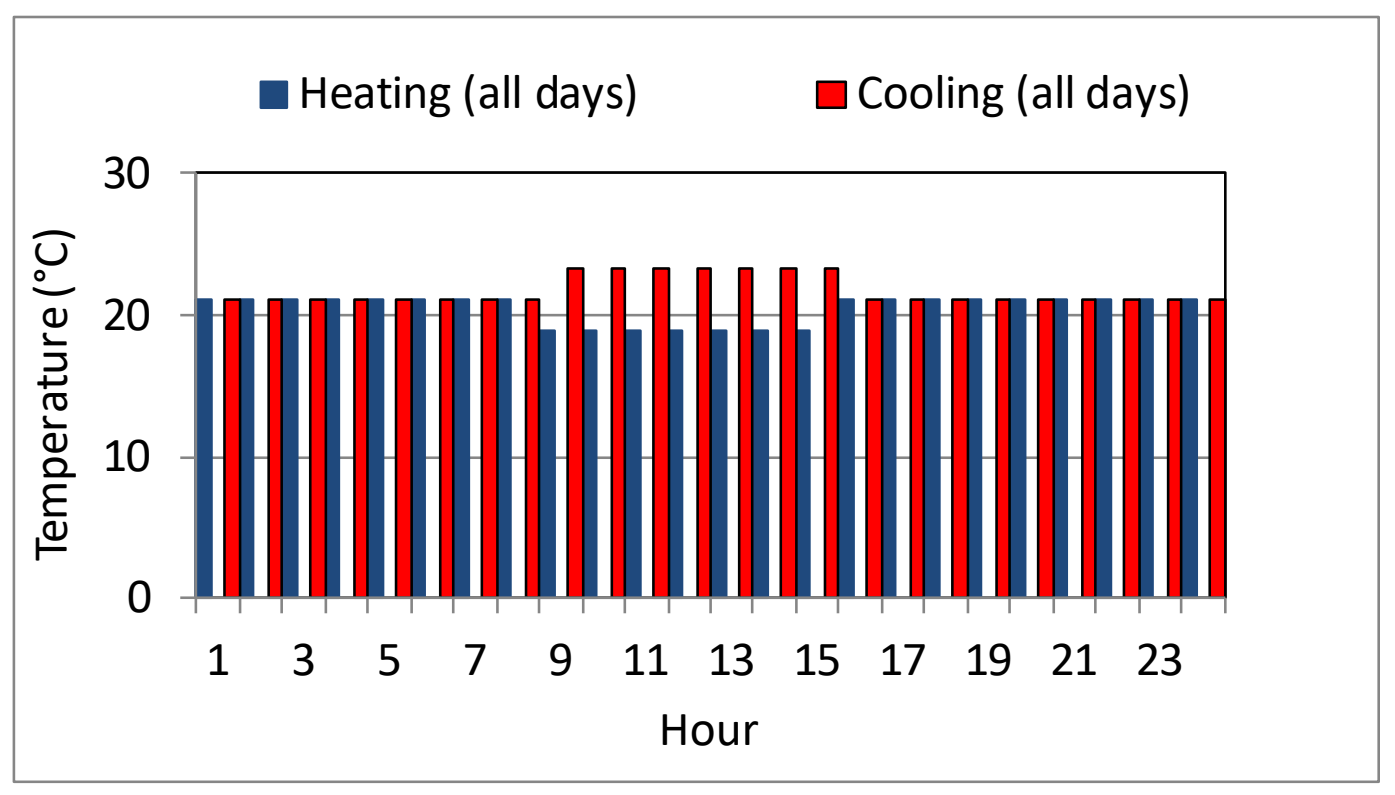

Figure 52. Thermostat setpoint schedule for Small Hotel (T:NGR, T:SGR) 


\subsection{Large Hotel}

Table 27 summarizes the zones modeled in CONTAM for the Large Hotel, their respective sizes, maximum occupancy, and thermostat setpoint schedules (Temp, Temp-GR-N, and Temp-GR-S to be discussed in the Thermostat Setpoints section).

Table 27. Summary of zones in Large Hotel

\begin{tabular}{|c|c|c|c|c|c|}
\hline Zone & Floor & Area $\left(m^{2}\right)$ & Height (m) & $\begin{array}{l}\text { Maximum } \\
\text { occupancy }\end{array}$ & $\begin{array}{l}\text { Thermostat setpoint } \\
\text { schedule }\end{array}$ \\
\hline Basement & $\mathrm{B}$ & 1919 & 2.44 & 106 & Temp \\
\hline Stair NW & B & 20 & 2.44 & 0 & Temp \\
\hline Elevator NW & B & 19 & 2.44 & 0 & Temp \\
\hline Stair SE & B & 11 & 2.44 & 0 & Temp \\
\hline Elevator SE & $\mathrm{B}$ & 10 & 2.44 & 0 & Temp \\
\hline Retail 1 & 1 & 67 & 3.96 & 11 & Temp \\
\hline Retail 2 & 1 & 78 & 3.96 & 13 & Temp \\
\hline Mechanical Room & 1 & 164 & 3.96 & 0 & Temp \\
\hline Storage & 1 & 95 & 3.96 & 0 & Temp \\
\hline Laundry & 1 & 78 & 3.96 & 8 & Temp \\
\hline Cafe & 1 & 189 & 3.96 & 142 & Temp \\
\hline Lobby & 1 & 1239 & 3.96 & 422 & Temp \\
\hline Stair NW & 1 & 20 & 3.96 & 0 & Temp \\
\hline Elevator NW & 1 & 19 & 3.96 & 0 & Temp \\
\hline Stair SE & 1 & 11 & 3.96 & 0 & Temp \\
\hline Elevator SE & 1 & 10 & 3.96 & 0 & Temp \\
\hline Restroom & 1 & 9 & 3.96 & 0 & Temp \\
\hline Room 1 & $2-5$ & 39 & 3.05 & 2 & Temp-GR-S \\
\hline Room 2 & $2-5$ & 39 & 3.05 & 2 & Temp-GR-N \\
\hline Room 3 (x19) & $2-5$ & 25 & 3.05 & 2 & Temp-GR-S \\
\hline Room 4 (x19) & $2-5$ & 25 & 3.05 & 2 & Temp-GR-N \\
\hline Room 5 & $2-5$ & 39 & 3.05 & 2 & Temp-GR-S \\
\hline Room 6 & $2-5$ & 39 & 3.05 & 2 & Temp-GR-N \\
\hline Corridor & $2-5$ & 329 & 3.05 & 0 & Temp \\
\hline Stair NW & $2-5$ & 20 & 3.05 & 0 & Temp \\
\hline Elevator NW & $2-5$ & 19 & 3.05 & 0 & Temp \\
\hline Stair SE & $2-5$ & 11 & 3.05 & 0 & Temp \\
\hline Elevator SE & $2-5$ & 10 & 3.05 & 0 & Temp \\
\hline Room 1 & 6 & 39 & 3.05 & 2 & Temp-GR-N \\
\hline Room 2 & 6 & 39 & 3.05 & 2 & Temp-GR-S \\
\hline Room 3 (x9) & 6 & 25 & 3.05 & 2 & Temp-GR-S \\
\hline Banquet & 6 & 332 & 3.05 & 250 & Temp \\
\hline Dining & 6 & 332 & 3.05 & 250 & Temp \\
\hline Kitchen & 6 & 103 & 3.05 & 22 & Temp \\
\hline Corridor & 6 & 311 & 3.05 & 0 & Temp \\
\hline Stair NW & 6 & 20 & 3.05 & 0 & Temp \\
\hline Elevator NW & 6 & 19 & 3.05 & 0 & Temp \\
\hline Stair SE & 6 & 11 & 3.05 & 0 & Temp \\
\hline Elevator SE & 6 & 10 & 3.05 & 0 & Temp \\
\hline Restroom & 6 & 41 & 3.05 & 0 & Temp \\
\hline
\end{tabular}




\section{Occupants:}

The peak number of people for each zone is listed in Table 27. Occupants in all building zones are scheduled according to Figure 53 and Figure 54. There are two different occupant schedules for the building. The occupancy schedules for the guestrooms (referred to as “Guest” occupancy) is shown in Figure 53. The occupancy schedule for the remaining zones is shown in Figure 54. There is a different occupancy schedule for weekdays, Saturdays, and Sundays/holidays.

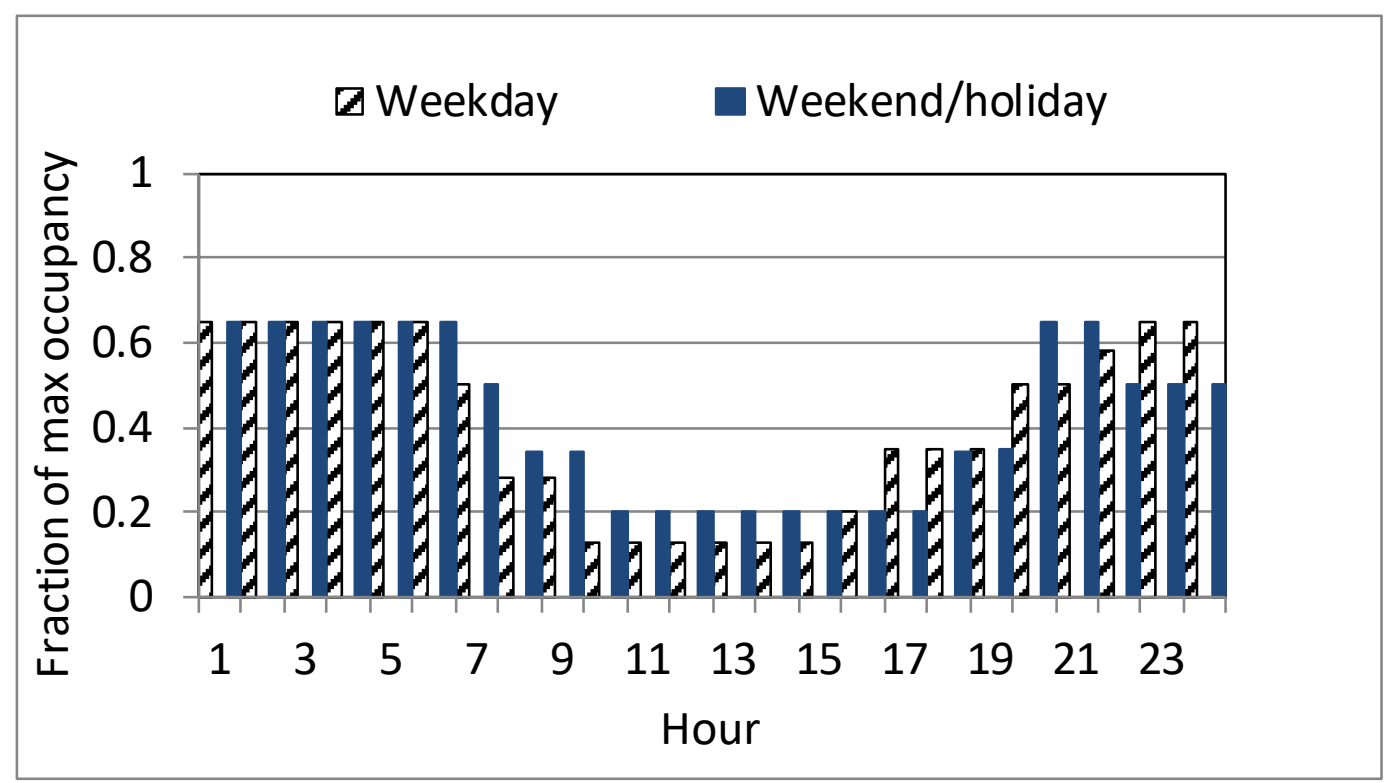

Figure 53. Occupancy schedules for Large Hotel (guestrooms)

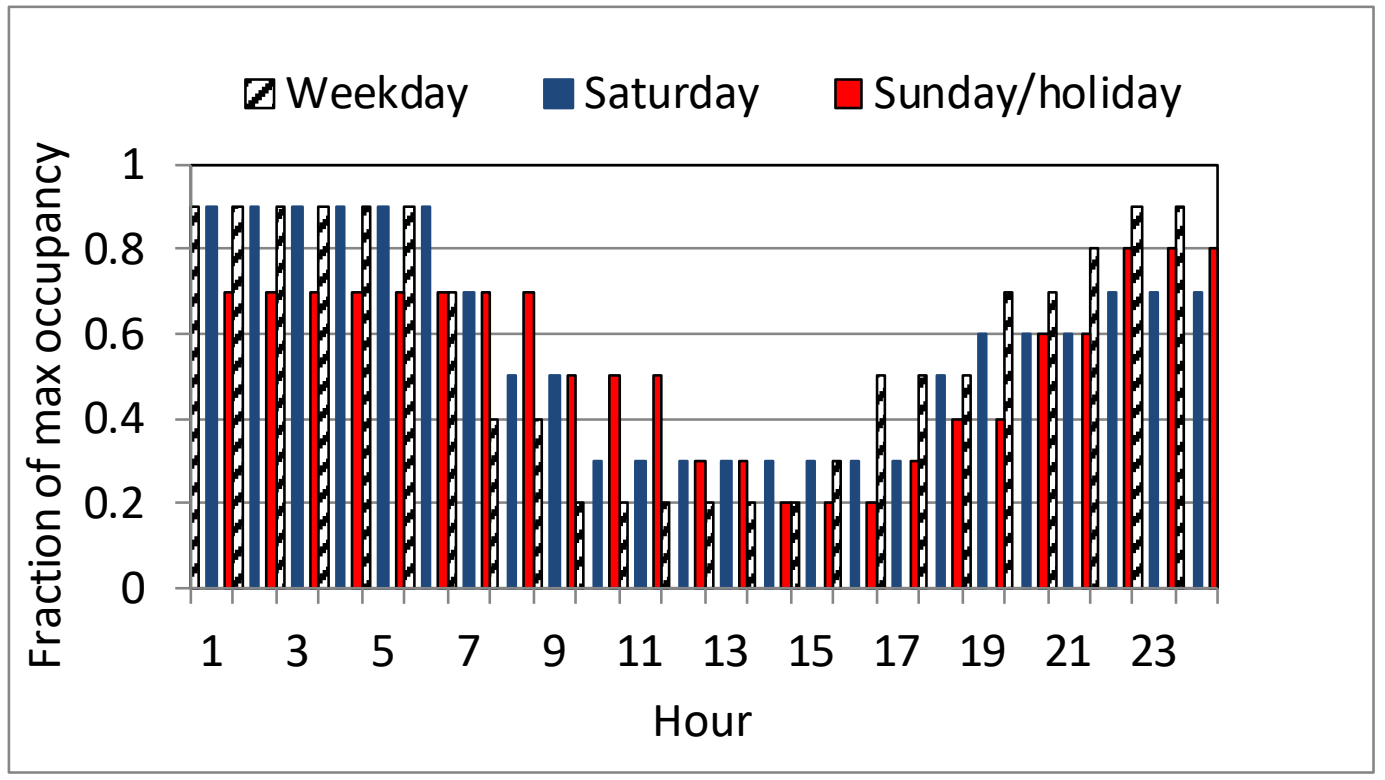

Figure 54. Occupancy schedule for Large Hotel (non-guestrooms) 


\section{Geometry:}

$1979 \mathrm{~m}^{2}$ footprint, six-story building (plus a basement) with flat roof. Total floor area is

$11345 \mathrm{~m}^{2}$ which includes the Basement. The EnergyPlus model has seven zones on the first

floor, 43 zones each on floors two to five, and 12 zones on the sixth floor. The upper floors

(floors two to five) have identical floor plans. On the upper floors, there are zones that represent several rooms lumped together (Room 3 and Room 4 in Figure 55b, and Room 3 in Figure 55c). These are also modeled as single zones in CONTAM.

In CONTAM, the following zones are added (shaded in Figure 55):

- A $3.05 \mathrm{~m} \times 3.05 \mathrm{~m}$ Restroom is added on the first floor between the Laundry and Storage zones, carved out of the Lobby;

- A $3.66 \mathrm{~m} \times 11.28 \mathrm{~m}$ Restroom is added on the sixth floor across from the Dining zone, carved out of the Corridor;

- A Stairwell and Elevator Shaft are added near the northwest corner of the building, carved out of the Lobby or Corridor. The Stairwell is $3 \mathrm{~m} \times 6.71 \mathrm{~m}$, and the Elevator Shaft is $2.79 \mathrm{~m} \times 6.71 \mathrm{~m}$;

- A Stairwell and Elevator Shaft are added near the southeast corner of the building, carved out of the Lobby or Corridor. The Stairwell is $3 \mathrm{~m} \times 3.66 \mathrm{~m}$ and the Elevator Shaft is $2.79 \mathrm{~m} \times 3.66 \mathrm{~m}$.

Large interior leakage paths were defined as follows:

- Between Retail 1 and Lobby on the first floor, and between Retail 2 and Lobby, zones, a single large leakage path of $4 \mathrm{~m}^{2}$ is modeled;

- Between Café and Lobby zones on the first floor, a single large leakage path of $8 \mathrm{~m}^{2}$ is modeled;

- Between Laundry and Restroom zones on the first floor, a single large leakage path of $4 \mathrm{~m}^{2}$ is modeled;

- Between Laundry and Lobby zones on the first floor, and between Restroom and Lobby zones on the first floor, a $0.186 \mathrm{~m}^{2}$ transfer grille is modeled;

- Between Restroom and Corridor zones on the sixth floor, two $0.186 \mathrm{~m}^{2}$ transfer grilles are modeled;

- For all the large interior leakage paths modeled in CONTAM above, it should be noted that a physical wall was modeled between the zones in EnergyPlus. The walls were modeled in this way to produce temperature differences between the zones, but no airflow between these zones was modeled in EnergyPlus;

- Between Kitchen and Dining zones on the sixth floor, a single large leakage path that is $50 \%$ of the total wall area between the spaces is modeled.

- A stairwell is defined using CONTAM's stair shaft model for closed treads and zero people;

- An elevator shaft is defined using CONTAM's elevator shaft model. 


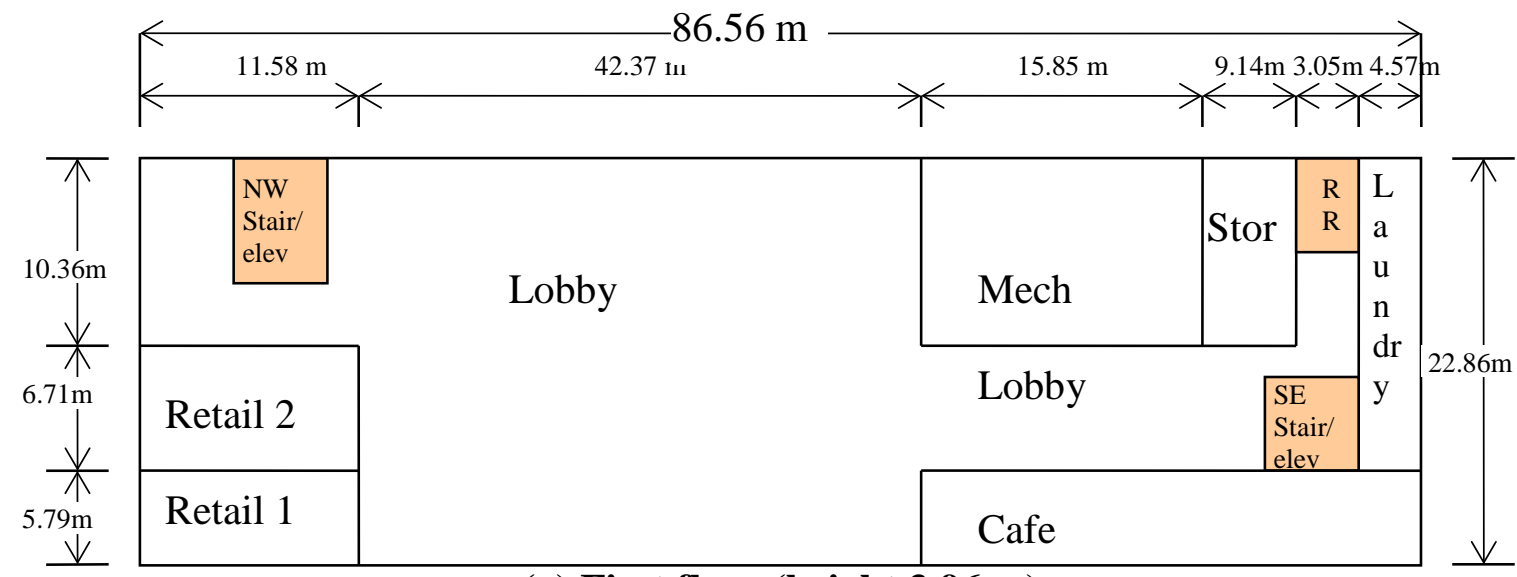

(a) First floor (height $3.96 \mathrm{~m}$ )
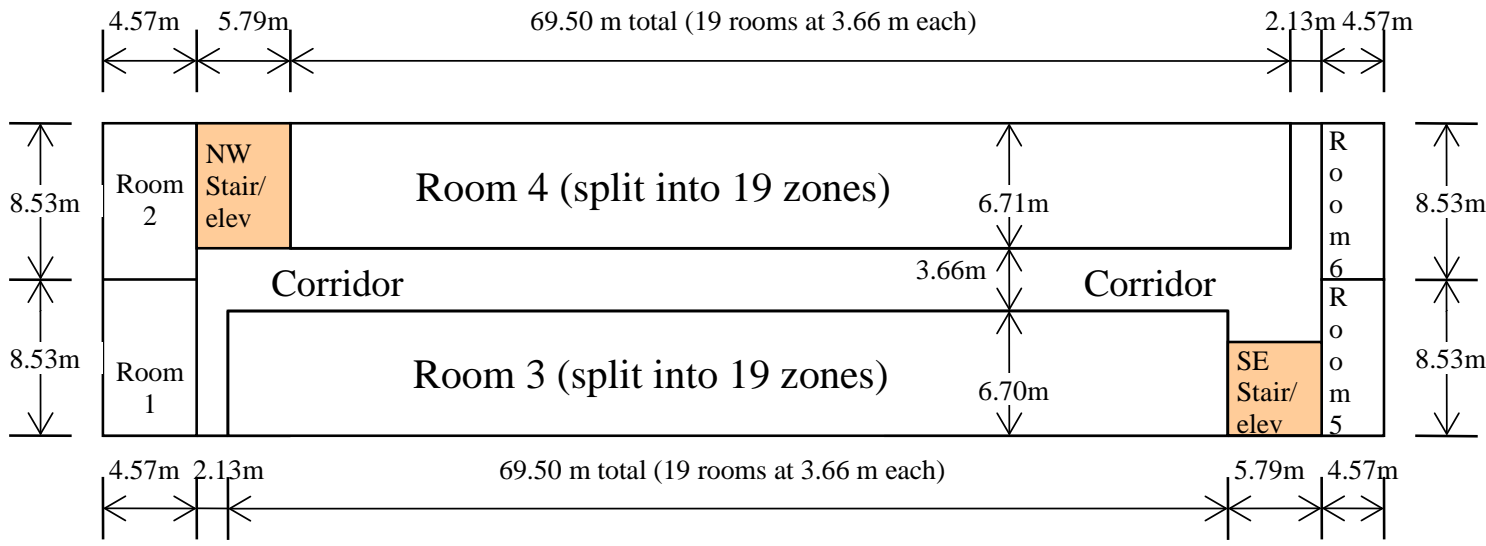

(b) Second to fifth floors (height $3.05 \mathrm{~m}$ )
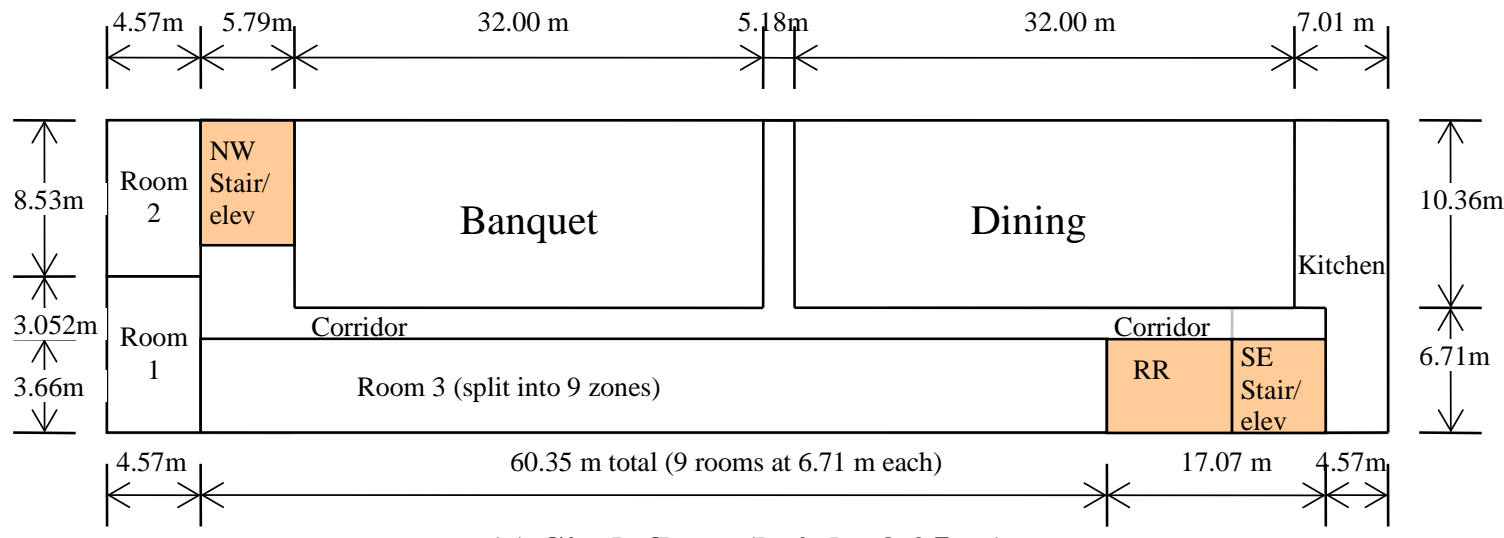

(c) Sixth floor (height $3.05 \mathrm{~m}$ )

Figure 55. (a) First, (b) second to fifth, and (c) sixth floors plans of Large Hotel 


\section{HVAC systems:}

The EnergyPlus model has one VAV system serving the common areas, including the Basement. The design supply flow rate calculated by EnergyPlus for each VAV system is used as the supply flow rate for the constant-volume system modeled in CONTAM for simplicity. The system modeled in CONTAM is still referred to as a "VAV" system in the body of this text. Varying the supply flow rate can be implemented in CONTAM using controls and/or schedules by users who wish to do so. The supply air, return air, outside air, and exhaust flow rates modeled in CONTAM are listed in Table 28. The exhaust flow rates for the Restrooms were modeled only in CONTAM, not in EnergyPlus.

In EnergyPlus, there was a Dining exhaust fan $\left(0.94 \mathrm{~m}^{3} / \mathrm{s}\right)$ and Banquet exhaust fan $\left(0.94 \mathrm{~m}^{3} / \mathrm{s}\right)$ in addition to the Kitchen exhaust fan $\left(1.88 \mathrm{~m}^{3} / \mathrm{s}\right)$. ZoneMixing objects were used in EnergyPlus to transfer this air from Dining and Banquet to the Kitchen. This is modeled in CONTAM using a large opening between the Dining and Kitchen zones (see above), and one exhaust fan in the Kitchen $\left(1.88 \mathrm{~m}^{3} / \mathrm{s}\right)$.

The EnergyPlus model has one dedicated outdoor air systems (DOAS) serving the guestrooms on floor two through six. Similarly, one constant-volume system is modeled in CONTAM. The supply air, return air and outside air, modeled in CONTAM are listed in Table 29.

In EnergyPlus, fan coil units in each guest room provide temperature control. They recirculate air locally within the zone and do not impact whole-building airflow or introduce outside air. In EnergyPlus, the sixth floor Corridor has a unit heater that recirculates air locally within the zone and does not impact whole-building airflow or introduce outside air. The fan coils and unit heater are not modeled in CONTAM.

In EnergyPlus, balanced HVAC systems are modeled in all zones. In an attempt achieve building pressurization in CONTAM, less air is returned than is supplied to each zone. In all areas (Table 28), the return airflow rate is set to $90 \%$ of the supply airflow rate. 
Table 28. Summary of VAV system flow rates $\left(\mathrm{m}^{3} / \mathrm{s}\right)$ in Large Hotel (common areas)

\begin{tabular}{llrrrr}
\hline Zone & Floor & Supply & Return & Outside Air & Exhaust air \\
\hline Basement & $\mathrm{B}$ & 4.96 & 4.46 & 0.85 & 0.00 \\
Retail 1 & 1 & 0.27 & 0.25 & 0.08 & 0.00 \\
Retail 2 & 1 & 0.32 & 0.28 & 0.09 & 0.00 \\
Mechanical Room & 1 & 0.67 & 0.60 & 0.00 & 0.00 \\
Storage & 1 & 0.39 & 0.35 & 0.06 & 0.00 \\
Laundry & 1 & 0.32 & 0.29 & 0.00 & 0.24 \\
Cafe & 1 & 0.77 & 0.69 & 0.68 & 0.00 \\
Lobby & 1 & 5.32 & 4.79 & 1.89 & 0.000 \\
Restroom & 1 & N/A & N/A & N/A & 0.21 \\
Corridor & $2-5$ & 1.22 & 1.10 & 0.12 & 0.00 \\
Banquet & 6 & 1.04 & 0.93 & 1.19 & 0.00 \\
Dining & 6 & 1.04 & 0.93 & 1.19 & 0.00 \\
Kitchen & 6 & 0.32 & 0.29 & 0.93 & 1.88 \\
Corridor & 6 & 1.29 & 1.16 & 0.13 & 0.000 \\
Restroom & 6 & N/A & N/A & N/A & 0.21 \\
\hline
\end{tabular}

Table 29. Summary of DOAS flow rates $\left(\mathrm{m}^{3} / \mathrm{s}\right)$ in Large Hotel (guestrooms)

\begin{tabular}{llcc}
\hline Zone & Floor & Supply & Return \\
& & & \\
\hline Room 1 & $2-5$ & 0.017 & 0.015 \\
Room 2 & $2-5$ & 0.017 & 0.015 \\
Room 3 (x19) & $2-5$ & 0.011 & 0.010 \\
Room 4 (x19) & $2-5$ & 0.011 & 0.010 \\
Room 5 & $2-5$ & 0.017 & 0.015 \\
Room 6 & $2-5$ & 0.017 & 0.015 \\
Room 1 & 6 & 0.017 & 0.015 \\
Room 2 & 6 & 0.017 & 0.015 \\
Room 3 (x9) & 6 & 0.011 & 0.010 \\
\hline
\end{tabular}

\section{HVAC Schedules:}

The VAV, DOAS, restroom exhausts, and laundry exhaust operate 24 hours per day every day of the year. Outside air is also supplied all of the time. The kitchen exhaust fan operates on the following schedule:

- Every day: on from 7:00 a.m. to 12:00 a.m., off otherwise

Temperature setpoints:

There are three thermostat setpoint schedules used in the EnergyPlus model of the Large Hotel (Table 27): Temp - common areas, Temp-GR-N - north guestroom, and Temp-GR-S - south guestroom. The stairwells, elevators, and restrooms were not in the EnergyPlus model so they were assigned the “Temp” schedule in CONTAM. The Temp is scheduled to maintain $21.1{ }^{\circ} \mathrm{C}$ 
during the heating months and $24{ }^{\circ} \mathrm{C}$ during the cooling months. The Temp-GR-N and TempGR-S schedules are the same and do not vary throughout the week (Figure 56).

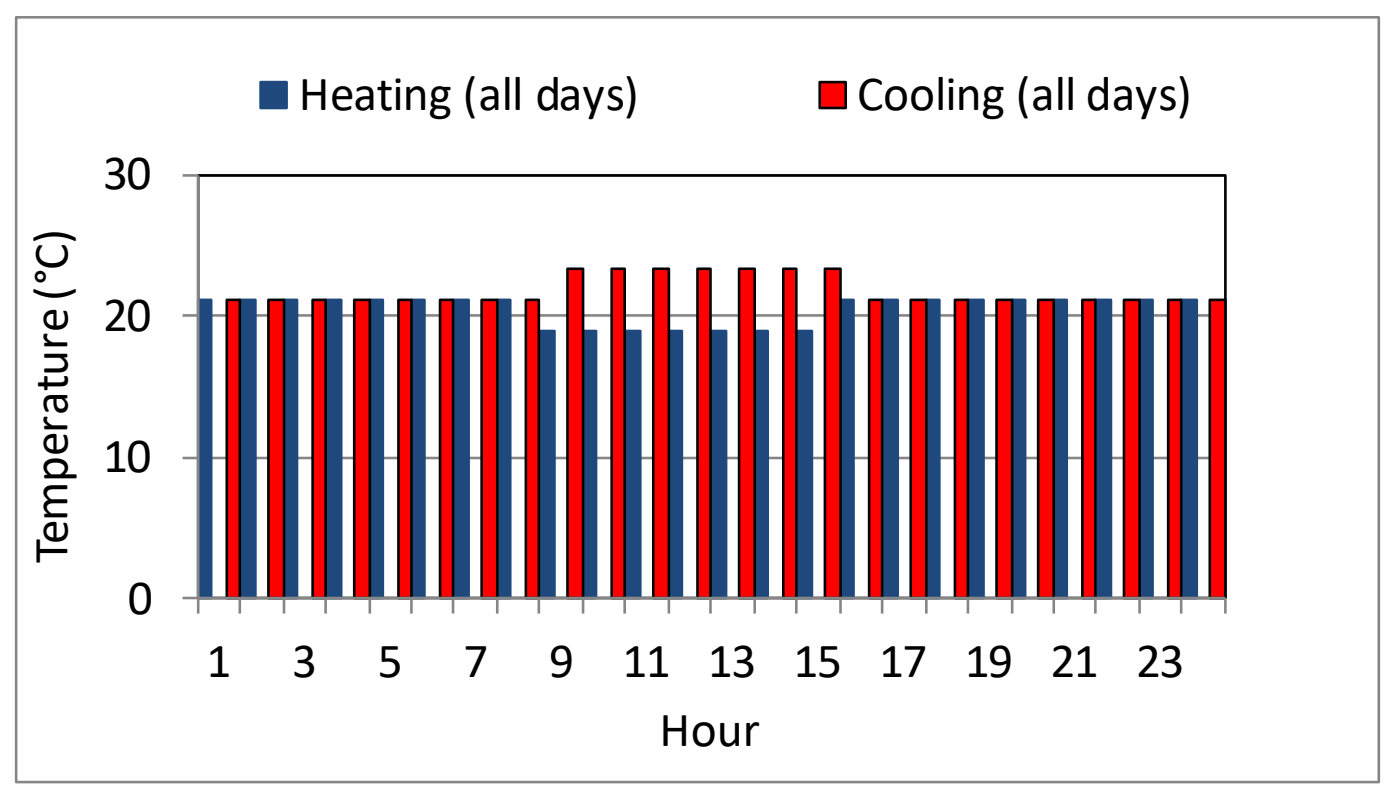

Figure 56. Thermostat setpoint schedule for Large Hotel (Temp-GR-N, Temp-GR-S)

\subsection{Hospital}

Table 30 summarizes the zones modeled in CONTAM for the Hospital, their respective sizes, and maximum occupancy. The table also lists the occupancy schedule for each zone (details given below under Occupants). Unlike the other prototype models, this building model was not scaled as part of the update to the CONTAM models of the reference buildings because it has a complex floor plan, making it cumbersome to scale. In addition, the Hospital model represents only about $3.5 \%$ of the U. S. building stock by floor area [42]. However, occupancy, HVAC, and indoor temperature schedules were updated in accordance with changes made in the EnergyPlus prototype models as noted in red text below. 
Table 30. Summary of zones in Hospital

\begin{tabular}{|c|c|c|c|c|c|}
\hline Zone & Floor & $\begin{array}{r}\text { Area } \\
\left(\mathbf{m}^{2}\right)\end{array}$ & $\begin{array}{r}\text { Height } \\
\text { (m) }\end{array}$ & $\begin{array}{l}\text { Maximum } \\
\text { occupancy }\end{array}$ & Occupancy schedule \\
\hline Basement & $\mathrm{B}$ & 3643 & 2.44 & 101 & Occupancy \\
\hline ER_Exam1_Mult4 & 1 & 28 & 4.27 & 6 & Extended Occupancy \\
\hline ER_Trauma-1 & 1 & 28 & 4.27 & 6 & Extended Occupancy \\
\hline ER_Exam3_Mult4 & 1 & 28 & 4.27 & 6 & Extended Occupancy \\
\hline ER_Trauma2 & 1 & 28 & 4.27 & 6 & Extended Occupancy \\
\hline ER_Triage_Mult4 & 1 & 28 & 4.27 & 6 & Extended Occupancy \\
\hline Office1_Mult4 & 1 & 14 & 4.27 & 1 & Occupancy \\
\hline Lobby_Records & 1 & 1440 & 4.27 & 2 & Occupancy \\
\hline Corridor & 1 & 473 & 4.27 & 6 & Occupancy \\
\hline ER_NurseStn_Lobby & 1 & 1236 & 4.27 & 18 & Occupancy \\
\hline OR1 & 2 & 56 & 4.27 & 3 & Extended Occupancy \\
\hline OR2_Mult5 & 2 & 56 & 4.27 & 3 & Extended Occupancy \\
\hline OR3 & 2 & 56 & 4.27 & 3 & Extended Occupancy \\
\hline OR4 & 2 & 223 & 4.27 & 12 & Extended Occupancy \\
\hline IC_PatRoom1_Mult5 & 2 & 21 & 4.27 & 1 & Extended Occupancy \\
\hline IC_PatRoom2 & 2 & 28 & 4.27 & 1 & Extended Occupancy \\
\hline IC_PatRoom3_Mult6 & 2 & 21 & 4.27 & 1 & Extended Occupancy \\
\hline $\mathrm{IC} \overline{\mathrm{U}}$ & 2 & 618 & 4.27 & 33 & Extended Occupancy \\
\hline ICU_NurseStnLobby & 2 & 669 & 4.27 & 10 & Occupancy \\
\hline Corridor & 2 & 473 & 4.27 & 6 & Occupancy \\
\hline OR_NurseStn_Lobby & 2 & 957 & 4.27 & 15 & Occupancy \\
\hline PatRoom1_Multt10 & 3 & 21 & 4.27 & 1 & Extended Occupancy \\
\hline PatRoom2 & 3 & 35 & 4.27 & 2 & Extended Occupancy \\
\hline PatRoom3_Mult10 & 3 & 20 & 4.27 & 1 & Extended Occupancy \\
\hline PatRoom4 & 3 & 35 & 4.27 & 2 & Extended Occupancy \\
\hline PatRoom5_Mult10 & 3 & 21 & 4.27 & 1 & Extended Occupancy \\
\hline PhysTherapy & 3 & 488 & 4.27 & 26 & Occupancy \\
\hline PatRoom6 & 3 & 28 & 4.27 & 1 & Extended Occupancy \\
\hline PatRoom7_Mult10 & 3 & 20 & 4.27 & 1 & Extended Occupancy \\
\hline PatRoom8 & 3 & 28 & 4.27 & 1 & Extended Occupancy \\
\hline NurseStn_Lobby & 3 & 850 & 4.27 & 13 & Occupancy \\
\hline Lab & 3 & 265 & 4.27 & 14 & Occupancy \\
\hline Corridor_SE & 3 & 518 & 4.27 & 6 & Occupancy \\
\hline Corridor_NW & 3 & 518 & 4.27 & 6 & Occupancy \\
\hline PatRoom1_Mult10 & 4 & 21 & 4.27 & 1 & Extended Occupancy \\
\hline PatRoom2 & 4 & 35 & 4.27 & 2 & Extended Occupancy \\
\hline PatRoom3_Mult10 & 4 & 20 & 4.27 & 1 & Extended Occupancy \\
\hline PatRoom4 & 4 & 35 & 4.27 & 2 & Extended Occupancy \\
\hline PatRoom5_Mult10 & 4 & 21 & 4.27 & 1 & Extended Occupancy \\
\hline Radiology & 4 & 488 & 4.27 & 26 & Occupancy \\
\hline PatRoom6 & 4 & 28 & 4.27 & 1 & Extended Occupancy \\
\hline PatRoom7_Mult10 & 4 & 20 & 4.27 & 1 & Extended Occupancy \\
\hline PatRoom8 & 4 & 28 & 4.27 & 1 & Extended Occupancy \\
\hline NurseStn_Lobby & 4 & 850 & 4.27 & 13 & Occupancy \\
\hline Lab & 4 & 265 & 4.27 & 14 & Occupancy \\
\hline Corridor_SE & 4 & 518 & 4.27 & 6 & Occupancy \\
\hline Corridor_NW & 4 & 518 & 4.27 & 6 & Occupancy \\
\hline
\end{tabular}




\begin{tabular}{lcrrrl}
\hline Zone & Floor & $\begin{array}{r}\text { Area } \\
\mathbf{( m}^{\mathbf{2}}\end{array}$ & $\begin{array}{r}\text { Height } \\
(\mathbf{m})\end{array}$ & $\begin{array}{r}\text { Maximum } \\
\text { occupancy }\end{array}$ & Occupancy schedule \\
\hline Dining & 5 & 641 & 4.27 & 75 & Occupancy \\
NurseStn_Lobby & 5 & 993 & 4.27 & 15 & Occupancy \\
Kitchen & 5 & 929 & 4.27 & 50 & Occupancy \\
Office1 & 5 & 70 & 4.27 & 5 & Occupancy \\
Office2_Mult5 & 5 & 70 & 4.27 & 5 & Occupancy \\
Office3 & 5 & 70 & 4.27 & 5 & Occupancy \\
Office4_Mult6 & 5 & 14 & 4.27 & 1 & Occupancy \\
Corridor & 5 & 454 & 4.27 & 5 & Occupancy \\
Restroom & 1 & 35 & 4.27 & 0 & N/A \\
Restroom & 2 & 56 & 4.27 & 0 & N/A \\
Restroom & 3 & 56 & 4.27 & 0 & N/A \\
Restroom & 4 & 56 & 4.27 & 0 & N/A \\
Restroom & 5 & 56 & 4.27 & 0 & N/A \\
Stair 1 & all & 24 & 4.27 & 0 & N/A \\
Stair 2 & all & 24 & 4.27 & 0 & N/A \\
Elev 1 & all & 24 & 4.27 & 0 & N/A \\
Elev2 & all & 24 & 4.27 & 0 & N/A \\
\hline
\end{tabular}

\section{Occupants:}

The peak number of people for each zone is listed in Table 30. Occupants in all building zones are scheduled according to two occupant schedules ("Occupancy" in Figure 57 and "Extended Occupancy” in Figure 58).

Though the occupancy in the Hospital allowed for the use of the default 12 day type scheduling feature in CONTAM, a CVF file was used to schedule the occupancy of the zones. The file "Hospital.cvf" is available for download with the prototype models on the NIST Multizone Modeling website under Case Studies. 


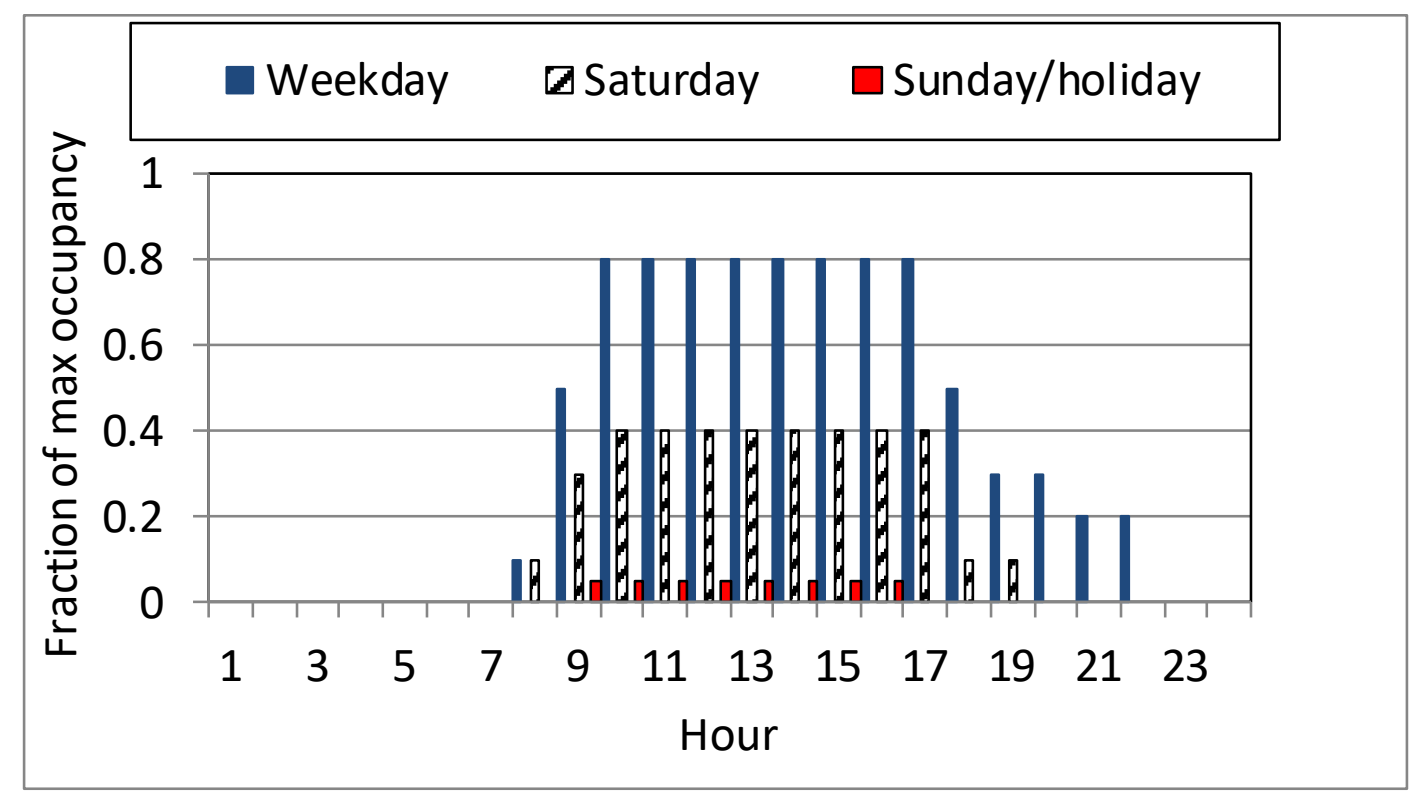

Figure 57. Occupancy schedule for Hospital

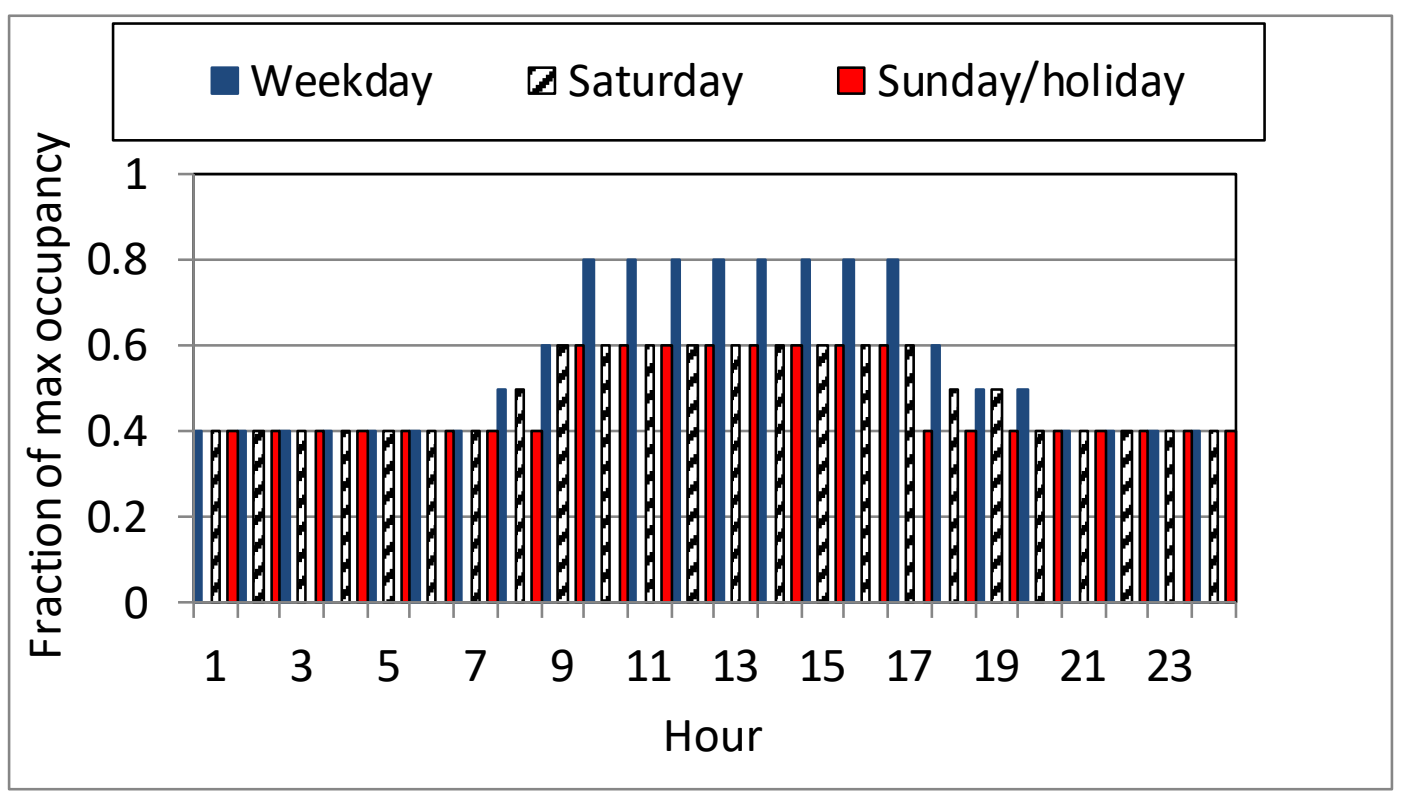

Figure 58. Extended occupancy schedule for Hospital

\section{Geometry:}

$3739 \mathrm{~m}^{2}$ footprint, five-story building (plus a basement) with flat roof. Total floor area is $22436 \mathrm{~m}^{2}$ which includes the Basement. The EnergyPlus model has nine zones on the first floor, 11 zones on second, 13 zones on third and fourth floors, and eight zones on the fifth floor (Figure 59 to Figure 62). The third and fourth floors have identical floor plans. 
In CONTAM, the following zones are added (shaded in Figure 59 to Figure 62):

- A $4.57 \mathrm{~m} \times 7.62 \mathrm{~m}$ Restroom is added on the first floor between the Office 1 and Corridor zones, carved out of the Lobby;

- A $6.10 \mathrm{~m} \times 9.14 \mathrm{~m}$ Restroom is added on the second floor, carved out of the OR Nurse Station;

- A $6.10 \mathrm{~m} \times 9.14 \mathrm{~m}$ Restroom is added on the third and fourth floors, carved out of the Nurse Station Lobby;

- A $4.57 \mathrm{~m} \times 12.19 \mathrm{~m}$ Restroom is added on the fifth floor, carved out of the Nurse Station;

- A Stairwell and Elevator Shaft are added on the north and south sides the building, carved out of the Basement, Corridors (floors 2-5), or Nurse Station (floor 6). Both the Stairwell and Elevator Shaft are $4.57 \mathrm{~m} \times 5.39 \mathrm{~m}$

There are patient rooms, exam rooms, operating rooms, and offices that are modeled in EnergyPlus using “multipliers”. These are modeled as single zones in CONTAM, except for three sets where the multiplied zones were not adjacent to one another. These are modeled as follows:

- On the first floor, ER Exam 3 is multiplied by a factor of four in the EnergyPlus model, with two times on each side of the building. It is modeled in CONTAM as two zones $($ ERExam $3 \times 2 \mathrm{a}$ and ERExam $3 \times 2 \mathrm{~b}-$ indicating that two rooms are grouped into a zone at each location);

- On the third and fourth floors, Patient Room 1 is multiplied by a factor of 10, with five on each side of the building. It is modeled in CONTAM as two zones (PatRm $1 \mathrm{a} \times 5$ and PatRm $1 b \times 5$ - indicating that five rooms are grouped into a zone at each location);

- On the third and fourth floors, Patient Room 5 is multiplied by a factor of 10 in the EnergyPlus model, with five on each side of the building. It is modeled in CONTAM as two zones (PatRm $5 \mathrm{a} \times 5$ and PatRm $5 \mathrm{~b} \times 5$ - indicating that five rooms are grouped into a zone at each location).

Large interior leakage paths were defined as follows:

- Between Lobby and Corridor zones on the first floor, a single large leakage path that is $50 \%$ of the total wall area between the spaces is modeled;

- Between ER Nurse Station and Corridor zones on the first floor, a single large leakage path of $8 \mathrm{~m}^{2}$ is modeled

- Between ICU Nurse Station and OR Nurse Station zones on the second floor, a single large leakage path of $8 \mathrm{~m}^{2}$ is modeled;

- Between Nurse Station Lobby and Corridors zones on the fifth floor, two large leakage paths of $4 \mathrm{~m}^{2}$ are modeled;

- Between Nurse Station Lobby and Dining zones on the sixth floor, one single large leakage path of $4 \mathrm{~m}^{2}$ is modeled;

- For all the large interior leakage paths modeled in CONTAM above, it should be noted that a physical wall was modeled between the zones in EnergyPlus. The walls were modeled in 
this way to produce temperature differences between the zones, but no airflow between these zones was modeled in EnergyPlus;

- All Restrooms are modeled with a $0.186 \mathrm{~m}^{2}$ transfer grille in the door between the zone and adjacent zone (Corridor for floors one to four, Dining for sixth floor).

- A stairwell is defined using CONTAM's stair shaft model for closed treads and zero people;

- An elevator shaft is defined using CONTAM's elevator shaft model. 


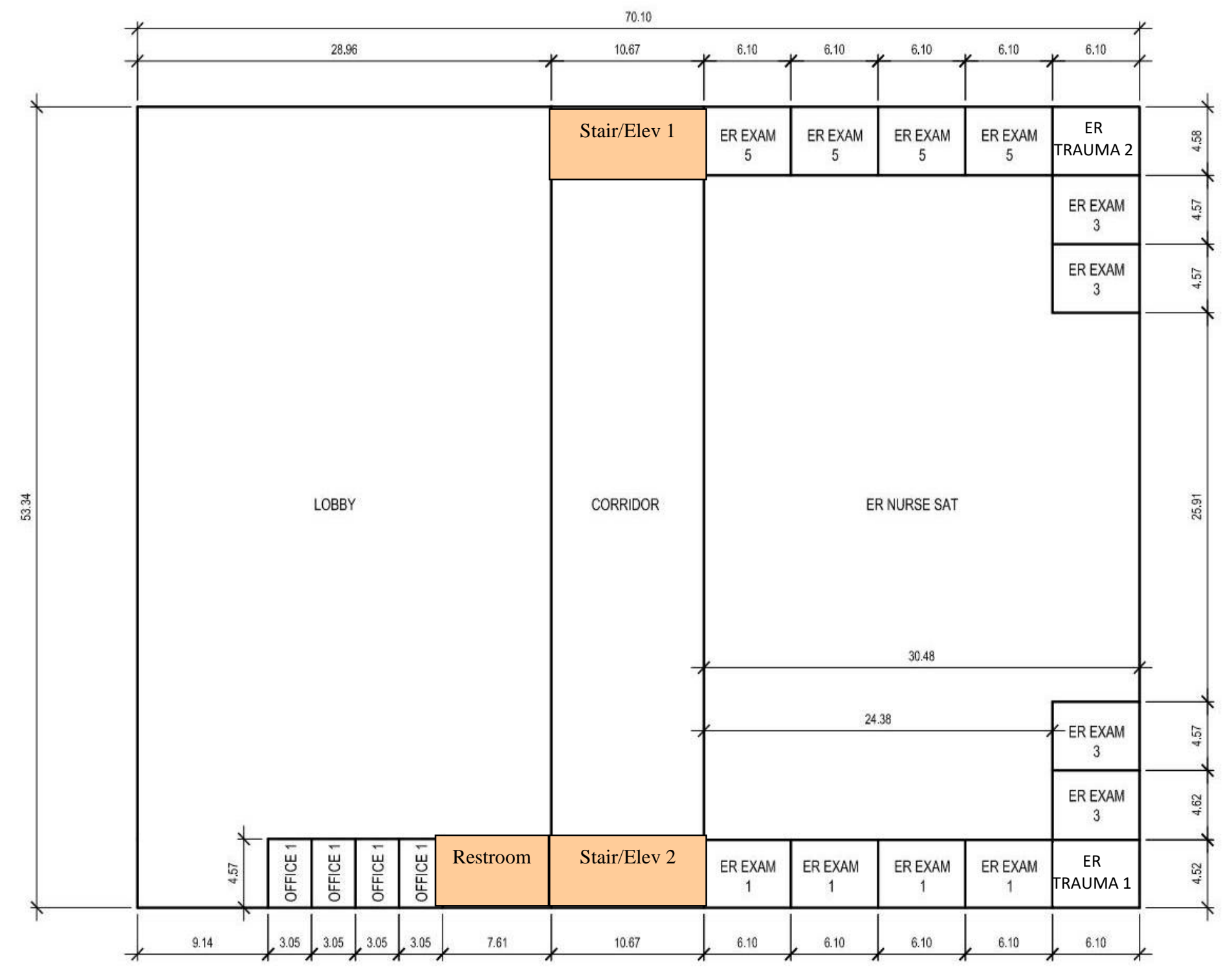

Figure 59. First floor plan of Hospital (height $4.27 \mathrm{~m}$ ), all dimensions in meters 


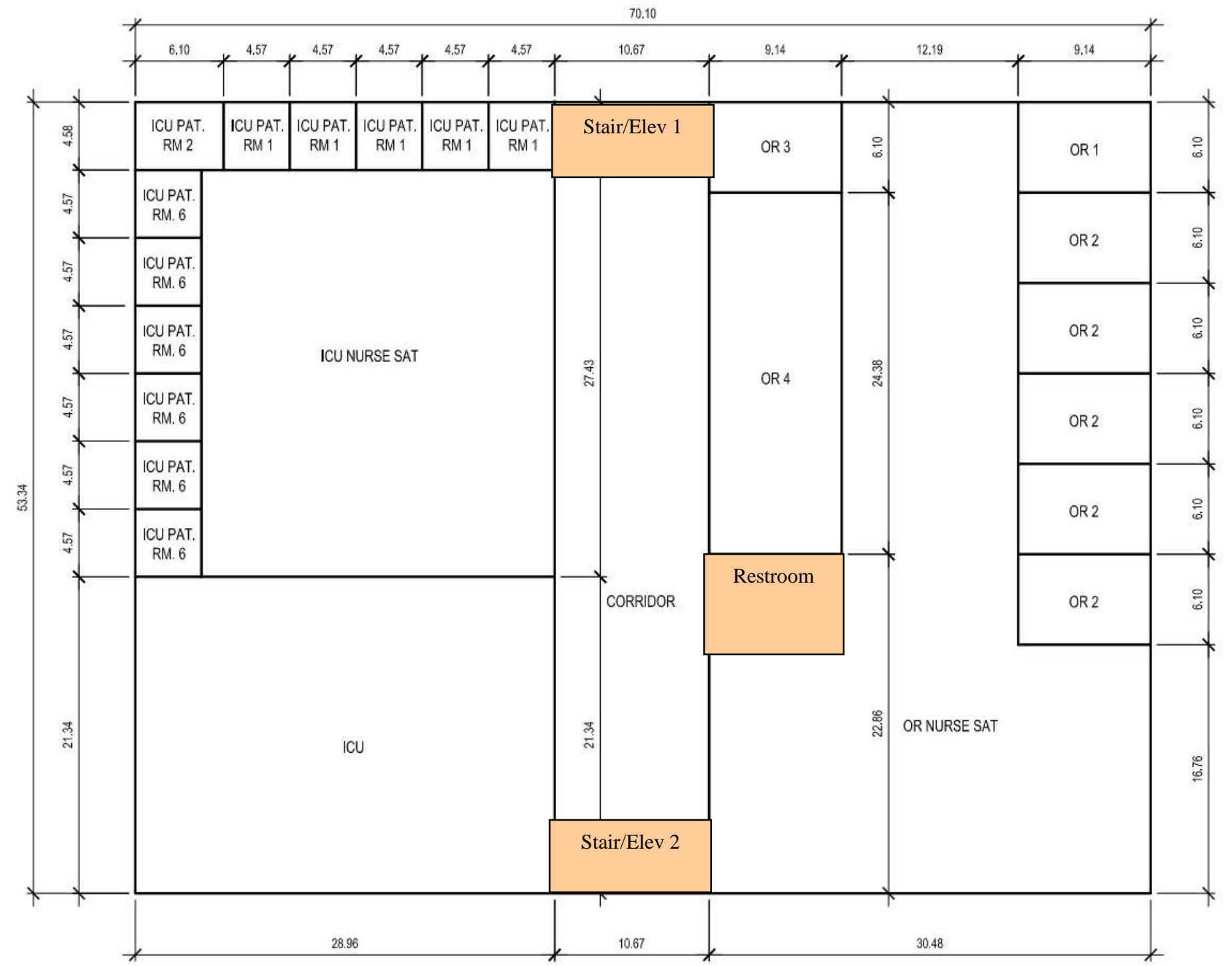

Figure 60. Second floor plan of Hospital (height $4.27 \mathrm{~m}$ ), all dimensions in meters 


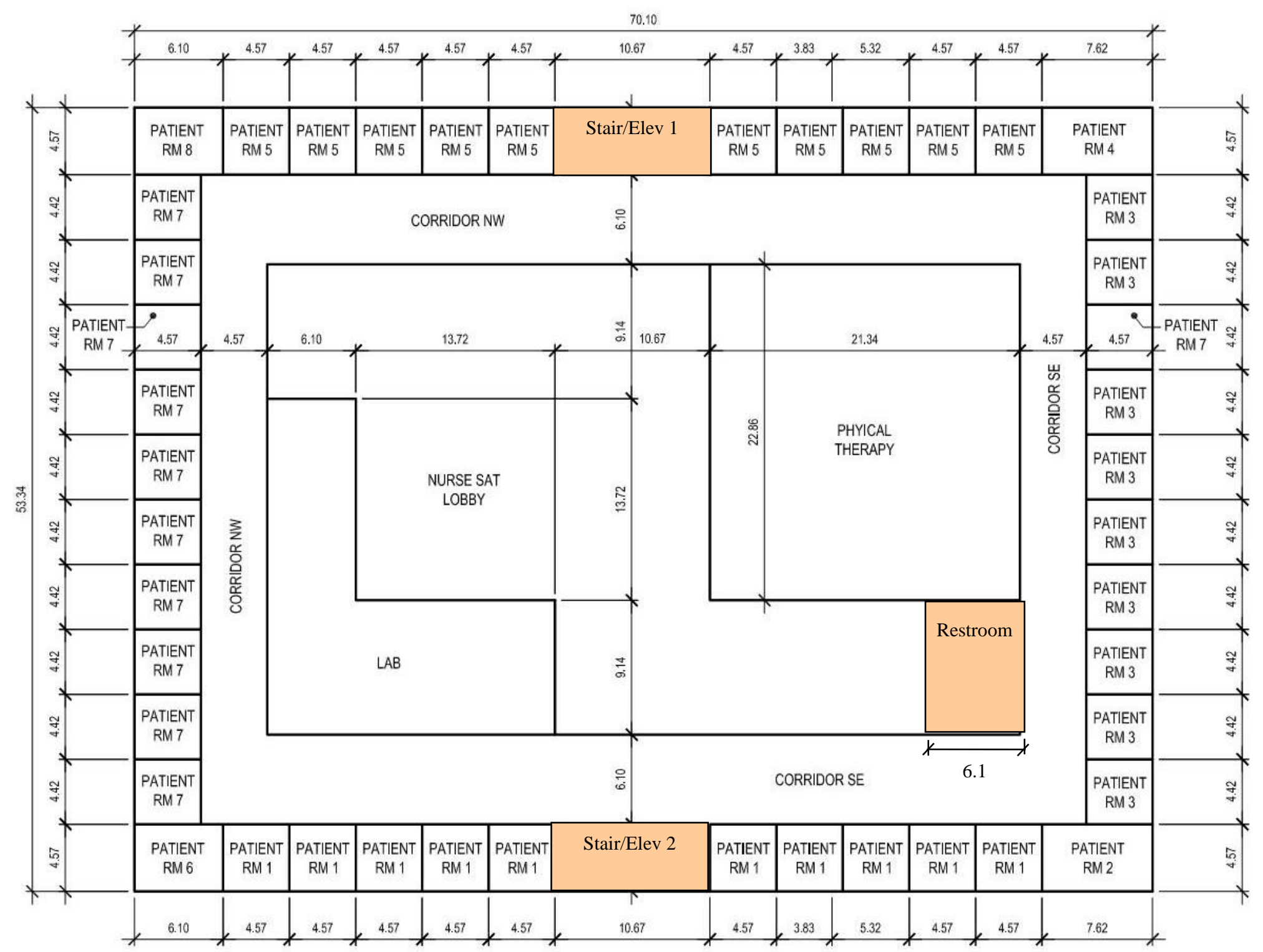

Figure 61. Third/Fourth floor plans of Hospital (height $4.27 \mathrm{~m}$ ), all dimensions in meters 


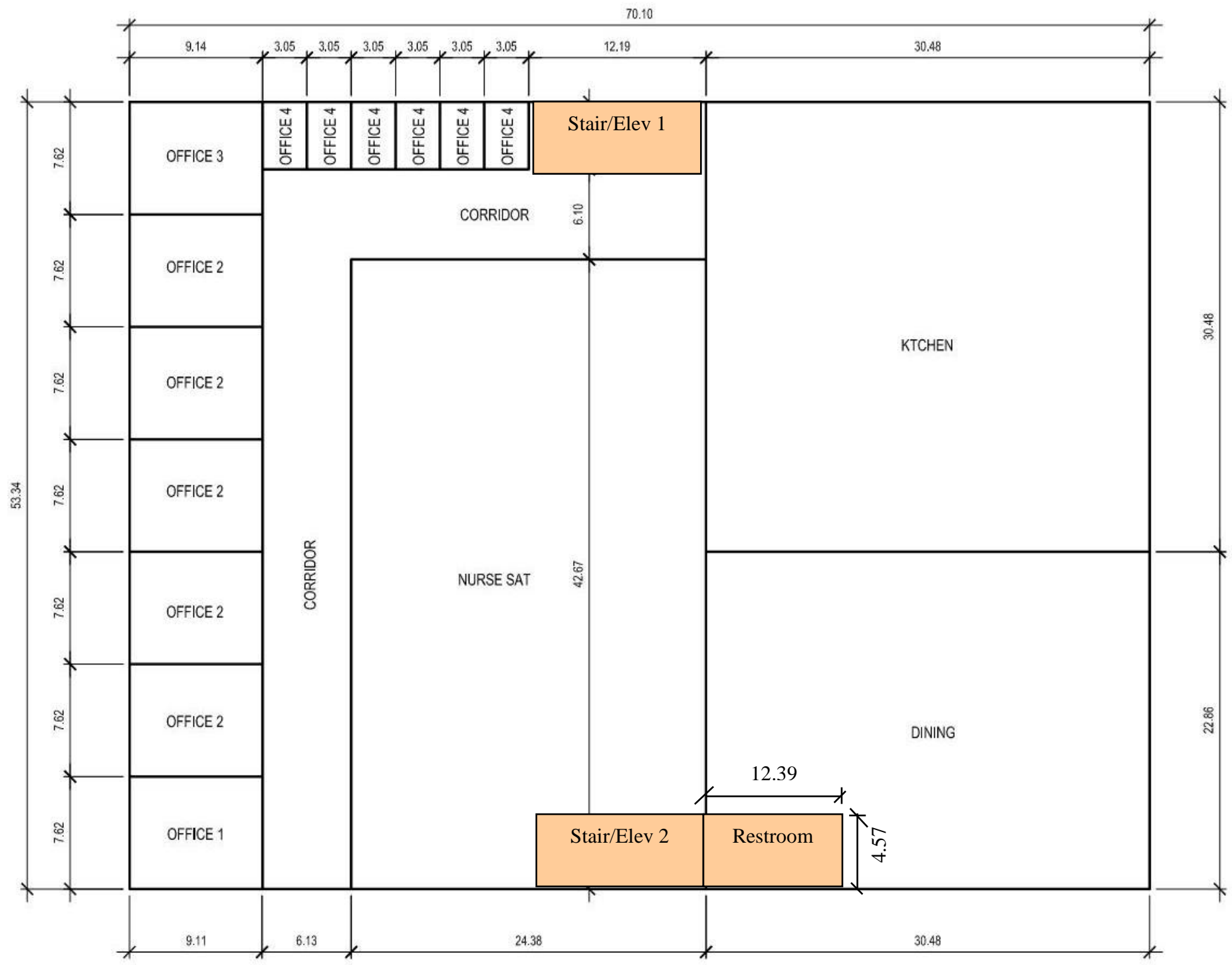

Figure 62. Fifth floor plans of Hospital (height $4.27 \mathrm{~m}$ ), all dimensions in meters 


\section{HVAC systems:}

The EnergyPlus model has seven VAV systems and one CAV systems. The CAV system serves Kitchen, and the seven VAV systems serve the rest of the building. The design supply flow rate calculated by EnergyPlus for each VAV system is used as the supply flow rate for the constantvolume system modeled in CONTAM for simplicity. The system modeled in CONTAM is still referred to as a "VAV" system in the body of this text. Varying the supply flow rate can be implemented in CONTAM using controls and/or schedules by users who wish to do so. The supply air, return air, outside air, and exhaust flow rates modeled in CONTAM are listed in Table 31 for both the VAV and CAV systems. Note that the flow rates were changed in the updated CONTAM model, as well as the VAV system the zone was assigned to. The exhaust flow rates for the Restrooms were modeled only in CONTAM, not in EnergyPlus.

There is a large opening between the Dining and Kitchen zones (see above) to allow for air transfer between these zones that are conventionally open to one another and one exhaust fan in the Kitchen $\left(3.4 \mathrm{~m}^{3} / \mathrm{s}\right)$. In the EnergyPlus model, the ZoneMixing object was used in EnergyPlus to transfer air to the Kitchen from the zones that the same floor. The transfer of air is only in one direction and there is no documentation on how the amount of transferred air $\left(1.48 \mathrm{~m}^{3} / \mathrm{s}\right)$ was chosen. This airflow is close to the air required to make up for the exhaust fan removing $3.4 \mathrm{~m}^{3} / \mathrm{s}$ from the space and requiring $1.88 \mathrm{~m}^{3} / \mathrm{s}$ in outdoor air $\left(3.4 \mathrm{~m}^{3} / \mathrm{s}-1.88 \mathrm{~m}^{3} / \mathrm{s}\right.$ $\left.=1.52 \mathrm{~m}^{3} / \mathrm{s}\right)$.

In EnergyPlus, balanced HVAC systems are modeled in all zones. In an attempt achieve building pressurization in CONTAM, less air is returned than is supplied to each zone. The return airflow rate is set to $90 \%$ of the supply airflow rate.

\section{HVAC Schedules:}

All the HVAC system and exhaust fans operate 24 hours per day every day of the year. Outside air is also supplied all of the time. 
Table 31. Summary of VAV and CAV system flow rates $\left(\mathrm{m}^{3} / \mathrm{s}\right)$ in Hospital

\begin{tabular}{|c|c|c|c|c|c|}
\hline Zone & Floor & Supply & Return & Outside air & Exhaust air \\
\hline Basement & $\mathrm{B}$ & 3.57 & 3.21 & & 0.00 \\
\hline Office1_Mult4 & 1 & 0.12 & 0.11 & & 0.00 \\
\hline Lobby_-_Records & 1 & 2.52 & 2.27 & & 0.00 \\
\hline Corridor & 1 & 0.82 & 0.74 & & 0.00 \\
\hline ER_NurseStn_Lobby & 1 & 2.16 & 1.95 & & 0.00 \\
\hline ICU_NurseStnLobby & 2 & 1.17 & 1.05 & & 0.00 \\
\hline Corridor & 2 & 0.82 & 0.74 & & 0.00 \\
\hline OR_NurseStn_Lobby & 2 & 1.67 & 1.51 & & 0.00 \\
\hline VAV 1 Total & & 12.86 & 11.58 & 3.13 & \\
\hline PhysTherapy & 3 & 1.21 & 1.09 & & 0.00 \\
\hline NurseStn_Lobby & $3-4$ & 4.21 & 3.79 & & 0.00 \\
\hline Corridor_SE & $3-4$ & 2.56 & 2.31 & & 0.00 \\
\hline Corridor_NW & $3-4$ & 2.56 & 2.31 & & 0.00 \\
\hline Radiology & 4 & 1.21 & 1.09 & & 0.00 \\
\hline Dining & 5 & 1.59 & 1.43 & & 0.00 \\
\hline NurseStn_Lobby & 5 & 2.45 & 2.21 & & 0.00 \\
\hline Office1 & 5 & 0.12 & 0.11 & & 0.00 \\
\hline Office2_Mult5 & 5 & 0.86 & 0.78 & & 0.00 \\
\hline Office3 & 5 & 0.17 & 0.16 & & 0.00 \\
\hline Office4_Mult6 & 5 & 0.21 & 0.19 & & 0.00 \\
\hline Corridor & 5 & 1.12 & 1.01 & & 0.00 \\
\hline VAV 2 Total & & 18.27 & 16.44 & 3.15 & \\
\hline ER_Exam1_Mult4 & 1 & 1.59 & 1.43 & & 0.00 \\
\hline ER_Trauma1 & 1 & 0.40 & 0.36 & & 0.00 \\
\hline ER_Exam3_Mult4 & 1 & 1.59 & 1.43 & & 0.00 \\
\hline ER_Trauma2 & 1 & 0.40 & 0.36 & & 0.00 \\
\hline ER_Triage_Mult4 & 1 & 1.59 & 1.43 & & 0.00 \\
\hline VAV ER Total & & 5.56 & 5.00 & 0.93 & \\
\hline IC_PatRoom1_Mult5 & 2 & 0.74 & 0.67 & & 0.00 \\
\hline IC_PatRoom2 & 2 & 0.20 & 0.18 & & 0.00 \\
\hline IC_PatRoom3_Mult6 & 2 & 0.90 & 0.81 & & 0.00 \\
\hline IC $\bar{U}$ & 2 & 4.43 & 3.99 & & 0.00 \\
\hline VAV ICU Total & & 6.27 & 5.65 & 2.08 & \\
\hline Lab & $3-4$ & 2.38 & 2.14 & & 0.000 \\
\hline VAV LABS Total & & 2.38 & 2.14 & 0.62 & \\
\hline OR1 & 2 & 0.99 & 0.89 & & 0.00 \\
\hline OR2_Mult5 & 2 & 4.96 & 4.46 & & 0.00 \\
\hline OR3 & 2 & 0.99 & 0.89 & & 0.00 \\
\hline OR4 & 2 & 3.97 & 3.57 & & 0.00 \\
\hline VAV OR Total & & 10.91 & 9.81 & 1.39 & \\
\hline PatRoom1_Mult10 & $3-4$ & 2.97 & 2.68 & & 0.00 \\
\hline PatRoom2 & $3-4$ & 0.40 & 0.36 & & 0.00 \\
\hline PatRoom3_Mult10 & $3-4$ & 2.87 & 2.59 & & 0.00 \\
\hline PatRoom4 & $3-4$ & 0.50 & 0.45 & & 0.00 \\
\hline PatRoom5_Mult10 & $3-4$ & 2.97 & 2.68 & & 0.00 \\
\hline PatRoom6 & $3-4$ & 0.40 & 0.36 & & 0.00 \\
\hline
\end{tabular}




\begin{tabular}{llrrrr}
\hline Zone & Floor & Supply & Return & Outside air & Exhaust air \\
\hline PatRoom7_Mult10 & $3-4$ & 2.87 & 2.59 & & 0.000 \\
PatRoom8 & $3-4$ & 0.40 & 0.36 & & 0.00 \\
\hline VAV PATRMS Total & & 13.38 & 12.05 & 4.45 & \\
\hline Kitchen (CAV) & 5 & 17.48 & 15.73 & 1.88 & 3.40 \\
Restroom (exhaust only) & $1-5$ & NA & NA & NA & 0.15 \\
\hline
\end{tabular}

Thermostat setpoints:

All the occupied zones were scheduled to maintain $21^{\circ} \mathrm{C}$ in the heating months and $24^{\circ} \mathrm{C}$ in the cooling months. The Restrooms, Stairwells, and Elevator shafts were scheduled with a constant temperature of $20^{\circ} \mathrm{C}$ in CONTAM because the EnergyPlus model did not have these zones.

\subsection{Outpatient Health Care}

Table 32 summarizes the zones modeled in CONTAM for the Outpatient Health Care, their respective sizes, and maximum occupancy. No changes to this CONTAM model were made for this update since it has a complex floor plan with 118 zones, making it cumbersome to scale. In addition, the Outpatient Health Care model represents only about $4 \%$ of the U. S. building stock by floor area [42].

Table 32. Summary of zones in Outpatient Health Care

\begin{tabular}{lllll}
\hline Zone & Floor & Area $\left.\mathbf{( m}^{\mathbf{2}}\right)$ & Height $(\mathbf{m})$ & Maximum occupancy \\
\hline Anesthesia & 1 & 10 & 3.05 & 0.00 \\
Bio Hazard & 1 & 5 & 3.05 & 0.00 \\
Café & 1 & 39 & 3.05 & 39.02 \\
Clean & 1 & 12 & 3.05 & 2.34 \\
Clean Work & 1 & 15 & 3.05 & 3.07 \\
Dictation & 1 & 12 & 3.05 & 0.59 \\
Dressing Room & 1 & 4 & 3.05 & 0.21 \\
Electrical Room & 1 & 9 & 3.05 & 0.00 \\
Elevator Pump Room & 1 & 8 & 3.05 & 0.00 \\
Humid & 1 & 5 & 3.05 & 0.25 \\
IT Hall & 1 & 13 & 3.05 & 0.00 \\
IT Room & 1 & 10 & 3.05 & 0.52 \\
Lobby & 1 & 58 & 3.05 & 17.34 \\
Lobby Hall & 1 & 22 & 3.05 & 0.00 \\
Lobby Toilet & 1 & 5 & 3.05 & 0.00 \\
Locker Room & 1 & 61 & 3.05 & 9.20 \\
Locker Room Hall & 1 & 46 & 3.05 & 0.00 \\
Lounge & 1 & 33 & 3.05 & 5.02 \\
Med Gas & 1 & 5 & 3.05 & 0.00 \\
MRI Control Room & 1 & 16 & 3.05 & 3.12 \\
MRI Hall & 1 & 14 & 3.05 & 0.00 \\
MRI Room & 1 & 41 & 3.05 & 8.18 \\
MRI Toilet & 1 & 5 & 3.05 & 0.00
\end{tabular}




\begin{tabular}{|c|c|c|c|c|}
\hline Zone & Floor & Area $\left(\mathrm{m}^{2}\right)$ & Height (m) & Maximum occupancy \\
\hline Nourishment & 1 & 17 & 3.05 & 3.38 \\
\hline Nurse Hall & 1 & 46 & 3.05 & 0.00 \\
\hline Nurse Janitor & 1 & 5 & 3.05 & 0.00 \\
\hline Nurse Station & 1 & 24 & 3.05 & 4.85 \\
\hline Nurse Toilet & 1 & 5 & 3.05 & 0.00 \\
\hline Office & 1 & 45 & 3.05 & 2.24 \\
\hline Operating Room 1 & 1 & 43 & 3.05 & 8.55 \\
\hline Operating Room 2 & 1 & 45 & 3.05 & 8.92 \\
\hline Operating Room 3 & 1 & 44 & 3.05 & 8.84 \\
\hline PACU & 1 & 10 & 3.05 & 2.01 \\
\hline Pre-Op Hall & 1 & 49 & 3.05 & 0.00 \\
\hline Pre-Op Room 1 & 1 & 18 & 3.05 & 1.76 \\
\hline Pre-Op Room 2 & 1 & 31 & 3.05 & 3.14 \\
\hline Pre-Op Toilet & 1 & 5 & 3.05 & 0.00 \\
\hline Procedure Room & 1 & 26 & 3.05 & 5.30 \\
\hline Reception & 1 & 47 & 3.05 & 14.19 \\
\hline Reception Hall & 1 & 12 & 3.05 & 0.00 \\
\hline Recovery Room & 1 & 50 & 3.05 & 10.03 \\
\hline Scheduling & 1 & 11 & 3.05 & 0.55 \\
\hline Scrub & 1 & 8 & 3.05 & 0.00 \\
\hline Soil & 1 & 12 & 3.05 & 2.34 \\
\hline Soil Hold & 1 & 5 & 3.05 & 1.04 \\
\hline Soil Work & 1 & 17 & 3.05 & 3.34 \\
\hline Step Down & 1 & 28 & 3.05 & 5.57 \\
\hline Sterile Hall & 1 & 57 & 3.05 & 0.00 \\
\hline Sterile Storage & 1 & 37 & 3.05 & 0.00 \\
\hline Storage & 1 & 85 & 3.05 & 0.00 \\
\hline Sub-Sterile & 1 & 18 & 3.05 & 0.00 \\
\hline Utility Hall & 1 & 24 & 3.05 & 0.00 \\
\hline Utility Janitor & 1 & 4 & 3.05 & 0.00 \\
\hline Utility Room & 1 & 33 & 3.05 & 0.00 \\
\hline Vestibule & 1 & 7 & 3.05 & 0.00 \\
\hline Conference & 2 & 31 & 3.05 & 15.61 \\
\hline Conference Toilet & 2 & 6 & 3.05 & 0.00 \\
\hline Dictation & 2 & 7 & 3.05 & 0.33 \\
\hline Exam 1 & 2 & 33 & 3.05 & 6.69 \\
\hline Exam 2 & 2 & 50 & 3.05 & 10.03 \\
\hline Exam 3 & 2 & 67 & 3.05 & 13.38 \\
\hline Exam 4 & 2 & 8 & 3.05 & 1.56 \\
\hline Exam 5 & 2 & 33 & 3.05 & 6.50 \\
\hline Exam 6 & 2 & 21 & 3.05 & 4.18 \\
\hline Exam 7 & 2 & 74 & 3.05 & 14.72 \\
\hline Exam 8 & 2 & 25 & 3.05 & 5.02 \\
\hline Exam 9 & 2 & 37 & 3.05 & 7.36 \\
\hline Exam Hall 1 & 2 & 17 & 3.05 & 0.00 \\
\hline Exam Hall 2 & 2 & 17 & 3.05 & 0.00 \\
\hline Exam Hall 3 & 2 & 17 & 3.05 & 0.00 \\
\hline Exam Hall 4 & 2 & 18 & 3.05 & 0.00 \\
\hline Exam Hall 5 & 2 & 18 & 3.05 & 0.00 \\
\hline Exam Hall 6 & 2 & 18 & 3.05 & 0.00 \\
\hline
\end{tabular}




\begin{tabular}{|c|c|c|c|c|}
\hline Zone & Floor & Area $\left(\mathrm{m}^{2}\right)$ & Height (m) & Maximum occupancy \\
\hline Janitor & 2 & 6 & 3.05 & 0.00 \\
\hline Lounge & 2 & 7 & 3.05 & 1.11 \\
\hline Nurse Station 1 & 2 & 14 & 3.05 & 2.79 \\
\hline Nurse Station 2 & 2 & 17 & 3.05 & 3.34 \\
\hline Office & 2 & 52 & 3.05 & 2.60 \\
\hline Office Hall & 2 & 41 & 3.05 & 0.00 \\
\hline Reception & 2 & 91 & 3.05 & 27.42 \\
\hline Reception Hall & 2 & 52 & 3.05 & 0.00 \\
\hline Reception Toilet & 2 & 12 & 3.05 & 0.00 \\
\hline Scheduling 1 & 2 & 30 & 3.05 & 1.51 \\
\hline Scheduling 2 & 2 & 32 & 3.05 & 1.59 \\
\hline Storage 1 & 2 & 5 & 3.05 & 0.00 \\
\hline Storage 2 & 2 & 11 & 3.05 & 0.00 \\
\hline Storage 3 & 2 & 13 & 3.05 & 0.00 \\
\hline Utility & 2 & 12 & 3.05 & 0.00 \\
\hline Work & 2 & 157 & 3.05 & 7.85 \\
\hline Work Hall & 2 & 77 & 3.05 & 0.00 \\
\hline Work Toilet & 2 & 5 & 3.05 & 0.00 \\
\hline X-Ray & 2 & 84 & 3.05 & 16.72 \\
\hline Dressing Room & 3 & 4 & 3.05 & 0.20 \\
\hline Elevator Hall & 3 & 34 & 3.05 & 0.00 \\
\hline Humid & 3 & 10 & 3.05 & 0.50 \\
\hline Janitor & 3 & 6 & 3.05 & 0.00 \\
\hline Locker & 3 & 11 & 3.05 & 1.67 \\
\hline Lounge & 3 & 71 & 3.05 & 10.58 \\
\hline Lounge Toilet & 3 & 18 & 3.05 & 0.00 \\
\hline Mechanical & 3 & 33 & 3.05 & 0.00 \\
\hline Mechanical Hall & 3 & 28 & 3.05 & 0.00 \\
\hline Office & 3 & 282 & 3.05 & 14.10 \\
\hline Office Hall & 3 & 77 & 3.05 & 0.00 \\
\hline Office Toilet & 3 & 5 & 3.05 & 0.00 \\
\hline Physical Therapy 1 & 3 & 121 & 3.05 & 24.15 \\
\hline Physical Therapy 2 & 3 & 55 & 3.05 & 11.00 \\
\hline Physical Therapy Toilet & 3 & 8 & 3.05 & 0.00 \\
\hline Storage 1 & 3 & 10 & 3.05 & 0.00 \\
\hline Storage 2 & 3 & 8 & 3.05 & 0.00 \\
\hline Treatment & 3 & 44 & 3.05 & 8.84 \\
\hline Undeveloped 1 & 3 & 211 & 3.05 & 0.00 \\
\hline Undeveloped 2 & 3 & 107 & 3.05 & 0.00 \\
\hline Utility & 3 & 20 & 3.05 & 0.00 \\
\hline Work & 3 & 53 & 3.05 & 2.67 \\
\hline NE Stair & all & 16 & 9.14 & 0.00 \\
\hline NW Elevator & all & 13 & 9.14 & 0.00 \\
\hline NW Stair & all & 18 & 9.14 & 0.00 \\
\hline SW Stair & all & 9 & 9.14 & 0.00 \\
\hline
\end{tabular}




\section{Occupants:}

The peak number of people for each zone is listed in Table 32. Occupants in all building zones are scheduled according to Figure 63. There is a different occupancy schedule for weekdays, Saturdays, and Sundays/ holidays.

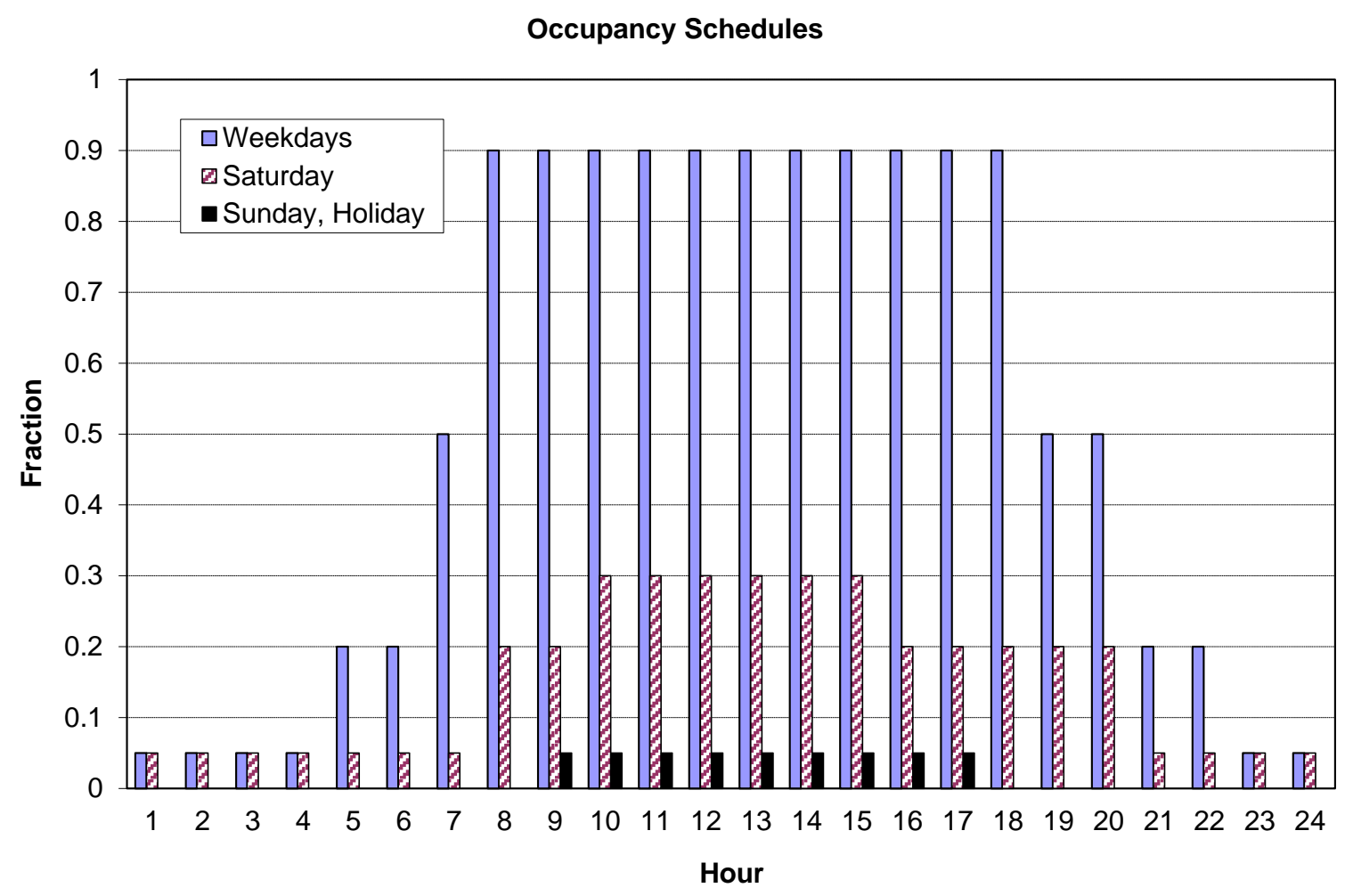

Figure 63. Occupancy schedule for Outpatient Health Care

\section{Geometry:}

$1373 \mathrm{~m}^{2}$ footprint, three-story building with flat roof. The second and third floors have a slightly smaller footprint of $1232 \mathrm{~m}^{2}$ each. Total floor area is $3837 \mathrm{~m}^{2}$. The EnergyPlus model has 55 zones on the first floor, 37 zones on second floor, and 22 zones the third floor. Three Stairwells and one Elevator Shaft are modeled in EnergyPlus as single tall zones with heights equal to the height of the building. In CONTAM, they are modeled as one zone per floor, with large leakage paths connecting them (see below).

Large interior leakage paths were defined as follows:

- All rooms with exhaust fans (see Table 33) are modeled with a $0.186 \mathrm{~m}^{2}$ transfer grille in the door between the zone and adjacent zone. The exception is the MRI room which does not have a transfer grille modeled.

- Between the following zones a single large leakage path of $4 \mathrm{~m}^{2}$ is modeled: 
First floor: Between Lobby Hall and Lobby

First floor: Between Lobby Hall and Reception

$\square$ First floor: Between Reception Hall and Pre-Op Hall

$\square$ First floor: Between Nurse Station and Nurse Hall

First floor: Between Locker Room Hall and Pre-Op Hall

$\square$ First floor: Between Nurse Hall and Pre-Op Hall

$\square$ Second floor: Between Reception and Work Hall

$\square$ Second floor: Between Reception and Reception Hall

$\square$ Second floor: Between Office Hall and Work Hall

$\square$ Third floor: Between Elevator Hall and Office Hall

$\square$ Third floor: Between Mechanical Hall and Office Hall

- A stairwell is defined using CONTAM's stair shaft model for closed treads and zero people;

- An elevator shaft is defined using CONTAM's elevator shaft model. 


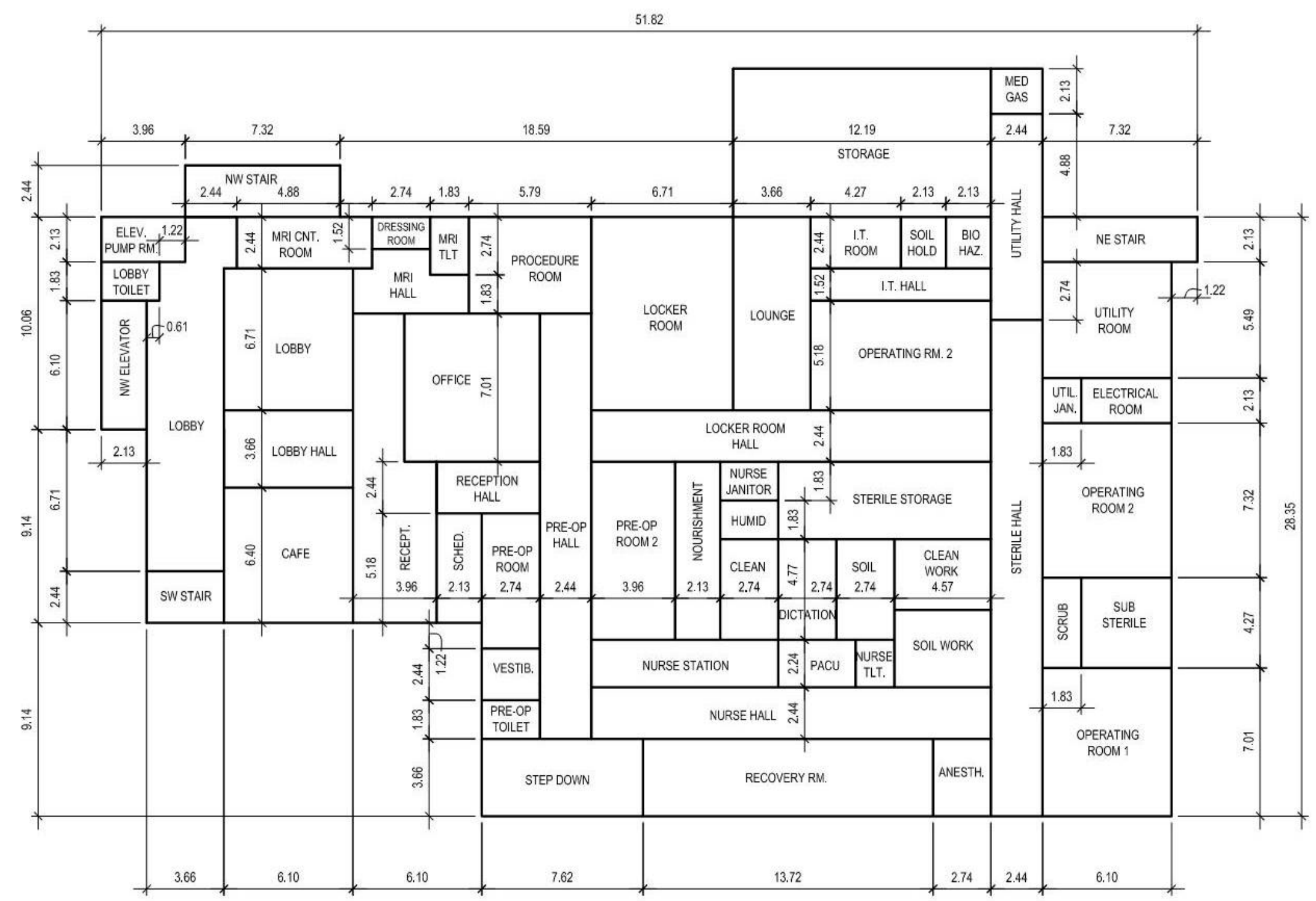

Figure 64. First floor plan of Outpatient Health Care, all dimensions in meters 


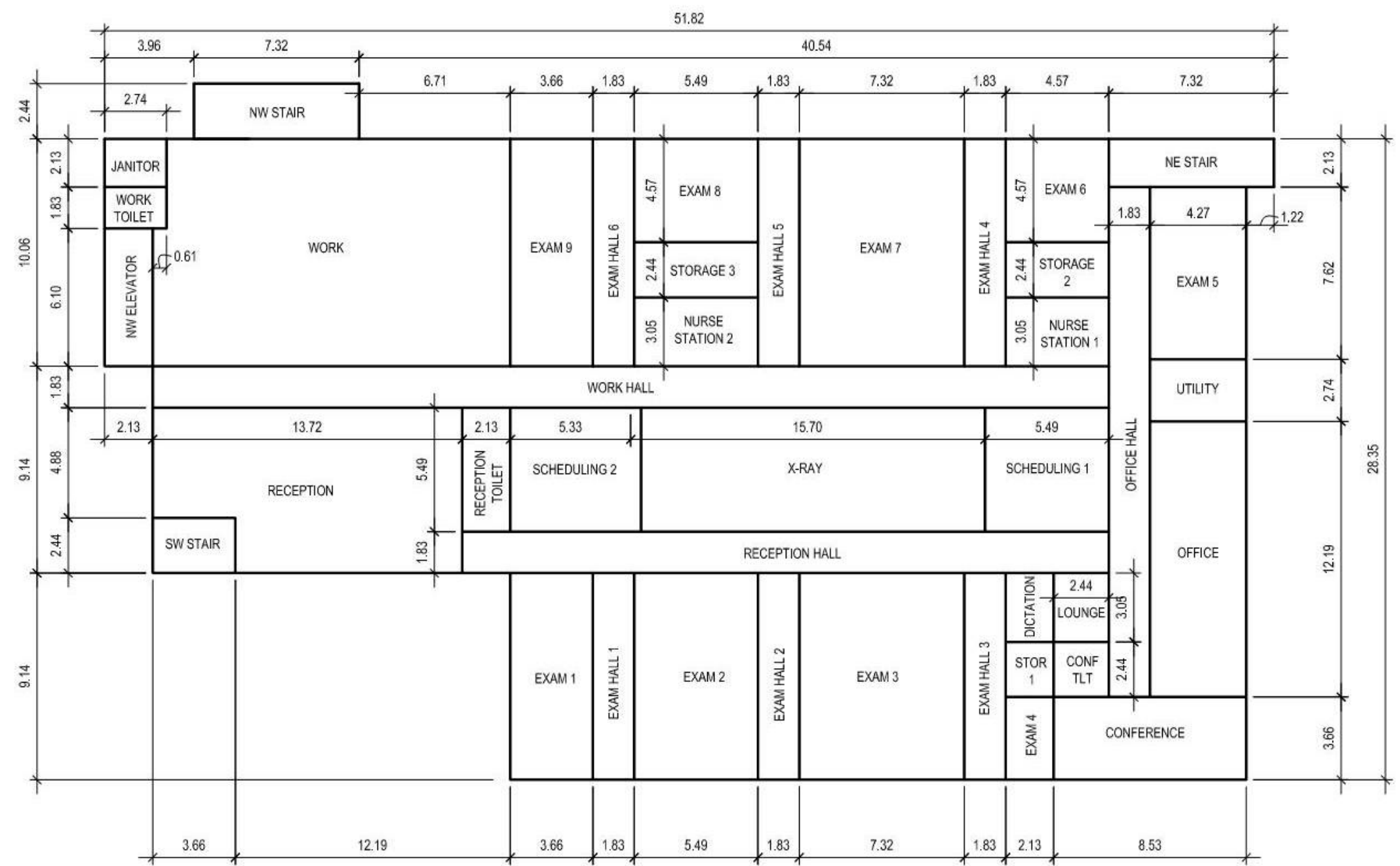

Figure 65. Second floor plan of Outpatient Health Care, all dimensions in meters 


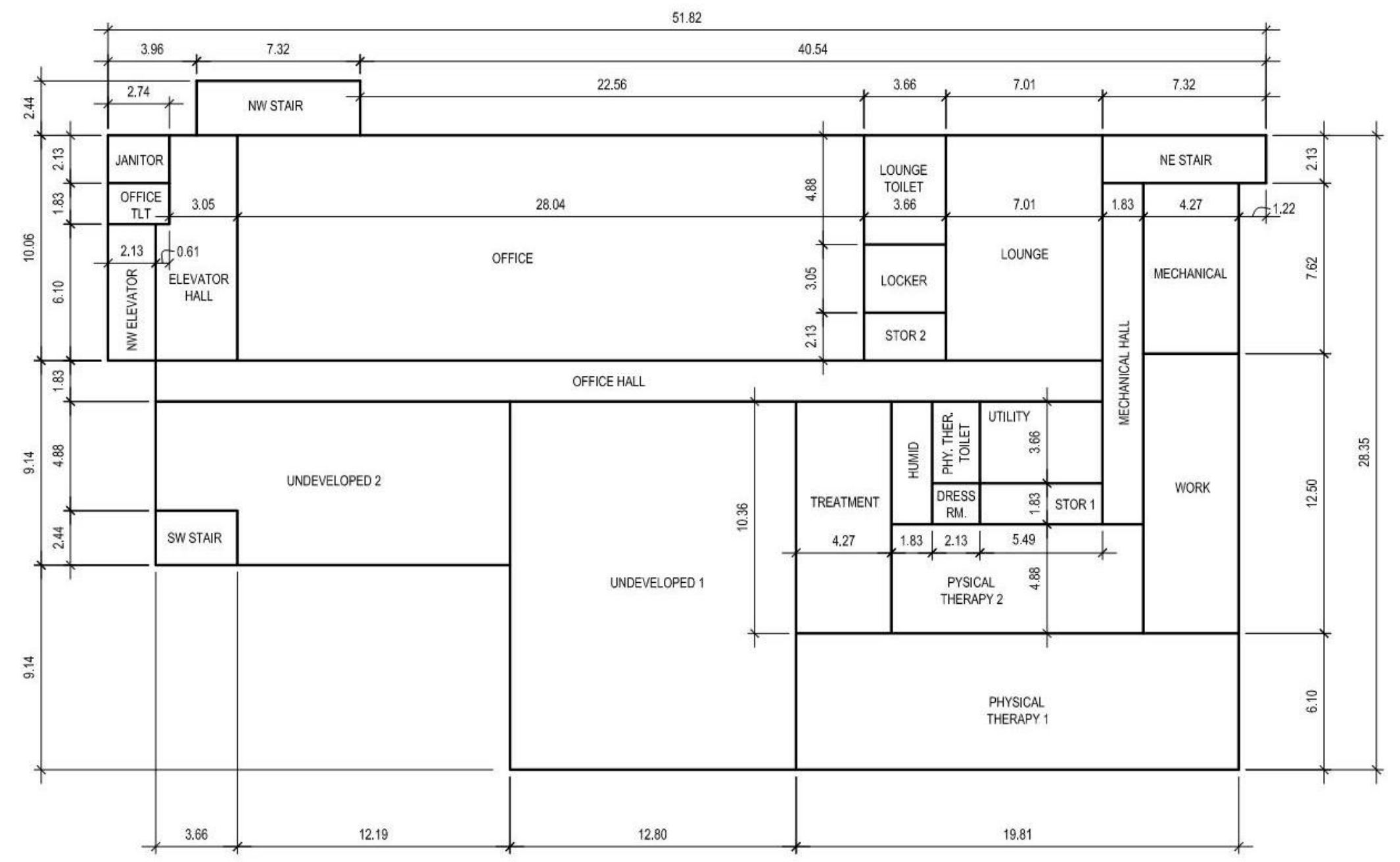

Figure 66. Third floor plan of Outpatient Health Care, all dimensions in meters 


\section{HVAC systems:}

The EnergyPlus model has two VAV (referred to as "AHU” systems here and in the models). One serves the first floor and the other serves the second and third floors. The design supply flow rate calculated by EnergyPlus for each VAV system is used as the supply flow rate for the constant-volume system modeled in CONTAM for simplicity. The system modeled in CONTAM is still referred to as a "VAV" system in the body of this text. Varying the supply flow rate can be implemented in CONTAM using controls and/or schedules by users who wish to do so. The supply air, return air, outside air, and exhaust flow rates modeled in CONTAM are listed in Table 33. In EnergyPlus, each HVAC system is assigned a minimum ventilation requirement and is modeled as such in CONTAM. For AHU 1, the minimum ventilation requirement is $1.82 \mathrm{~m}^{3} / \mathrm{s}$ and $1.90 \mathrm{~m}^{3} / \mathrm{s}$ for AHU 2 .

All of the exhaust flow rates (except for the "Toilet” zones) are modeled in EnergyPlus and CONTAM. The exhaust flow rates for the "Toilet" zones were modeled only in CONTAM, not in EnergyPlus. In CONTAM, the exhaust fans are modeled either as direct (on an exterior wall) exhaust fans or using ducts, depending on whether the room has an exterior wall.

The EnergyPlus model specifies a constant rate of air exchange between several zones that have no local exhaust. These zones also have no mechanical supply air. Thus, this is a method to drive air movement in the building. In CONTAM, this is done by pressurizing the building and allowing some transfer air to occur through natural driving forces and transfer grilles.

In EnergyPlus, balanced HVAC systems are modeled in all zones. In an attempt achieve building pressurization in CONTAM, less air is returned than is supplied to each zone. The return airflow rate is set to $90 \%$ of the supply airflow rate. In CONTAM, only the MRI Room is neutrally pressurized. The return airflow rate is the supply airflow rate minus the exhaust rate.

\section{HVAC Schedules:}

The AHU 1 and first floor exhaust fans operate on the following schedule:

- Weekdays: 4:00 a.m. to 9:00 p.m., off otherwise

- Saturdays: 4:00 a.m. to 9:00 p.m., off otherwise

- Sundays and holidays: off all day 
Outside air for AHU 1 is supplied according to this schedule as well.

The AHU 2 and second and third floor exhaust fans operate on the following schedule:

- Weekdays: 6:00 a.m. to 6:00 p.m., off otherwise

- Saturdays: 6:00 a.m. to 6:00 p.m., off otherwise

- Sundays and holidays: off all day

Outside air for AHU 2 is supplied according to this schedule as well.

Table 33. Summary of VAV system flow rates $\left(\mathrm{m}^{3} / \mathrm{s}\right)$ in Outpatient Healthcare

\begin{tabular}{llrrrr}
\hline Zone & Floor & Supply & Return & Outside air & Exhaust air \\
\hline Anesthesia & 1 & 0.08 & 0.07 & 0.01 & 0.07 \\
Bio Hazard & 1 & 0.01 & 0.01 & 0.01 & 0.00 \\
Café & 1 & 0.43 & 0.39 & 0.07 & 0.00 \\
Clean & 1 & 0.06 & 0.05 & 0.01 & 0.00 \\
Clean Work & 1 & 0.08 & 0.07 & 0.01 & 0.00 \\
Dictation & 1 & 0.03 & 0.03 & 0.01 & 0.00 \\
Dressing Room & 1 & 0.04 & 0.04 & 0.01 & 0.00 \\
Electrical Room & 1 & N/A & N/A & 0.00 & 0.00 \\
Elevator Pump Room & 1 & N/A & N/A & 0.00 & 0.00 \\
Humid & 1 & 0.02 & 0.01 & 0.00 & 0.00 \\
IT Hall & 1 & 0.02 & 0.02 & 0.00 & 0.00 \\
IT Room & 1 & 0.03 & 0.03 & 0.01 & 0.00 \\
Lobby & 1 & 0.53 & 0.47 & 0.09 & 0.00 \\
Lobby Hall & 1 & 0.03 & 0.03 & 0.01 & 0.00 \\
Lobby Toilet & 1 & N/A & N/A & 0.00 & 0.04 \\
Locker Room & 1 & 0.35 & 0.32 & 0.06 & 0.00 \\
Locker Room Hall & 1 & 0.07 & 0.06 & 0.01 & 0.00 \\
Lounge & 1 & 0.18 & 0.16 & 0.03 & 0.00 \\
Med Gas & 1 & 0.05 & 0.05 & 0.01 & 0.00 \\
MRI Control Room & 1 & 0.08 & 0.07 & 0.01 & 0.08 \\
MRI Hall & 1 & 0.02 & 0.02 & 0.00 & 0.00 \\
MRI Room & 1 & 2.39 & 2.18 & 0.38 & 0.21 \\
MRI Toilet & 1 & N/A & N/A & 0.00 & 0.04 \\
Nourishment & 1 & 0.09 & 0.08 & 0.01 & 0.00 \\
Nurse Hall & 1 & 0.07 & 0.06 & 0.01 & 0.00 \\
Nurse Janitor & 1 & N/A & N/A & 0.00 & 0.00 \\
Nurse Station & 1 & 0.12 & 0.11 & 0.02 & 0.00 \\
Nurse Toilet & 1 & N/A & N/A & 0.00 & 0.04 \\
Office & 1 & 0.12 & 0.11 & 0.02 & 0.00 \\
Operating Room 1 & 1 & 1.11 & 1.00 & 0.21 & 0.00 \\
Operating Room 2 & 1 & 1.18 & 1.06 & 0.22 & 0.00 \\
Operating Room 3 & 1 & 0.97 & 0.87 & 0.18 & 0.00 \\
PACU & 1 & 0.06 & 0.06 & 0.01 & 0.00 \\
Pre-Op Hall & 1 & 0.07 & 0.06 & 0.01 & 0.00 \\
Pre-Op Room 1 & 1 & 0.09 & 0.08 & 0.01 & 0.00 \\
Pre-Op Room 2 & 1 & 0.16 & 0.14 & 0.03 & 0.00
\end{tabular}




\begin{tabular}{|c|c|c|c|c|c|}
\hline Zone & Floor & Supply & Return & Outside air & Exhaust air \\
\hline Pre-Op Toilet & 1 & $\mathrm{~N} / \mathrm{A}$ & $\mathrm{N} / \mathrm{A}$ & 0.00 & 0.04 \\
\hline Procedure Room & 1 & 0.34 & 0.30 & 0.05 & 0.00 \\
\hline Reception & 1 & 0.26 & 0.23 & 0.04 & 0.00 \\
\hline Reception Hall & 1 & 0.02 & 0.02 & 0.00 & 0.00 \\
\hline Recovery Room & 1 & 0.38 & 0.34 & 0.07 & 0.00 \\
\hline Scheduling & 1 & 0.04 & 0.04 & 0.01 & 0.00 \\
\hline Scrub & 1 & 0.01 & 0.01 & 0.00 & 0.00 \\
\hline Soil & 1 & 0.10 & 0.09 & 0.02 & 0.10 \\
\hline Soil Hold & 1 & 0.04 & 0.04 & 0.01 & 0.04 \\
\hline Soil Work & 1 & 0.14 & 0.13 & 0.02 & 0.14 \\
\hline Step Down & 1 & 0.27 & 0.24 & 0.05 & 0.00 \\
\hline Sterile Hall & 1 & 0.10 & 0.09 & 0.01 & 0.00 \\
\hline Sterile Storage & 1 & 0.03 & 0.03 & 0.01 & 0.00 \\
\hline Storage & 1 & N/A & N/A & 0.00 & 0.00 \\
\hline Sub-Sterile & 1 & 0.09 & 0.08 & 0.02 & 0.00 \\
\hline Utility Hall & 1 & 0.14 & 0.13 & 0.03 & 0.00 \\
\hline Utility Janitor & 1 & N/A & N/A & 0.00 & 0.00 \\
\hline Utility Room & 1 & N/A & N/A & 0.00 & 0.00 \\
\hline Vestibule & 1 & 0.07 & 0.06 & 0.01 & 0.00 \\
\hline AHU 1 Total & & 10.55 & 9.52 & 1.82 & \\
\hline Conference & 2 & 0.36 & 0.33 & 0.06 & 0.00 \\
\hline Conference Toilet & 2 & N/A & N/A & 0.00 & 0.05 \\
\hline Dictation & 2 & 0.03 & 0.03 & 0.01 & 0.00 \\
\hline Exam 1 & 2 & 0.44 & 0.40 & 0.07 & 0.00 \\
\hline Exam 2 & 2 & 0.33 & 0.30 & 0.05 & 0.00 \\
\hline Exam 3 & 2 & 0.44 & 0.40 & 0.07 & 0.00 \\
\hline Exam 4 & 2 & 0.07 & 0.06 & 0.01 & 0.00 \\
\hline Exam 5 & 2 & 0.33 & 0.30 & 0.05 & 0.00 \\
\hline Exam 6 & 2 & 0.16 & 0.14 & 0.03 & 0.00 \\
\hline Exam 7 & 2 & 0.45 & 0.41 & 0.07 & 0.00 \\
\hline Exam 8 & 2 & 0.18 & 0.16 & 0.03 & 0.00 \\
\hline Exam 9 & 2 & 0.23 & 0.21 & 0.04 & 0.00 \\
\hline Exam Hall 1 & 2 & 0.05 & 0.04 & 0.01 & 0.00 \\
\hline Exam Hall 2 & 2 & 0.05 & 0.04 & 0.01 & 0.00 \\
\hline Exam Hall 3 & 2 & 0.05 & 0.04 & 0.01 & 0.00 \\
\hline Exam Hall 4 & 2 & 0.05 & 0.05 & 0.01 & 0.00 \\
\hline Exam Hall 5 & 2 & 0.05 & 0.05 & 0.01 & 0.00 \\
\hline Exam Hall 6 & 2 & 0.05 & 0.05 & 0.01 & 0.00 \\
\hline Janitor & 2 & N/A & N/A & 0.00 & 0.00 \\
\hline Lounge & 2 & 0.06 & 0.05 & 0.01 & 0.00 \\
\hline Nurse Station 1 & 2 & 0.09 & 0.08 & 0.02 & 0.00 \\
\hline Nurse Station 2 & 2 & 0.11 & 0.10 & 0.02 & 0.00 \\
\hline Office & 2 & 0.42 & 0.38 & 0.07 & 0.00 \\
\hline Office Hall & 2 & 0.12 & 0.11 & 0.02 & 0.00 \\
\hline Reception & 2 & 0.87 & 0.78 & 0.13 & 0.00 \\
\hline Reception Hall & 2 & 0.24 & 0.22 & 0.04 & 0.00 \\
\hline Reception Toilet & 2 & N/A & N/A & 0.00 & 0.10 \\
\hline Scheduling 1 & 2 & 0.12 & 0.11 & 0.02 & 0.00 \\
\hline Scheduling 2 & 2 & 0.13 & 0.12 & 0.02 & 0.00 \\
\hline
\end{tabular}




\begin{tabular}{lcrrrr}
\hline Zone & Floor & Supply & Return & Outside air & Exhaust air \\
\hline Storage 1 & 2 & N/A & N/A & 0.00 & 0.00 \\
Storage 2 & 2 & N/A & N/A & 0.00 & 0.00 \\
Storage 3 & 2 & N/A & N/A & 0.00 & 0.00 \\
Utility & 2 & N/A & N/A & 0.00 & 0.00 \\
Work & 2 & 0.67 & 0.60 & 0.11 & 0.00 \\
Work Hall & 2 & 0.21 & 0.19 & 0.03 & 0.00 \\
Work Toilet & 2 & N/A & N/A & 0.00 & 0.04 \\
X-Ray & 2 & 0.43 & 0.38 & 0.07 & 0.00 \\
Dressing Room & 3 & 0.02 & 0.02 & 0.00 & 0.00 \\
Elevator Hall & 3 & 0.15 & 0.14 & 0.02 & 0.00 \\
Humid & 3 & 0.05 & 0.05 & 0.01 & 0.00 \\
Janitor & 3 & N/A & N/A & 0.00 & 0.00 \\
Locker & 3 & 0.09 & 0.08 & 0.01 & 0.00 \\
Lounge & 3 & 0.62 & 0.56 & 0.09 & 0.00 \\
Lounge Toilet & 3 & N/A & N/A & 0.00 & 0.15 \\
Mechanical & 3 & N/A & N/A & 0.00 & 0.00 \\
Mechanical Hall & 3 & 0.11 & 0.10 & 0.02 & 0.00 \\
Office & 3 & 1.52 & 1.37 & 0.25 & 0.00 \\
Office Hall & 3 & 0.30 & 0.27 & 0.04 & 0.00 \\
Office Toilet & 3 & N/A & N/A & 0.00 & 0.04 \\
Physical Therapy 1 & 3 & 1.09 & 0.98 & 0.18 & 0.00 \\
Physical Therapy 2 & 3 & 0.36 & 0.33 & 0.06 & 0.00 \\
Physical Therapy Toilet & 3 & N/A & N/A & 0.00 & 0.07 \\
Storage 1 & 3 & N/A & N/A & 0.00 & 0.00 \\
Storage 2 & 3 & N/A & N/A & 0.00 & 0.00 \\
Treatment & 3 & 0.30 & 0.27 & 0.04 & 0.00 \\
Undeveloped 1 & 3 & N/A & N/A & 0.00 & 0.00 \\
Undeveloped 2 & 3 & N/A & N/A & 0.00 & 0.00 \\
Utility & 3 & N/A & N/A & 0.00 & 0.00 \\
Work & 3 & 0.44 & 0.39 & 0.07 & 0.00 \\
\hline AHU 2 Total & & $\mathbf{1 1 . 8 6}$ & $\mathbf{1 0 . 6 7}$ & $\mathbf{1 . 9 0}$ & \\
\hline & & & & & \\
\hline
\end{tabular}

\subsection{Warehouse}

Table 34 summarizes the zones modeled in CONTAM for the Warehouse, their respective sizes, and maximum occupancy.

Table 34. Summary of zones in Warehouse

\begin{tabular}{lrrr}
\hline Zone & Area $\mathbf{( m}^{\mathbf{2}} \mathbf{)}$ & Height $\mathbf{( m )}$ & Maximum occupancy \\
\hline Office & 233 & 4.27 & 5 \\
Fine Storage & 1393 & 8.53 & 0 \\
Bulk Storage & 3205 & 8.53 & 0 \\
Restroom & 4 & 4.27 & 0 \\
\hline
\end{tabular}




\section{Occupants:}

The peak number of people for each zone is listed in Table 34. Occupants in all building zones are scheduled according to Figure 67. Only the Office is occupied. The occupancy schedule is the same for weekdays and Saturdays. Sundays and holidays are unoccupied.

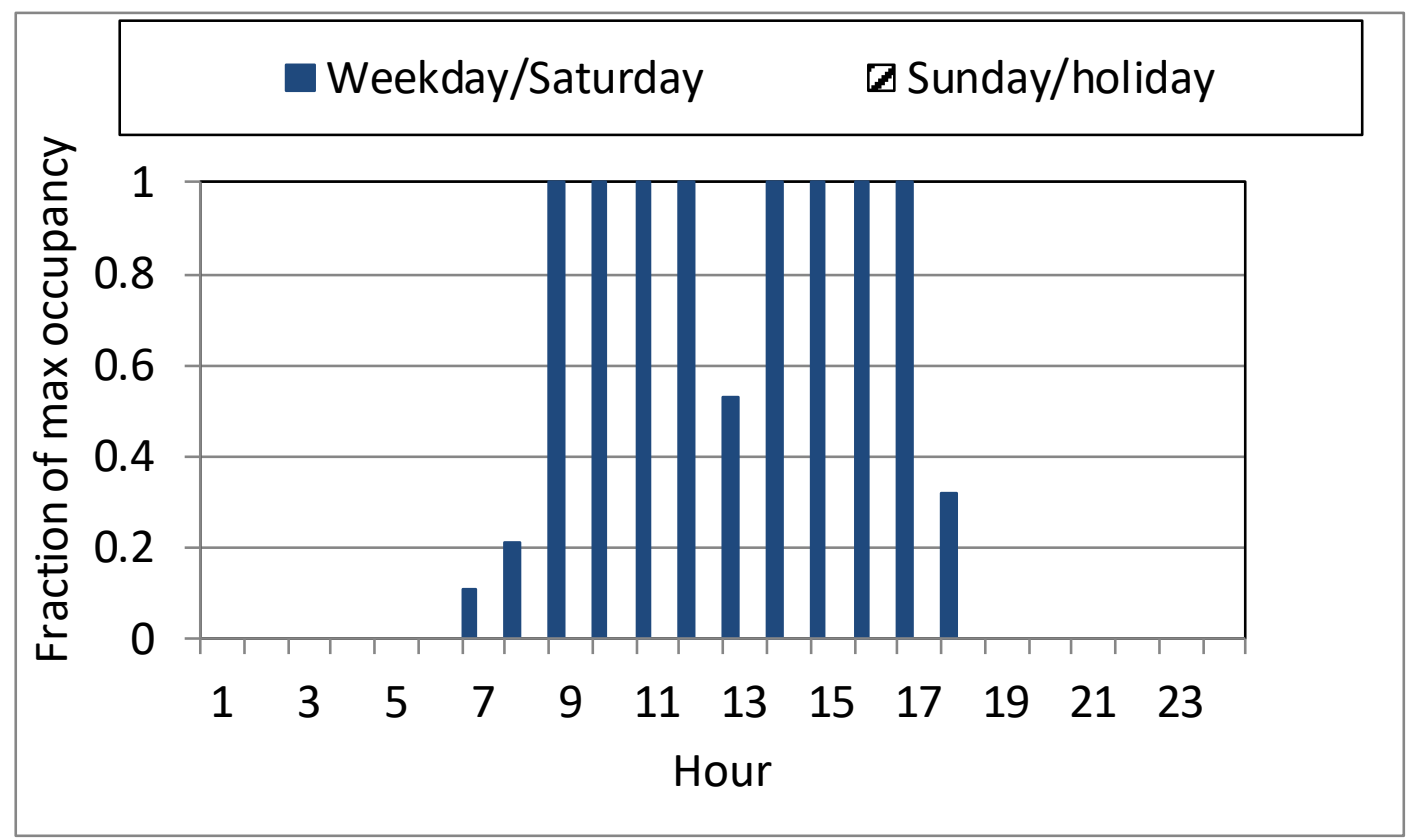

Figure 67. Occupancy schedule for Warehouse (Office zone)

\section{Geometry:}

$4598 \mathrm{~m}^{2}$ footprint, one-story building with flat roof. The EnergyPlus model has three zones.

Only the Office zone is $4.267 \mathrm{~m}$ high. The area above the Office is open to the Fine Storage, adding to the volume of that zone. The remaining zones are all $8.534 \mathrm{~m}$ high. In the CONTAM model, a Restroom (shaded in Figure 68) with a footprint of $2 \mathrm{~m} \times 2 \mathrm{~m}$ was carved out of the Office.

Large interior leakage paths were defined as follows:

- Between Bulk and Fine Storage zones, a single large leakage path of $32 \mathrm{~m}^{2}$ is modeled;

- Between Restroom and Office zones, a $0.025 \mathrm{~m}^{2}$ door undercut is modeled. 

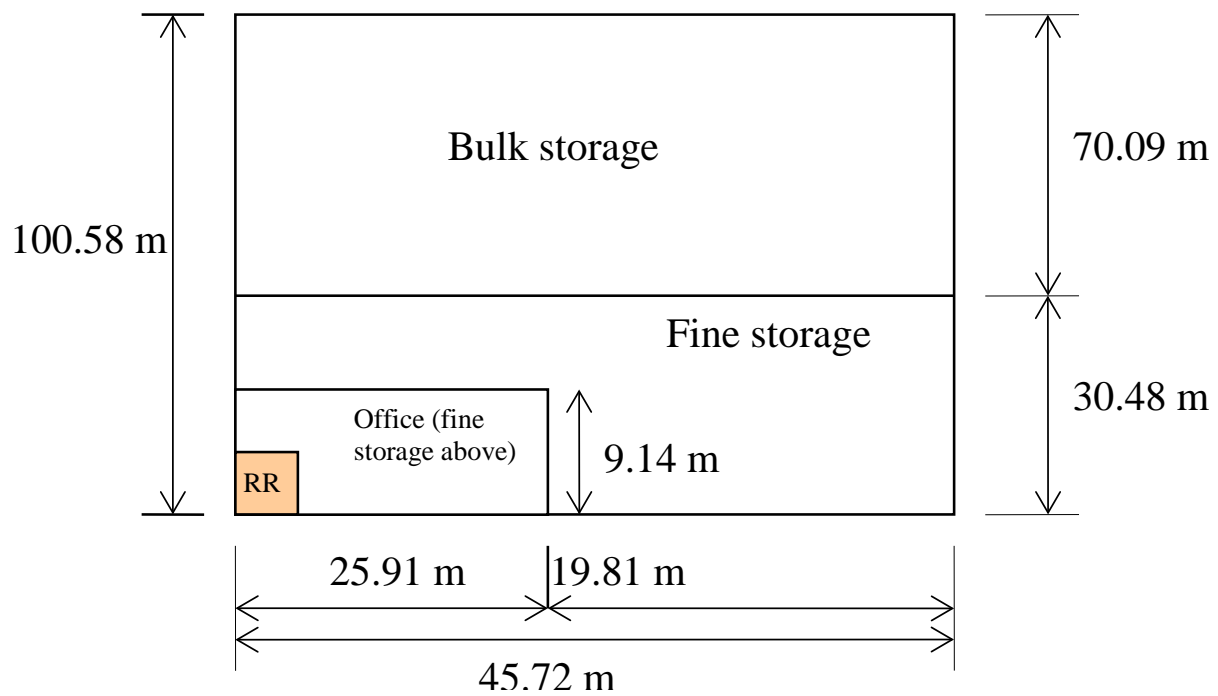

\section{Figure 68. Floor plan of Warehouse (height $8.534 \mathrm{~m}$, except for Office which is $4.267 \mathrm{~m}$ high)}

\section{HVAC systems:}

The EnergyPlus model has two CAV systems. One serves the Office and the other serves the Fine Storage zone. The supply air, return air, outside air, and exhaust flow rates modeled in CONTAM are listed in Table 35. The exhaust flow rate for the Restroom is modeled only in CONTAM, not in EnergyPlus.

The Bulk Storage also has a unit heater in EnergyPlus that recirculates air locally within the zone and does not impact whole-building airflow or introduce outside air. Therefore, the unit heater is not modeled in CONTAM.

In EnergyPlus, balanced HVAC systems are modeled in all zones. In an attempt achieve building pressurization in CONTAM, less air is returned than is supplied to each zone. The return airflow rate is equal to $90 \%$ of the supply airflow rate. The building is neutrally pressurized between 7:00 a.m. and 8:00 a.m. on weekdays and Saturdays when the system operates but no outside air is being supplied, which reflects the operation modeled in EnergyPlus. 
Table 35. Summary of CAV system flow rates $\left(\mathrm{m}^{3} / \mathrm{s}\right)$ in Warehouse

\begin{tabular}{lrrrr}
\hline Zone & Supply & Return & Outside air & Exhaust air \\
\hline Office & 1.44 & 1.30 & 0.10 & 0.00 \\
Fine Storage & 0.51 & 0.46 & 0.42 & 0.00 \\
Bulk Storage & N/A & N/A & N/A & 0.00 \\
Restroom & N/A & N/A & 0.00 & 0.03 \\
\hline
\end{tabular}

\section{HVAC Schedules:}

The HVAC and exhaust fans operate on the following schedule:

- Weekdays, Saturdays: 7:00 a.m. to 6:00 p.m., off otherwise

- Sundays and holidays: off all day

The outside air for the HVAC systems operates on the same schedules as those above except the start time is one hour later on all of them.

\section{Temperature setpoints:}

There are two thermostat setpoint schedules used in the EnergyPlus model of the Warehouse: Temp_Ofc for Office and Temp_FS for Fine Storage. For Temp_Ofc, the schedules changes for weekdays/Saturdays and Sundays/holidays (Figure 69). Temp_FS maintained a temperature of $15.6^{\circ} \mathrm{C}$ during the heating months and $29.4^{\circ} \mathrm{C}$ during the heating months. Bulk Storage did not have thermostat setpoints in the EnergyPlus model so it was maintained at $23{ }^{\circ} \mathrm{C}$ all year in the CONTAM model. Similarly, the Restroom was not in the EnergyPlus model so it was also maintained at $23^{\circ} \mathrm{C}$ all year in the CONTAM model. 


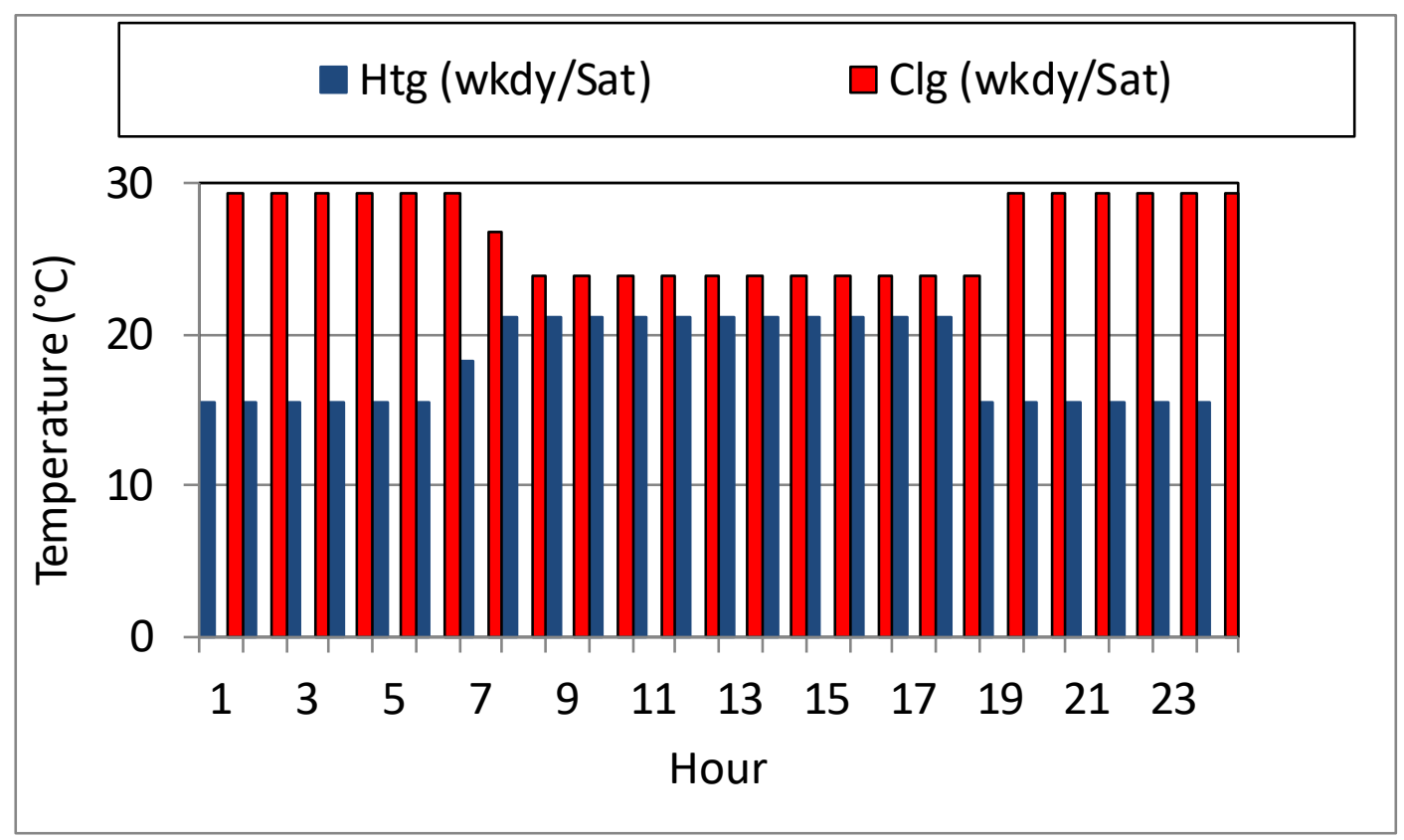

Figure 69. Thermostat setpoint schedule for Warehouse (Office zone)

\subsection{Midrise Apartment}

Table 36 summarizes the zones modeled in CONTAM for the Midrise Apartment, their respective sizes, maximum occupancy, and outside air rates.

\section{Occupants:}

The peak number of people for each zone is listed in Table 36. Occupants in all building zones are scheduled according to Figure 70. There are two different occupancy schedules. One schedule for the apartments, and one for the Office. The Office is unoccupied on weekends and holidays. 
Table 36. Summary of zones in Midrise Apartment

\begin{tabular}{|c|c|c|c|c|}
\hline Zone & Floor & Area $\left(\mathrm{m}^{2}\right)$ & Height (m) & Occupants \\
\hline G SW APT & 1 & 88 & 3.05 & 2.5 \\
\hline G NW APT & 1 & 88 & 3.05 & 2.5 \\
\hline OFFICE & 1 & 88 & 3.05 & 1 \\
\hline G NE APT & 1 & 88 & 3.05 & 2.5 \\
\hline G N1 APT & 1 & 88 & 3.05 & 2.5 \\
\hline G N2 APT & 1 & 88 & 3.05 & 2.5 \\
\hline G S1 APT & 1 & 88 & 3.05 & 2.5 \\
\hline G S2 APT & 1 & 88 & 3.05 & 2.5 \\
\hline M SW APT & 2,3 & 88 & 3.05 & 2.5 \\
\hline M NW APT & 2,3 & 88 & 3.05 & 2.5 \\
\hline M SE APT & 2,3 & 88 & 3.05 & 2.5 \\
\hline M NE APT & 2,3 & 88 & 3.05 & 2.5 \\
\hline M N1 APT & 2,3 & 88 & 3.05 & 2.5 \\
\hline M N2 APT & 2,3 & 88 & 3.05 & 2.5 \\
\hline M S1 APT & 2,3 & 88 & 3.05 & 2.5 \\
\hline M S2 APT & 2,3 & 88 & 3.05 & 2.5 \\
\hline T SW APT & 4 & 88 & 3.05 & 2.5 \\
\hline T NW APT & 4 & 88 & 3.05 & 2.5 \\
\hline T SE APT & 4 & 88 & 3.05 & 2.5 \\
\hline T NE APT & 4 & 88 & 3.05 & 2.5 \\
\hline T N1 APT & 4 & 88 & 3.05 & 2.5 \\
\hline T N2 APT & 4 & 88 & 3.05 & 2.5 \\
\hline T S1 APT & 4 & 88 & 3.05 & 2.5 \\
\hline T S2 APT & 4 & 88 & 3.05 & 2.5 \\
\hline T CORRIDOR & 4 & 69 & 3.05 & 0 \\
\hline G CORRIDOR & 1 & 69 & 3.05 & 0 \\
\hline M CORRIDOR & 2,3 & 69 & 3.05 & 0 \\
\hline Stairwell & $1-4$ & 8 & 3.05 & 0 \\
\hline Elevator shaft & $1-4$ & 8 & 3.05 & 0 \\
\hline
\end{tabular}

Note: The "G" means ground, "M" means middle, and "T" means top. "APT" is apartment. 


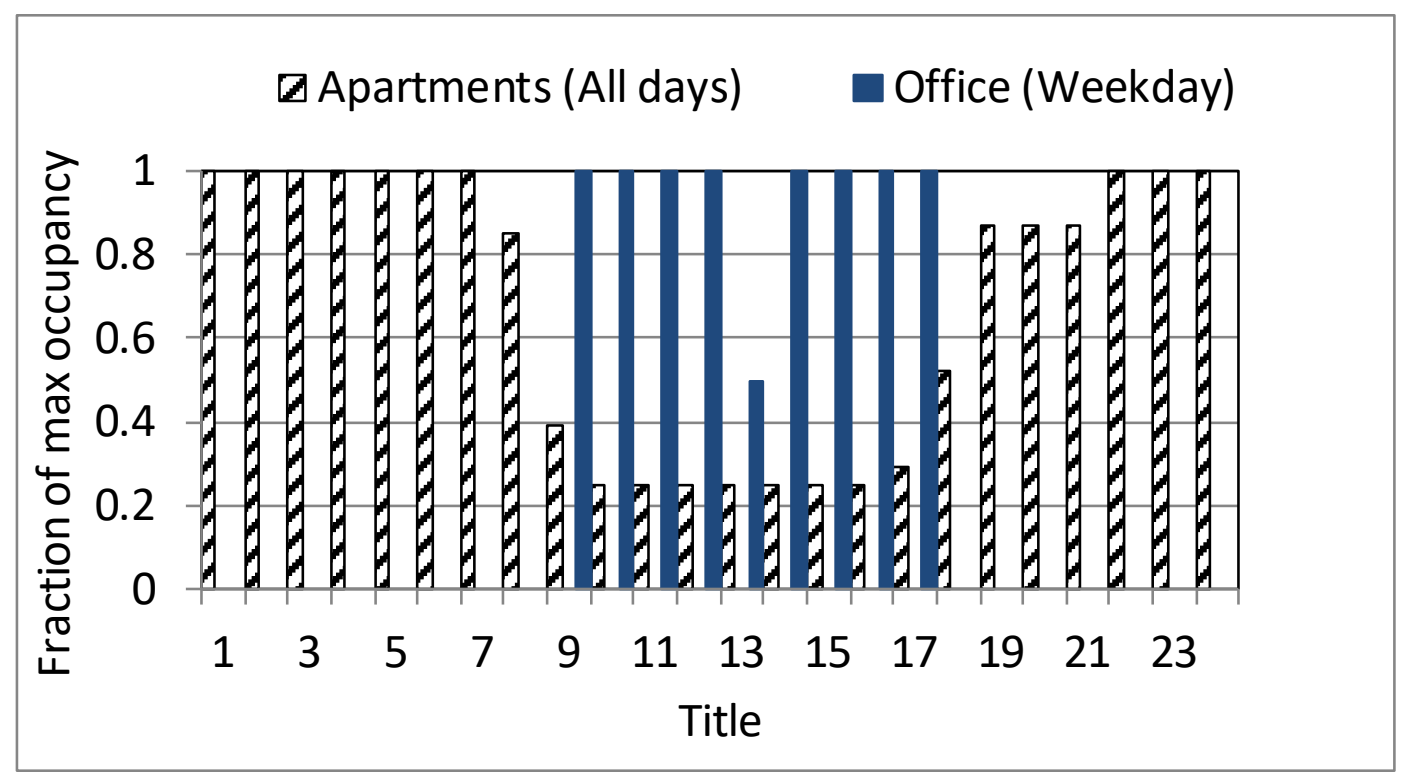

Figure 70. Occupancy schedules for Midrise Apartment

\section{Geometry:}

$784 \mathrm{~m}^{2}$ footprint, four-story building with flat roof. The EnergyPlus model has 9 zones per floor. All floors have identical floor plans. In the CONTAM model, a Stairwell and Elevator Shaft (shaded in Figure 71) with footprints of $1.68 \mathrm{~m} \times 4.0 \mathrm{~m}$ each were carved out of the Corridors.

Large interior leakage paths were defined as follows:

- A stairwell is defined using CONTAM's stair shaft model for closed treads and zero people;

- An elevator shaft is defined using CONTAM's elevator shaft model.

\section{HVAC systems:}

The EnergyPlus model has 24 packaged single-zone constant-volume systems, each serving a zone. The supply air, return air and outside air modeled in CONTAM are listed in Table 37. There are no exhaust fans modeled in the EnergyPlus model of this building. Thus, this was reflected in the CONTAM model.

In EnergyPlus, the Corridors have a unit heater that recirculates air locally within the zone and does not impact whole-building airflow or introduce outside air. Therefore, they are not modeled in CONTAM. 
In EnergyPlus, balanced HVAC systems are modeled in all zones. Based on discussion with apartment designers, it is most realistic to model the Midrise Apartment with a balanced system in CONTAM as well.

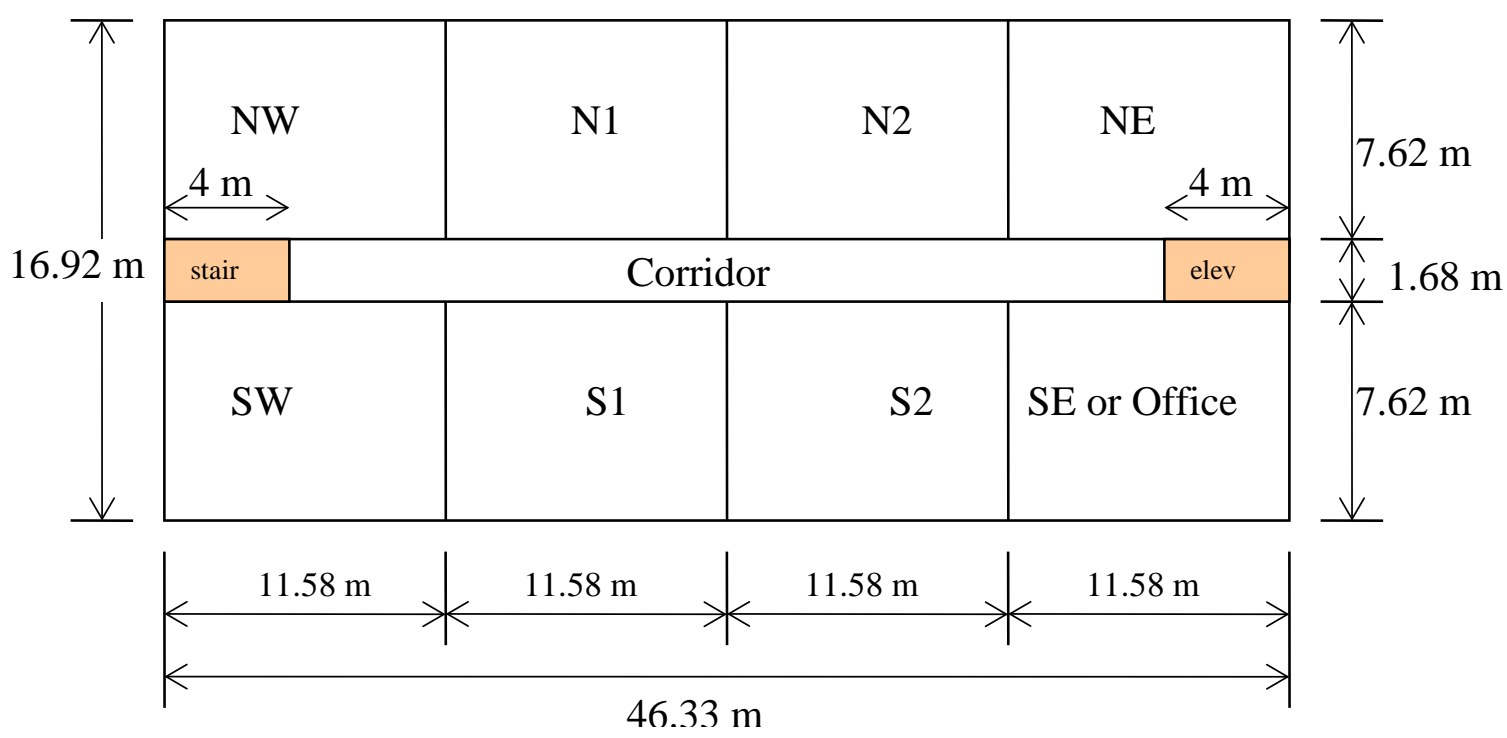

Figure 71. Floor plan of Midrise Apartment (height 3.05 m) 
Table 37. Summary of CAV system flow rates $\left(\mathrm{m}^{3} / \mathrm{s}\right)$ in Midrise Apartment

\begin{tabular}{llrrr}
\hline Zone & Floor & Supply & Return & Outside air \\
\hline G SW APT & 1 & 0.16 & 0.16 & 0.027 \\
G NW APT & 1 & 0.15 & 0.15 & 0.026 \\
OFFICE & 1 & 0.43 & 0.43 & 0.038 \\
G NE APT & 1 & 0.12 & 0.12 & 0.026 \\
G N1 APT & 1 & 0.09 & 0.09 & 0.026 \\
G N2 APT & 1 & 0.09 & 0.09 & 0.026 \\
G S1 APT & 1 & 0.10 & 0.10 & 0.024 \\
G S2 APT & 1 & 0.11 & 0.11 & 0.026 \\
M SW APT & 2,3 & 0.22 & 0.22 & 0.026 \\
M NW APT & 2,3 & 0.21 & 0.21 & 0.026 \\
M SE APT & 2,3 & 0.20 & 0.20 & 0.026 \\
M NE APT & 2,3 & 0.17 & 0.17 & 0.026 \\
M N1 APT & 2,3 & 0.13 & 0.13 & 0.026 \\
M N2 APT & 2,3 & 0.13 & 0.13 & 0.026 \\
M S1 APT & 2,3 & 0.15 & 0.15 & 0.026 \\
M S2 APT & 2,3 & 0.15 & 0.15 & 0.026 \\
T SW APT & 4 & 0.28 & 0.28 & 0.026 \\
T NW APT & 4 & 0.26 & 0.26 & 0.026 \\
T SE APT & 4 & 0.27 & 0.27 & 0.026 \\
T NE APT & 4 & 0.24 & 0.24 & 0.026 \\
T N1 APT & 4 & 0.19 & 0.19 & 0.026 \\
T N2 APT & 4 & 0.19 & 0.19 & 0.026 \\
T S1 APT & 4 & 0.22 & 0.22 & 0.026 \\
T S2 APT & 4 & 0.22 & 0.22 & 0.026 \\
T CORRIDOR & 4 & N/A & N/A & N/A \\
G CORRIDOR & 1 & N/A & N/A & N/A \\
M CORRIDOR & 2,3 & N/A & N/A & N/A \\
\hline
\end{tabular}

\section{HVAC Schedules:}

All the HVAC system fans operate 24 hours per day every day of the year. Outside air is also supplied 24 hours per day for the apartments and office.

\section{Temperature setpoints:}

There are two thermostat setpoint schedules used in the EnergyPlus model of the Midrise Apartment: Temp_Apt for the apartments and Temp_Ofc for the Office. Temp_Apt maintained a temperature of $21.7^{\circ} \mathrm{C}$ during the heating months and $24.4^{\circ} \mathrm{C}$ during the cooling months. For Temp_Ofc, the schedule changes for weekdays (Figure 72). During the weekends/holidays, a temperature of $15.6{ }^{\circ} \mathrm{C}$ was maintained in the heating months and 29.4 ${ }^{\circ} \mathrm{C}$ was maintained in the cooling months. The Corridors did not have thermostat setpoints in the EnergyPlus model so it was maintained at $21^{\circ} \mathrm{C}$ during the heating months and $26{ }^{\circ} \mathrm{C}$ during the cooling months in the CONTAM model. The Stairwells and Elevator shafts were 
not in the EnergyPlus model so they were set to the outside temperature for every hour of the year in the CONTAM model.

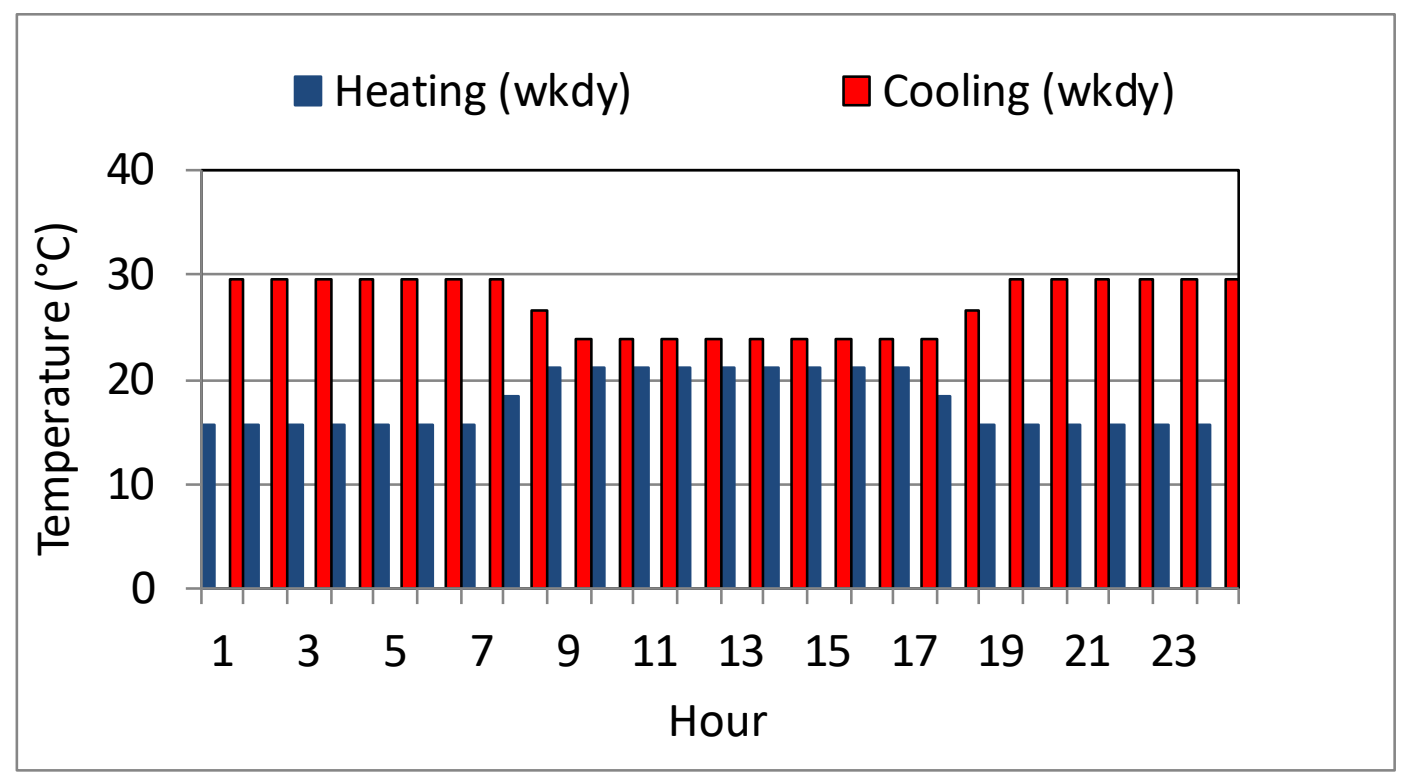

Figure 72. Thermostat setpoint schedule for Midrise Apartment (Office zone)

\subsection{Highrise Apartment}

The Highrise Apartment is a new building added to the prototype building models set released by DOE. Table 38 summarizes the zones modeled in CONTAM for the Highrise Apartment, their respective sizes, maximum occupancy, and outside air rates.

Table 38. Summary of zones in Highrise Apartment

\begin{tabular}{llrrr}
\hline Zone & Floor & Area $\left(\mathbf{m}^{2}\right)$ & Height $(\mathbf{m})$ & Occupants \\
\hline NW APT & $1-10$ & 89 & 3.05 & 2.5 \\
N1 APT & $1-10$ & 89 & 3.05 & 2.5 \\
N2 APT & $1-10$ & 89 & 3.05 & 2.5 \\
NE APT & $1-10$ & 89 & 3.05 & 2.5 \\
OFFICE (SE APT) $)^{b}$ & $1-10$ & 89 & 3.05 & $1(2.5)$ \\
S1 APT & $1-10$ & 89 & 3.05 & 2.5 \\
S2 APT & $1-10$ & 89 & 3.05 & 2.5 \\
SW APT & $1-10$ & 89 & 3.05 & 2.5 \\
CORRIDOR & $1-10$ & 70 & 3.05 & 0.0 \\
Stairwell & $1-10$ & 7 & 3.05 & 0.0 \\
Elevator shaft & $1-10$ & 7 & 3.05 & 0.0 \\
\hline
\end{tabular}

Note:

a. "APT” is apartment.

b. This zone is in the southeast corner of the Highrise Apartment. It is the Office zone on $1 \mathrm{~F}$ and SE APT on floors 2-10. The Office has an occupancy of 1 person and the SE APT has an occupancy of 2.5 people. 


\section{Occupants:}

The peak number of people for each zone is listed in Table 38. Occupants in all building zones are scheduled according to Figure 73. There are two different occupancy schedules. One schedule for the apartments, and one for the Office. The Office is unoccupied on weekends and holidays.

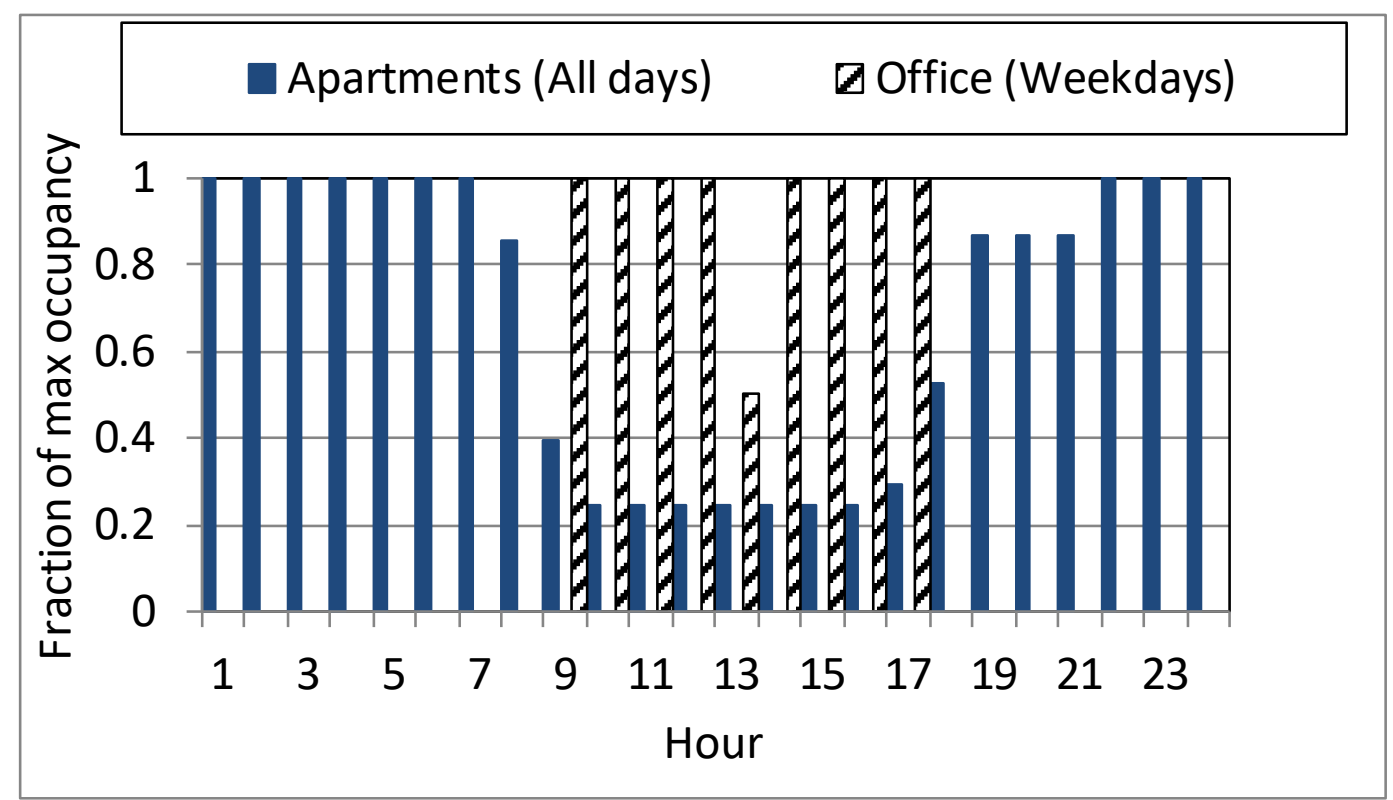

Figure 73. Occupancy schedules for Highrise Apartment

\section{Geometry:}

$794 \mathrm{~m}^{2}$ footprint, 10-story building with flat roof. The EnergyPlus model has 9 zones per floor. All floors have identical floor plans. In the CONTAM model, a Stairwell and Elevator Shaft (shaded in Figure 74) with footprints of $1.83 \mathrm{~m} \times 3.66 \mathrm{~m}$ each were carved out of the Corridors.

Large interior leakage paths were defined as follows:

- A stairwell is defined using CONTAM's stair shaft model for closed treads and zero people;

- An elevator shaft is defined using CONTAM's elevator shaft model. 


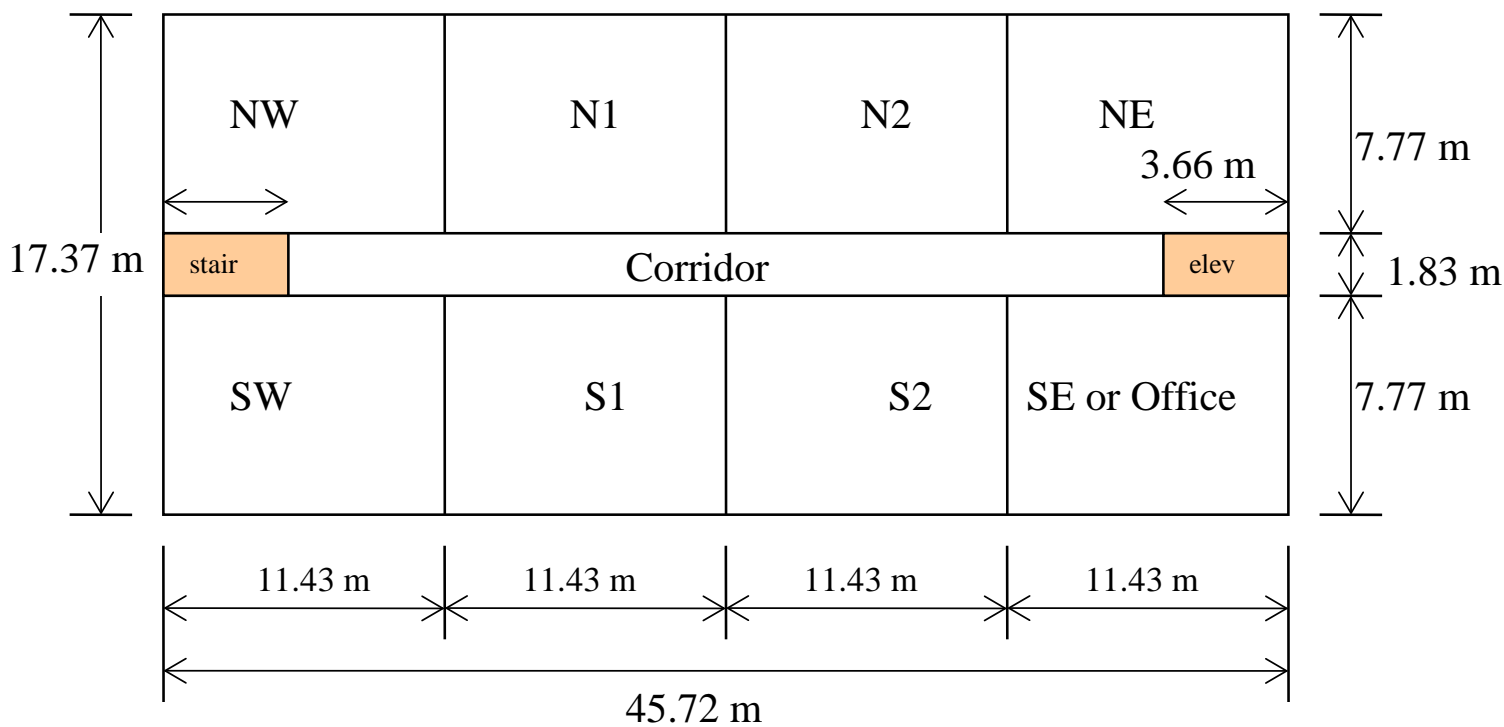

Figure 74. Floor plan of Highrise Apartment (height 3.05 m)

HVAC systems:

The EnergyPlus model has 80 packaged single-zone constant-volume systems, each serving a zone. The supply air, return air and outside air modeled in CONTAM are listed in Table 39. There are no exhaust fans modeled in the EnergyPlus model of this building. Thus, this was reflected in the CONTAM model.

In EnergyPlus, balanced HVAC systems are modeled in all zones. Based on discussion with apartment designers, it is most realistic to model the Highrise Apartment with a balanced system in CONTAM as well. It should be noted, however, that this will not take into account infiltration which varies around the building and thus affect the actual pressurization of the building.

HVAC Schedules:

All the HVAC system fans operate 24 hours per day every day of the year. Outside air is also supplied all of the time for the apartments and office. 
Table 39. Summary of CAV system flow rates $\left(\mathrm{m}^{3} / \mathrm{s}\right)$ in Highrise Apartment

\begin{tabular}{|c|c|c|c|c|}
\hline Zone & Floor & Supply & Return & Outside air \\
\hline NW APT & 1 & 0.20 & 0.20 & 0.03 \\
\hline N1 APT & 1 & 0.10 & 0.10 & 0.03 \\
\hline N2 APT & 1 & 0.10 & 0.10 & 0.03 \\
\hline NE APT & 1 & 0.15 & 0.15 & 0.03 \\
\hline OFFICE & 1 & 0.29 & 0.29 & 0.04 \\
\hline S1 APT & 1 & 0.13 & 0.13 & 0.03 \\
\hline S2 APT & 1 & 0.14 & 0.14 & 0.03 \\
\hline SW APT & 1 & 0.21 & 0.21 & 0.03 \\
\hline NW APT & 2 & 0.26 & 0.26 & 0.03 \\
\hline N1 APT & 2 & 0.14 & 0.14 & 0.03 \\
\hline N2 APT & 2 & 0.14 & 0.14 & 0.03 \\
\hline NE APT & 2 & 0.20 & 0.20 & 0.03 \\
\hline OFFICE & 2 & 0.26 & 0.26 & 0.03 \\
\hline S1 APT & 2 & 0.17 & 0.17 & 0.03 \\
\hline S2 APT & 2 & 0.18 & 0.18 & 0.03 \\
\hline SW APT & 2 & 0.27 & 0.27 & 0.03 \\
\hline NW APT & 3 & 0.26 & 0.26 & 0.03 \\
\hline N1 APT & 3 & 0.14 & 0.14 & 0.03 \\
\hline N2 APT & 3 & 0.14 & 0.14 & 0.03 \\
\hline NE APT & 3 & 0.21 & 0.21 & 0.03 \\
\hline OFFICE & 3 & 0.25 & 0.25 & 0.03 \\
\hline S1 APT & 3 & 0.18 & 0.18 & 0.03 \\
\hline S2 APT & 3 & 0.18 & 0.18 & 0.03 \\
\hline SW APT & 3 & 0.28 & 0.28 & 0.03 \\
\hline NW APT & 4 & 0.26 & 0.26 & 0.03 \\
\hline N1 APT & 4 & 0.14 & 0.14 & 0.03 \\
\hline N2 APT & 4 & 0.14 & 0.14 & 0.03 \\
\hline NE APT & 4 & 0.21 & 0.21 & 0.03 \\
\hline OFFICE & 4 & 0.24 & 0.24 & 0.03 \\
\hline S1 APT & 4 & 0.18 & 0.18 & 0.03 \\
\hline S2 APT & 4 & 0.18 & 0.18 & 0.03 \\
\hline SW APT & 4 & 0.28 & 0.28 & 0.03 \\
\hline NW APT & 5 & 0.26 & 0.26 & 0.03 \\
\hline N1 APT & 5 & 0.15 & 0.15 & 0.03 \\
\hline N2 APT & 5 & 0.14 & 0.14 & 0.03 \\
\hline NE APT & 5 & 0.21 & 0.21 & 0.03 \\
\hline OFFICE & 5 & 0.25 & 0.25 & 0.03 \\
\hline S1 APT & 5 & 0.18 & 0.18 & 0.03 \\
\hline S2 APT & 5 & 0.18 & 0.18 & 0.03 \\
\hline SW APT & 5 & 0.28 & 0.28 & 0.03 \\
\hline NW APT & 6 & 0.26 & 0.26 & 0.03 \\
\hline N1 APT & 6 & 0.14 & 0.14 & 0.03 \\
\hline N2 APT & 6 & 0.14 & 0.14 & 0.03 \\
\hline NE APT & 6 & 0.21 & 0.21 & 0.03 \\
\hline OFFICE & 6 & 0.24 & 0.24 & 0.03 \\
\hline S1 APT & 6 & 0.18 & 0.18 & 0.03 \\
\hline S2 APT & 6 & 0.18 & 0.18 & 0.03 \\
\hline
\end{tabular}




\begin{tabular}{llrrr}
\hline Zone & Floor & Supply & Return & Outside air \\
\hline SW APT & 6 & 0.28 & 0.28 & 0.03 \\
NW APT & 7 & 0.26 & 0.26 & 0.03 \\
N1 APT & 7 & 0.14 & 0.14 & 0.03 \\
N2 APT & 7 & 0.14 & 0.14 & 0.03 \\
NE APT & 7 & 0.20 & 0.20 & 0.03 \\
OFFICE & 7 & 0.24 & 0.24 & 0.03 \\
S1 APT & 7 & 0.18 & 0.18 & 0.03 \\
S2 APT & 7 & 0.18 & 0.18 & 0.03 \\
SW APT & 7 & 0.27 & 0.27 & 0.03 \\
NW APT & 8 & 0.26 & 0.26 & 0.03 \\
N1 APT & 8 & 0.14 & 0.14 & 0.03 \\
N2 APT & 8 & 0.14 & 0.14 & 0.03 \\
NE APT & 8 & 0.20 & 0.20 & 0.03 \\
OFFICE & 8 & 0.24 & 0.24 & 0.03 \\
S1 APT & 8 & 0.18 & 0.18 & 0.03 \\
S2 APT & 8 & 0.18 & 0.18 & 0.03 \\
SW APT & 8 & 0.27 & 0.27 & 0.03 \\
NW APT & 9 & 0.27 & 0.27 & 0.03 \\
N1 APT & 9 & 0.15 & 0.15 & 0.03 \\
N2 APT & 9 & 0.15 & 0.15 & 0.03 \\
NE APT & 9 & 0.21 & 0.21 & 0.03 \\
OFFICE & 9 & 0.25 & 0.25 & 0.03 \\
S1 APT & 9 & 0.18 & 0.18 & 0.03 \\
S2 APT & 9 & 0.18 & 0.18 & 0.03 \\
SW APT & 9 & 0.28 & 0.28 & 0.03 \\
NW APT & 10 & 0.31 & 0.31 & 0.03 \\
N1 APT & 10 & 0.17 & 0.17 & 0.03 \\
N2 APT & 10 & 0.17 & 0.17 & 0.03 \\
NE APT & 10 & 0.24 & 0.24 & 0.03 \\
OFFICE & 10 & 0.30 & 0.30 & 0.03 \\
S1 APT & 10 & 0.23 & 0.23 & 0.03 \\
S2 APT & 10 & 0.24 & 0.24 & 0.03 \\
SW APT & 10 & 0.33 & 0.33 & 0.03 \\
\hline & & & &
\end{tabular}

\section{Temperature setpoints:}

There are two thermostat setpoint schedules used in the EnergyPlus model of the Highrise Apartment: Temp_Apt for the apartments and Temp_Ofc for the Office. Temp_Apt maintained a temperature of $21.7^{\circ} \mathrm{C}$ during the heating months and $23.9^{\circ} \mathrm{C}$ during the cooling months. For Temp_Ofc, the schedule changes for weekdays (Figure 75). During the weekends/holidays, a temperature of $15.6{ }^{\circ} \mathrm{C}$ was maintained in the heating months, and 29.4 ${ }^{\circ} \mathrm{C}$ was maintained in the cooling months. The Corridors did not have thermostat setpoints in the EnergyPlus model so it was maintained at $22.1{ }^{\circ} \mathrm{C}$ during the heating months and $26.2{ }^{\circ} \mathrm{C}$ during the cooling months in the CONTAM model. The Stairwells and Elevator shafts were not in the EnergyPlus model so they were set to Corridor schedule in the CONTAM model. 


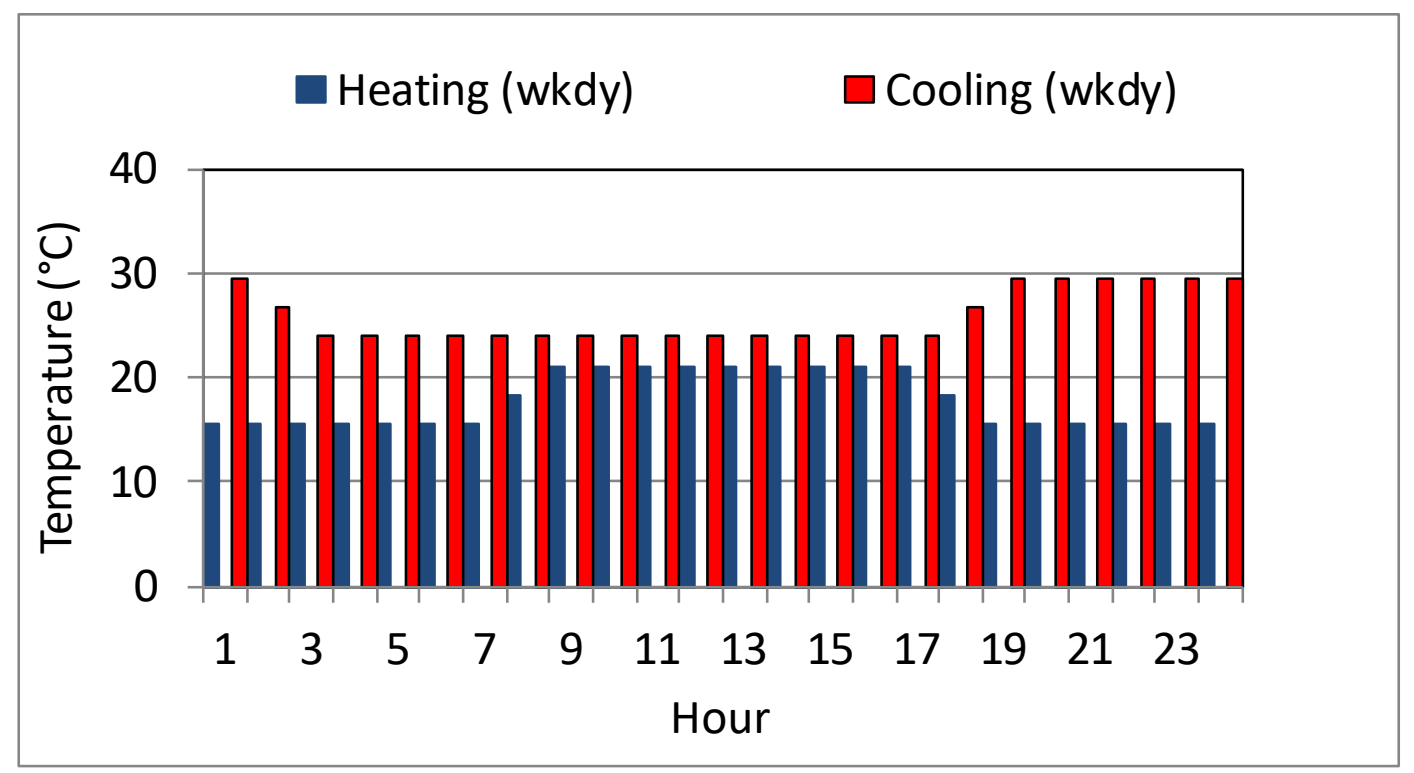

Figure 75. Thermostat setpoint schedule for Highrise Apartment (Office zone)

\section{Discussion}

\subsection{Building models for airflow and energy analyses}

While the development of CONTAM models of the prototype buildings furthers the ability to conduct simultaneous energy, airflow and contaminant transport simulations, it also reveals a number of challenges in doing so. One key issue is that building models developed for performing airflow and IAQ analyses employ different building representations and require different data than those used for energy analyses. CONTAM, and other multizone airflow and indoor air quality (IAQ) models, consider buildings as networks of interconnected zones. Airflow rates are then calculated based on physical relationships between flow and pressure analogous to the relationship between heat transfer and temperature differences in energy models. Thus, it is important that multizone building airflow models capture the geometry of the whole building, its weather exposure, interzone leakages, and ventilation system airflows. In contrast, building models for energy analysis are focused on accounting for thermal loads of different building zones, system efficiencies in meeting these loads, and selecting equipment types and sizes. As discussed below, the zones used in energy calculations are therefore based on the similarity and differences between their thermal loads, while the zones used in airflow modeling are based on pressure relationships and differences in ventilation airflows. 
For example, zones with small or insignificant thermal loads, such as stairwells, elevator shafts, and restrooms, are often not included in energy models. However, stairwells and elevators shafts need to be included in multizone models because they have a major effect on building pressure relationships and constitute important airflow paths between zones, particularly in taller buildings. In addition, zones, even floors, with similar thermal loads are often "multiplied" in energy models to simplify model inputs. Such spaces are input once and the resulting loads are multiplied without modeling the individual interior spaces. In multizone models, however, each zone and floor must be modeled separately to account for horizontal air movement and contaminant transport and for the effects of elevation on airflow and contaminant transport.

In addition to different approaches to building zoning, another key difference between airflow and energy models is how they manage airflow balances and interzone airflow. EnergyPlus generally maintains a balance between the ventilation flows into (supply) and out of (return and exhaust) each zone. Interzone airflows are sometimes input, but a net airflow balance between entering and leaving air is maintained for each zone. Infiltration airflows are not part of this balance but are considered only as they impact the thermal loads of the zone. In contrast, CONTAM and other multizone airflow models use the mass balance of air for each zone to determine the amount of infiltration and exfiltration for each zone to the outdoors and/or adjacent zones. Therefore, the system flows are an input while temperature differences and wind pressures serve as boundary conditions, which in conjunction with leakage values of the zone boundaries are used determine these infiltration and exfiltration flows.

For example, equal airflows are specified between dining and kitchen zones in the EnergyPlus models of the restaurants. The value of this interzone airflow is based on minimum ventilation requirements for these zones, but does not reflect the actual physics driving the airflow. In contrast, CONTAM and other airflow models calculate this airflow based on the interzone pressure difference across the openings between the zones.

Another difference is the manner in which energy and airflow models manage the common practice in commercial building design of maintaining an excess of supply over return airflow to reduce envelope infiltration. As noted above, energy models maintain a net 
balance between incoming and outgoing ventilation airflows, so an excess of supply air is not reflected in these models. Airflow models on the other hand need to consider these ventilation airflow differences, as they are key in determining building pressure relationships. It's worth noting that while the EnergyPlus models included kitchens with their excess exhaust flow, that flow did not impact the building airflow dynamics. CONTAM, on the other hand, included both kitchen and restroom exhausts and calculated their impacts on building pressures and airflows. Spaces with local exhaust flows must also be included as separate zones to properly account for their effects on building pressures.

The most important differences in how multizone and energy building models handle infiltration. The infiltration rates in the EnergyPlus models are input assuming that the indoor-outdoor pressure differences are always 4 Pa, i.e., air enters the buildings at all points on the exterior envelope. Although the EnergyPlus models of the prototype buildings do model infiltration that varies with wind speed, the effects of indoor-outdoor temperature differences are not included. This does not reflect the physical dependence of infiltration on weather conditions. Thus, a more accurate treatment of infiltration should be applied to EnergyPlus models and building energy simulation in general. As an alternative to performing multizone analysis using tools like CONTAM, simple empirical relationships between infiltration rates, airtightness, system operation and weather have been developed for use in energy simulation [21, 22]. The studies showed that using CONTAM results to develop weather-correlated infiltration inputs resulted in annual increases of $3 \%$ and $8 \%$ respectively in annual HVAC electrical and gas use over using the infiltration models included in the original EnergyPlus models (Sec. 3.2). There are Open Studio Measures available to implement these correlations (https://bcl.nrel.gov/search/site/nist\%20infiltration). Another alternative approach is to utilize the CONTAM Results Export Tool [43] to convert CONTAM infiltration rates to schedules that can be used in EnergyPlus simulations, which have been applied in the development of an online airtightness savings calculator [23, 24].

\subsection{Limitations of CONTAM models}

The CONTAM models of the prototype buildings provide important tools to evaluate the ventilation and IAQ performance of various building and system design options in conjunction with EnergyPlus analyses. However, there are a number of limitations to the CONTAM models that need to be considered and potentially addressed in the future. As 
discussed in Sec. 3.3, to simplify CONTAM modeling, the maximum supply airflow rates calculated by EnergyPlus were used in the CONTAM models. Therefore, variable-air volume (VAV) system effects were not included. Also, the CONTAM simulations maintained a constant indoor temperature and used the minimum amount of outdoor ventilation air specified in EnergyPlus for each zone (or HVAC system) with no economizer cycle. Thus, future applications of CONTAM to these models may consider varying supply airflow rates, varying indoor temperatures, and economizer operation.

It is also important to note that the interdependence between airflow and heat transfer cannot be fully captured by performing independent airflow and thermal simulations, which is especially important for modeling natural or hybrid ventilation approaches. Current methods of coupling airflow-thermal simulations include dynamic, quasi-dynamic, or fullysimultaneous [9, 25, 27]. Dynamic coupling passes airflow and temperature values between two modules within each time step until convergence is obtained. Quasi-dynamic coupling passes airflow and temperature values between simultaneously running processes only once within each time step. Lastly, fully-simultaneous coupling solves the airflow and energy equations within a co-dependent regime. Fully- simultaneous coupling is the most computationally intensive of the three coupling methods but may more accurately capture the airflow-thermal interactions. The most appropriate coupling method depends in part to the degree with which the airflow-thermal problem is coupled. The more highly coupled the interaction, such as in naturally ventilated buildings where large temperature gradients may exist and are important drivers of airflow, the more sophisticated the coupling method will need to be. Other important factors in selecting an appropriate airflow-thermal coupling method include: achievable convergence of airflow and thermal values, and the differences in time scales between the airflow (on the order of minutes or hours) and thermal (on the order of seconds to hours) problem. Wang, Dols and Emmerich (44) presented a fully-simultaneous coupling method and compared its performance to a quasi-dynamic simulation for a buoyancy-driven problem. The study found numerical instabilities with the quasi-dynamic method. The fully-simultaneous coupling method was not subject to these instabilities for the case studied and with reduced computational cost. Katal, et al. (45) tested various fullysimultaneous, semi-simultaneous, and segregated strategies on an analytical case, a threezone case and a light well (natural ventilation) test case. The semi-simultaneous coupling 
solves the airflow and energy equations for one zone in an internal loop and repeats this for all zones in sequence. The segregated coupling solves the airflow equations for all zones, they are provided to the energy equations and then temperatures calculated for all zones. They found that the fluctuations in the solutions existed for the -simultaneous and semisimultaneous solvers. There was good convergence for the segregated solver. Dols, Emmerich and Polidoro (25) verified the co-simulation between CONTAM and EnergyPlus using a three-zone analytical test case, and a comparison between the co-simulation and the Airflow Network capability of EnergyPlus was performed that revealed limitations of the methods. Other applications of co-simulation between CONTAM and EnergyPlus have been demonstrated to evaluate both energy and IAQ in both residential and commercial buildings [46-48].

\subsection{Future work}

The EnergyPlus and CONTAM models of the prototype buildings serve as baseline cases, which can be used in future analyses to support the design and implementation of strategies to simultaneously reduce building energy use while maintaining or improving IAQ, such as alternative ventilation approaches, enhanced filtration and contaminant source control. Among these ventilation approaches, heat recovery ventilation can maintain outdoor air ventilation rates while providing "free” heat exchange between warmer air returned to the system and colder air entering from outdoors in the winter. Demand control ventilation can reduce outdoor air ventilation rates during periods of low occupancy, thus reducing the energy required to condition outdoor air. Economizer operation can increase outdoor air ventilation while also reducing the amount of mechanical cooling when weather conditions and outdoor air quality are suitable. Source control and enhanced filtration also have the potential to improve IAQ while potentially reducing energy use if ventilation rates can be decreased. Natural and hybrid (or mixed mode) ventilation also has the potential to simultaneously reduce energy consumption and improve IAQ, however the analysis of these and other approaches can be limited by the inability of current simulation tools to model building airflow and contaminants in a physically reasonable fashion.

\section{Conclusion}

The reference buildings created by DOE in EnergyPlus are intended for assessing new technologies and developing energy codes. Since the release of the DOE reference building 
models, updates have been made so that the modeled buildings comply with newer versions of ASHRAE Standard 90.1 Energy Standard for Buildings Except Low-Rise Residential Buildings and the International Energy Conservation Code (IECC). However, infiltration rates were assumed in the models (not calculated), which may have a substantial impact on predicted energy impacts of some of these technologies. Also, the limited ability of EnergyPlus to model contaminant transport greatly limits the ability to assess the impact of these technologies on IAQ. Based on these limitations, CONTAM models of the 16 prototype buildings were created (and updated as outlined in this report) in order to perform airflow and IAQ analyses. All CONTAM models of the prototype buildings required updates to the building envelope airtightness, ventilation airflow rates, ventilation system operation, occupancy, and thermostat setpoint schedules. The EnergyPlus and CONTAM models of the prototype buildings serve as baseline cases, which will be useful in future analyses to support the design and implementation of alternative ventilation and IAQ control approaches that can simultaneously reduce building energy use while maintaining if not improving IAQ.

\section{Acknowledgments}

The authors would like to thank the NIST Pathways students that have contributed to the updates of the CONTAM models: Nelson Ojeda Quiles, Lindsey Kinser, and Gabe Grajewski. Without their hard work and attention to detail, this work would not have been accomplished.

\section{References}

[1] Ng LC, Musser A, Emmerich SJ, Persily AK (2012) Airflow and Indoor Air Quality Models of DOE Reference Commercial Buildings. (National Institute of Standards and Technology, Gaithersburg, MD).

[2] Deru M, Field K, Studer D, Benne K, Griffith B, Torcellini P, Liu B, Halverson M, Winiarski D, Rosenberg M, Yazdanian M, Huang J, Crawley D (2011) U.S. Department of Energy Commercial Reference Building Models of the National Building Stock. (National Renewable Energy Laboratory, Colorado), February 2011.

[3] ASHRAE (2013) ANSI/ASHRAE/IES Standard 90.1-2013: Energy Standard for Buildings Except Low-Rise Residential Buildings. (American Society of Heating, Refrigerating and Air-Conditioning Engineers, Atlanta).

[4] ICC (2015)- International Energy Conservation Code (International Code Council, Washington, D. C.). 
[5] Goel S, Athalye R, Wang W, Zhang J, Rosenberg M, Xie Y, Hart R, Mendon V (2014) Enhancements to ASHRAE Standard 90.1 Prototype Building Models. (Pacific Northwest National Laboratory, Richland, WA).

[6] DOE (2010) Building Energy Data Book (U.S. Department of Energy, Washington), p 245.

[7] DOE (2008) Building Technologies Program 2008 Multi-Year Program Plan (U. S. Department of Energy, Washington, DC). Available at http://www1.eere.energy.gov/buildings/commercial_initiative/goals.html.

[8] Persily AK , Emmerich SJ (2012) Indoor Air Quality in Sustainable, Energy Efficient Buildings. HVAC\&R Res 18(1):1-17.

[9] Ng LC , Persily AK (2011) Airflow and Indoor Air Quality Analyses Capabilities of Energy Simulation Software. Indoor Air 2011, (International Society of Indoor Air Quality and Climate).

[10] ASTM (2010)- ASTM E779-10 Standard Test Method for Determining Air Leakage Rate by Fan Pressurization (American Society of Testing and Materials, Philadelphia).

[11] Emmerich SJ , Persily AK (2011) U.S. Commercial Building Airtightness Requirements and Measurements. $32^{\text {nd }}$ Air Infiltration and Ventilation Centre Conference, ed Cent. AIV (Air Infiltration and Ventilation Centre, Belgium).

[12] ASHRAE (2004) ANSI/ASHRAE/IESNA Standard 90.1-2004: Energy Standard for Buildings Except Low-Rise Residential Buildings. (American Society of Heating, Refrigerating and Air-Conditioning Engineers, Inc., Atlanta).

[13] Walton GN (1989) AIRNET - A Computer Program for Building Airflow Network Modeling. (National Institute of Standards and Technology, Gaithersburg, MD), NISTIR 89-4072.

[14] Feustal HE , Smith BV (2001) COMIS 3.1 - User's Guide. (Lawrence Berkeley National Laboratory, Berkeley).

[15] ASHRAE (2013)- ANSI/ASHRAE/IES Standard 90.1-2013: Energy Standard for Buildings Except Low-Rise Residential Buildings (American Society of Heating, Refrigerating and Air-Conditioning Engineers, Atlanta).

[16] ASHRAE (2013)- ANSI/ASHRAE Standard 62.1-2013: Ventilation for Acceptable Indoor Air Quality (ASHRAE, Atlanta).

[17] Ng LC, Musser A, Persily AK, Emmerich SJ (2013) Multizone airflow models for calculating infiltration rates in commercial reference buildings. Energ Buildings 58(0):11-18. https://doi.org/http://dx.doi.org/10.1016/j.enbuild.2012.11.035

[18] Ng LC, Emmerich SJ, Persily AK (2014) An Improved Method of Modeling Infiltration in Commercial Building Energy Models. (National Institute of Standards and Technology, Gaithersburg, MD), Technical Note 1829. https://doi.org/http://dx.doi.org/10.6028/NIST.TN.1829

[19] Ng LC, Emmerich SJ, Persily AK (2014) An Improved Method of Modeling Infiltration in Commercial Building Energy Models. 2014 ASHRAE/IBPSA-USA Building Simulation Conference, (National Institute of Standards and Technology, Atlanta, GA).

[20] Ng LC, Emmerich SJ, Persily AK (2014) Energy Modeling: Improving Infiltration in Energy Modeling. ASHRAE Journal 56(7):70-72. 
[21] Ng LC, Ojeda Quiles N, Dols WS, Emmerich SJ (2018) Weather correlations to calculate infiltration rates for U. S. commercial building energy models. Build Environ 127(Supplement C):47-57. https://doi.org/https://doi.org/10.1016/j.buildenv.2017.10.029

[22] Ng LC, Persily AK, Emmerich SJ (2015) Improving infiltration modeling in commercial building energy models. Energ Buildings 88(0):316-323.

https://doi.org/http://dx.doi.org/10.1016/j.enbuild.2014.11.078

[23] Bhandari M, Hun D, Shrestha S, Pallin S, Lapsa M (2018) A Simplified Methodology to Estimate Energy Savings in Commercial Buildings from Improvements in Airtightness. Energies 11(12):3322. https://doi.org/10.3390/en11123322

[24] Shrestha SS, Ng L, Emmerich S, Hun D, Desjarlais A, Dalgleish L (2016) Online Infiltration Calculator for the US, Canada and China. Thermal Performance of the Exterior Envelopes of Whole Buildings XIII International Conference, (Oak Ridge National Laboratory, Clearwater, FL).

[25] Dols WS, Emmerich SJ, Polidoro BJ (2016) Coupling the multizone airflow and contaminant transport software CONTAM with EnergyPlus using co-simulation. Building Simulation 9:469-479. https://doi.org/10.1007/s12273-016-0279-2

[26] Dols WS , Underhill LJ (2018) Cross-platform, Public Domain Simulation Tools for Performing Parametric IAQ and Energy Analysis. 7th International Building Physics Conference, (Syracuse, NY, USA).

[27] Dols WS, Wang L, Emmerich SJ, Polidoro BJ (2015) Development and application of an updated whole-building coupled thermal, airflow and contaminant transport simulation program (TRNSYS/CONTAM). Journal of Building Performance Simulation 8(5):326-337. https://doi.org/10.1080/19401493.2014.938699

[28] Emmerich SJ, Ng LC, Dols WS (2018) Analysis of potential energy savings from air sealing retrofits of commercial buildings. ASTM Symposium on Whole Building Air Leakage: Testing and Building Performance Impacts, ed ASTM (ASTM, San Diego, CA).

[29] Dols WS , Polidoro B (2016) CONTAM User Guide and Program Documentation. (National Institute of Standards and Technology, Gaithersburg, MD), Technical Note 1887.

[30] Haghighat F , Megri AC (1996) A Comprehensive Validation of Two Airflow Models - COMIS and CONTAM. Indoor Air 6(4):278-288.

[31] Chung KC (1996) Development and validation of a multizone model for overall indoor air environment prediction. HVAC\&R Res 2(4):376-385.

[32] Emmerich SJ, Nabinger SJ, Gupte A, Howard-Reed C (2004) Validation of multizone IAQ model predictions for tracer gas in a townhouse. Building Services Engineering Research and Technology 25(4):305-316.

[33] Emmerich SJ (2001) Validation of Multizone IAQ Modeling of Residential-Scale Buildings: A Review. ASHRAE Tran 107(2):619-628.

[34] Gowri K, Winiarski D, Jarnagin R (2009) Infiltration Modeling Guidelines for Commercial Building Energy Analysis. (Pacific Northwest National Laboratory, Richland, WA).

[35] Swami MV , Chandra S (1987) Procedures for calculating natural ventilation airflow rates in buildings. (Florida Solar Energy Center, Florida). 
[36] Walton GN, Dols WS (2005) CONTAM User Guide and Program Documentation. (National Institute of Standards and Technology, Gaithersburg), NISTIR 7251, Vol. NISTIR 7251.

[37] Lstiburek JW (2006) Understanding Attic Ventilation. (Building Science Corporation, Massachusetts).

[38] ASHRAE (2013) ANSI/ASHRAE Standard 62.1-2013: Ventilation for Acceptable Indoor Air Quality. (ASHRAE, Atlanta).

[39] NREL (2015) National Solar Radiation Data Base - 1991-2005 Update: Typical Meteorological Year 3. Available at http://rredc.nrel.gov/solar/old_data/nsrdb/19912005/tmy3/.

[40] ASHRAE (2017)- ASHRAE Handbook Fundamentals (American Society of Heating, Refrigerating and Air-Conditioning Engineers, Atlanta).

[41] DOE (2011) Commercial Reference Buildings (U.S. Department of Energy, Washington, D.C.). Available at http://energy.gov/eere/buildings/commercialreference-buildings.

[42] Liu B, Rosenberg M, Athalye R (2018) National Impact of ANSI/ASHRAE/IES Standard 90.1-2016. 2018 Building Performance Analysis Conference and SimBuild, ed ASHRAE/IBPSA-USA (ASHRAE).

[43] Polidoro B, Ng LC, Dols WS (2016) CONTAM Results Export Tool. (National Institute of Standards and Technology, Gaithersburg, MD), Technical Note 1912. https://doi.org/http://dx.doi.org/10.6028/NIST.TN.1912

[44] Wang L, Dols WS, Emmerich SJ (2012) Simultaneous solutions of coupled thermal airflow problem for natural ventilation in buildings. HVAC\&R Res 18(1-2):264-274. https://doi.org/10.1080/10789669.2011.591258

[45] Katal A, Wang L, Dols WS, Polidoro BJ, Tiesinga E, Makrides C, Li M, Kotochigova S, McAllister TP, Wang N (2018) An Investigation of Different Strategies For Solving Coupled Thermal Airflows By Multi-Zone Network Method. Computer Science 2018.

[46] Clark JD, Less BD, Dutton SM, Walker IS, Sherman MH (2019) Efficacy of occupancy-based smart ventilation control strategies in energy-efficient homes in the United States. Build Environ 156:253-267. https://doi.org/10.1016/j.buildenv.2019.03.002

[47] O'Neill ZD, Li Y, Cheng HC, Zhou X, Taylor ST (2019) Energy savings and ventilation performance from CO2-based demand controlled ventilation: Simulation results from ASHRAE RP-1747 (ASHRAE RP-1747). Science and Technology for the Built Environment:1-25. https://doi.org/10.1080/23744731.2019.1620575

[48] Ng L, Poppendieck D, Dols WS, Emmerich SJ (2017) Evaluating indoor air quality and energy impacts of ventilation in a net-zero energy house using a coupled model. Science and Technology for the Built Environment 24(2):124-134. https://doi.org/https://doi.org/10.1080/23744731.2017.1401403 